

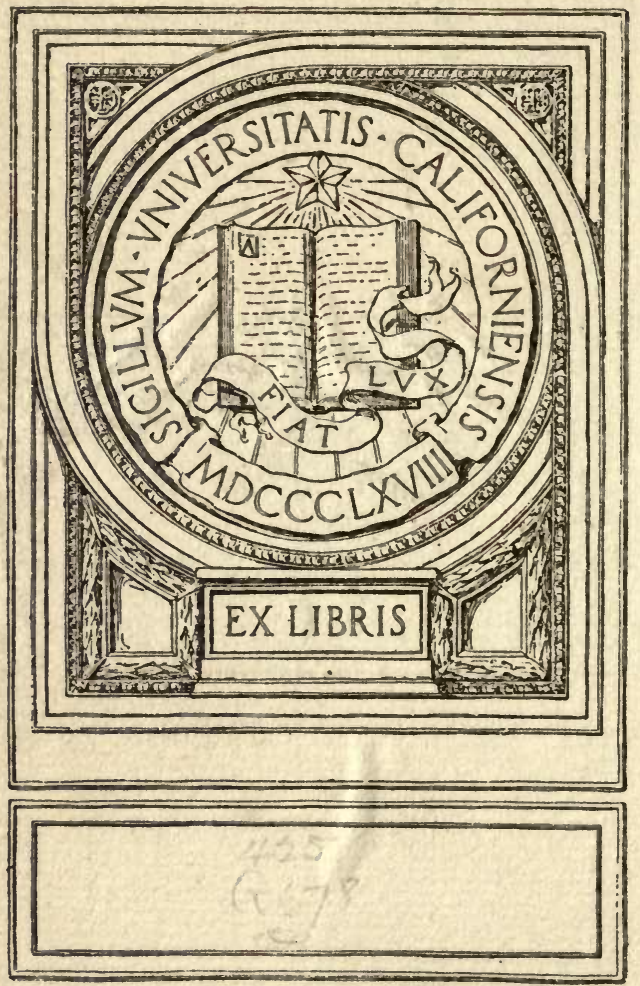

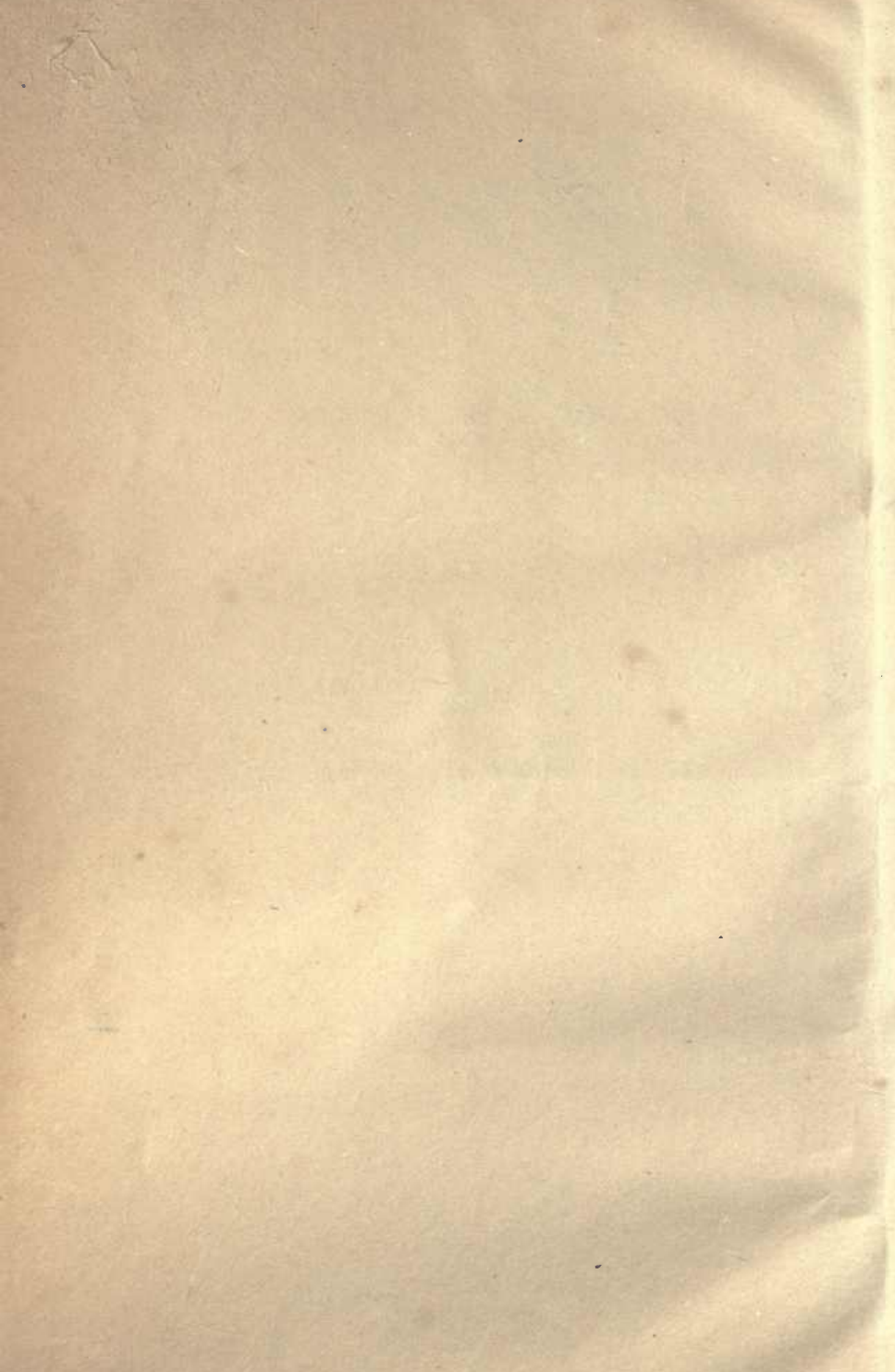
PLE, Naltur, 1895.

CANADIÂN NATURALIST. 
LONDON :

PRINTED BY SAMUEL BENTLEY,

Bangor House, Soe Lane. 
THE

\title{
CANADIAN NATURALIST.
}

\author{
A SERIES OF CONVERSATIONS
}

ON THE

NATURAL HISTORY OF LOWER CANADA.

BY

\section{P. H. GOSSE.}

COR. MEM. OF THE NAT, HIST. SOC. OF MONTREAL, AND OF THE LIT. AND HIST. SOC. OF QUEBEC.

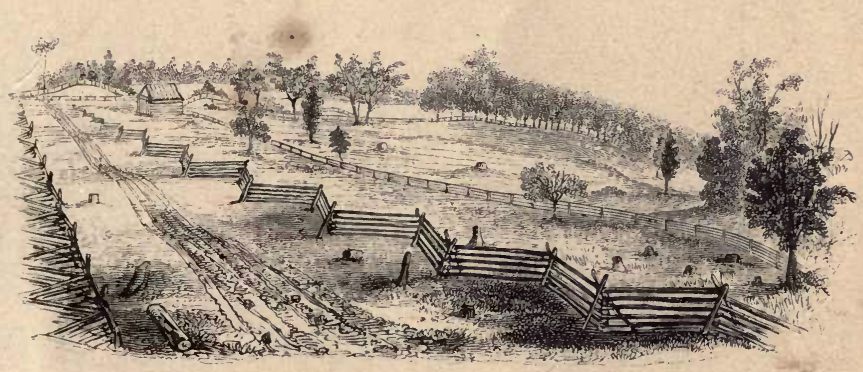

" Every kingdom, every province, should have its own monographer." .

Gildert White.

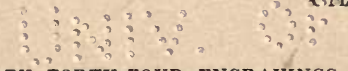

ILLUSTRATED BY FORTY-FOUR ENGRAYINGS.

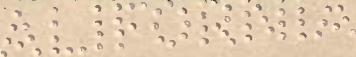

\section{O N D O N :}

JOHN VAN VOORST, 1, PATERNOSTER ROW. 
$Q H 106$

की 


\section{THOMAS BELL, ESQ. F.R.S. F.L.S. \&c.}

PROFESSOR OF ZOOLOGY IN KING'S COLLEGE, LONDON,

THIS LITTLE VOLUME,

AS A SMALL TOKEN OF ESTEEM FOR HIS VIRTUES, AND OF ADMIRATION OF HIS TALENTS,

IS AFFECTIONATELY INSCRIBED,

By his GRATEFUL RELATIVE,

THE AUTHOR. 



\section{PREFACE.}

CANADA having become, of late, a very prominent and engrossing object of attention, it is hoped that it may not be altogether uninteresting to the public, to consider it in a new point of view. It is here presented in a light on which there can be no clashing of opinion, no discordancy of sentiment : the smiling face of Nature, the harmony and beauty of the works of God, may be turned to by men of all parties as a refreshing relief from the stern conflict of political warfare. During a residence of some years in the Lower Province, the Author has felt it to be no common privilege to be able to solace himself by these simple but enchanting studies, amidst the fatigues of labour, and the stormy politics and martial alarms of the times; and even now, the recollection of those pleasant scenes sheds forth a lustre which gilds the 
edge of many a dark cloud. He does not expect by written words to be able to communicate the vividness of those impressions which are produced by actual observation; it will suffice, if an additional source of innocent gratification be pointed out, or an additional testimony borne to the wisdom and goodness of our beneficent Creator.

The plan of the Work consists of a series of conversations on the subject of natural history, supposed to pass between a father and son, during successive walks, taken at the various seasons of the year: so that it may be considered as in some degree a kind of Canadian "Naturalist's Calendar." As the form of dialogue has of late become somewhat "out of fashion," the Author feels it to be due to the public to explain the reasons which induced him to throw the Work into such a shape. He thought that by taking the reader, as it were, and transporting him into the midst of the very scenes and objects represented, a life and a vigour might be preserved, which would be wanting in a formal narrative. And many little trifles might be thus touched, which could be noticed in no other form, but which, nevertheless, all help to make up a true picture. Thus, too, we may ramble from one subject to another (as the humming-bird waywardly shoots from flower to flower), often by a transition more abrupt than could be permitted in a systematic discourse. If these transitions in any case appear to be too 
abrupt, the reader is at liberty to suppose the lapse of what interval he pleases between the former and latter subjects; or the notice of any passing occurrence, which has changed the current of conversation. Of course, the subject is very far from being exhausted: the Author has confined his remarks, with very few exceptions, to those phenomena which have passed under his personal observation: and every one acquainted with out-of-door natural history, knows that each recurring season presents to the admiring observer facts that were before hidden and unknown.

A word respecting the character of the Work. The Author is fully aware how very limited is his acquaintance with this boundless science; having lived in the far-off wilds of the west, where systems, books, and museums are almost unknown, he has been compelled to draw water from Nature's own well, and his knowledge of her is almost confined to her appearance in the forest and the field. With the systems, which men of enlarged minds have, with patient perseverance and studious research, arranged, - the most laborious, but not the least useful part of the science, he has had little opportunity of making himself familiar. It may be asked, "why, then, under these disadvantages, has he written at all?" Not to instruct the learned, at whose feet he is willing to sit as a learner; but partly to set forth the praise of the great and glorious God, who 
made all these things, and partly because, having himself tasted the calm delights flowing from an observation of His works, he would fain make known to others the source of the same sweet and soothing pleasures.

Of the illustrations, three are from the pencil of Mr. Dickes; the remainder are from original drawings by the Author, transferred to the wood partly by himself, and partly by Mr. James de Carl Sowerby.

It merely remains to add, that the village of Compton, in the immediate neighbourhood of which these observations were made, is situated on the river Coatacook, a tributary of the St. Francis, in the county of Sherbrooke, in what are called the Eastern Townships of Lower Canada ; very near the angle formed by a line drawn south from Quebec, and one drawn east from Montreal. It is thirteen miles distant from the town of Sherbrooke, and about twenty from the border of the State of Vermont.

London, Jan. 1840. 


\section{ILL USTRATIONS.}

Vignette-View of the Author's Farm at Compton . . . Title Spruce (Pinus Nigra) • . . . . . . PAGE 8

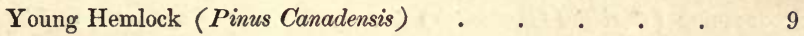
Old Hemlock

Balsam (Pinus Balsamea) . . . . . . . 10

White Cedar (Thuja Occidentalis) . . . . . 13

Elm (Ulmus Americana) in a clearing . . . . . 14

Elm in the forest . . . . . . . . . 15

A Hair of the Deer, magnified . . . . . . 23

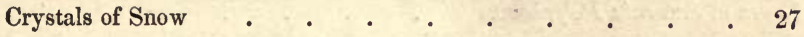

Black Wolf (Canis Nubilus) . . . . . . 37

Canadian Lynx (Felis Canadensis) . . . . . . 41

Moose (Cervus Alces) . . . . . . . . 56

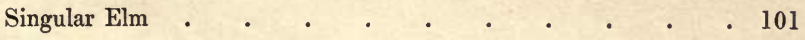

Woodchuck (Arctomys Monax) . . . . . . 121

Spotted Fanwing (Acrydium Ornatum) . . . . 122

Copper-spot Carab (Calosoma Calidum) . . . . . 123

Yellow Dog-tooth Violet (Erythronium Americanum) . • . 124

Scarlet Tanager (Tanagra Rubra).. . . . . . 134

White Death-flower (Trillium Pictum) . . . . . 160

Breeches Flower (Corydalis Cucultaria) . . . . 161

Horned Owl (Strix Virginiana) . . . . . . 176

Red Squirrel (Sciurus Hudsonius) • • • . . 178

Tiger Swallowtail Butterfly (Papilio Turnus) . . . . 183 
Imago and Pupa-skin of Coënomyia Pallida • • . 199

Barred Owl (Strix Nebulosa) . . . . . . . 204

Maple (Acer Saccharinum) in a clearing . . . . 215

Maple in the forest . . . . . . . . . 216

Larva, Pupa, and Imago of the Banded Purple Butterfly (Limenitis

Arthemis) . . . . . . . . . 220

Baltimore Fritillary (Melitaa Phaeton) • . . . . 227

Giant Waterfly (Pteronarcys Regalis) . . . . . 232

Pearly-eye Butterfly (Hipparchia Andromacha) . . . . 246

Pink Arches Moth (Thyatira Scripta) . . . . . 249

Skunk (Mephitis Americana) . . . . . . . 254

Royal Tiger-moth (Arctia Virgo) . . . . . . 260

Archippus Butterfly (Danais Archippus) . . . . 262

Canadian Pearl-fly (Chauliodes Pectinicornis) . . . . 263

Deer-mouse (Gerbillus Canadensis) . . . . . . 267

Touch-me-not (Impatiens noli-tangere) . . . . . . . . 274

Indian Hen (Ardea Minor) . . . . . . . . 275

Thorax and Abdomen of a Hymenopterous Pupa . . . 277

Gold-belted Hawkmoth ( Egeria — ?) . . . . 279

Needle Ichneumon (Pelecinus Polycerator) . . . . . 290

Pitcher-plant (Sarracenia Purpurea) . . . . . 301

Larva of Saturnia Polyphemus _ . . . . . . 309 


\section{THE}

\section{CANADIAN NATURALIST.}

I.

IANIIARV $1 \mathrm{am}$

ERRATA.

Page 122, line 30, for "Cur-culio," read "Curculio." 144 , line, 25, for "stiking," read "striking." 212 , line 11 , for " basis," read "bases." 226, line 7, for "Buprsetis," read "Buprestis." 238 , line 11, omit the word "have." 285, line 3, for" "Andecote," read "Anecdote."

c nuvrery paur uo pursue, wut as your tme since the age of understanding has been spent in England, your personal acquaintance with our natural history must of necessity be slight and limited. I mean your out-of-door researches; which have been confined to the desultory observations you have made during the few months that have elapsed since your arrival in this country. An attentive eye, it is true, cannot fail to acquire information, ever new, among the countless objects of creation, at all times, and under all circumstances ; but the more fully to avail ourselves of our 
Imago and Pupa-skin of Coënomyia Pallida . $\quad$. $\quad . \quad$. 199

Barred Owl (Strix Nebulosa) . . . . . . . 204

Maple (Acer Saccharinum) in a clearing . . . . 215

Maple in the forest . . . . . . . 216

Larva, Pupa, and Imago of the Banded Purple Butterfly (Limenitis

Arthemis) . . . . . . . . . 220

Baltimore Fritillary (Melitca Phaeton) . . . . 227

Giant Waterfly (Pteronarcys Regalis) . . . . . 232

Pearly-eye Butterfly (Hipparchia Andromacha) . . . . 246

Pink Arches Moth (Thyatira Scripta) • • • • • 249

Skunk (Mephitis Americana) . . . . . . . 254

Royal Tiger-moth (Arctia Virgo) . . . . . . 260

Archippus Butterfly (Danais Archippus) . . . . 262 
THE

\section{CA N A D I N NATURALIST.}

I.

JANUARY 1sT.

Pleasures of Natural History.-Plan of investigation.-Aërial Spiculæ. -Expansive power of Frost in Trees.-Opacity of Snow-Blue Tint. - Hairy Woodpecker-Food, Manners, Services.-Other Species of Picus - their Conformation. - Black-timbered Land.-White Pine. Spruce.-Hairy Lichen.-Hemlock.-Balsam-its height.-Tamarack. - Strobiles. - White Cedar - Rails. - Variety in Forms of Trees-Instances : Rock Maple-Beech-Basswood-Elm-Ash-ButternutBirch - Cherry - Poplar - Balm of Gilead. - Variety in all created Objects.

Father.-My son, you have begun to taste the delights of the study of Nature, and have found it a pleasant and a flowery path to pursue; but as your time since the age of understanding has been spent in England, your personal acquaintance with our natural history must of necessity be slight and limited. I mean your out-of-door researches; which have been confined to the desultory observations you have made during the few months that have elapsed since your arrival in this country. An attentive eye, it is true, cannot fail to acquire information, ever new, among the countless objects of creation, at all times, and under all circumstances; but the more fully to avail ourselves of our 
opportunities, I would propose to you a more regular and definite course of investigation. Let us from time to time, as circumstances permit, make excursions in forest or in field, to watch the progress of Nature through the changing seasons, to mark the half-hidden, half-apparent phenomena that occur, and to trace the guiding and sustaining hand of God, who " ruleth over all."

Charles. - Few things would give me greater pleasure. I have often felt the want of a companion in my walks, who, by his superior judgment, information, and experience, might remove my doubts, gratify my curiosity, and direct my attention to those subjects which are instructive as well as amusing; for I anticipate both instruction and amusement from our inquiries, and enter into your proposal with delight.

$F$.- Let us then begin with the year: it is not so cold as to be unpleasant, and a few miles' walk will promote health. We will go down to the North bridge, if you please, then after tracing the hard-frozen river until we reach Spafford's bridge, we will return by the village road.

C. - I have never followed the Coatacook up as far as that, and I should like it much : the morning is delightfully fine, and the air feels quite exhilarating. I notice that the air is full of minute dancing atoms, like the motes of summer; but these sparkle and flash in the sun, and reflect the tiny beams that fall on them, with a radiance unknown to the motes of dust.

$F$. - It is a common phenomenon on all bright cold days in winter. I conceive them to be either small particles of frozen moisture floating in the air, or, more probably, minute fragments of the fine powdery snow, which have been taken up by the wind, and continue to float by their lightness. They give a brilliancy to the air, which it would not otherwise possess. 
C. - What loud noise is that in the forest? It sounds like the report of a large gun. I heard it too, while you were speaking.

$F$. - It was the expansion of a tree. Old trees, when cut down, are often found to have the heart-wood so separated from the sap-wood, as to fall apart when a $\log$ is split through the centre ; and we find that the crevice or intermediate space has been occupied by a film of ice. This explains those loud reports which we heard just now, and which so often occur in the forest in frosty weather. Some water has lodged in the tree - perhaps in some maggot's or woodpecker's hole, - which, freezing, rends the wood by its irresistible force of expansion; into the rent so formed, the water percolates as soon as a thaw comes, and freezing again, extends the crevice downwards, each rent attended with these sudden and startling sounds. Sometimes we may observe a long crack in the trunk of a tree, extending through the sapwood and bark; and often an old bough is found to be nearly torn from the trunk; both of which, I suppose, are caused by the same occurrence, the freezing of water.

C. - How dazzling the snow is in the sunshine! Why is it opaque and white, instead of being transparent and colourless as ice? Is there any difference in the formation of the two?

$F$. - I believe not. The reason of the opacity and whiteness of snow is, that it is composed of very minute films of ice, which in falling rest in every possible angle, and reflect the light in every possible direction: if you take a single crystal of snow, you will see that it is perfectly transparent; and if all the particles rested on each other in the same plane, the whole mass would be transparent as a similar mass of 
ice. But here is another phenomenon, no less curious : if you make a hole obliquely in a heap of snow, so that the light shall not shine directly into it, you will see that the light which is transmitted through the snow is of a brilliant blue colour, varying in depth of tint, according to the thickness of the mass.

C. - I perceive it is so. What is the cause of it ?

$F$. - The cause I cannot with certainty make known. That blue is the natural colour of the purest water is proved by two facts; the first of which is however very little known to landsmen; namely, that the sea, when out of soundings, is of a bright deep blue, (although a tumbler-full taken up is as clear as pure spring-water, ) the green tint of the sea near shore, being caused by the nearness of the bottom. The other fact is, that the blueness of the sky, distant mountains, \&c. depends on the particles of water held in vapour in the atmosphere; the tint of these objects being deepened in intensity by an increase of moisture in the air. I have thought that possibly the phenomenon we have just noticed, may be but another exemplification of the same law; the medium through which the light is transmitted being but water frozen; and that the continual breaking of the rays of light through such a multitude of particles may have the same effect as the loss of light in passing through a large mass of water. But this is only a conjecture.

C. - There is a woodpecker in the act of boring that decayed tree; he makes the hollow woods echo with his loud and rapid taps. By his grey back, scarlet poll, and spotted wings, I know him to be the Hairy Woodpecker (Picus Villosus). What can he find in that old tree?

$F$. The grubs of some insects. Many species of beetles, 
such as Buprestis, Elater, and Cerambyx;-the Sirexes; some of the larger Tipuloe, \&c., inhabit the wood of trees in the larva state; and pupæe of moths, with many perfect insects, are often concealed beneath the bark.

C. - He appears to have some success: for see how he renews his exertions : how he scales off the pieces of bark, and makes the rotten wood fly about. Ha! there he goes, with his harsh laughing cry; he has alighted on yonder dead spruce. He appears to prefer dead trees for his researches.

$F$. - Yes; he knows that insects are not to be found in sound healthy trees, and they are all that he seeks. His instinct, however, discovers the incipient decay long before it is manifest to our senses, and eagerly probes for the hidden author of the mischief.

C. - Some of the old apple-trees in the orchard have their trunks almost covered with holes; in as regular rows as they could have been drilled by a carpenter.

F. - Perhaps, at every one of those holes, the useful woodpecker dragged forth a grub; so rendering an essential service by keeping down the race of these destructive insects; not by assisting the tree, for I suppose its doom is sealed before the bird attacks it.

C. - How many of the woodpeckers are indigenous?

$\boldsymbol{F}$. - It is probable that nearly all the American species are found in Canada. The Gold-winged ( $P$. Auratus), the Red-headed (P. Erythrocephalus), the Hairy (P. Villosus), are abundant, and $I$ have seen the noble Pileated ( $P$. Pileatus), with his high pointed scarlet cap, and the Downy (P. Pubescens), the smallest of all the woodpeckers. Wilson speaks of $P$. Varius and $P$. Carolinus, also, as inhabiting Canada. I have likewise seen the Northern three-toed Woodpecker (P. Tridactylus), so very common in Newfoundland, known by its bright yellow crown. There are, 
perhaps, no birds more admirably calculated to prove design and intelligence in their formation than the woodpeckers; whether we consider their large feet for grasping the inequalities of the bark, the rigid, sharp-pointed tail to support the body against the tree, the wedge-shaped beak, almost as strong and sharp as steel, the barbed tongue for bringing out the worm from the hole when bored, or the curious mechanism for lengthening the tongue, by carrying its bone, the os hyoides, round the back of the skull to the nostril, so that it shall be sufficient to probe to the inmost recesses of the holes, and bring the insidious inhabitant to the light of day. All manifest infinite wisdom and skill.

C. - The land here on both sides is "black-timbered." What a sombre and even gloomy appearance such a forest has, when compared with the hard-woods.

$F$. - That is partly owing to the black-wood or evergreen trees being in thick foliage, while the hard-wood or deciduous trees are leafless and open to the light; but it is so in a degree even in summer, and arises from the fact, that the foliage is opaque, or at least not so pellucid as the deciduous leaves; besides, that the timber on such land is usually much more close and dense.

C. - The evergreens appear in winter of a much brighter hue than in summer.

F. - That is merely a deception: the hue is the same, a dark green; which shows to advantage contrasted with the brown twigs and grey trunks of winter; but in summer, when compared with the rich and massive green of the beech or maple, seems almost black. In spring, the tops of the evergreens assume a more verdant appearance, as the young leaf-buds then open; but amidst the greater change which is 
then taking place in all the trees of the wood, the alteration in these is scarcely observable.

C.-Will you mention the principal of our resinous evergreens?

F. - The white Pine (Pinus Strobus), usually called by way of eminence, Pine; the Hemlock ( $P$. Canadensis), the Spruce (P. Nigra, and P.Alba), the Balsam or Fir (P. Balsamea), and the Tamarack (P. Pendula). There are others, but little known except to botanists. Of these the pine is the most valuable, as from the ease and smoothness with which it is worked, added to its large and straight growth, it is in great request for sawing into boards.

C. - There is not much pine growing in our neighbourhood; but I have seen some very large logs drawn out to Smith's mill. Moore told me the other day that he was then going in for a pine-log six feet in diameter: he had three yoke of oxen attached to his sled.

F. - That must have been one of unusual size.

C. - The pine makes a prettier appearance than the other species; the diverging fascicles of leaves give it more the appearance of a deciduous tree, by making the surface more irregular: and it is not so conical as the others.

$F$. - Tastes differ: you do not then admire the conical form of the evergreens?

C. - Perhaps a prejudice against the whole genus, on account of the general barrenness of the land where they grow, has prevented my seeing the beauty which they really possess; though a tall and slender balsam is certainly a very beautiful object. The inspired prophet considers the fir an emblem of beauty ; "instead of the thorn shall come up the fir tree ;"- but of course it is not the same species as ours.

F. - The spruce is the most valuable after the pine, for 
which it is in some degree a substitute, though spruce boards do not possess the good qualities of pine in the same degree. It is much used in building. The hemlock, as you are aware, is a majestic tree, though of very little use ; and as it grows on the poorest and most swampy land, it is generally regarded as an incumbrance, not worth the labour of felling. Yet it is sometimes sawn into board and plank; the former, though rough-grained, answers for under-covering of roofs, and for fencing; and the latter, from its solidity, is well enough adapted for the flooring of barns. But as many goodlooking trees prove unsound at heart, it is not much sought for, and is often burnt on the land when cut down, after having been first stripped of its bark, which is bought at a good price by the tanners.

C. - What is that yellow hair-like substance, which depends in long ragged masses from the hemlock and other trees, but most abundantly from the spruce?

$F$. - A friend of mine gave it the name of "Absalom's Hair." It is a Lichen, but I do not know its name. It chiefly entwines about the upper branches of the tree, to which I should suppose it is very prejudicial, as those trees which are covered with it seem almost in a dying state. It 
resembles the Tillandsia Usneoides of the Southern States, but only in appearance: it is probably an Usnea.

C. - How different is the appearance of a young hemlock from that of an old one! the former has a feathery and graceful lightness, bending to the slightest breeze; but when old it has become sturdy, the bark rough and deeply furrowed, full of gnarled snags, and broken limbs, the top generally blighted and dead, and the foliage almost deprived of that pencilled grace which gave such a charm to its youthful days.
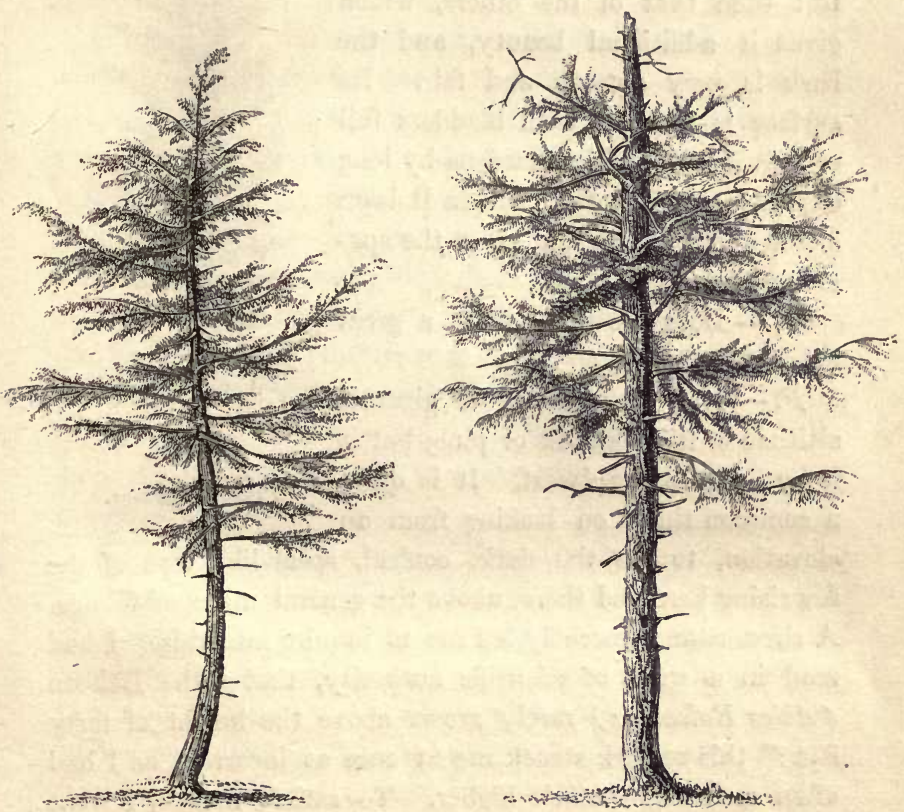

YOUNG HEMLOCK.

OLD HEMLOCR.

Pinus Canadensis. 
F. - Like nobler creatures, it often survives its beauty. The fir or balsam is the most elegant of the pine family : it usually grows very straight; the branches project all at the same angle, and grow to a length which diminishes with great regularity as they approach the top; giving to the tree the form of a slender but very regular cone. The foliage is dense, and of a greener tint than that of the others, which gives it additional beauty, and the bark is very smooth and fair. Its surface is covered with bladders full of a fluid resin, which hardens by long exposure: this is the Canada Balsam of the apothecaries, and gives the specific name.

C. - Does the fir grow to a great height?

$F$. Not perhaps to the gigantic altitude of the hemlock or pine, but it is by no means a dwarf. It is quite a common thing, on looking from an

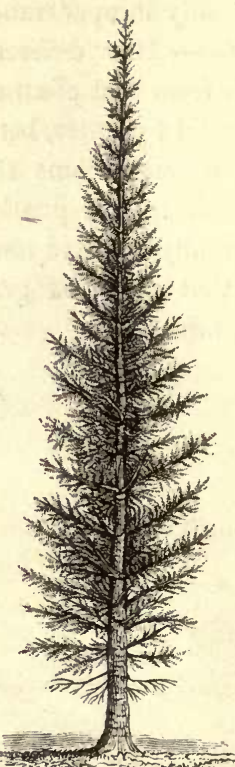

BALSAM.

Pinus Balsamea. elevation, to see the dark, conical, spear-like tops of the firs rising here and there, above the general mass of foliage. A circumstance recently led me to inquire into this. I had read in a work of scientific authority, that "the Balsam (Abies Balsamea) rarely grows above the height of forty feet :" this remark struck me at once as incorrect, as I had often seen them much higher. To satisfy myself, I went into the woods, and felled almost the first I saw, one of by no means extraordinary stature, and found the height, by 
careful measurement, seventy-six and a half feet : it was in full and vigorous growth, bearing no marks of age: the diameter at the base was about eighteen inches. Mr. Bill informs me that he has taken two mill-logs of fourteen feet each, fit for sawing, from the butt of a balsam, leaving of course a good length of " top." This must have been a large tree, as the part which would be suitable for boards, could not probably have been more than one-third of the whole, which would make the height eighty-four feet.

C. - The wood of the fir is not often used for sawing, I believe.

F. - No: it does not make good board: the timber, however, is valuable for staves of casks and buckets, and is likewise made into sap-troughs for the sugary. These are very simply manufactured : a log of balsam, two feet long, is split through the centre, the middle of each half is then hollowed out with the axe, and two troughs are finished. The larch or tamarack, though I mentioned it among the evergreens, from its belonging to the same family, is really deciduous; losing its leaves in October, and resuming them in May. Its wood is very little used; sometimes, however, it is hewn for building, or applied to other more trivial purposes: it is close-grained and hard, when seasoned.

C. - We do not use any of these woods for fuel.

$F$. - When green they burn, notwithstanding their resinous nature, with difficulty ; and even when dry, they consume so quickly, and so continually throw out lighted fragments, "flankers," as they are called, that they are confined to our close stoves. You are aware that the seeds are produced in strobiles, or cones, with imbricated woody scales, which are very closely pressed together, to protect the seeds, one of which is beneath each scale. The strobiles open in 
spring, and the seed is scattered. After I had felled the balsam I spoke of, I was surprised to see near the top, great numbers of upright pointed stalks, like thorns, about an inch and a half long; but found on examination that these were the axes or centres of the cones, which had been stripped of their scales in falling, by the shock; for from the cones that were still perfect, (it was in March,) the scales, which were standing loosely out at right angles to the axis, came off on the slightest touch; and the snow for many feet round the top of the fallen tree was thickly strewn with those which had been shaken off.

C. - I have observed in all trees of this family, that the cones are congregated at the extreme summit of the tree. Have you mentioned all the resinous trees?

$F,-$ No: there is one of majestic size, and of no little importance, which I have omitted:- the White Cedar, which belongs, notwithstanding its general resemblance to the pines, to a different genus. It is the Thuja Occidentalis of botanists. The leaves are small, and curiously imbricated or lapped over each other; the branches slender, and usually pendent; the bark fibrous and stringy: from the facility with which it is split, but chiefly from its great durability, almost incorruptibility, it is in great request for the rails that compose those unsightly zigzag fences, so offensive to the eye of one accustomed to the verdant and blooming hedgerows of England. Cedar rails may be exposed to every vicissitude of weather for a man's lifetime, without manifesting any symptom of decay, except the separation of the bark. It chiefly grows in marshes, and so densely as to render them almost impenetrable. A cedar swamp is a valuable addition to a Canadian farm; and with us they are already getting scarce, and no providence seems to be manifested for the future. 


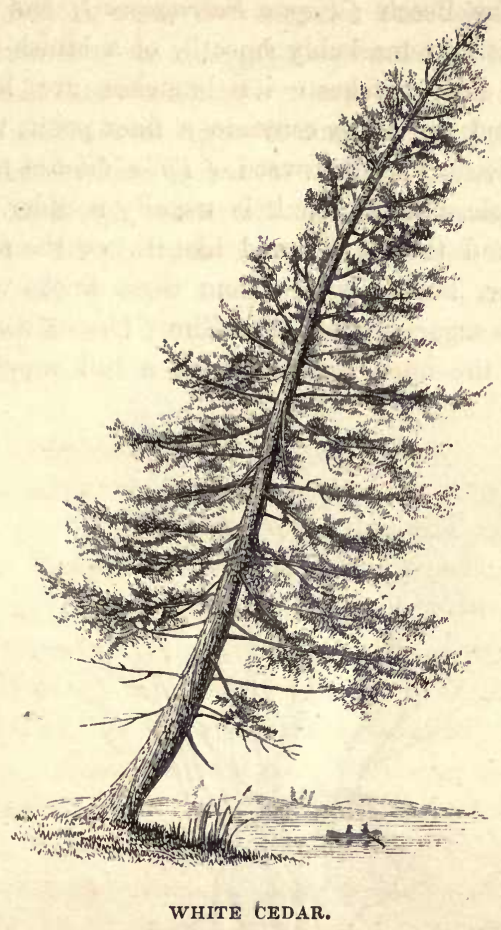

Thuja Occidentalis.

C. - How great a variety is displayed in the form, or manner of growth, of the different trees.

$F$. - So much, that even when divested of their leaves, it is quite easy to name any tree, by a view of the trunk and limbs alone. The Rock Maple (Acer Saccharinum), sends up a straight trunk, disfigured with hard and gnarled protuberances, shooting out its branches nearly at right angles, which are bent and contorted in every possible di- 
rection. The Beech (Fagus Ferruginea), has a straight trunk, but it is remarkably smooth, of a bluish-grey, with white and dark patches: its branches are longer and straighter, and the twigs come to a finer point, than those of the maple. The Basswood (Tilia Glabra), is much like the maple, but the trunk is usually rounder, and more pillar-like, and though fissured like it, yet the fissures are more regular, and it is free from those knobs which characterize the sugar-rnaple. The Elm (Ulmus Americana), growing in the open clearing, with a full supply of light

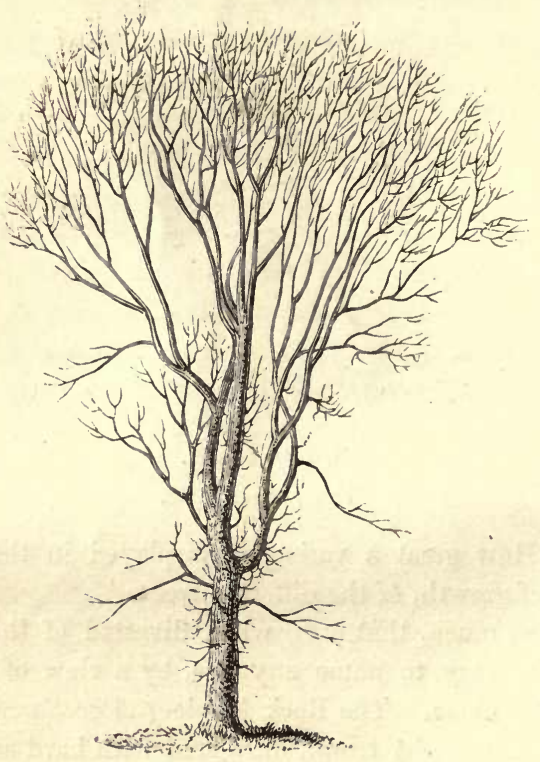

ELM (Ulmus Americana) IN A CLEARING. 
and air, divides near the bottom, into several leading branches, which continue to grow upward to a great length, dividing and subdividing into many smaller ramifications, which pursue the same upward direction, gradually spreading outwards, which gives the tree a broad and somewhat flattened top, while all the other trees are conical or rounded. In the forest, the elm is the most lofty of

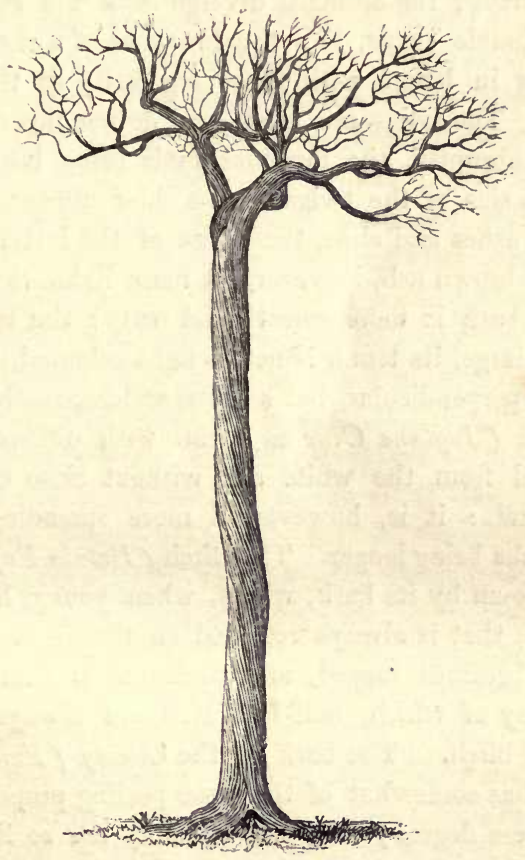

ELM (Ulmus Americana) IN THE FOREST. 
trees, with a remarkably straight round trunk, deeply furrowed, and almost white, without a branch till the top, which is small for the height and size of the tree, and much contorted.

C. - In the clearing, the elm is marked by having the trunk and limbs covered with branches of little ragged twigs, as if clothed with tufts of hair.

F. - The White and Brown Ash (Fraxinus Acuminata and $\boldsymbol{F}$. Sambucifolia), growing in the clearing, are graceful trees; the branches diverge from the central stem, with a double curve, like the branches of a chandelier, diminishing in length with great regularity as they proceed upward. The twigs are thick, and do not taper to a point, but end abruptly, the terminal buds being large. In the forest the size of the twigs is the chief difference between the large ashes and elms, the twigs of the latter being very fine; the brown ash, however, is more liable to be crooked, and the bark is more smooth and scaly: the white rarely grows so large, its trunk is not so light coloured, and its furrows not perpendicular, but somewhat lozenge-shaped. The Butternut (Juglans Cinerea), can with difficulty be distinguished from the white ash without close examination of the buds: it is, however, a more spreading tree, the lower limbs being longer. The Birch (Betula Papyracea) is easily known by its bark, which, when young, has a satiny glossiness, that is always retained on the limbs: when old the bark becomes ragged, and peels off in thin paper-like rolls, many of which, half-separated, are always to be seen on an old birch. The bark of the Cherry (Prunus Virginiana), has somewhat of the same peeling property, but in a much less degree; it is not so silky nor so flexible, and is more of a scaly nature : it generally has a purplish tinge. The Poplar (Populus Tremuloides), is remarkable for the 
colour of its bark; a smooth greenish white, which comes off on being touched, as if it were whitewashed. The Balm of Gilead (Populus Balsamifera), has a similar appearance, but the trunk is furrowed, and the terminal buds are much larger.

C. - In fact, every species of tree seems to have an individuality stamped on it, which, amidst all its accidental contortions, is sufficient to distinguish it from others. The variety is indeed remarkable.

F. - It is not, however, confined to trees; it pervades all the works of God. Indeed, I doubt if there were ever two objects created, of whatever kind, between which there was not some difference, if our senses were acute enough to appreciate it. It is a fact worthy to be noted, that even where the materials and component parts are uniform, the same variety exists. Who has not observed this, in the "human face divine?" Though the same features, and maintaining the same relative position, exist in all, yet what two countenances were ever so much alike as not to be at once distinguished on familiar acquaintance? This fact gives me an exalted conception of the Divine wisdom, of the inexhaustible resources of the mind of God. "How unsearchable are his judgments, and his ways past finding out!" This amazing diversity in all the realms of Nature of which we have any cognizance, has induced me to think, that if, as is most reasonable to conclude, other worlds are peopled by intellectual beings, they probably possess forms, senses, and powers, of which we have not the slightest conception. We find the plants and animals of England differing from those of France; still more from those of Africa or Asia : in America or New Holland we find an almost total change of form. A far greater difference is found between the organic remains of this globe 
prior to the Adamic creation, and the inhabitants of the present state.* Where are now the mastodons, the megatheriums, the saurian giants of those days? But surely if we make so vast a leap as from one world to another, the very forms of terrestrial things would be obliterated, and a corresponding difference appear, which nothing but infinite Wisdom could devise.

This we may never know till we become denizens of that changeless state to which time and space are nothing: when we shall know as we are known.-But we have completed our circumambulation, and are just at home.

* It is scarcely necessary to remark, that there is nothing in the Word of God, which opposes the commonly received opinion, that this world had an existence in a habitable state, previous to the chaos which prevailed at the commencement of the Sacred narrative. 
II.

\section{FEBRUARY 1 st.}

Silver Thaw.-Brilliance of the Meteor-its fragility.-Youthful Prospects.-Love of Nature.-Cause of the Phenomenon.-Virginian Deer. -Rackets.-Hair of the Deer.-Black-capped Titmouse-its FoodSong.-Anecdote.-Flakes of Snow-their beauty, variety, and regularity-difficulty of viewing and delineating them.-Perfection of the Divine Work.-Frosted Windows.-Uses of Snow.-Notes of the Winter of 1837-8.

FATHER.-A rain has fallen during the night, which has touched the face of Nature with a magician's wand. Come, and I will show you such a scene of splendour, as you will not see every day. Observe the woods : every little twig of every tree, every bush, every blade of grass, is enshrined in crystal : here is a whole forest of sparkling, transparent glass, even to the minute needle-like leaves of the pines and firs. What are the candle-light lustres and chandeliers of the ball-room, compared with this? Now the sun shines out ; see, what a glitter of light! how the beams, broken as it were, into ten thousand fragments, sparkle and dance as they are reflected from the trees.

Charles. - It is very beautiful. It reminds me of some of the fairy scenes in the Arabian Nights.

$F$. - Yes; it is a scene of brilliance; but beautiful as it is, it is no less fragile: a slight touch from a rude hand is sufficient to destroy it: on my striking the trunk of this tree, see! the air is filled with a descending shower of the glittering fragments, and the potent spell is broken at once; 
the splendour has vanished; the crystal pageant has returned to its old sober appearance, and is now nothing more than a brown leafless tree. What a figure of youthful hopes and prospects! when we first enter into life how buoyant are our feelings, how flattering our expectations! everything promises enjoyment: life seems to be but another word for joy : every object appears clothed with crystal, and tinged with the colour of the rose. But years pass on, -

"Time, the churl, he beckons, And we must away, away!"

- the rush of years shivers the crystal tree; years of toil, struggles for the means of existence, blighted hopes, intercourse with a cold world, destroy the illusion, and rob life of its poetry and romance.

"There was a time, when meadow, grove, and stream,

The earth, and every common sight,

To me did seem

Apparell'd in celestial light,

The glory and-the freshness of a dream.-

It is not now as it hath been of yore;

Turn wheresoe'er I may,

By night or day,

The things which I have seen, I now can see no more."

Yet to a well-constituted mind, a mind whose peace is made with God, this life is not without many unalloyed pleasures : though the freshness of early days is passed away, other joys, of a more sober character, it is true, are still offered to our grasp. Among these, not the least is the power of seeing God in his works, "the habit of wishing to discover the good and the beautiful in all that meet and surround us ;" even in the minutest and humblest objects of creation. This taste I have long cultivated in myself, and I would wish to awaken it in you, that you may still have sources of 
pleasure, wide and deep, after the rapture of youth is felt only in memory.

C. - Dear father, I already love the study of natural history; I scarcely know a greater delight than to bury myself in the woods, and watch the habits of the birds and insects, or inquire into the hidden causes of the phenomena which present themselves to my observation. What is the cause of the brilliant appearance we are now observing? Is it common?

$F$. - I have not often observed it here, but in Newfoundland it is by no means rare, where it is known by the name of "silver thaw." It is caused by rain descending when the stratum of air nearest the earth is below the temperature of $32^{\circ}$, and consequently freezing the instant it touches any object: the ice accumulates with every drop, until a thick transparent coating is formed. I was once exposed to a shower of this kind; the rain fell fast "on my coat, and I wondered that the drops did not soak into the cloth; on feeling them with my finger, I found, to my surprise, that they were hard frozen, and that my clothes were covered with little glassy buttons of ice. It would then change to a hail shower, then rain again, and so on; hail, and freezing rain alternating at intervals of a minute or two, for about half-an-hour, when it terminated in a heavy snow-storm. I infer from these circumstances, that there is a close resemblance between the phenomenon we now observe, and hail ; that the silver thaw would be hail if the freezing drops had a few yards farther to fali.

C. - Is not this a favourable time for hunting the deer?

$F$. - Yes: the freezing rain has covered the snow with a slight crust, which is not sufficient to sustain the weight of the deer, but on which a man on snow-shoes can travel 
with considerable rapidity. You have seen snow-shoes or rackets?

C. - Richardson showed me a pair : he is an experienced hunter, and is provided with all such things. They are made of a piece of white-ash, or other tough wood, bent and secured in an oval form, and a network of interlaced thongs of deer-skin is stretched across, on which the foot rests, and two straps of leather fasten it on. I tried them on, but I could not walk with them, the rims struck my ankles at every step.

$F$. - Like most other things, they require practice to be of much service. The deer seem to be aware of their inferiority on these occasions, for I have been told that sometimes they will not attempt to run, nor make the slightest effort to escape, until the hunters come up, and pass the knife across their throats.

C. - Is not our common deer the Cervus Virginianus of naturalists?

$F$. - Yes: we have only the Virginian deer and the Moose (C.Alces), that I am aware of; though the Caribou, or Reindeer (C. Tarandus), is, I believe, found north of the St. Lawrence. This last is common in Newfoundland. The Moose is the Elk of Europe; but the "Elk" of the Americans is a much smaller species, though still a very fine animal; it is the Wapiti (C. Wapiti), which is confined to the Western States. There is a remarkable peculiarity which is said to belong to that curious animal, the Pronghorned Antelope of the Rocky Mountains (Antilope Furcifer), which I have observed in our common deer. (C.Virg.) It is the singular form and texture of the hair. In winter the hair is very tubular, like a bird's quill, and so inelastic as to crumple on the slightest pressure ; when bent, it crushes into a sharp angle, in which shape it remains: it is ex- 
ceedingly soft and brittle; its colour is mostly white, tinged with red, but some of it is dark brown just at the tip : the root of every hair is more slender than the other part, the transition being abrupt; and this part looks exactly like the barrel of a quill in miniature: the extremity is generally waved. I believe this conformation is peculiar to this northern climate, and to winter, even here; in summer, the hair resembles that of other animals. Its coat is then of an uniform reddish brown, but in winter its colour is a greyish russet, not easily to be described. The venison is very juicy, and of delicious flavour; but to an American palate, a piece of fat pork has far greater charms.

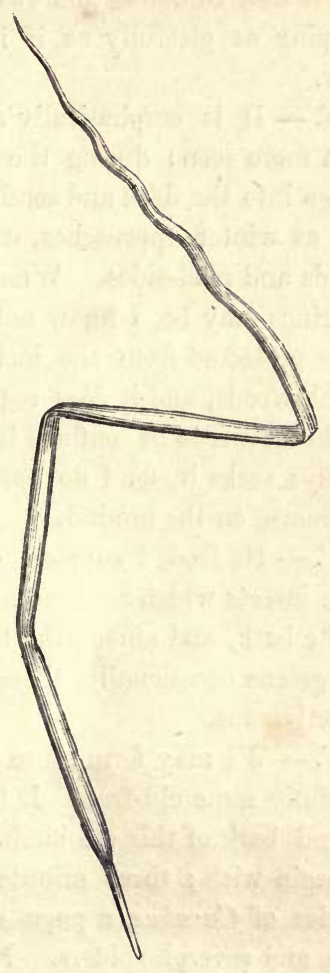

A HAIR OF THE DEER MAGNIFIED.

C. - Here is our constant merry little friend, the Blackcapped Titmouse (Parus Atricapillus). The coldest weather he seems to regard with indifference: though the mercury a day or two ago stood more than $30^{\circ}$ below zero, yet enveloped in his warm feathery coat, he has weathered it all, 
and is now tumbling and twisting around the branches, and chirping as gleefully as if it were "the glorious summer time."

F. - It is emphatically a winter bird ; or at least it is then more seen: during the whole year we may find it, if we go into the dark and sombre recesses of the cedar swamps, but as winter approaches, it comes out to the edges of the woods and road-sides. What the cause of this visit to the clearings may be, I know not; I should think it would be more protected from the inclemency of the winter's storms in the woods, and it does not appear that food is its object, as this seems to be confined to the trees; on which, indeed, it always seeks it, for I do not remember ever having seen a Titmouse on the ground.

C. - Its food, I suppose, consists of the numberless minute insects which are concealed during winter in the crevices of the bark, and among the twigs of the trees, with seeds of evergreens occasionally, though from its bill it is evidently. insectivorous.

F. - We may form some idea of its success by examining carefully some old tree. Let us look among the curled and ragged bark of this old birch. Here are two Ichneumonida to begin with; three minute Chrysomelina, an Elater, two species of Carabus, a pupa of a small moth, three or four flies, and several spiders. No bad meal for a little bird; and as he is a most restless little fellow, all day long engaged in the search, with the twofold advantage of instinct and experience, no doubt he fares well.

C. - Its song, without being very musical, is cheerful; and there is considerable variety in the two or three notes which compose it.

$F$. - In spring, it is fond of a chirp which much resembles the words "sweet weather." I recollect a rather laughable incident connected with this note. In Newfound- 
land, in the latter part of May, after the sealing voyage is closed, among other preparations for the cod-fishery, the crews are sent into the woods to cut rinds. A rind is the whole bark, for about five feet in length, of a young fir, or spruce, which, (an incision all round at each end, and a longitudinal division, having been made,) is at that season easily stripped off: when pressed flat, they are used as a covering for piles of fish in wet weather. A crew were thus engaged one bright morning, after a light fall of snow ; the heat of the sun made the snow run in a continual dripping from the trees; and the little tomtits were hopping round them, saying "sweet weather," in a tone that seemed to indicate the highest enjoyment. One poor fellow, of a somewhat testy disposition, annoyed by the dripping, and almost blinded by the perspiration running into his eyes, took it into his head that the bird was taunting him with the peculiar appropriateness of the weather to his occupation; or perhaps was vexed that the bird should show so much enjoyment at what was to him so uncomfortable. However, he presently flew into a violent passion, flung his little hatchet at the tomtit, and pursued him in a rage from tree to tree, crying "Sweet weather! is it? I'll tell ye what sort o' weather 'tis ;" and so on, till fairly exhausted with his silly exertions, he returned somewhat crest-fallen, to his jeering comrades, leaving the bird to enjoy its own opinion respecting the weather, or any other subject of its meditations.

C. - A particularly amiable disposition, which could find sources of vexation in the bright sun of spring, and the song of an innocent bird! But perhaps there was some excuse.

$F$. - The clouds are gathering to windward, and from their blackness I fear a snow-storm : we had better return homeward.

C. - A few scattered flakes are already falling.

$F$. - It is a good opportunity to direct your attention to 
the very great beauty which is shown in the forms of flakes of snow : a beauty and regularity that is as little seen or suspected by people in general, as if it had no existence. Take this pocket magnifier, and examine with it some of those on your sleeve.

C. - They are elegant and beautiful indeed: thin and flat stars of transparent crystal, resembling in beauty and variety of shape the forms produced by the kaleidoscope. Scarcely two are found agreeing in shape.

F. - Can you find no point in which they all agree?

C. - On closer examination, I perceive that all have exactly six rays or points, and no more.

$F$. - That circumstance reveals the secret of their regularity : all crystallizing substances shoot out needles or points at a certain definite angle; which never varies in the same substances, but has an almost infinite variety in different substances. This is called the angle of crystallization: in the freezing of water, this angle is one of sixty degrees, exactly a sixth part of a circle: whatever part of a flake of snow we examine, however complex it may be, we shall always find the needle forming with the line from which it shoots, an angle of $60^{\circ}$. We sometimes find fragments of stars, but if there are two rays still attached, they bear this unvarying relation to each other.

C. - It would be a pleasing amusement to observe and delineate the various forms of the flakes.

$F$. - It is attended with difficulty : only in the open air can they be examined; for so frail is their nature, that the slightest elevation of temperature above the freezing point instantly destroys them. Even out of doors, unless the weather be very cold, the close proximity to the eye to which they must be brought for microscopic examination is sufficient to obliterate their form; and the open air, at a temperature far below freezing, during a snow-storm, is by no means 
a favourable scene for the occupation of drawing. I have, however, copied a few crystals, which attracted my observation, and which I will show you. Captain Scoresby, in his

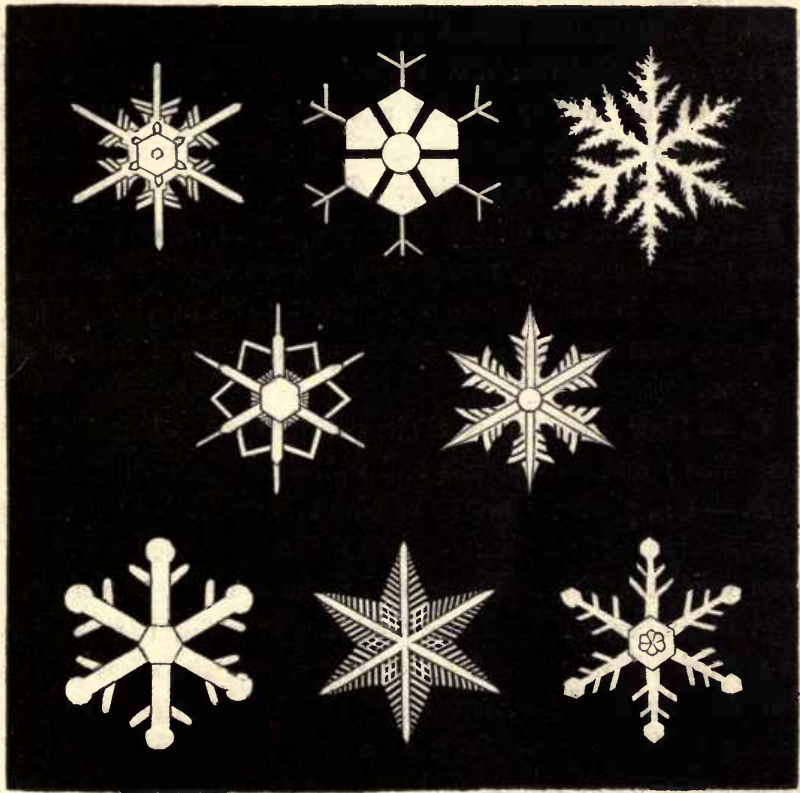

CRYSTALS OF SNOW.

very interesting work on the whale fishery, has, if I recollect right, a considerable number represented: but it is many years since I saw that work, and I have no opportunity of referring to it.

C. - I am surprised that I never observed them before.

$F$. - Several circumstances must combine to produce a favourable occasion for viewing them : if there is any current of mild air, through which they pass, they become soft and 
adhere to each other, making those shapeless masses which we call large flakes, and which we justly consider a sign that the snow will end in rain, as indicating a temperature high enough to melt the falling snow. If the arr near the earth is warmer than that above, the crystals melt as soon as they are deposited : if there is any wind, the crystals are blown about, and so beaten against each other as to be broken into minute fragments, forming small snow, which never falls except during wind. They must be received on a dark substance to display them properly, and even at the best, their minuteness, rarely exceeding an eighth of an inch in diameter, is sufficient to cause them to be overlooked by any eye, but one accustomed to pry into the minutix of creation.

C. - How brilliant is their polish, even when highly magnified; and how perfect and well-defined their outline!

$F$. - Oh, yes! the works of God alone will bear a close examination. If we take the most delicate production of human workmanship, and subject its parts to the power of a high magnifier, we shall see that however fair it appeared as a whole, it was composed of ragged and shapeless parts, and that its beauties were only produced by the defective nature of our senses. Look at a fine miniature painting: it is made up of minute dots, which, when magnified, are seen to be uncouth blotches, coarse and without form. But examine the Divine handiwork; take a minute animal ; a house-fly from the window; its head appears little more than an atom, yet it contains various organs of sensation as elaborate as ours : bring one of its eyes beneath a microscope, - it is composed of a vast multitude of convex lenses, hexagonal in shape, polished, and transparent, and each one endowed with all the parts requisite for perfect and independent vision. Nothing coarse or shapeless is there; and 
it is so in every case : the most minute crystal or point on your sleeve is of faultless regularity and beauty.

C. - How are the crystals on windows formed? those which are called frosted flowers, and which are so often seen in our bedrooms on cold mornings.

$F$. - By the shooting out of radiating needles in the manner I have described; but why these crystals take the fantastic forms of leaves and flowers, instead of regular angles, I cannot explain. Perhaps, if our instruments were of sufficient power, we should find that the individual crystals do shoot in the usual direction, but are so minute that we lose them in the whole. As an apparent circle may be formed of very short right lines.

C. - When these leaf-like figures are large, they possess considerable elegance. Why are they smaller in very cold weather?

$F$.-Probably, because then the freezing or crystallization begins at more points at once, each point being the centre of its own radiation, and the needles meet each other at shorter distances. But in milder weather, the surface not being cooled so rapidly, the crystals have more time and longer space to shoot in, and so make larger figures ; as there are fewer centres of radiation. I have sometimes seen the hoar frost stand up perpendicularly from the glass to the height of half an inch, and nearly as thick as snow : but this has been when the room has been much charged with vapour, and the exterior air at a very low temperature.

C. - It is well we have gained the shelter of home: how thickly and how fast the flakes of snow descend: they coalesce, and are become quite large.

F. - And how noiselessly they descend : it bids fair to be a heavy fall : probably by the morning light a dense coat of many inches will have covered the earth; yet not the slightest 
sound will have given us warning of such an event. - It is a pretty sight to take a candle to the window: the feeble light can penetrate but a little way into the deep pitchy darkness, but every foot of that blackness is thickly studded with the white descending flakes, which the light makes prominent.

C. - I know that nothing is created in vain, or without an end: but I should like to be informed, what are the uses of the winter's snow.

$F$. - From the lightness of snow, it is a poor conductor of caloric: that is, the matter of heat does not readily pass through it, or into it from contiguous substances.

C. - I recollect reading of a woman who was lost in a storm, and lay for several days buried up in an immense snow-drift; and who declared that she had not suffered from cold, the snow having kept her warm like a blanket.

$F$. - Just such a purpose does the snow serve to the earth : the grand scene of Nature's operations during winter is below the surface of the ground, where she is preparing the germs and roots soon to shoot forth; elaborating juices and consolidating parts, previous to the active vegetation of spring. But if the ground were left bare, in cold climates, it would be hard frozen to a great depth, and the vegetative life would be either destroyed or suspended; and the spring would be very far advanced before the earth could be thawed. To prevent these ill effects, God has mercifully ordained that a soft and warm covering shall be provided, the offspring of that very cold which is to be guarded against, thus making the evil work its own remedy. Among the subordinate uses, may be reckoned the advantage of having good roads made by it, for the conveying of produce to markets, drawing wood, manure, \&c. : a benefit by no means small, and one which the farmer well knows how to appreciate. This was manifest in the winter of 1837-38, a winter remarkable for the 
extreme mildness of the greater portion of it. Here are some notes I thought worth taking at the time. December had been rather cold with a little snow, sufficient to facilitate travelling. At the commencement of the year 1838, we had mild weather, with little snow on the ground, but the roads were still in excellent condition. From the third to the eighth of January we had a thaw with heavy rains, which took away all the snow: the state of nature exactly resembled spring: sheep and cattle feeding in the fields, streams and brooks flooded, roads filled with deep mud, travelling performed wholly on wheels or on horseback, instead of sleighs; and I read that in Upper Canada even some trees had burst their leaf-buds. The roads continued bare, with some slight frosts, until the nineteenth, when about four inches of snow falling, a new life was put into every kind of business; the roads were thronged with sleds loaded with hay, grain, carcasses of meat, and all other necessaries, which had been so long prevented from travelling by the state of the roads, as to cause great inconvenience, and in some cases even distress. To the end of January, the weather continued mild, but the whole of February was very severe, and this month, with the latter part of December, was in fact all that we could really call winter; for as early as the first of March, the snow began rapidly to disappear from the roads and fields; by the tenth, the sap of the sugar maple was flowing freely; the catkins of the poplars and willows opened about the middle of the month; the spring birds and insects appeared, and all things promised a very early season, which was, however, much retarded by continued cold weather in April. It was followed by an unusually wet and warm summer. 


\section{FEBRUARY 15 th.}

Masses of Snow on the Evergreens. - Foot-marks of Field Mouse. Squirrel.-Wolf. - Anecdotes.-Description of Black Wolf. - Ferocity of Carnivorous Animals.-Puma.-Lynx.-Otter.-Beaver.Musk-rat. - Equalization of Blessings of Providence.-Tokens of extreme Cold.-Sunset.-Northern Lights.

Charles.-How clear and cloudless is the sky, and how exhilarating is the atmosphere after last night's snow ! There is not a breath of air even to stir the hemlocks and spruces, whose flat branches are clothed with a thick mantle of pure unsullied snow.

Father. - I much admire the soft-woods after a heavy fall of snow: the form of the boughs causes it to appear like hanging drapery, and the great contrast between the sombre foliage and the brilliant whiteness of the masses of snow, has a fine effect.

C. - Here are some tiny tracks in the snow; little feet must have made these : their path is not more than half an inch wide.

$F$. - They are probably made by the Field Mouse ( $A r$ vicola Pennsylvanicus), though I have once seen the domestic mouse in the snow at a considerable distance from a house. But here our well-known nimble little friend, the Red Squirrel (Sciurus Hudsonius), has crossed the road: he makes a very singular trail; his two fore feet being so short, make their marks close to each other, while the hind footstepss are quite 
wide apart, and now and then there is a little sweep from his brush of a tail.

C. - Oh! the rogue! see, he has come direct from the barn; I warrant with some grains of wheat in his mouth, to be deposited in his hole beneath the gnarled root of some tree.

$F$. - The squirrel is particularly assiduous in his attentions to the barn as long as the wheat remains in it; nor does he altogether treat the oats with contempt. But if we want tracks, let us seek the woods. We will go a little way into the swamp. W What do you suppose are these?

C. - A fox's tracks.

$F$. - Oh, no! they are much too large : a wolf has passed here since last evening.

C. - Had we not better return? I hardly like to be so near him.

F. - You need not fear: he is before this time snugly concealed in some hollow log, far in the gloomiest and densest part of the swamp: he would not trust himself abroad by daylight.

C. - Would he not attack a man, however, if he met him abroad?

$F$. - I think not, even under any circumstances, except when so hemmed up as to render escape difficult, or made desperate by hunger.

C. - I suppose they are dangerous when they do attack a man.

$F$. - Yes : they are stronger than a dog of the same size, and their mode of biting is very different from that of a dog: instead of retairing his hold as a dog does, when he seizes his enemy, the wolf bites by repeated snaps, given, however, with great force. As illustrative of this habit, I may mention a farmer in New Hampshire, not very far from this 
place, who was one night awakened by a noise in his hogpen; on looking out he saw what he supposed to be a fox on the low sloping roof of the sty. He immediately ran out in his shirt, but found that the animal was a Grey Wolf, which, instead of making off, fiercely attacked him, rushing down the roof towards him, and before the man had time to move back, the wolf had bitten his arm three times, with these quick and repeated snaps, lacerating it from the elbow to the wrist : then, however, he leaped from the roof to the ground, and by so doing lost his advantage: for the man succeeded in seizing him on each side of the neck, with his hands, and held him firmly in that position till his wife, whom he called out, came up with a large butcher's knife, and cut the beast's throat. It was three' months before the man's arm was healed : every incision, it was said, piercing to the bone.

C. - The woman must have had some courage, to cut the animal's throat. - Is any bounty given for the destruction of the wolf?

F. - Ten dollars are given in this province; but I believe double that amount is paid in the state of New Hampshire, where this encounter took place. The ears of the wolf are considered in law as the representative of the animal : these being burnt in the presence of any justice of the peace, the bounty is claimed.

C. - Is there more than one species of wolf found in this country?

F. - There are two, the Black (Canis Nubilus), and the Grey (Canis Lupus, var. Borealis). The former is considered the more ferocious and dangerous, but is rather less common. Both kinds have within a few years become alarmingly numerous, after having been for a considerable time almost unknown in the settlements. Last fall we used to hear their dismal howlings in the adjacent woods almost 
every evening; and many of the neighbours lost their sheep, when left in the field: sometimes I have known as many as ten sheep killed out of a flock in one night.

C. - What means are used for destroying them?

$F$. - Sometimes, when considerable havoc has been made among the sheep, a general assembly of the neighbourhood is called, who proceed to the swamp where the wolves are supposed to harbour by day, armed with guns, pitchforks, or clubs: they then separate, to surround the swamp, and travel towards the centre, lessening the circle as they proceed. Whatever animals are in the swamp are of course roused, and are generally killed. One of these hunts I attended last fall, but we had not a sufficient number of men to be close to each other: we put up a Black Wolf, but he broke through the ring, and escaped, though shot at. But the more ordinary methods of taking them are by traps or poison, which are chiefly set in winter. When caught in a trap, the wolf is generally so cowed as to allow a man to go up to him and handle him like a dog; though it is a dangerous experiment. A very large grey wolf was poisoned a few weeks ago by J. Hughes; I went to his house to see it, but was disappointed, as he had sent it to Sherbrooke. $\mathrm{He}$ told me that it measured six feet in length, including the tail, and that it stood about three feet high: though very poor, it was as large round as a good-sized sheep: and probably would weigh about seventy pounds. The mode of setting poison is this: the kernels or seeds of nux vomica are grated or pounded, then mixed up with three or four times their bulk of fat or grease, and honey-wolves are very fond of the latter-and made into balls about as large as a hen's egg. These are placed in the woods, covered with a piece of flesh or tripe, and some offal is hung on a tree near the spot to attract the wolves by its scent. Hughes says, that a large space round the tree was beaten hard, by the 
wolf's walking round, and leaping up, in endeavouring to reach the offal. He had not run above eight rods from the poisoning place before he died. I was afterwards more successful : hearing that Captain Sleeper had poisoned one, I called to see it, and made a careful examination of it; that is, of the stuffed skin. It was a black wolf: it had not been opened at the belly, but the carcass had been drawn out at the mouth, which of course had to be enlarged, so that I could form little idea of the shape of the head, or size of the mouth. The length of the animal was four feet from the nose to the insertion of the tail ; the tail one foot eight. inches; from the nose to the eye, four and a half inches; from the nose to the ear, ten inches; distance between the ears, three and a half inches; (the ears had been cut off for the bounty, so that I could not ascertain their length;) the height at fore shoulder, two feet three inches: length of fore legs, one foot four inches; girth of body, about two feet seven inches. The general colour of the body was brownish black, somewhat mottled with darker; the belly was much lighter, but a broad stripe of black, undefined at the edges, ran from the breast down the middle of the belly: the back was blackish, very slightly mottled with white, caused by the intermixture of different hairs; the body was covered with a soft thick down, light grey at the root and brownish grey at the end; besides this fur there was likewise a longer hair, which gave the colour of the animal; this hair on the back was white at the root, then black, then pure white, then black at the tip; this gave a speckled appearance to the back. The tail was large and bushy; the hair long, loose, and nearly black: the throat and breast were nearly black; the feet and legs black; the hair on the front of the legs close, shining, and bristly : the head was black, the face covered with short close hair; the nose pointed, small, and black: the ears were said to be short, pointed, and upright. It was a female, and was with young at the time. 


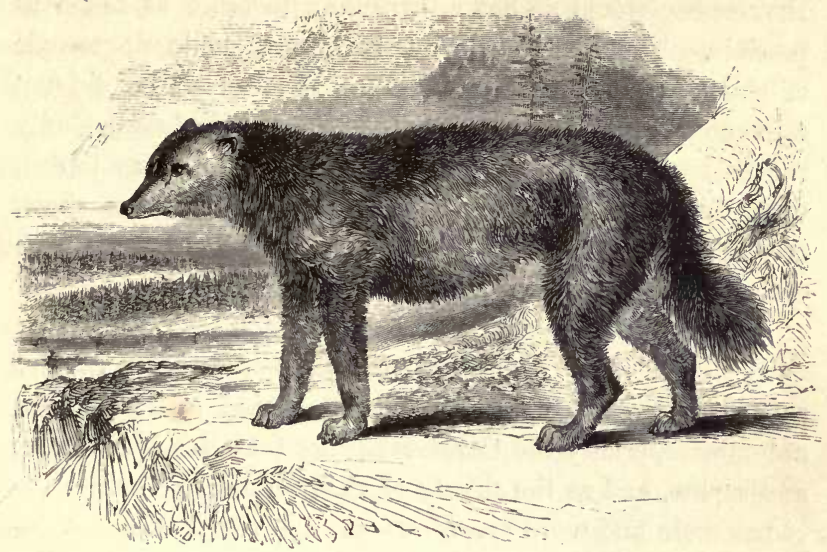

BLACK WOLF.

Canis Nubilus.

C. - Have you never seen a living one?

$F$. - Soon after I had seen the skin I have just described, I saw at Sherbrooke, in the possession of Mr. Robert Armour, a full grown black wolf, which had been caught in a trap by one of the fore feet, and had received by it a severe wound; this was then healing, by the animal's being in the habit of continually licking it. It was kept in a dark closet, fastened by a chain round the neck, but quite unmuzzled. The woman who showed it to me, on opening the closet, which stank abominably, seized the chain, and dragged him, maugre his efforts to remain concealed, into daylight. While in the room, he showed no sign of ferocity, except the wild fiery glare of his eye, but extreme timidity, darting from side to side, as far as his chain would allow him, huddling into a corner, and when disturbed, rushing into another. He could 
not be made to stand on his feet, but when pulled out of the corners, would lie down, shrinking together as much as possible. The woman, a stout Irish girl, made no scruple of going up to him and handling him, which he did not attempt to resent; but when his chain. was slackened, gladly rushed back to his odoriferous closet. His tail was bushy, much like a fox's ; his nose very sharp; and his ears short, erect, pointed, and black : the general colour and appearance were similar to those of Sleeper's.

C. - Does the wolf attain to a great age?

$F$. We have very limited means of arriving at any satisfactory conclusion respecting the period of life of wild. animals, especially the Carnivora. As they live by violence and rapine, and as the supply of their wants necessarily becomes more and more precarious as the vigour of youth departs, it is probable they do not often nearly complete the period of life allotted to their respective species. Some instances, however, no doubt occur, in which the animal attains the utmost verge of existence. A few years ago, some men were going up Lee's Pond, a lake about six miles long, near Stanstead, which was frozen at the time, when they saw before them a party of wolves crossing the pond. One in the centre appeared sick, and was surrounded by the rest in the manner of a body-guard. One of the men, who had a gun, pursued them, when some of the wolves took to flight, leaving others with the supposed sick one, which, however, dropped off one by one as the pursuit grew hotter, leaving at last only two with it: the man then fired at one of these two, but without killing it, and they both then fled. On coming up to the remaining one, they found it was an old she-wolf, completely blind, as was supposed from age alone, as her teeth were almost worn down. After her last attendants had left her, she attempted to continue her course, but in a very uncertain manner, sometimes turning on her steps, 
or going in a circle. The men put a rope round her, and led her to the town. In the woods they found her den, strewed with a vast number of deer's bones, fragments of flesh, \&c. all around which, the snow, though three feet deep, was trodden hard and smooth, and from the number of paths leading to this spot, it appeared evident that this aged wolf had for a long time been supplied with prey by the assiduous attentions of others.

C. - This story raises the wolf in my estimation: I had always had a very bad opinion of his moral character.

$F$. - All carnivorous animals are on a par in this respect : it is absurd to say that any animal is "fierce without provocation, and cruel without necessity ;" or that "it scarcely finds time to appease its appetite, while intent upon satisfying the malignity of its nature." Their thirst for blood is an irresistible instinct implanted in them by an allwise God, and the tiger or the wolf could no more exist without slaughter, than the sheep without cropping the herbage. That they often kill without devouring the carcasses, is not by any means the effect of a blind and aimless ferocity, but a proof that to their palates the blood is the most agreeable part of their victim; and of course it is ridiculous to expect that they should manifest any moral scruples of indulging their appetite, whenever they have the power or opportunity. Some are more sluggish, or more timid, or less desirous of blood than others, but surely no praise is due to them for superior virtue.

C. - Is the wolf the most formidable of our beasts of prey?

F. - I suppose he may be esteemed such; though there is reason to believe that a much nobler animal, the Couguar, or Puma, has, formerly at least, been seen in this province. I have heard both Nathan and Amos Merrill speak of a large cat, which was killed in the township of Bolton, about 
fifteen years ago, and which they call a Catamount, but which from the description they give of it, I believe to have been no other than the Puma (Felis Concolor of Linnæus). A man was going into the woods with his axe, when he was met by another man, who having just been alarmed by the sight of the animal in question, advised him not to go on. He however proceeded, and soon discovered the puma under the root of a fallen tree: having cut a stout club for himself, he threw his axe with his utmost force at the beast, but missed his aim, and it slowly walked away. The man returned to the settlement, and having procured guns and assistance, again proceeded to the woods, and found the animal near the place where he had been before seen. They fired and killed him, carried him home in triumph, and stuffed the skin; this trophy was preserved many years at the house of Captain Copps, in Georgeville, in whose hall, I am told, it presented to a stranger entering, a very startling object. Both of the Merrills have seen it many times, Amos having resided within three miles of the house : they describe it as being four or five feet in length, exclusive of the tail, which was two and a half or three feet; that it stood near three feet high, was in all respects a cat, with a round flattened face, large round paws, \&c.; the colour was a dull red, without marks or spots. Supposing the dimensions given to be exaggerated, through defective memory, there can be no doubt that the animal in question was a puma, as there is no other of the large cats to which the description will at all apply. Both of them are well acquainted with the lynx, of which they gave me a very correct general description, noticing particularly the black ear tufts, and the blue colour. The length of the tail too, as well as the hue, is a sufficient proof that it was not the Canadian Lynx. The species may possibly even yet be found, though rarely, in our almost interminable forests. 
C. - I have seen a specimen of the Lynx (Felis Canadensis) in the museum of the Literary and Historical Society at Quebec: it is stoutly built, and has a very fierce look, so that I should think it a somewhat formidable adversary.

$F$. - I do not believe that it would face a man; at least I have never heard of an instance: its attacks appear to be confined to birds, and the smaller quadrupeds, which it pursues chiefly on trees: its colour is elegant, and its eye is said to have peculiar brilliancy. I have never seen a living specimen, though they are numerous in the northern part of the province, and are much hunted for their skins.

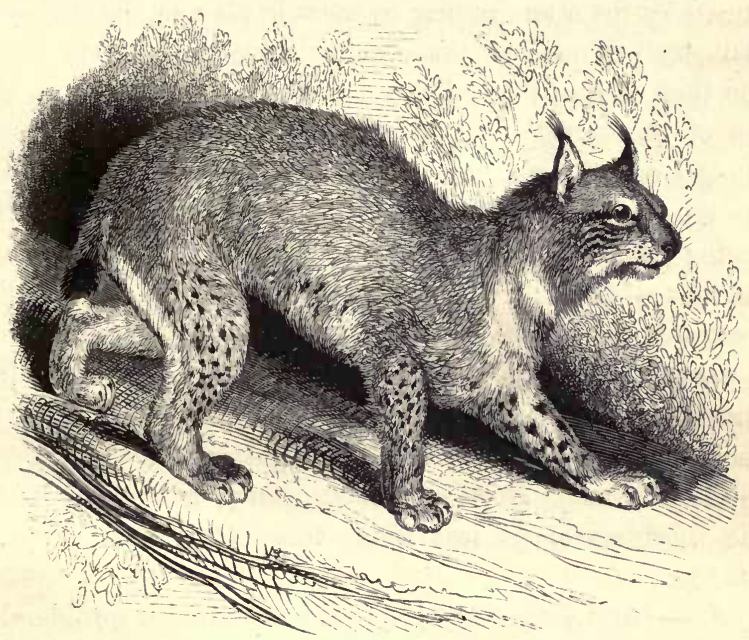

CANADIAN LYNX.

Felis Canadensis.

C. - Yonder is the river: what is that black thing swimming in that small space of open water?

F. - It is the head of an Otter (Lutra Canadensis): he 
is fishing; and by his diving he appears to be successful. It is a curious fact, that the otter will not eat the hind part of a fish, rejecting all but the head and shoulders. This is the only brute animal that appears to enjoy play for its own sake, merely for amusement, in adult age. Some years ago, I was travelling on foot in Newfoundland, from St. Mary's on the southern coast, to Trinity Bay. It was in the month of January, and there was a considerable depth of snow on the ground. The old furrier, who acted as my guide, showed me many "otter slides." These were always on a steep sloping bank of a pond or stream, where the water remained unfrozen. They were as smooth and slippery as glass, caused by the otters sliding on them in play, in the following manner:-Several of these animals seek a suitable place, and then each in succession, lying flat on his belly, at the top of the bank, slides swiftly down over the snow, and plunges into the water. The others follow, while he crawls up the bank at some distance, and running round to the sliding place, takes his turn again, to perform the same evolution as before. The-wetness running from their bodies freezes on the surface of the slide, and so the snow becomes a smooth glitter of ice. This sport, I was assured, is frequently continued with the utmost eagerness, and with every demonstration of delight, for hours together.

C. - Is not the otter a slow-moving animal on land ? the shortness of its legs seems to adapt it but poorly for running.

F. - On the contrary, it is said to run with considerable speed : but if I am rightly informed, it occasionally aids its velocity in a very ridiculous manner. A neighbour, on whose word I could rely, told me that he once saw an otter on a pond in these townships, which he pursued. It was winter, and the snow was about knee-deep, but had a slight crust. The otter would run a few yards, then rearing himself up, and 
throwing his hind legs forward, would slide on his haunches for about two feet; then he would again run a few yards, rear up, and slide as before. Notwithstanding the apparent awkwardness of this manner of progression, he managed to make way faster than his pursuer, who, observing this, and perceiving whither he was tending; endeavoured to cut off his retreat, by heading him in his course; but before he had reached him, the otter had gained his hole, and had disappeared within the pond.

C. - Is the otter of any value ?

$F$. - In some countries they are so far tamed as to be used in catching fish ; but with us they are procured wholly for the sake of their fur, which is much prized. The hair is very smooth and shining, somewhat bristly, of a brownish black; but there is a sort of thick, soft down, which lies next the skin, and is not seen; it is of a greyish colour. In taking off the pelt, the skin is not cut open at the belly, but at the head, and is drawn off the body inverted, as we pull off a stocking. A long board is then thrust into the pelt, so as to make it quite flat, the fur being inwards; this board is drawn out when the skin is dry. Otter fur is examined by thrusting the arm up the inside of the pelt; if, on withdrawing it, hairs stick to the sleeve of the coat, the skin is not merchantable; but if it is quite clean, the fur is in prime condition. The price of an otter skin in Newfoundland is usually about the same as that of a beaver.

C. - The Beaver is, I believe, a Canadian animal. Can you give me any information respecting it ?

$F$. - None but what I have gained from books, to which you also have access. Though abundant in some parts of Canada, I do not know that they are found within many miles of this place. I have seen their houses in Newfoundland; but have never had an opportunity of opening one. 
I once partook of the hind-quarters of this animal roasted, which I thought more delicious than any meat I had ever tasted. The tail is a particular delicacy; it is almost wholly composed of fat. Beaver skins are usually sold by weight.

C. - The Musk-rat (Arvicola Zibethicus) is much like the beaver; is it not?

$F$. - So much that Linnæus, in one of his editions of Systema Naturæ, placed it in the same genus. Its skin has a very pleasant smell of musk, which it retains long after death; the fur is so much like that of the beaver, as scarcely to be distinguished from it. It may often be seen in our rivers in summer, in the banks of which it burrows.

We perceive that the most valuable furs are the productions of the colder climates: and this is but one instance of the beneficence of God, in giving to every habitable country some compensation in itself for its peculiar inconveniences. While we find no spot on earth to be a paradise, a place of unmixed repose and pleasure, no land is altogether cheerless and desolate; and this distribution of gifts is made with a far more equal hand than we at first suppose. Some countries which are eminent for fertility, for luxuriance of vegetation, or beauty of scenery, are balanced by political restrictions, unhealthiness, or the languor and inactivity caused by heat. Others are cold and sterile, but have a pure and salubrious air, and are possessed by a free and industrious people. In some, where the inhabitants have a liberal government, and the comforts of a high state of civilization, the many find a difficulty in obtaining an honest livelihood, and almost an impossibility of gaining independence: in others, the loss of home-comforts, and the privations of the forest, are rewarded by increasing wealth and a certain prospect of competence. 
C. - We have wandered far; and shall scarcely be at home before nightfall. The temperature of the air is falling rapidly, as indicated by the crispness of the snow, which crunches beneath our feet.

$\boldsymbol{F}$. - Yes; we shall have a cold night: we must walk fast to keep a rapid circulation, or we shall run the risk of having our noses or cheeks frozen.

C. - My eyelashes freeze together, for an instant, when I wink, already: and your whiskers are as white, with your frozen breath, as if they were silvered with age. The severe cold makes the cheeks tingle, as if the points of needles were running into them. It is pleasant to think that we have a comfortable home, and a cheerful fire to look forward to.

$F$. - The sun has set: we are apt to associate a glowing sunset with summer, and warm weather; but here is one which is not often surpassed. Observe how rich the crimson near the horizon; in what bold relief the shaggy hemlocks of yonder mountain stand out against the fiery sky; mark, too, the beautiful gradation of colour as it approaches the zenith! the glowing, furnace-like red becomes orange, then changes to bright flame-colour, deep yellow, pale strawyellow, diluting till at length every warm tinge is lost in the cool and soft blue of the general sky-the yellow lost in the blue without the least hue of greenness where they unite.

C. - The black hills, and dark masses of cloud make the clear sky seem more rich and brilliant by their contrast.

$F$. - The most brilliant sunsets I have ever seen were at sea, in June and July; there the sky is often bathed in the most gorgeous tints, glowing in crimson and gold, and the clouds take the form of a beautiful country, interspersed with groves and thickets, and bright lawns ; with calm lakes, studded with little islets; and these so accurately imaged 
forth, as to need no stretch of imagination in the sea-worn mariner, to convey to him the idea of land. I used to look upon the scene, till I could scarcely persuade myself it was unreal; it reminded me of that bright and beautiful land, which the Indian hopes for " beyond the mountains," the land of the blessed, the land of spirits. It was in the same voyage, that I observed a more singular, though not a more lovely sunset. The sun, as he approached the horizon, gradually became laterally elongated, until the form of the disk was a perfect oval. The atmosphere was clearer than I recollect to have ever seen it, and the appearance of the sun, like burning gold, without a cloud or mist to intercept his rays, as he sunk slowly beneath the waves, was very beautiful. When about half hidden, he appeared like a hemispherical island of fire in the sea; and as the light diminished to a thin line, it was tinged distinctly green by the blueness of the waves. The total absence of those fleecy clouds, generally visible at sunset, and which reflect a brilliant glow, even after the sun has disappeared, contributed not a little to the singularity of the spectacle.

C. - The northern lights are beginning to play : can you tell me the origin of that splendid phenomenon?

$F$. - Its cause and nature, notwithstanding the observations and researches of the most acute philosophers of the present age, are still, I believe, a mystery. That hypothesis which attributes it to the agency of electricity appears to be most reasonable; it is true the officers and savans of the North-west expeditions, who had excellent opportunities for observing the Aurora, could never detect the slightest influence on their electrical and magnetical instruments; but this may be accounted for by the fact that its usual elevation is very far above the atmosphere. 
C. - How can this be ascertained?

$F$. - By the same Aurora being visible from distant parts of the world at the same moment.

C. - But if I rightly recollect, Captain Parry records an instance in which he saw a beam of the Aurora Borealis shoot down between him and an opposite hill, not more than a mile or two distant.

$F$. - I suppose that to have been a very uncommon case.

C. - Have you ever heard any sound accompanying it ?

$F$. - Never : though I have seen very many, and some very splendid ones; and though I have often eagerly and intently listened: yet I cannot doubt the fact; for I have been assured by persons of undoubted veracity, that they have distinctly heard an accompanying sound, though exceeding rarely. Some of these individuals could not be suspected of having taken the idea from books, yet the character of the sound attributed to the Aurora exactly agrees in all the recorded instances in which it has been heard. It was described to me as being like the rustling of a silk flag in a smart breeze. These were all heard in Newfoundland, where it is much more common than in this country. For two or three years past we have had a very brilliant coloured Aurora about this time: in February, 1837, the whole of the sky appeared of a splendid crimson, which was reflected from the surface of the snow beneath, and had almost an awful, though very beautiful appearance. I saw a fine one, though inferior to this, on the evening of the 21 st of February, 1838, of which I recorded some particulars. I first observed it about half past eight o'clock; a long, low, irregular arch of bright yellow light extended from the north-east to the north-west, the lower edge of which was well defined; the sky beneath this arch was clear and appeared black, but it was only by contrast with the light, for on examination, I 
could not find that it was really darker than the other parts of the clear sky. The upper edge of the arch was not defined, shooting out rays of light towards the zenith: one or two points in the arch were very brilliant, which were varying in their position. Over head, and towards the south, east, and west, flashings of light were darting from side to side: sometimes the sky was dark, then instantly lighted up with these fitful flashes, vanishing and changing as rapidly; sometimes, a kind of crown would form around a point south of the zenith, consisting of short converging pencils. At a quarter before nine, I looked at it again : the arch was as before, but slightly changed in form ; the zenith, too, much the same. About nine, the upper and southern sky was filled with clouds or undefined patches of light nearly stationary; the eastern part, near the top, being deep crimson, which speedily spread over the upper part of the northern sky; a series of long converging pencils was now arranged around a blank space about $15^{\circ}$ south of the zenith, the northern and eastern rays blood-red, the southern and western pale yellow ; the redness would flash about as did the white light before, still not breaking the general form of the corona. In a few minutes all the red hue had vanished, leaving the upper sky nearly unoccupied. The arch also was now totally gone, and in its place there were only irregular patches of yellow light, of varying radiance. At a quarter past nine, the upper sky was again filled with pale flashes; in the north were perpendicular pillars of light comparatively stationary. At half past nine, no material change : at ten, all had assumed a very ordinary appearance, merely large clouds of pale light were visible; after which I took no farther notice of it. I listened, as on other occasions, with great attention, but could not hear the slightest sound proceeding from the meteor. The southern sky, near the horizon, was unoccupied during the whole of the continuance of the Aurora. 
C. - The brightness of the meteor, and the rapid and sudden changes of position among the beams, resembling the evolutions of an army, are calculated to strike awe into the minds of the vulgar and ignorant, especially where its appearance is an unusual occurrence; but even here, where it is so common, when an Aurora of unwonted splendour occurs, I have often heard people, sagely shaking their heads, prophesy that "something" is going to happen.

$F$. - No doubt some of the accounts of armies fighting in the air, of which we read in profane history, may safely be supposed to be nothing more than the Aurora Borealis : but I am very far from thinking with many of the philosophers of our day, that all the portents and wonders of ancient days are to be reduced to the effects of natural causes. Do not these men, endeavouring to be "wise above that which is written," forget that the "immutable laws of nature," so called, are but the laws which God has been pleased to impose upon the objects of His creation, and which he has undoubted right to suspend at His pleasure? Still farther am I from believing that the clashing hosts, and fiery falchions suspended in the air, over devoted Jerusalem, during her last struggle, were, as some would persuade us, but a bright Aurora. Oh! no: they were foretold by our Lord: "fearful sights and great signs shall there be from heaven ;" and were no doubt contrived by the skill of the "Prince of the power of the air," who, it was said, should, with his lying wonders, deceive almost the very elect : the reprobate Jews, for their unparalleled sin, being given up to judicial blindness, to strong delusion, that they might believe a lie. * * * But yonder is a light more cheering, if less splendid, than the Aurora, - the rays from our own cottage windows. 
IV.

\section{MARCH 1st.}

"Sundog."-Insects.-Pine Grosbeak.-White-winged Crossbill.-Common Crossbill.-Pine Finch.-Tree Sparrow.-Golden Eye.-Snow Owl.-Masuippi River.-American Hare.-Operation of "Twisting." -Moose.-Anecdote.

Charles. - A few evenings ago, I observed a curious phenomenon: about half an hour before sunset, the sun being about $4^{\circ}$ above the horizon, at the distance of about $22^{\circ}$ on each side was a fragment of a halo, marked with the prismatic colours; each arc resting on the horizon, somewhat like a pillar of coloured light: the red rays were next the sun, the green, blue, violet, and indigo were very faint, yet perceptible: the height to which the arcs extended from the horizon was about $6^{\circ}$, but they were not quite uniform in this respect. The sky was bright and cloudless, except a slight haze in the west, near the horizon, sufficient to cast a dimness over the distant mountains. The day had been very cold, the thermometer in the morning soon after sunrise standing at $17^{\circ}$ below zero. As the sun approached the horizon, the meteor became fainter; and gradually disappeared, when the sun was sunk.

Father. - The phenomenon is not uncommon: I have seen it about sunrise as well as in the evening: the common people call it a "sundog." I do not know that it differs from a common halo, except in having the prismatic colours, which I am not meteorologist enough to explain. The tints of a rainbow are caused by each falling drop of rain decom- 
posing the ray that enters it; but in this case it was far too cold for any rain : if anything was falling between you and the sun it must have been snow, and if anything was floating in the air, it must have been minute spiculæ or crystals of ice. The haze you speak of was doubtless the cause, and the reason why the circle was not perfect was, that the mist extended no higher than the point at which the arcs ceased to be visible.

C. - After the sun was set, the mist was much more distinctly visible, and I observed that it abruptly ended at about that height.

F. - You have not yet observed any symptoms of activity in the insect tribes, I presume?

C. - Few, except such as are to be found throughout the winter, are to be met with : a few tipulidan gnats fly abroad on sunshiny days. I have lately observed in pine-woods in one particular place, several insects crawling about the snow, exactly resembling small Tipula, even having halteres, but totally destitute of wings. They are about one-fourth of an inch in length : they have been rather numerous; I took six of them in one evening.

$F$. - They are doubtless the Chionea Araneoides : it is singular that I have observed these in company with another very remarkable apterous insect, belonging to a winged family, (Panorpida,) in some numbers. I allude to Boreus Hyemalis, an insect much like a flea. I have never seen either but in one spot, the black-woods to the south of the Masuippi, near its junction with the Coatacook; it was at this season and on the snow.

C. - That is the same place at which I found them. And what is likewise remarkable, I found, a few days ago, a moth crawling on the snow, a rather large Tortrix; but 
putting it into a pocket-box, before I had opportunity of examining it, it had quite defaced its wings, by fluttering about.

F. - The appearance of a living moth at this season is indeed worthy of note. - Ah! there is a flock of those beautiful birds, the Pine Grosbeaks (Loxia Enucleator). They are by far the most splendid of our winter birds; observe how rich the crimson of the males: the females, as in most instances where the males are red, are of a yellowish-olive colour. They delight in the horrors of winter, for even in the desolate region around Hudson's Bay, they are only transient spring visitors, passing on still farther to the north. I have seen the species in Newfoundland, but I believe that there, as here, it is rare.

C. - Among some of the common little crossbills that were hopping about the house yesterday, I noticed one that differed from them, by having two bands of white across the wing. Was it a distinct species?

$F$. - Yes : it is called the White-winged Crossbill (Curvirostra Leucoptera). This is another of our rare birds ; so much so, that the indefatigable Wilson, in his researches over this continent, appears never to have met with more than one specimen. Bonaparte says it is common round Hudson's Bay, and on the borders of Lake Ontario. I observed a pair last spring, as late as the 29th of April, in a flock of the common species, which I closely and particularly examined. They were fearless, and allowed me to stand within ten feet of them, for some time. I observed in the male, a black mark proceeding from the back of the eye, curving outward, and ending about half an inch below the eye, which Wilson has not noticed: the tips of the quill feathers appeared to be edged with white, forming as the wings met across the rump, three or four short white bands. The female had the white bars on the wing narrower than the 
male, and the curved mark near the eye was visible only by a slightly darker shade.

C. - The common Crossbill (Curvirostra Americana) is a pretty bird, and seems to be a general favourite: probably because, like the Redbreast of our own country, he manifests such a saucy familiarity with us; hardly making room for us to pass by, and immediately returning to his picking at the dish-washings of the sink, or the scraps of the kitchen. Perhaps too, we prize him more, because birds are now scarce, and he reminds us of brighter and sunnier days.

$F$. - When I was in Newfoundland, a friend one winter's day knocked a Crossbill from the summit of a young pine, which proving to be only stunned, we put into a cage. He became immediately very familiar, and much amused us by his tricks, crawling about the inside of his cage, and even from the roof, like a parrot, grasping the wires with his claws, and using his bill as a third foot, to help himself along. After a few days we opened his cage, but he did not appear to have pined much for liberty, for he crawled out and in for some considerable time before he brought himself to bid adieu to his wiry home. The very remarkable conformation of the bill in this genus has been, by purblind philosophists, stigmatized as a defective organization; but in reality it is peculiarly adapted, like all the other works of the allwise and benevolent God, to the purposes for which it is designed ; its mode of obtaining its food being as follows :The seeds of the coniferous trees, on which it principally subsists, are concealed beneath hard, woody scales, lying tightly and closely on each other. The bird, bringing the tips of the mandibles together, inserts the united points beneath the scale, then separating the points, forces it outwards, and extracts the seed.

C.-What other birds are to be met with at this season? F. $-I$ believe I saw the Pine Finch (Fringilla Pinus) 
around our house a few days ago; a plain-coloured, but pretty little bird. The Tree Sparrow (Fringilla Arborea), easily known by a brown spot on the breast, is numerous every day, in cattle yards and around barns. I have observed some small flocks of the Golden Eye (Anas Clangula), swimming in those parts of the Masuippi River, which are unfrozen : it is a pretty little duck, and when it flies its wings make such a loud whirring as to be heard at a considerable distance. Mr. Armour of Sherbrooke showed me a fine specimen of that handsome bird, the Snow Owl (Strix Nyctea), which had been shot in that neighbourhood. It stands about two feet high; the plumage is soft and beautifully white, with crescent-shaped spots of dark brown all over the body. These, beside the Snow-bunting, the Titmice, Woodpeckers, Blue and Canada Jays, are, I believe, all that have lately fallen under my observation.

C. - What is the reason that the Masuippi is not frozen so solid as the Coatacook?

$F$. - I suppose it is owing to its greater rapidity: it is always open much later, and breaks up much earlier, and there are frequently patches of open water through the winter.

C. - Yonder goes a rabbit.

F. - More properly the American Hare (Lepus Americanus), the rabbit being unknown on this continent, though it is, with us, universally called by that name. 'It is found pretty generally over North America, from this province even to the Gulf of Mexico, where it is more common than it is with us. Here its winter coat is nearly white, as in the one which we have just seen, but in summer it is of a yellowish brown, with a white tail. It makes a nest or bed of moss and leaves in some hollow tree or old log, whence it issues chiefly by night. Though not so much addicted to gnawing as the squirrels, yet as its teeth are formed in the 
same manner, it probably resembles them in its food, eating various kinds of nuts and seeds, as well as green herbs. It is said also occasionally to peel off the bark from apple and other trees. - A singular mode of taking small furred animals out of hollow trees, logs, \&c. is practised in the south, called " twisting." I once saw it performed on a rabbit (so called); the dogs had tracked him and driven him to his hole in the bottom of a hollow hickory tree. The hole was too small to admit the hunter's hand with convenience, so we made the negroes cut down the tree, which was soon effected. When it fell, we watched the butt, to see that the rabbit did not run out, but he did not make his appearance. The hunter then got some long slender switches, and probing the hollow, found that the rabbit was at the farther end, several feet up the trunk. He now commenced turning the switch round .in one direction, a great many times, until the tip of it had become so entangled in the animal's fur, as to bear a strong pull. He then began to pull steadily out, but the rabbit held on as well as he could, and made considerable resistance, crying most piteously, like a child: at last the skin gave way, and a great mass of fur and skin came out attached to the switch, pulled off by main force. He now took a new switch, and commenced twisting again, and this time pulled the little thing down, but the skin was torn almost completely off the loins and thighs of the poor little creatare, and so tightly twisted about the end of the stick, that we were obliged to cut the skin to get the animal free. I thought it a curious, but cruel expedient.

C. - What large cloven-footed animal has made this trail ?

$F$. - It is probably nothing more than some stray cow; but the footmarks have been enlarged by the late thaw, without losing their shape. I was once deceived by a simi- 
lar trail, into the belief that actually a moose had passed; nor could I easily bring myself to relinquish that opinion. Indeed it would be nothing extraordinary, as a Moose ( Cervus Alces) was this winter killed near Sherbrooke, of the flesh of which I partook.

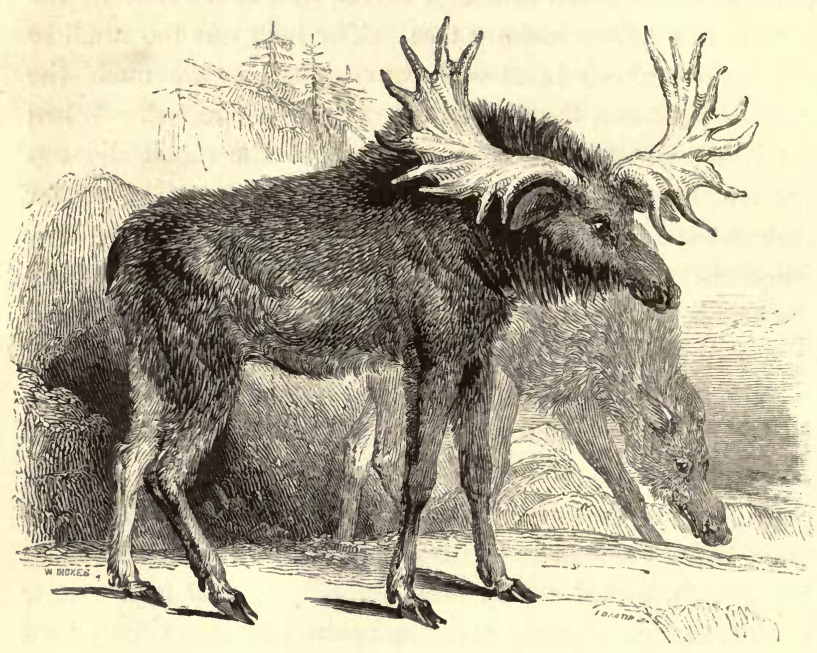

MOOSE.

Cervus Alces.

C. - What was it like?

F. - Much like beef in appearance, but more juicy and tender: I thought it of very delicate flavour. Captain Colclough kept one at Sherbrooke alive, for some years. Moose are frequently taken in the Indian-stream territory, a kind of neutral ground on the boundary of this province and New Hampshire, claimed by both governments. Paths are worn by the feet of these animals, leading to the brook, whither 
they resort to drink; and they are caught by traps laid in these paths. I am told that they are almost always dead when found, as they soon kick and worry themselves to death. I saw a stuffed moose at Quebec, but it was not well mounted : if I recollect rightly, it was taller than a horse. "There is an opinion prevalent among the Indians, that the moose, among the methods of self-preservation, with which he seems more acquainted than almost any other animal, has the power of remaining under water for a long time. Two credible Indians, after a long day's absence on a hunt, came in and stated that they had chased a moose into a small pond; that they had seen him go to the middle of it and disappear; and then, choosing positions from which they could see every part of the circumference of the pond, smoked and waited until evening; during all which time they could see no motion of the water, or other indication of the position of the moose. At length, being discouraged, they had abandoned all hope of taking him, and returned home. Not long afterwards came a solitary hunter, loaded with meat, who related, that having followed the track of a moose for some distance, he had traced it to the pond before mentioned; but having also discovered the tracks of two men, made at the same time as those of the moose, he concluded they must have killed it. Nevertheless, approaching cautiously to the margin of the pond, he sat down to rest. Presently, he saw the moose rise slowly in the centre of the pond, which was not very deep, and wade towards the shore where he was sitting. When he came sufficiently near, he shot him in the water. The moose is more shy and difficult to take than any other animal. He is more vigilant, and his senses more acute, than those of the buffalo or caribou. $\mathrm{He}$ is fleeter than the elk, and more prudent and crafty than the deer. In the most violent storm, when the wind, and the thunder, and the falling timber are making the loudest and most inces- 
sant roar, if a man, either with his foot or his hand, breaks the smallest dry limb in the forest, the moose will hear it : and although he does not always run, he ceases eating, and rouses his attention to all sounds. If in the course of an hour, or thereabouts, the man neither moves nor makes the least noise, the animal may begin to feed again, but does not forget what he has heard, and is for many hours more vigilant than before." I know not whether the moose has ever been tamed, but $I$ think it not improbable, that it could be trained to harness, as well as its congeners the reindeer and the wapiti : and it would, from its size and strength, be more serviceable than either of them. But in a new country, like this, where alone the opportunity for such an experiment is to be found, the inhabitants generally have little time, and less inclination, for innovations. 


\section{V.}

\section{MARCH 15 th.}

Red-bellied Nuthatch - Voice and Habits - Fear of Man. - Insects. Torpidity.-Power of resisting Cold.-Mammals.-Birds.-Temperature of Cold-blooded Animals. - Why polished Surfaces are cold.-Laying up of Food by Insects. - Chambers of Mining Ants. - Mosses and Lichens on Trees.

Charles. - What bird makes that singular noise, "quank, quank, quank?" Yonder woods are resounding with it; I should think it is a large bird from the noise it makes.

Father. - We will go towards it: perhaps we may see it.

C. - The sound still seems to recede as we advance.There it passes directly over our heads, yet no bird is visible. Hark! now it proceeds from the right hand, seemingly about two hundred yards distant.

F. - Look at that old maple, a yard or two on your right: - watch the trunk.

C. - I see nothing. Oh! yes : there are two little bluebacked birds, crawling up and down, something like mice. Can it be possible that the notes which I supposed so far off proceed from them?

$F .-$ Yes : but how faintly they are now uttered; and even while we look at them we can scarcely believe that the sound does not reach us from a considerable distance. But they have observed that we are watching them: see how warily they keep on the opposite side of the tree. Stand still a few moments, and we shall see them again. 
C. - Ah ! there they are, peeping round the edge : how curious they seem respecting us! how they stretch out their necks to observe us !

$F$. - It is the red-bellied black-capped Nuthatch (Sitta Varia): its food is insects, which it finds even at this season, beneath the bark, and in the crevices of the trees. Its feet are large and strong; fitted to take hold of the projections and roughnesses of the bark, by which it is able to crawl freely on the perpendicular trunk, with the head either upward or downward; or even on the under surface of the branches.

C. - Where are they gone? These woods, which just now were full of their notes, are now quite deserted and silent: even the titmice have left us too: all the birds have gradually sneaked off, thinking us disreputable or dangerous neighbours.

$F$. - The unvarying effect of the Divine decree: "the fear of you, and the dread of you, shall be upon every beast of the earth, and upon every fowl of the air, upon all that moveth upon the earth, and upon all the fishes of the sea." It is not, however, always a subject of gratification to a benevolent mind, to find oneself an object of terror and detestation ; though it must be confessed it is not a causeless dread; for man has most tyrannically abused the dominion over the inferior animals, which was given him for better purposes.

C. - See: there are some tokens of returning spring: the small flies, different species of Muscida, are busy preening their wings, and rubbing their feet together, on the dunghill. They have probably been newly hatched by the heat.

$F$. - That is scarcely likely; for as the manure has all accumulated through the winter, it is not at all pro- 
bable that it would contain pupæ: I should rather say, that these are all the insects of last summer, and being now revivified by the increasing warmth of the season from their long torpidity, are at once setting about the business of their lives. For this purpose they resort to the dunghill, as from its genial warmth it is a fit nidus for the deposition of their eggs. Insects have but one object in existence, in the perfect state, - the continuation of their race: this is suffcient to overcome every other passion, and even almost to conquer death itself; for it is exceedingly difficult in most instances to deprive a female insect of life, before she has deposited her eggs, except by actual demolition.

C. - It is strange how animals so small, and with so little vital heat, can survive the severity of a winter like ours.

$F$. - It would appear from many experiments and observations, that insects, and perhaps all animals with cold fluids, are able to resist the effects of very low degrees of temperature. I have myself had larvæ so hard frozen as to be broken in two like a piece of solid ice, and yet found that on being thawed, those which had not been broken, but had been just as solid as the others, were quite lively and apparently uninjured. A few days ago, I found a large thick larva of a Chafer (Melolontha? ) in the heart of a birch-tree, surrounded by its ejecta, which, as well as the grub itself, were hard frozen. In this instance too, the insect was found to be alive, when thawed by the warmth of the house. I have had ants (Formica) inclosed in the midst of a piece of solid ice, having fallen into the water before it had frozen, which, on being melted out, and placed awhile in the sunbeams, gradually gave signs of life, and at length crawled about, as if nothing had happened. These and other observations show that insects sustain, without injury, severities of cold which would be fatal to the superior animals ; but it seems that in 
general those species which survive the winter in the imago state become torpid; and this negative sort of existence is found in other animals to be a preventive of the ordinary effects of great cold on vitality.

C. - How is it that animals can remain in a state of torpidity without food, when a few days' fast, in ordinary circumstances, would be fatal ?

$F$. - In a state of health, I believe (without knowing much of physiology) the sensible and insensible evacuations continue whether food be supplied or not. But if the supply of nutriment be cut off, the secretions and evacuations going on, with nothing to make up the deficiency, life ceases from absolute exhaustion. In some diseases, in which the secreting organs are disordered, though scarce any food be taken, yet hunger is not felt. It is probable that in total torpidity, as in the case of the cold-blooded animals, reptiles and insects, secretion ceases altogether; while it would seem that in the case of such mammalia as hybernate, as the bear, marmot, dormouse, \&c. secretion goes on, but very languidly. To supply the waste occasioned by this secretion, these animals on going into their retreats are very fat; but on coming out in the spring, they are invariably poor and lean, proving that this superfluous fat has been absorbed into the system, so that it may be considered as a magazine of nutriment.

\section{$C$ - Do birds ever become torpid?}

$F$. - From their superior powers of locomotion, there is not the same necessity in their case, as they can, and most of them do, migrate from one country to another at the approach of winter, yet as some species do remain in the coldest countries, at least as far north as Hudson's Bay, this does not altogether account for the difference. The blood of birds is much warmer than that of any other animals, and their peculiar covering is perhaps the most perfect non-conductor of heat, of all known substances. There have not been 
wanting men, however, and among them some names of the highest rank in natural science, who have believed the reports of swallows having been found during winter in holes and caves, or beneath the mud of ponds, in a state of torpidity. But it does not appear that these reports rest on any evidence of sufficient weight to command belief, and they are now generally exploded.

C. - Is there no heat at all evolved by cold-blooded animals? or are they always of exactly the same temperature as the surrounding atmosphere?

$F$. - I have some reason to think that a very small quantity of heat is evolved by their circulation; sufficient to be quite appreciable by the senses, where many are confined in a small space; as when a thickly-peopled hive of bees is about to swarm, the temperature within is considerably above that of the external air : this heat can only be produced by the bees themselves. Another proof is, I think, to be found in the fact, that insects seek crevices and corners to hybernate, especially during the pupa state; this may be partly for concealment, but chiefly I conceive for protection from cold. The same end is probably designed in the silken cocoons of many of those moths which pass the winter in pupa, as silk is a non-conductor of heat. But if their temperature were not superior to that of the atmosphere, they would need no protection from non-conducting substances, as the air could abstract no heat from them.

C. - But if you touch a caterpillar or a chrysalis, it seems much colder than the air.

$F$. - Our senses are not to be at all depended on, in estimating the comparative temperature of different bodies. The feeling cold, or warm, depends on the greater or less power of abstracting heat from our body, and this power depends in a great measure on the smoothness, as well as texture of the abstracting substance. 
C. - Why do polished substances conduct heat with more facility than rough ones?

$F$. - When we ask the reasons of those laws which we find imposed on nature, we are very apt to lose ourselves in the labyrinths of doubt and uncertainty ; yet if I might presume humbly to venture an opinion on this subject, I should conjecture that it may be owing to this fact : polished bodies come into a closer and more general contact with the substance that touches them, and consequently abstract heat from a larger surface, whereas, rough bodies touch only at the minute prominences which cause their roughness, and so abstract heat only from those points with which these prominences have contact.

C. - Do any species of insects lay up a store of food for their consumption in winter?

$F$. - I am not aware that any do, except bees : it is very generally supposed that ants collect grains of corn, and store them up; and this is believed to be confirmed by the words of Agur; "The ants are a people not strong, yet they prepare their meat in the summer:" and those of Solomon, "Go to the ant, - which provideth her meat in the summer, and gathereth her food in the harvest."-Prov. xxx. 25.- and vi. 6. 8. But in the first place here is nothing said about laying up for winter, but merely that she works while she can, makes the best use of her time; and in the next place, the Scriptures are not designed to teach us facts in natural history; it is quite sufficient for their purpose if the illustrations of truths, drawn from nature, are commonly supposed to be correct. Modern naturalists have proved that the ant does not feed on corn, but on saccharine or animal substances; and that what are thought to be grains of corn in their nests, and often in their mouths, are neither more nor less than the pupæ, or rather the cocoons containing them. Besides this, in cold climates, 
ants become torpid in winter, and where the climate is not cold enough to suspend their animation, it is probable they can always find food throughout this season.

C. - I have often found ants in a torpid state, in the trunks of trees, which they have mined into galleries and chambers ; but I have never found any store of grain, or other food.

$F$. - The chambers of the wood-mining ants, especially the large species that we often find in the wood of cedartrees, \&c. (Formica Pubescens?) are very curious : it would seem impossible to construct partitions so thin and so smooth with no other instruments than their jaws. They are often as thin as paper, and without any roughness on the surface, although generally formed in the soft-timbered trees, which do not readily bear a smooth surface. It is effected altogether by the tedious process of abrading minute particles by means of the jaws; though by what instinct they ascertain when the requisite thinness is attained, we know not. The formation of the thin cells of the honeycomb of bees is said to proceed on nearly the same principle; a block or mass of wax is first laid down, and the cells are excavated out of it, by the jaws of the bees: the walls or partitions being left, and the remainder abraded away, and redeposited in another place.

C. - What causes the remarkable variegations, of different colours, which mark the barks of many forest trees?

$F$. - They are chiefly owing to parasitic plants of the cryptogamous class; mosses and lichens. The bark of the beech and maple, particularly the soft maple, (Acer Rubrum?) is marked with patches of white and yellow, which if we look closely, we shall find to be a thin and papery lichen. The loose scales, of which the external bark of the spruce is composed, are sometimes spotted with a similar substance, perhaps the same species. On the beech and 
maple is likewise found another curious lichen (Jungermannia) consisting of a multitude of small, very close, brownishblack ramifications : these black patches are usually small. Ash, elm, leverwood, basswood, and sometimes birch, have their trunks clothed with larger and thicker masses: a branchy moss (Hypnum?) of a dull green, occurs, mixed with a bright green moss (Hypnum?), in large loose bunches, covering great portions of the trunk together. With these there is often found a large, broad lichen (Pulmonaria), pale brownish grey, palmated like the horns of a deer : this is usually found on leverwood (Ostrya Virginica.) The first mentioned, and perhaps some of the others, often occurs on rails and boards which have been much exposed to the weather.

C. - There seems to be great variety in the different lichens.

$F .-Y e s$; and their number is very great; but from the minuteness of many, and the obscurity which exists in the fructification of all, much difficulty is found in arranging them, and they are yet comparatively unknown, even to botanists. Indeed the study of the Cryptogamia may be considered as a science in itself, requiring a close, undivided, and continued attention.

$C$ - The spring begins to announce its approach by the increasing power of the sun; the snow melts, and becomes soft and "rotten" as it is called, even when the temperature in the shade is much below $320^{\circ}$ The runners of sleighs cut through the snow, and rest on the ground: travelling will soon be over for a while.

$F-$ We may have heavy snow-storms, and some very cold weather yet. Spring does not come in a day : old Winter is loth to give up his dominion, and does not resign it without many struggles. 
VI.

\section{APRIL 1st.}

Sugaring.-Tapping the Maple.-Yield.-Favourable kind of Weather.Extent of a Sugary.-Collecting Sap.-Boiling down.-Rude Implements.-Syrup.-Sugaring off.-Maple-honey.-Cooling.-Sugar from other Trees.-Sap of the Birch.-Cocoon of a Moth.-Catkins of Poplars and Willows._Lombardy Poplar.-Caterpillars. - Silpha. - Spiders.-Ox-Gadfly.-Muscles.-Canada Goose.-Bare Ground around Stumps. - Resort of Insects. - Caterpillar of Buff-Leopard Moth.Clouded Water-fly.-Larva of Dragon-fly.-Progressive Motion.-Singular Organ.-Mouth.-Mode of taking its Prey.

Father. - Will you accompany me, Charles, on a walk? The late heavy rains have removed nearly all the snow, and the present fine weather is exhilarating to the spirits.

Charles. - Yes, it is indeed a beautiful morning, and the advances which all nature is making to a renewal of life and animation make it still more cheerful.

$\boldsymbol{F}$. - Let us lift our hearts to our beneficent Father, in gratitude for His providential love to His creatures, and for His constant care for the happiness of even the meanest of them. - We will go into the Sugary, where the men are collecting the sap from the maple-trees, which has been flowing for two or three days.

C. - I have a curiosity to see the process, for I cannot understand how sugar can be made of the sap of a tree: I always thought until lately that it was procured only from the sugar-cane of tropical climates.

F. - The sugar is in itself the same, whether produced 
by the cane, the maple, or the beet ; for from all these it is manufactured for consumption. But few substances are more generally diffused through the vegetable creation than sugar, and it is even found in animal substances. It is true that in many of these it can be detected only by the chemist, but in dried fruits, in germinating grain, especially barley, in many roots, as turnips, parsnips, \&c., in the stalks of maize, and even in straw, it can be readily appreciated by the senses. A most singular discovery has been made, that starch and sugar are chemically the same, composed of the same elements, and in the same proportions, and that in certain circumstances, the former becomes changed to the latter in every property. The cereal grains, or corn in general, are principally composed of starch, which in the process of germination is transformed to sugar; this is the manner in which malt is made out of barley.

C. - I suppose these tubs are set at the foot of the trees to receive the flowing sap.

$F$. - Yes ; one to every tree, except where two grow so close to each other as to flow into one tub or bucket. You see, a hole is first bored in the trunk with an auger, about an inch deep; some cut an oblique notch with the axe, but this wounds the tree unnecessarily, and causes premature decay. Beneath the hole or notch a semicircular incision is made with a large iron gouge, called a tapping iron, into which a spout rnade of pine wood, guttered down the centre, is driven, to catch the sap as it flows from the hole above, and conduct it down to the bucket beneath. This is our custom; but in the state of Vermont, I have seen a much handier way. A nail is driven into the tree just below the spout, and on this the bucket is hung by a hole in one of the staves ; the advantages are, that a shorter spout serves, and the sap cannot be overturned by hogs or stray cattle, as it frequently is when it stands on the ground. 
C. - How much sap does a maple yield in a day?

$F$. - That varies exceedingly, according to the size, age, health, and sifuation of the tree, and to the weather. Sometimes a tree will yield in twenty-four hours, a gallon or two; at other times not a drop can be collected. A young tree, provided it has attained a growth of about a foot in diameter, yields better than an old one; and one growing in a clearing, that is, raised there, better than a forest tree.

C. - What weather is most favourable?

$F$. - A warm, sunny day, after a frosty night. In frosty, cold weather, or rainy weather, or when the nights are mild, the sap almost ceases to flow; but let such a night as we have just had, be succeeded by such a warm day as this, and, as you see, the sap drops rapidly, and keeps the men going. Sometimes, it runs all night.

C. - How many trees generally compose a sugary?

$F$. - From two to three hundred are as many as can conveniently be attended to, at one boiling place or camp. but sometimes a thousand are tapped, with two or three camps. If the trees generally are near together, more can be tended than if they are scattered; and when little or no snow lies on the ground, more business can be done than in deep snow, owing to the greater facility of carrying the sap to the camp. I have known the snow more than two feet deep at the sugar season, causing it to be very laborious for the men to move about; and from the shelter of the forest it continues unmelted there much later than in the fields and roads.

C. - How can the men carry the sap? the buckets have no handles.

$F$. - These are not nearly full either. They carry a couple of pails suspended from each end of a yoke fitted on their shoulders, as you have seen milkmen carry their pails at home. They go a regular round with these, visiting every 
tree in succession, emptying into their pails the contents of each bucket, and replacing it under the tree, until their pails are filled, when they carry them to the camp, empty them into a large cask called a holder, and proceed again on their round. When this holder is nearly full, it is considered time to begin boiling. - Taste this sap, and tell me how you like it.

C. - It is a pleasant drink, perceptibly sweet, but not cloying : it is like water with a very little sugar dissolved in it. How much sugar will a tree produce in one season, on an average?

$F$. - From two to four pounds, in a favourable season, for as much depends on the season in this, as in any other object of the farmer's attention. Two thousand pounds weight are sometimes made by a farmer in one spring, worth perhaps fivepence per pound, making a sum of upwards of forty pounds currency.

C. - What are the men engaged in, when not carrying sap, or boiling?

$F$. Chiefly in felling trees, and cutting and splitting them up for firewood, to be used in boiling down, as this process consumes a large quantity of fucl. They select those hard-wood trees that stand near the camp, such as superannuated maples, beeches, birches, \&c.

C.. I I see a fire yonder: I suppose that is the camp.

$F$. - Yes : we will go thither, as they are boiling; it may interest you to see it. — You perceive here are two forked poles stuck into the ground, across which another strong pole is laid, from which the large boiling kettle is suspended by a chain over the fire. In some parts of the process it is necessary to stop the boiling very suddenly, and we do this by throwing shovelfuls of snow on the fire; but I have seen it managed in a much neater manner, thus :- The 
kettle is suspended over the fire from the short arm of a long lever, which works around a pivot on some stump near: by pushing the long arm of this lever, a man can instantly swing the kettle off the fire with all ease; and these posts and cross-beam are not needed. But we are a very unimproving people. See the elegance of our utensils! Here is a tin basin with a long crooked stick for a handle; this is to bale the sap or sugar in or out; here is a tin skimmer, with a similar handle, to scum the liquor; a shovel made with the axe, out of a piece of board ; and a poker, made of a beech sapling. We take as many of our materials as we can, you see, from the surrounding woods, perhaps in compliment to the presiding dryads and satyrs of the place; or, perhaps, -from necessity.

C. - What is in the pot now?

$F$. - It was filled this morning with sap out of the holder, that large cask that stands beside you, and as the watery part has been evaporated, its place has been supplied by repeated fillings-up from the same reservoir. If you taste it, you will find that it has become very sweet and much thicker than the sap. A piece of fat pork thrown in, has the effect of refining it, by making all extraneous matters rise in a thick coat of scum, which is carefully taken off from time to time as it accumulates. When it has boiled to a considerable consistence, about that of oil, it is baled out into this other cask, and is called syrup. The first part of the process, the first boiling, is then complete.

C. - What more remains to be done?

$F$. - The same process is repeated, when they have sap enough; and the syrup is added to what is already in the cask, until there is a sufficiency collected to "sugar off," as it is called; that is, to complete the process, by boiling the syrup over again, until it will granulate or crystallize. This 
is a delicate operation, and requires constant attention; they fill the kettle with syrup, adding the indispensable piece of pork for the same purpose as before; as the syrup wastes away, it is refilled, and kept constantly skimmed ; it is needful to keep a regular fire, and towards the close of the business to watch the sugar attentively, to stop the boiling at the right instant, as a minute's delay may spoil the whole, or at least greatly injure it. When it is about half done, it is called maple-honey, from its resemblance to honey in taste, consistence, and appearance; it is, however, to some more agreeable, being less cloying. In this state, the good matrons generally come, and take a tribute, and it forms a pleasant addition to the simple fare of our tea-table.

C. - How is it known when it is time to remove it from the fire?

$F$. - By a very simple, but infallible test. They take a twig, and bend the end of it into a loop or circle, about an inch wide : dipping this into the kettle, and taking it out, a film of the sugar is stretched across the bow ; they gently blow on this with their breath; if the breath breaks through, it is not done, but if the film is sufficiently glutinous to be blown out into a long bubble, it is ready to granulate; and out goes the fire.

C. - Is the sugar then made?

$F$. - Yes : it is immediately baled out of the kettle, and carried home in the buckets : if soft sugar be intended to be made, it is poured, when somewhat cooled, and granulating, into wooden vessels, the bottoms of which are bored with holes : the surface and sides soon become hard, having crystallized first ; this crust is repeatedly broken, and the whole stirred together: the molasses gradually drains through the bottom, and the sugar is left, exactly resembling the canesugar; I have seen some as light-coloured as any from the Mauritius or East Indies. But it is more usual to let the 
sugar cool in vessels, without either disturbing it, or draining off the molasses, so that it becomes a mass, nearly as hard as rock, and very dark in colour.

C. - The maple is a very useful tree; does any other species produce sugar?

F. - The White Maple (Acer Eriocarpon?) yields sap more readily than the Rock Maple (A. Saccharinum), and it is said to be more abundant in sugar; but it is comparatively rare as a large tree. The Butternut (Juglans Cinerea) likewise will yield sugar from its sap, and probably other trees. The Birch (Betula Papyracea) is often tapped, and the sap, (evaporated by boiling) exposed to the summer's sun, by which it is made into a good vinegar; whence I conclude it must contain sugar, probably mixed with other matters. The fresh sap of the birch has a pleasant, slightly acid taste. It has a curious property, peculiar to itself, I believe, for I have never observed it in the sap of any tree but the birch ; whereever it flows, it leaves a mass of fungus-like, mucilaginous substance, of a delicate pink hue, which probably has some affinity with what is called "the mother" in vinegar. From the stumps of trees which have been felled during the winter, the sap flows in spring so profusely, that I have seen them covered with this substance,-a great resort of insects.

C. - How large must the maple become before it will yield saccharine juice?

$F$. - The sap contains sugar from the first period of its existence, but it is not usual to tap a tree until it. attains about the diameter of a foot at the bottom; too early tapping is injurious to the health of the tree, and causes premature decay; old trees, too, produce little or none, and are cut down for fuel.

C. - Is there never more than one incision made in a tree at one time?

$F$. - With us there is no more; but in the United States 
it is not unusual to tap a maple in three or four places at once. Michaux, in his North American Sylva, quotes a curious fact from the Greensburgh Gazette :- "Having introduced," says the writer, "twenty tubes into a sugarmaple, I drew from it, the same day, twenty-three gallons and three quarts of sap, which gave seven and a quarter pounds of sugar;-thirty-three pounds have been made this season from the same tree, which supposes one hundred gallons of sap." No doubt more sap could be collected by this means, but I conceive it must be very detrimental to the health of the tree to extract so large a quantity. of its nutritive juices.

C. - How long does the sugar season continue?

$F$. - Generally it lasts about three or four weeks; but there are many days in this period, during which nothing at all can be done. If the spring is late, it is sometimes necessary to close the sugaring prematurely, in order to commence the more important operations of agriculture. As I suppose your curiosity is satisfied, we may as well prolong our walk, and see what is going on in the world of Nature, especially as the weather is so inviting.

C. - I picked up, some days ago, on the bank of the Coatacook, a cocoon, lying on the snow, resembling in texture those of the large Cimbexes, but much larger, nearly of the size of a pigeon's egg, of a dirty flesh-colour. It had evidently been spun in the midst of leaves, ( $I$ think those of the beech,) for it showed every fibre of them indented, like the impression of a seal, on every part of the surface. It contained nothing but the brown exuvia of a large caterpillar, probably of a Saturnia; for the skins even of green caterpillars become brown when cast. There was an opening in the side. 
F. - I know Saturnia Polyphemus is found here, and I think it probable $S$. Luna too; both of them splendid moths. - Here are the first signs of returning spring that I have yet seen in the vegetable creation. The catkins of the Poplar (Populus Tremuloides), and those of some of the Willows (Salix), are just beginning to show their silky heads out of their bursting envelopes. These trees, like many others, blossom before they put forth their leaves; the catkin, or ament, as it is botanically called, being a spike of close-set, minute flowers. Both of these genera, the poplar and the willow, have the male and female flowers on different plants, but the catkins resemble each other. Of the genus Salix, Professor Eaton gives, in his excellent "Manual of Botany," no less than forty species as indigenous to North America. They chiefly delight in wet places, but do not abound in the primitive forests. Of all the plants in this class, fertile seeds can be produced only by the proximity of the two sexes, so that the farina from the stamens may impregnate the pistils. Common as that graceful species, the Lombardy Poplar (Pop. Dilatata) is, both here, and all over the United States, it is said, that no pistillate or female plant of this species has ever been brought to America, and consequently, being all males, no seed has ever been produced here.

C. - How have they then been multiplied?

$F$. - By suckers or shoots, which take root very readily; but as these twigs or suckers, "however recently inserted, feel the effects of age in the same degree as the twigs remaining on the original tree, the species is becoming enfeebled with age in our country, so that very recent shoots will hardly withstand a severe winter. We see but the feeble limbs of an exile in dotage, though yet sustained in a thousand localities."

C. - I have lately observed several caterpillars, thinly 
covered with dusky hair, crawling on the snow; and yesterday I found in the same situation, a great many specimens of a small Carrion Beetle, about one-sixth of an inch long, with antennæ slightly clubbed (Omalium - ?); they gave out a rank smell. These are the first beetles I have yet seen abroad. A few small brown spiders were likewise straggling over the melting snow.

F. - The larvæ of the Ox Gad-fly (Oestrus Bovis), commonly called wormuls, (originally worm-holes,) are now to be found in the bodies of oxen and cows. They make large lumps chiefly in the backs of these cattle, in the middle of which is a hole large enough to admit a quill: if you press the lump, a quantity of pus comes through the orifice, and if the pressure be increased, the large, fat, white maggot himself is squeezed out. I forced out two from one of our oxen this morning. They will not go into the pupa state, after having been thus violently ejected. —_ Let us walk on the ice of the river: here are some large Muscles (Anadonta?), and a number of their empty shells lying on the mud at the bottom of the water. I can see them through the open space between the ice and the bank of the river: as the water is shallow we may reach them with our hands. I have occasionally eaten them, and could not perceive any difference in taste between them and marine muscles.

C. - What trumpet-like note is that?

F. - It is the "honk" of the Wild Goose (Anas Canadensis): yonder is the bird, standing on the frozen river; some stray individual out of the many flocks which at this season are pursuing their aërial course to the desolate regions around Hudson's Bay, or perhaps yet farther north.

C. - Has the Canada Goose been domesticated?

$F$. - Yes; it is extensively kept as a domestic fowl in Europe, and is not the least important addition which 
America has made to the domestic ornithology of the old world. Its form and colour are handsome, and its flesh of approved flavour.

C. - It does not seem much alarmed at the sight of us, for it does not take to flight.

$F$. - It is a heavy bird, and rises awkwardly; and although when fairly launched on its course, a bird of powerful wing, its first flight is low, and appears heavy and laborious, as you may yourself observe; for now it rises.

C. - He is gone; probably to join the first flock he meets with, where he may sound his trumpet in concert. Where do they spend the winter?

$F$. - The flocks that pass over us in autumn in a southerly direction, probably scatter themselves over the estuaries and inlets of the deeply indented coast of the United States, particularly Chesapeake Bay, that paradise of water-fowl, the resort of uncounted myriads of aquatic birds of almost all species. In spring, the birds collect again in flocks, and their migrations northward are an unfailing indication that "winter is over and gone."

"When cloud-cleaving geese to the lakes are a-steering ;"

as Wilson has it ; though their destination seems far beyond the lakes.

C. - Why is the ground bare for a considerable distance around trees and stumps, when the snow still lies on the surrounding ground?

F. - Partly because the earth is always more elevated in such situations by the roots beneath, and therefore becomes sooner exposed; but the principal reason is, the radiation of heat from the central object; as we find that even when the snow has fallen to the depth of one or two feet, every weed or stalk of grass which rises above the surface of the snow, 
has, after a day or two's sunshine, melted a space round it of more than an inch from itself, so that it stands in a kind of tube of snow. ${ }^{x}$ Any dark-coloured object lying on the surface of snow, will speedily wear a passage for itself to the ground, on account of its power of receiving heat from the solar rays.

C. - Such situations are the resort of the few insects that are already stirring. See, around this dead maple-stump are several of those serricorn beetles with soft, brown elytra, and pink thorax (Brachynotus Bennettii). They eject from many parts of the body, when handled, a white glutinous fluid, which has a strong smell, and is perhaps intended as a defence. Here, too, are little green Cicadelle, hopping about very briskly ; and the Muscidae are as busy as bees, buzzing in the sunshine, and rubbing their feet together, and then off to another place: pioneers of the hosts that in a few weeks will make all nature alive with their gaiety. And here is a caterpillar of the Buff-leopard Moth, covered with thick tufts of short hair, tawny red in the middle, and black at each end of the body. It is one of the last caterpillars that crawl in autumn, and one of the first that appear in spring.

F. - This insect (Arctia Isabella) is called a rare species by Abbott, (speaking, however of Georgia,) who figures it on the Elephant's foot (Elephantopus Scaber), and mentions wild plantain, corn, and peas, as its food. His figure of the caterpillar is bad, as it does not give the idea of its hairiness. With us, common as it is, I do not know its food; I have often found it on the raspberry, but could not get it to eat. Yonder is a fly, which, from the peculiar fluttering motion of its wings, I take to be four-winged; probably it is either a moth or a Phryganea: run and catch it; it flies so slowly that you will have no difficulty.

C. - I have it ; it is neuropterous, but it does not appear to be a Phryganea, as the wings are incumbent. 
$F$. - It belongs to a tribe which I call Water-flies, as I have never seen any of the species except in the immediate vicinity of water. The species are numerous in this continent, forming the genus Semblis of Fabricius. This is an early kind, the clouded Water-fly (Perla Clio).

C. - What is this curious insect at the bottom of this little pond? It is an awkward, sprawling creature, something like a spider, of a light brown colour.

$F$. - It is the larva of a Dragon-fly, and an animal which, from its curious habits and conformation, may afford you some instruction and amusement. Take him up, and put him into your pocket box, with a little wet moss, that we may examine him at home; - you need not be afraid, it is perfectly harmless.

C. - Here is another long, semi-transparent worm, without feet, with a head retractile into the body. Of what is this the larva?

$F$. - Of some dipterous fly, probably one of the larger Tipula. I see some small larvæ of gnats and flies; catch them as food for your Libellula grub. - We have today seen many tokens of approaching spring: Nature is bursting from the icy chains with which she has been bound for so many months, soon again to teem with life and gladness. Yet many wintry storms, many bleak days and cold nights must pass, before we can say, spring has actually come.

C. - Now we are at home, what shall I do with my Dragon-fly grub?

$F$. - Put him into this basin of water. I would first have you notice his very singular mode of progression.

C. - He goes with a graceful sort of gliding or rather shooting motion, in a straight line, stretching out his legs 
behind close to his sides; but I do not see how he moves; he has no fins, and it is not by means of his legs.

$F$.-If you look closely, you may observe that previously to every motion the minute floating particles of earth, \&c. rush in a current towards its tail, and are then forcibly driven away; at which moment the insect shoots ahead. The tail of this grub is, in fact, a complete syringe, being furnished with a piston capable of being drawn towards the head, or thrust towards the tail, at will. On drawing it inward, the water rushes in; then this piston is forcibly thrust downward, ejecting the contained water in a jet or stream, which, by the resistance of the surrounding fluid, throws the insect forward. If you hold it under water in your fingers, so as to see the tail, you may observe the operation.

C. - The tail is composed of three triangular pieces, which meet exactly together, when shut; and when open, show another valve opening outwardly when the water is ejected. What a curious contrivance!

$F$. - But you do not yet know the whole use of this singular organ : it is a breathing apparatus as well as a means of locomotion; and every inspiration of water is an act of respiration. The piston, as we call it, is composed of the trachea or air-vessels, whose office is to extract oxygen from the water, in the same manner as the gills of fishes. Here is additional matter for wonder: but wonder is not the only sentiment which such an organization should awaken in our minds: it surely calls for admiration of the infinite wisdom of God the Creator, in thus adapting an organ to purposes so widely different; while at the same time so perfectly is each operation performed, that it would seem, on considering either of the two processes to be effected, as if the organ were created for that express purpose alone. Again, it gives us exalted ideas of the benevolence and all-pervading love of God, to observe such astonishing skill of contrivance displayed for the comfort of so mean a reptile; a creature 
unknown to ninety-nine out of a hundred of mankind, yet not beneath the care of Him, "who openeth His hand and satisfieth the desire of every living thing." - But we have not done with our Libellula, the mouth is as singularly formed as the tail ; put in a few of the gnat-worms, and watch his motions.

C. - He waits until they are at rest; now he sees one, and creeps slowly towards it: he has got it: but what great flap was that which suddenly flew out from his head and seized the prey?

$F$. - We will let him eat his morsel, and then examine his face. Now, you see he has no apparent mouth, but the whole face is composed of a long flat kind of mask, ending in a rounded point, and divided in the middle (as you see when I separate it with a pin) by serratures, like the teeth of a saw, which fit into each other. These valves it throws open, and darts out to a great length by means of a double fold, as you saw, on the approach of prey, to seize it, and carry it to the mouth which is concealed within, and the serrated teeth are said to hold it firmly while it is being devoured. Altogether it is a very formidable apparatus, and one well worth observation and examination.

C. - I did not think so ugly a creature could have afforded me half so much pleasure! Concealed among the mud of a pond, its curious formation seems thrown away, and hidden from our observation.

$F$. - Should not this very thing " hide pride from man?" So much care bestowed upon an animal altogether out of the pale of general observation, and evidently without any reference to him ! It affords is, too, another instance of how admirably every creature is adapted for the situation in which it is placed, and that no situation is so barren but that it may be made to afford life and sustenance to some order of sentient beings. 


\section{VII.}

\section{APRIL 15th.}

Song of Birds.--Song Sparrow.-Snow-bird.-Crossline Moth.-Striped Feather Moth.-Powdered Red. - Pearlhead. - Comma Butterfly. Beetles. - Water-beetle.-Larvæ of Ephemeræ. - Caddis-fiies. - Agarics.-Yellowbird.-Crows.-Ruffed Grouse.-Honey-bees.-Plants.Orford Mountain.-The Owl's Head.-Exhilarating Effect of high Elevations.-Lesser Red-poll.-Hop.-Maskilonge.--Strange note of Blue Jay. - Curious Fact connected with the Barn Swallow.-Breaking up of the Coatacook. - The Masuippi and the St. Francis. - Mysterious Voice of the Saw-whetter.-Piping Frogs.

FATHER.— Spring, delightful Spring, has at length opened upon us : " the winter is past, the rain is over and gone ;the time of the singing of birds is come." Let us walk forth, and listen to the sweet music.

Charles. - It is the first real song we have heard, and very melodious it is. From what birds does it proceed?

F. - From the Song Sparrow (Fringilla Melodia). I have not seen nor heard a single individual before, yet this morning they appear in considerable numbers, in company with another little bird of the same genus, the Snow-bird (Fringilla Nivalis), which likewise makes his appearance all of a sudden. They are both plain little birds, and the latter has no song to recommend it, save a single "chip," but as putting us in mind of brighter days, and as the harbingers of sunny spring, they are trebly welcome.

C. - Have we not seen the Snow-bird at intervals through the winter? 
$F$. - No : you are thinking of the Snow Bunting, a bird of a different genus, Emberiza, from which this may be easily distinguished by its colour : it being of a dark slate colour, with a very light, almost white, bill, the contrast of which with the nearly black head, makes it a very marked bird. It is here vulgarly called the Chip-bird. This Fringilla does not winter with us; I believe its name of Snowbird is derived from its appearing in Pennsylvania about the time of first snow. It is the earliest comer of our spring visitants, usually arriving a day or two before the Song Sparrow. It is of a more elegant shape than most of its tribe.

C. - How very pleasant it is to listen to the warbling, after the long, dull silence of winter.

$F$. - I never hear the song of birds under any circumstances, without feeling my spirits raised, my heart gladdened, and filled with delightful emotions. It is not so much the song itself, as the thousand associations of time, place, and circumstances, which are at once conjured up : it brings the verdant meadow, the blossomed hedgerow, or the softened sunbeams playing through the leafy trees, with the happy, gleeful days long gone by. I know not how it is, but on looking back on days past and gone, in which, at the time, sorrow was at least as prominent as joy, - they seem stripped of all that was painful, and the pleasing and happy circumstances connected with them seem to stand out in bold relief, and give the prevailing hue to the picture. In this case, too,

"'Tis distance lends enchantment to the view,

And clothes the mountain in its azure hue."

C. - But independently of association, there is something inherently delightful in the warbling of birds : the sense of hearing is gratified with melody; and it is surely not a little thing to consider it as an instance of the benevolence of God in 
making even His humblest creatures happy ; for no one can look upon a bird pouring out its soul in harmony, without feeling that it is an outburst of gladness and joy.

$F$. - That is at least a pleasanter belief than the one which would make the bird a mere machine, and its song the effect of an instinctive impulse, uttered with no more emotion than the ticking of a clock. If this be philosophy, indeed-

$$
66
$$
'Tis folly to be wise."

C. - I have noticed some more insects abroad, and within a few days past I have made some captures for my cabinet. About a week ago, I took the Crossline Moth, a rather pretty little Noctua, and the first lepidopterous insect that I have observed, except the Tortrix I found in the winter. Yesterday I took two small moths; one a very little Tinea, the Striped Feather, the other a plain Tortrix, the Powdered Red. Today I caught in the house a pretty Tinea, the Pearlhead.

F. - I saw a butterfly in flight several days ago, but was not near enough to distinguish the species : it was probably one of the Commas (Grapta).

C. - Under stones, in the fields, many beetles may now be found, some nearly torpid, but others quite active. I have found two or three species of Carabida, a little black Chrysomela, with scarlet thorax, (Crioceris Collaris?) very common in autumn, and several minute Staphylini (Poderus Riparius). These last form a very pretty microscopic object: the head, the tip of the abdomen, and the small wing cases, are black, or rather steel-blue, and the thorax, and most of the abdomen, are bright orange. They are very nimble, and have the same habit of turning up the tail as the larger species, the Rove Beetle, \&c.

F. - Let us look into this little pool, and see if we can 
discover anything stirring. Yonder are two black Water Beetles (Colymbetes); see how they hurry to the top of the water, then scuttle down again to the bottom, and hide under the mud.

C. - I have one of them.

$F$. - This insect is worth a moment's observation. Observe how smooth its surface is, without any projections, to adapt it for swift progress through so dense a medium as water: the elytra shut very closely, to prevent the wings beneath, which are large and long, from becoming wet and unfit for use : the fore and middle feet are small and weak, but the hindmost pair are very large and strong, and thickly fringed with hair ; they are used as oars to propel the insect through the water, and we may see how admirably they are fitted for this purpose, by observing the effect produced; for the motion of the aquatic beetles is very swift. There are many species of the tribe, but all agree in these particulars : some are of very large size; this is but a small kind.

C. - Here are some larvæ of the Ephemera. They keep the fin-like appendages at their sides constantly in a waving motion, even when they themselves are at rest: what can be the reason?

$F$. - I believe these fins are connected with the air-pipes, and are in fact breathing organs: and as they extract the oxygen from that portion of the water with which they are immediately in contact, I suppose their constant vibration is necessary to produce a current, and so bring fresh particles of water to be inhaled. But I apprehend these likewise perform a double office, and are also organs of locomotion.

C. - There is a serpentine motion of the abdomen when they swim, which perhaps aids them in some degree; but they do not appear to swim with the same facility as most water-insects. I see some of these are in the pupa state, by 
the size and dark colour of the rudimentary wings on each side of the thorax. Caddis Flies (Phryganea) may be seen flying in the marshy woods on almost any fine day.

F. - I noticed a cluster of Agarics springing from the dunghill, a few days ago: they are an ephemeral race, " that come up in a night, and perish in a night ;" but some of them possess great delicacy of form and beauty of colour: these were, however, of a plain drab hue, but I noticed them as symptoms of vegetative activity.

C. - What little birds are flocking about that apple-tree? they seem fond of company, for when one moves, they all accompany it.

F. - It is the Yellow-bird, or American Goldfinch (Fringilla Tristis), in its olive-coloured winter plumage: in this state it is not very easy to distinguish them from others of our finches, unless we approach pretty near them; but their flight in curves, sinking and rising, and their weak but not unmusical song, are sufficient to identify them. When they twitter all together, as they do now, it has a pleasing effect ; their favourite note resembles the word "babée," the last syllable protracted and much higher than the first. Though this bird leaves our inhospitable climate in autumn, for the sunnier regions of the south, yet I am not sure that individuals do not pass the winter with us. I have observed a flock of them picking up oats and seeds around the homestead as late as the 25th of December, and have noticed small flocks twittering and chasing each otherabout the trees in the orchard as early as the 19th of March. They will soon begin to change, but it will be the middle of May before they attain their gay summer dress.

C.- I have noticed Crows (Corvus Corone) flying over the woods and fields for some days past ; and the other day I roused a Ruffed Grouse (Tetrao Umbellus) on the borders of the woods. 
F. - I think the Grouse winters here, though it is not much seen in winter. They will soon begin to drum, which is the sexual call of the male. It is a curious noise: Wilson compares it to the striking together of two blown bladders, slowly at first, but more and more quickly, until the strokes run into one another, and have the effect of one continued rumbling sound, gradually dying away. He says it is performed thus :- " The cock, standing on an old prostrate log, generally in a retired and sheltered situation, lowers his wings, erects his expanded tail, contracts his throat, elevates the two tufts of feathers on the neck, and inflates his whole body, something in the manner of the turkey-cock, strutting and wheeling about with great stateliness. After a few manœuvres of this kind, he begins to strike with his stiffened wings in short and quick strokes, which become more and more rapid until they run into each other, as has been already described."

C. - The Honey-bees are busy: how soon they find out the nectar of the poplar and willow catkins! they are thronging around those trees in considerable numbers.

F. - The Buttercup (Ranunculus Acris), Clover (Trifolium Pratense), and wild Strawberry (Fragaria Virginiana), begin to put forth their young leaves; and I see the grass is sprouting in the woods and sheltered places.

C. - What very remarkable mountain is that to the westward, so elevated above all the neighbouring land? the snow on its summit and sides shines brightly in the sun, and strongly contrasts with the azure tint of the wooded parts.

$F$. - It has often struck my own attention, as being so conspicuous an object from this road, as well as from its evident height, and the singularity of its shape, somewhat resembling that of a couching lion. I have had no opportu- 
nity of visiting it myself, which I should much like to do, but feeling much curiosity respecting it, I applied to my friend, Alphonso Wells, Esq. a gentleman whose acquaintance with the localities of this province is very extensive, for information respecting it. He says, "this mountain I take to be the highest mountain in all this part of Canada. It rises about two thousand three hundred feet above the level of the head waters of Missisquoi River, which take their rise at the western side of its base. It is called Orford Mountain, and its highest peak is about three-quarters of a mile from the south and west limits of the township of Orford, near the south-west corner. I have never examined the nature of the formation, but believe that a considerable portion of it is granite. A small lake, about a mile in length, lies at the south end of this mountain, in the township of Bolton, and the stage road passes in a cut, made out of the solid rock, about fifty feet above the level of the surface of the water of this lake, the edge of which rock rises nearly perpendicularly from the water. At this cut I have found large quantities of asbestos in the fissures of the rock.

"The view from the summit of this mountain is truly grand and magnificent. The mountains of Montreal, Montarville, Belœil, Mounoir, Rougemont, and Yamaska, all of them rising out of a flat level country, appear in a westerly direction. Shefford, Brome, and Farnham mountains also appear, lying more near, in a west and south-westerly course. Still more to the south, is seen Pinnàcle mountain, in the east part of the Seigniory of West Ormond ; and south, and still more to the east, are seen Sutton, Bolton, and Potton mountains. In Potton, rising abruptly from the west shore of the Lake Memphramagog, and about four miles and a half from the Province line, is a high, conical, and very steep mountain, called ' the Owl's Head,' which is a very conspicuous point in the view from Orford Mountain, and, next to it, is supposed 
to be the highest land in this part of Canada. It is a current belief with the common people, that the Owl's Head contains some precious minerals, and much digging and excavating have been done in places upon it, by those who wished to possess themselves of them, but without success as yet. I believe that no experienced mineralogist has ever yet explored the mineral kingdom of this, nor indeed of any other considerable part of Canada. The sides of this, and of Orford Mountain, are covered to the very summits, with a thick growth of maple, birch, spruce, and hemlock timber. The range of Green Mountains, in the State of Vermont, the White Mountains in New Hampshire, and the outlines of most of what are called the Eastern Townships, together with about eighteen small lakes, are all visible from the summit of Orford Mountain, in clear weather."

C. - It would give me very great pleasure to visit the mountain, and enjoy the prospect of so extensive a country.

$F$. - The distance is considerable, but perhaps at some future time we may find opportunity for a visit and a personal examination. But the day wanes, and it is time to return.

C. - There is something very exhilarating in standing at a great elevation; arising probably from the rarity of the air in such situations.

$F$. - The purity of the air, its freedom from noxious and heavy vapours, acting on the body, is no doubt one cause of the buoyancy of spirits which one usually feels at great heights, joined to the purely mental excitement, which the enlarged prospect, and the distance from the ordinary bustle of life, are calculated to produce in minds of a certain temperament. That such an effect is produced, I have myself often proved. 
C. - There is a pair of pretty birds in the road before us : the crown of the head is bright crimson, and one of them has a red breast. What are they?

$F$. - They are called the Lesser Red-poll (Fringilla Linaria); this is one of the few birds which are found both in Europe and America. It is not by any means a common bird, as I have very rarely seen it. These, too, are finches, and feed principally, if not wholly, on seeds : it is probable they breed with us, as they are northern birds, but I have never met with their nests.

C. - The fields are beginning to look green in some places; and here are the young leaves of the Hop plant (Humulus Lupulus) growing in a corner of the fence.

$F$. - Professor Eaton gives the hop as a native of this continent: but for his high authority, I should have rather supposed that it had been introduced from Europe. The hop grows remarkably fast; I have known a shoot to grow more than two inches and a quarter in twenty-four hours.

C. - What large fish are those, which the man who just passed us carried in his hand?

F. - They are called here "Longe," in other parts, "Maskilonge;" and are esteemed fine eating. They are caught in the neighbouring lakes, but I know nothing of their natural history. They are often taken of great size.

C. - I yesterday heard the voice of a bird near the edge of the second-growth-poplar woods, which sounded strange to me: it was like the words "pwilhelly, pwilhelly." I approached, to try to get a sight of it, but found that it receded before me, faster than I could pursue it, and it was finally lost in the distance.

$F$. - It was no stranger : neither more nor less than your noisy acquaintance, the Blue Jay (Corvus Cristatus); the screaming rogue has so many notes and strange cries, that 
his most intimate acquaintance will scarcely know him by his voice; but I have heard him utter the note you describe. - My friend, Mr. Jaques, informed me of a curious circumstance which occurred a few days ago. He found on his barn floor, just fallen from the roof, a Barn Swallow ( $\mathrm{H} i$ rundo Americana), dead and dry. He showed it to me: the feet were extended, as if sitting on a plane surface; it appeared to be a young bird (though perfectly fledged), from its size, being not more than five inches in length, and from the exterior feathers of the tail being scarcely longer than the others: but what is most curious, is the fact, that a perfect egg was attached to the vent, stuck on to the feathers, apparently by some glutinous substance. This egg Mr. J. broke in taking it up; the yolk was yellow, not putrified, but thickened in consistence. I was at a loss to account for the fact of a full-fledged young bird and a sound egg being in the same nest; but mentioning the circumstance to an experienced ornithologist, he threw much light upon it, by telling me, that towards the end of the season, the swallow becomes very irregular with respect to the time of its laying. The young bird was probably deserted, owing to its not being sufficiently matured to accompany the parents in their migration. It was no doubt the dung of the bird which caused the egg to adhere to its feathers.

C. - See! the Coatacook is breaking up; as we came over this bridge a few hours ago, the ice appeared firm and solid, though covered with water; but now it is cracking, and going down the large open channel in the middle of the river.

$\boldsymbol{F}$.-I knew it had been unsafe for many days : the large holes around the posts of the bridge, the openings near the banks, and the depth of water that covered the main body of ice, all have shown that the disruption could not be far 
off. The Masuippi has been open for some weeks; and in going to Sherbrooke last week, I observed large fragments of ice swiftly floating down that ropid river, the St. Francis.

C. - Notwithstanding the day has been so warm, now that the sun is down, the air is chilly and even cold. Listen to the singular sound proceeding from yonder cedar swamp. It is like the measured tinkle of a cow-bell, or regular strokes upon a piece of iron quickly repeated. Now it has ceased.

$F$. - There it is again. I will give you all the information I can about it; and that is very little. In spring, that is, during the months of April, May, and the former part of June, we frequently hear, after nightfall, the sound you have just heard; from its regularity it is usually thought to resemble the whetting of a saw, and hence the bird from which it proceeds is called the Saw-whetter. I say "the bird," because, though I could never find any one who had seen it, I have little doubt that it is a bird. I have asked Mr. Titian Peale, the venerable Professor Nuttall, and other ornithologists of Philadelphia, about it, but can obtain no information on the subject of the author of the sound: it seems to be-

"Vox et præterea nihil."

Carver, in his amusing travels, mentions it as being heard near Lake Superior, naming it, if I recollect rightly, the Whetsaw. It may possibly be known, but I find nothing of it in Wilson or Bonaparte. Professor Nuttall was acquainted with the note, but told me plainly the bird was unknown. I conjecture it may be some of the herons or bitterns; or, possibly, from a passage in Bonaparte's Orni- 
thology, the Evening Grosbeak (Fringilla Vespertina). He says of that bird, "their note is strange and peculiar; and it is only at twilight that they are heard crying in a singular strain. This mournful sound, uttered at such an unusual hour, strikes the traveller's ear, but the bird itself is seldom seen." One season I heard it several nights in succession, early in March, and going into the State of Vermont in the same month, I likewise heard it there, but invariably proceeding from the most sombre and gloomy recesses of the black-timbered woods. Once, and but once, I heard it before the sun was set; I have watched in the woods from which I was in the habit of hearing it proceed, for some time after sunset; but could not succeed in hearing it then. I was once coming from Sherbrooke near midnight, when everything was profoundly still, and not a sound broke the deep silence, except the measured tramp of my horse's feet on the frozen road; on a sudden, from a thick forest, about half a mile distant, came the metallic tinkle of the saw-whetter. The unexpectedness of the sound struck me forcibly, and, cold as it was, I stopped my horse for some time to listen to it. In the darkness and silence of midnight, the regularly recurring sound, proceeding too from so gloomy a spot, had an effect on my mind, solemn, and almost unearthly, yet not unmixed with pleasure. Perhaps the mystery hanging about the origin of the sound tended to increase the effect. I have been told by one of my neighbours that it is a bird, about the size of a cuckoo, but as I could not find that he himself had seen it in the act of uttering its notes, little heed is to be given to the supposition.

C. - It is very singular. I should think it might be discovered by perseverance.

F.-You may watch for it, if you please; but I apprehend it is very shy, and you would not be aware of its presence 
so soon as it would be aware of yours: so that the bird would have a decided advantage over you. Accident may throw light on this, as it has done on many other subjects.

C. - There is another sound, which I have not heard before: as if a score of persons were whistling together: it is not so far off as the saw-whetter, for it evidently comes from this field, and but a few yards distant.

$F$. - Many are engaged in the concert; but if you listen attentively, you will perceive that each whistles three short and quick notes, two alike, and the third much higher in tone. There is not much doubt about the origin of this. It proceeds from some of the Reptilia; it is usually called the Piping Frog, but I believe it in reality a small lizard. ${ }^{x}$ Like the saw-whetter, it reserves its music to enliven the night season, and makes up in pertinacity what it wants in melody. This field is wet and marshy, in which situations alone this reptile delights. I think it likely that the lizard is beneath the surface of the ground, at the time of making this piping noise ; at least, sometimes, if not always : for once I heard many of them in my own field before it was dark, and being quite near, I looked, but could see nothing: presently the tune struck up from the ground a yard or two from me. I went cautiously to the spot, and found that it had evidently proceeded from a small hole in the earth, but no musician was visible. If I had had a spade, I might have brought him forth to daylight, or rather to twilight, to receive the applause due to his musical powers. - But here we are, once more at home. 


\section{5}

\section{VIII.}

\section{MAY 1st.}

Robin.-Green Comma Butterfly. - Compton Tortoise B. - Camberwell Beauty B. - Moths. - Cocoons. - Musca. - Cicadæ. - Barn Swallow. - Musquito. - Black Fly. - Sand Fly. — " Smudge." - Early Settlers. - Curious Elm. - Whirl Beetles. - Freshets. - Slides. - Martin-houses. - Purple Martin. - View of Hatley. - Canada Thistle. Chestnut Chafer.-Purple Carabus. - Rosy Casefly. - Forked Butterfly. - Cattle in pastures.-Emigration to Canada.-Misstatements of Writers. - Instance of Infatuation.-Evils of a new Country.-Glory of Nature.-First Flower of Spring.-Pewit Flycatcher. - Early Elder. - Chequered Snake-becomes torpid-casts its skin-its food.Wild Leek.-Cackling of Frogs.

Father. - I have business which calls me to Hatley to-day, a village about seven miles distant. The village is more properly called Charleston, but as it is in the township of Hatley, it is more usually known by the former name. If you would like to accompany me, get your pony and let us go.

Charles. - A walk or ride with you is always pleasant, for I always find many new things to observe and to inquire about. I will join you immediately.

$F$. - Now then, if you are ready. Our road lies through a very varied country, now through dense woods, and then amidst wide clearings, sometimes on lofty hills, and then into valleys as deep.

C. - We cannot go a step out now, without seeing something new either in the vegetable or animal world. In my 
rambles about the farm and neighbourhood, for a week or two past, I have observed many things worth noticing.

$F$. - I, too, have not walked with my eyes shut: but what tokens of spring's advance have you observed since our last walk?

C. - About a fortnight ago, the Robin appeared: I saw a flock then, and since that time I have observed several flocks. They are hopping very familiarly about the wet grass-lands, and the ploughed fields, searching, as I suppose, for worms and insects. He is commonly called the Robin, though I perceive no resemblance between him and our English robin, except in the single circumstance of his having a red breast.

F. - The American Robin is a species of thrush (Turdus Migratorius). In Newfoundland, where it is very common, it is always called the Blackbird, It is a saucy, familiar bird, fond of man's neighbourhood, and more seen in our fields and gardens than in the woods. Its song is not contemptible, but by no means comparable to that of the Song Sparrow. The robin is a very general favourite, but this does not protect him from the assaults of any idle boy that can procure a gun. The flesh is savoury, and great numbers of them are shot for the table; in Newfoundland especially, a constant warfare is carried on against them, without any apparent diminution of their numbers.

C. - About the same time I saw the first butterflies this season. In the woods, a small brown one flew by me, but I was in a hurry, and could not stay to pursue it. The same afternoon, I saw two, one of which I caught, and found it to be the Green Comma (Grapta Progne?). Three or four days ago, I saw the Compton Tortoise Butterfly (Vanessa J.Album), and the noble Camberwell Beauty (Van. Antiopa).

F. - These are fine butterflies, both in size and colour. 
There is a very striking resemblance between the Compton tortoise and its congeners the Tortoiseshells of England, both in colours and distribution of the tints, and the similarity is equally striking in both the upper and under surfaces, though these differ so much from each other. The Camberwell beauty, a rarity in England, is here extremely common, chiefly in autumn, and is one of the latest seen of all our butterflies. The first you named is a pretty fly ; the under surface of the wings is very beautifully and richly variegated. The genus Grapta is not, I believe, generally adopted; but it seems as natural a genus as almost any other of the Nymphalida. I have found four species in this place, and one in the south, all of which can scarcely be distinguished from each other on the upper side, but vary greatly beneath. They are all marked by a silver crescent in the centre of the hinder wings, on the under surface: the Compton tortoise resembles them in this particular, but this is a true $V$ anessa.

C. - I have two new moths added to my collection, both of them of small size. One is a very pretty Tinea, taken about ten days ago ; the other I caught last evening, a small but handsome Geometra. The cocoons of the Muff Moth (Lophocampa Tesselaris) and Panther Moth (Spilosoma Acria), may both be found under stones or boards, lying on the ground. A pretty little bug, about as broad as it is long, of a polished black, with a white margin (Cydnus -?), crawls about. Ichneumons and Musca are numerous.

F.-I have noticed, buzzing about the dead leaves which lie under the maples, a large Musca that I have not seen before; the abdomen changeable blackish-grey, the head light brown, with dark brown eyes, and rather long antennæ. It is numerous.

C.- Among those same leaves, if we disturb them, we 
find hundreds of the little Crimson-striped Cicadæ (Tettigonia 4-vittata), and a green species, still smaller (Tettigonia Mollipes), hopping in every direction. I suppose they have remained all the winter among these leaves, under the snow.

$F$. - These things are all signs of spring; but there is a bird which, when it appears in any considerable numbers, is considered peculiarly as the harbinger of summer. I allude to the Swallow: as early as the 21st of April, numbers of them appeared. I was standing on the bridge near Smith's mills, and could not but admire their beauty, as they darted under the arches of the bridge just beneath my feet ; they seemed to take great delight in skimming along the surface of the water, sometimes just touching the surface, perhaps catching minute insects, too minute to be discoverable by our obtuse senses; while their backs and heads glistened in the sunbeams with the most glossy blue; and their breasts, and inner surface of their wings, showed a bright chestnut, visible as they occasionally swept over head. The species was the Barn Swallow (Hirundo Americana), the most numerous of all the species of this swift-winged race, that enliven the air during our short summers.

C. - Is this the species that builds its nest under the eaves of barns, as the English martin does under the eaves of dwelling-houses?

$F$. - Yes: I have seen between thirty and forty nests under the eaves of one side of a barn, nearly as thick as they could be placed, besides many which were on the other side and at the ends of the building. But this species likewise builds within the barn, attaching its nest to the rafters and beams. Square or lozenge-shaped holes are usually cut in the boards at each end of a barn, to admit the birds; and it is astonishing to observe the precision with which they fly through these holes, which are so small as frequently to compel them to half close their wings in passing through. 
Yet in summer they may be seen flying to and fro, through these holes, many hundreds of times in a day.

C.-Why are the farmers so accommodating to this bird?

$F$. - All the species of swallows are universal favourites; and they well deserve to be cherished around our dwellings, on account of the incessant and successful warfare which they carry on against those insect pests, the musquitoes, sandflies and other similar races.

C. - I have observed the musquito or gnat already abroad; but I have not yet been so unfortunate as to know by experience the effect of their bites. .

F. - You will not live long in that state of happy ignorance: before this month is ended, we shall have them swarming around us, and our bodies will be continually covered with large white tumours, attended with intolerable itching, and followed by much inflammation and pain. It is more particularly by night that they make their insidious attacks; they swarm in our bed-chambers, and it is a very common thing to see in the morning many of them lazily pitched about the walls, and ceiling, their abdomens distended, and almost bursting, with the blood which they have extracted from our veins at their leisure. It is almost impossible to do anything in the fields after sunset, as one hand is perpetually in requisition to drive them from our faces; but they return most pertinaciously to the attack, and, notwithstanding all our efforts, manage to cover our faces, necks, heads, hands, and legs, with their bites. Their ringing hum, which always announces their approach, is listened to with a feverish anxiety, and as it approaches the ear, is heard with a dread and horror that is almost laughable when we consider the size of the enemy.

C. - Is there more than one species that is so annoying?

$F$. - There are two species at least, if not more, of the true musquito (Culex); and besides them there is the Black 
Fly, a small species of dipterous fly, with black body, the legs ringed with black and white (Simulia-?), whose bite is similar in its effects to that of the musquito, but it does not usually come into our houses. There is also a very minute insect likewise dipterous, with mottled wings, the Sandfly, or Midget, so small as to be scarcely visible: they appear in myriads at nightfall, and bury their heads in the flesh; their bite is not unlike a spark of fire, but it is not followed by tumours; a slight inflammation continues for a few minutes, with itching. Neither of these two utters any sound as it approaches, so that their attack is still more insidious than that of the musquito.

C. - But is there no way of guarding against their assaults? are we altogether at their mercy?

$F$. - When they are too bad to be borne any longer, our housewives make what they call a smudge; that is, little fires to windward of the house, covered with wet chips and earth, which, smothering the flame, make a dense smoke; this being wafted by the wind around the house, prevents the approach of the flies, as they cannot abide smoke: so we tolerate one inconvenience to dispel a greater. There is no other help, but patience. Salt dissolved in water, rubbed on a recent bite, prevents much of the evil effect. But we know little, after all, of this evil, compared with those bold and hardy men who first penetrated this vast wilderness, and set up their solitary dwellings in the midst of the forest, before roads were cut, or clearings made, or marshes drained; when clouds of venomous insects rose out of the rank swamps, to which those we encounter are as nothing. I have heard some of the first settlers declare, that they did not dare to go out to work without a pine torch continually blazing on their hats, to keep, by its smoke and flame, a small space around their heads clear of these minute but formidable foes. But enough of them. - There is a tree, if I recollect rightly, somewhere 
about this place, which I wish you to see, for it is quite a curiosity. It is an elm of considerable size: one of the main branches, apparently the leading limb, has been partly broken off; but being held by the under part, only inclines toward the ground, without touching it; from this broken bough three vigorous and branchy shoots have arisen at some distance from each other, presenting the curious appearance of three young trees growing in the air. We shall come to it soon, if we have not passed it unobserved. Yonder it is, on the left hand side of the road.

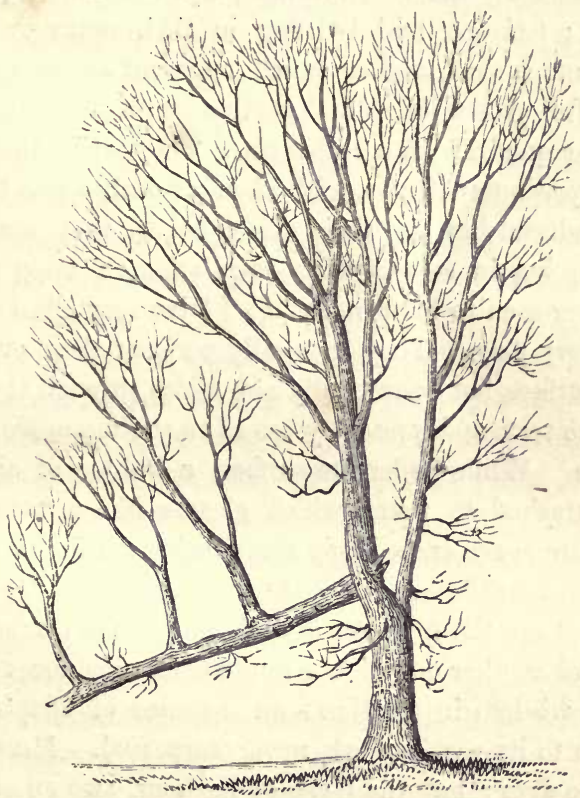


C. - It has indeed a very remarkable appearance. If you will stay a few moments, I should like to take a hasty sketch of it.

F. - Do so: I have seen several other instances of upright shoots springing from a half-broken limb, but none having so singular a look as this one. While you are drawing, I will go and look at this little pool by the roadside.

\section{C. - I have finished, and am ready to proceed.}

F. - I have found in the pool a group of those merry little creatures, the Whirlbeetles (Gyrinus Aneus, \&c.) in full play; twisting and twirling in their mazy evolutions, with as much skill, and as much apparent enjoyment, as a band of full-grown ladies and gentlemen perform the mysteries of the quadrille in a ball-room. They whirl in and out with surprising swiftness, and when a number are together, it is wonderful how, in their giddy dance, they manage to avoid coming in contact with each other, a thing which I have never seen to happen, though I have very often watched their merry play. They generally perform their evolutions on the surface, but occasionally one glides through the water, under the rest, and presently comes to the top again, as dry as before. While under the surface, a bubble of air is always attached to them, which gleams like a little pearl. The antennæ are exceedingly short, being nothing more than little knobs on the head, to the naked sight; but the eyes of this insect are the most remarkable part of its conformation, and afford another out of the innumerable instances of prospective wisdom in creation-an instance of adaptation of an organ to its use, perhaps never surpassed. Most beetles have two eyes; but the Gyrinus has four, two on each side of the head: why is this remarkable exception to the general rule? The sphere of action of this beetle is the surface of 
the water, on which it swims with about half its body submerged. Now it has need to guard against enemies from above and below: eyes which would see well in the air, would not see well in the water, on account of the difference in the density of these media, and besides, one pair of eyes could not be in both the air and water at once. To obviate this inconvenience, the Gyrinus has one pair just above the surface, and another pair just below, very close together, yet sufficiently separate to be in different elements. Insect anatomists find that the two eyes, that is, the upper and lower eye on each side, are joined internally, and connected with one optic nerve,-an example of economy of materials by no means uncommon.

C. - Going down to Spafford's bridge yesterday, I observed that the river had overflowed its banks, and inundated the extensive meadows and low lands on each side, so that it looked like a large lake: the road was impassable for foot passengers.

$F$.- These freshets, as they are termed, occur every spring, and are caused by the melting of the accumulated snows of the past winter. It is true our snow has disappeared some time, and the roads are comparatively dry, but it is in the mountains that these freshets originate. The snow there does not melt so soon as in less elevated regions; and as all the springs and rivers have their sources among the hills, they are comparatively little affected, until the melting of the mountain snows. - On such of our rivers as have steep banks, as the St. Maurice and the Magog, I am informed it is not uncommon for slides to occur at this season. Heavy spring rains undermine the earth, while yet frozen, and loosen it from the subsoil, when large portions of the surface, with all their trees and bushes, slide off the rock beneath, and 
descend like an avalanche into the river. Sometimes, the side of a hill will slide, after a heavy and continued rain, in the summer months, and do great damage.

C. - What can be the intention of those little houses stuck on poles?

F. - Have you not seen them before? they are common enough in this country, though we have none in our immediate neighbourhood. They are put there solely for the accommodation of the Purple Martin, a still greater favourite than the Barn Swallow. The Purple Martin (Hirundo Purpurea) is the largest of all our swallows; his colour is nearly uniform, a deep glossy purple; he generally arrives about the same time with the barn swallow, though I have not seen, or at least observed, any before those I now see flying about their little painted houses. As soon as they come, they find lodgings ready prepared; for very many of our farmers, as well as those in the neighbouring States, have taken the trouble to provide boxes for the martin: some erect them on poles, as in this instance; others fasten them on the very peak or corner of the roof of their dwellinghouse. The making of the box in the form of a house, with holes in the shape of doors and windows, with the roof painted red, and the sides white, is the taste of the provider, but it is a pretty general one. In the southern States, I have seen gourds hung on the cut branches of a young tree, near the planters' houses ; a mode which Wilson mentions as practised by the Indians : and as far as I could see, the martins were as well satisfied with this homely abode, as with the painted and shapely houses of the North. I believe the providing of a house for the martin is confined to the American inhabitants: I have never seen one erected by an English emigrant.

C. - I suppose the reason of their being petted is the service they render in destroying flies.

$F$. - Like all the tribe, the purple martin feeds exclu- 
sively on insects; but its chief service is its domineering disposition : it attacks crows, hawks, and even eagles; and as its powers of flight are sufficient to secure its own safety, it makes a bold and fearless assault, and with such success as effectually to drive any bird of these kinds from its vicinity.

Now draw in your horse a moment, and look at the prospect from this hill : yonder white building is the Methodist church, which, with its high tower surmounted by a cupola, is a conspicuous object, and, together with the handsome dwelling-houses near it, agreeably contrasts with the dark woods at the back: here in front are the fields just putting on the verdant livery of spring; behind, and to the right, we see a silver sheet of water, smiling as peacefully as if its surface had never been ruffled by a storm; that is Lake Masuippi. From its very edge rise steep and high mountains, shagged with wood to the summits; and the whole picture is finished by the blue and distant hills of Vermont ; hills of all shapes, mountain rising beyond mountain, as far as the eye can see. This hill to the left hides Charleston village from our sight, which is not more than two or three miles distant. But let us go on.

C. - I observe by the roadside the young leaves of the thistle are appearing.

$F$. - The sprouting of this plant, the Canada Thistle (Cnicus Arvensis) I noticed about a week ago. It is one of the most pestiferous weeds that are found amongst us, and has of late years increased so rapidly as to become an object of considerable alarm among farmers. It springs up among the grain crops, and its sharp spines are so formidable as to cause great difficulty in reaping grain in which the thistle is growing. It spreads rapidly too in grass lands.

C. - But is there no way to eradicate it? 
$F$. - If suffered to ripen, its downy seeds are borne by the wind in clouds, in every direction; and as they readily take root, and as the plant likewise is perennial-rooted, that is, springs from the old root, it is difficult to keep it down. Much might be done, however, if farmers were unanimous, but the plant is in many cases permitted to grow and ripen by the sides of the roads, whence the seeds are scattered over the fields. Repeated mowings in summer will cause the roots to wither and die; and if each one would take the trouble to cut off the flowering heads of those that grow in the roads of his own farm, the plant would be prevented from seeding. - This is the house at which I have business; it will not detain me long: if you please you can go in with me, or take a look at the village.

C. - I will ramble about until you are ready. I shall find sources of amusement, I dare say.

F. - Now, Charles, it is time to see about returning. What do you think of Charleston?

C. - It is a much prettier village than Compton ; it contains handsomer and more tasteful houses, and more of them. But I have not been in the village all the time you have been engaged; I have been entomologising in the fields.

F. - Have you had much success?

C. - Not very much: I have turned over stones, and found under them several specimens of a large chestnut-coloured chafer, with flexible elytra; it is something like the cockchafer, but much more sluggish and inactive.

$F$. - It is frequently turned up by the plough, when breaking up grass.land: and I have likewise turned up large larvæ of a scarab, which I take to be this species (Rhizotroga Fervens). 
C. - Besides these, I found the handsome Purple Carabus (Carabus Catena); and a Rosy Casefly (Phryganea - ?). I also found two of a broad-winged Ichneumon (Ophion Luteum), a Green Byrrhus (Byrrhus Varius), and a Black Water-measurer (Gerris), sprawling on a brook : these three are Newfoundland insects. These, with one or two others of little note, are all I have collected.

$F$. - What goes yonder? That is a butterfly we have not seen this season before. It is the Forked (Vanessa Furcillata), a species common enough here, but in Newfoundland the most abundant of all the butterfly tribe. $\mathrm{Mr}$, Say speaks of having met with it in his travels, "several times," as if it were quite uncommon in the States ; and this is not the only instance in which insects common with us are marked by the American naturalists as great rarities.

C. - It is rather a pretty butterfly, though it has not much variety of colour. Its larva, I believe, feeds on the nettle.

$F$. - I perceive many persons have turned their cattle out into the pastures, but it is little that they can pick up yet ; they eat a good deal of the dead and bleached grass of last year, which fills their stomachs, but yields them no nutriment. The length of time necessary to stable his cattle is one of the greatest drawbacks to a farmer's profit in this country. We put up our cattle in October, and it is the latter part of May before they can support themselves in the fields, so that we have to provide dried fodder for our stock for upwards of seven months of the year. On this account we are compelled to leave a very large portion of our farms in grass, which otherwise might be more profitably put under tillage.

C. - But hay usually bears a good price; is it not therefore as profitable to mow land as to till it? 
F. - Sometimes to an individual it is : but you must recollect that the hay is sold from one farmer to another; the farmer is the consumer after all; what one gains another loses; the farmers, as a class, reap no advantage from the very highest price of hay, whatever profit individuals may realise.

C. - What do you think of this country as a place of emigration for the farming class at home?

F. - My opinion is, that much exaggeration, and very highly coloured, if not absolutely false, statements have been made in many of the pamphlets, and in some works of higher pretensions, holding out expectations to the settler, which, in a majority of cases, he no more realises than the loon who chased the rainbow, in the hope of obtaining the golden cup. Travellers generally come here in summer, when the country is clothed with beauty; they see the crops growing, they have no anxieties, no labours, and are usually inclined to be pleased with all they meet with; they pass a few months in going through the pleasantest part of the country, and then think themselves qualified to give a description of $\mathrm{Ca}$ nada, setting forth in glowing colours all the pleasures, and never noticing the disagreeables, probably because they know nothing about them. A very remarkable instance of this infatuation has come under my own personal knowledge. A person whom I had known thought of emigrating to Canada; but previously, he determined on coming to see it. Accordingly he arrived here in July, was of course kindly received by his friends, who, as was natural, laid aside all gloom and care, and even the ordinary labours of the farm, to entertain him, and endeavoured to make him welcome to the best they had. He was charmed, enraptured, with all he saw; purchased a farm at once ; built all sorts of castles in the air, in projecting alterations and improvements; remained a few weeks; and then returned to bring his family to his estate in the fol- 
lowing spring. On his return, he published an account of his journey in the most flaming and hyperbolical terms, quite laughable to those acquainted with the country by experience. Supposing that because his friends sacrificed a portion of their time to his amusement, they had therefore nothing to do, he seemed to consider a farmer's life in Canada as one of ease and pleasure, of abundance and luxury. He returned the next summer to his paradise, found that there was some labour, and toil, and privation, which he had not anticipated; did nothing to his farm, spent his means, and the next spring gave up his purchase at a considerable loss, and went back poor and miserable. I fear this is too common a case.

C. - But I have seen some very favourable accounts from persons resident here.

$F$. - They are generally from gentlemen who have capital; or at least means enough to make them comfortable, without personal labour, in any country. These, suffering none of the inconveniences and privations which assail ordinary settlers, usually write as they feel ; and these accounts are mostly given while the novelty of a forest life, and the excitements of a new country, are fresh; before they have begun to feel the want of that society to which they have been accustomed, and of those luxuries and refinements which only an old state of things can give. Perhaps it is not uncharitable to suppose that some of the praises bestowed may arise from the principle developed in the fable of the fox who had lost his tail ; the friends they have left are anxious about their welfare, and they feel reluctant to let those kind friends suppose they are disappointed, and endeavour to persuade themselves they are not. I have known something of this feeling myself. - I have resided here some time, and have engaged personally in the labours of agriculture, and have made many inquiries ; and I do not know an instance, with one single exception, of an English emigrant, who is not dissatisfied 
with his exchange. The exception is one of a gentleman who has money at his disposal, and who has been here but a short time, who, I have heard, takes off his hat, and blesses God that ever He brought him to such a garden of Eden as this. A subsistence can be procured here; but it is by incessant labour: the land is in general infertile, and the season of preparing the ground for the summer's crops so exceedingly short, that a man can do but little with his unassisted exertions. We cannot usually harrow our fall-ploughed land until May is considerably advanced, on account of the frost in the ground, and the consequent wetness. Then, there is all the grain to be sown, and the potatoes to be planted, during the remainder of May and a small part of June, or no return can be expected. The summer is short, though warm; early frosts frequently destroy or greatly injure the wheat before it is ripe, and often quite cut off the buckwheat and potato plants. I have known severe night-frost as early as the twelfth of August, doing incalculable injury. It is not an uncommon thing for potatoes to be frozen and spoiled in the ground, before they can be secured in autumn. Weeds, smut, rust, and flies are full as pernicious here as in other places, and all tend to diminish the farmer's means of existence. The extreme sevetity of the winter, the thermometer frequently falling more than $20^{\circ}$ below zero, sometimes more than $30^{\circ}$, is another inconvenience severely felt by the poor farmer. The tending of his cattle, and the cutting and, drawing of firewood, are sufficient to occupy nearly all his time in the short days of winter. - The advantages are, freedom from tithes and taxes, a pure air, healthy climate, excellent water in abundance, and the prospect of gradually but slowly increasing his comforts, and leaving an inheritance for his family. Whether these outbalance the disadvantages, I can hardly tell. If a farmer in England finds that with all economy he grows poorer, and thinks he could put up with these evils, and 
another which I have not mentioned, the evil of exile from country and home, he might better his condition by coming hither, if he has the means of setting himself agoing when he arrives. But in common justice, in common humanity, he ought to have both sides of the question fairly laid before him, that he may know beforehand the difficulties he will have to encounter, and not have to repent of his choice when repentance is too late. I do not speak against emigration in general; but I think that emigrant makes a very unfortunate choice, who fixes on the eastern townships of Lower Canada as his place of residence. From what I have heard from many sources, I believe that Upper Canada offers an incomparably greater advantage to the settler, without the peculiar drawbacks of this country.

There is a class of emigrants, however, to whom these townships hold out a very fair prospect. I mean the class of agricultural labourers, who would be content to work for hire. One of our greatest evils is the want of hands in busy seasons, such as haymaking, harvest, \&c. It is often very difficult to hire labour at any price; and good, and even high wages may at all times be secured. But that class of men, as soon as they come here, almost invariably become discontented, because everything is not exactly like-England ; and generally go into the States, probably going farther and faring worse. Those that remain accumulate money so fast, that the spirit of independence comes over them, and they become farmers ; so that the lack of labourers continues, from year to year, unsupplied.

C. - Have you not drawn too dark a picture? I have found the winter very severe, and very dull; but I have met with many pleasant things, especially of late, since the spring has begun to open.

$F$. - The naturalist finds gratification in any scene, and at any season, if he can but get abroad among the works of 
God; and the bursting forth of life and vegetation, as the glorious spring gladdens all creation, is an abundant source of enjoyment to every benevolent mind. But the minds of that class of men to whom I allude, are often incapable of drawing water out of these wells, or at least a taste for such enjoyments has never been awakened. And even if it had, the tangible evils I have mentioned would be sufficient to counterbalance the pleasures of the imagination.

C. - Let us return to our more accustomed and, I may say, more interesting subjects of conversation. I observed, yesterday, the first flower of spring; it is a low yellow syngenesious flower, much resembling in appearance a dandelion, but with a thicker and a solid stem, covered with scaly bracts ; it had no leaves.

$F$. - I too have observed it in preceding years : it is the common Coltsfoot ( Tussilago Farfara) so useful in catarrhal affections, but it is not abundant with us. The leaves spring from the root, and do not appear until sometime after the flower. A pretty little bird was shown to me a few days ago, which had no doubt just arrived from the south. It was the Pewit Flycatcher (Muscicapa Nunciola); it had been caught within a house. The plumage, like that of many of the flycatchers, is olive on the upper parts, with a dark head; the under parts are yellowish white. It has a simple, rather monotonous note, "pewee ;" its habits are like those of the rest of the tribe; it is fond of taking its station on a particular twig, whence it makes its frequent sallies after flies, and to which it as constantly returns; keeps its tail in a continual motion, and often erects the dark feathers of the head, like the kingbird, and others of this genus.

C. - The buds of the elder are opening.

F. - The early Elder (Sambucus Pubescens) always opens its flower-buds the first of our shrubs and trees, except some of the catkin-bearing trees. We have two species 
of elder, both abundant in the corners of our fences, and much resembling each other: the second species (S. Canadensis) is called the late elder. These plants multiply and spread rapidly; and in some of the agricultural publications of the neighbouring States, I have seen complaints of them as pernicious weeds, with inquiries for the best modes of extirpating them.

C. - There is a snake crossing the road. Are there miany species of snakes found in this country?

$F$. - I have never seen any but this species, the common Chequered Snake, (Coluber-?) but it is possible there may be more.

C. - Is it venomous?

$F .-$ No, perfectly harmless; as I have proved by examining the mouth: all venomous serpents have two or more large curved fangs in the upper jaw, which are wanting in harmless ones. "In general it may be said that innocent serpents have four rows of teeth in the upper jaw; two on the palate, and one on each side: but that poisonous serpents have no other outward or side-teeth but the fangs." When attacked, this snake, like many other harmless kinds, rears itself up in a threatening attitude, dilates its body, brightens its colours, and darts in and out and vibrates its red forked tongue : this organ, called by the vulgar "its sting," and supposed to be the weapon of offence, is considered an undoubted token of its venomous nature. But in reality, all these motions are but menaces; there is no power to do hurt, though they no doubt often serve as a protection. In common with the whole serpent race, it is the object of universal enmity : every person seems to consider it a sort of duty to kill snakes whenever they can be met with, perhaps in consequence of the curse entailed on the serpent that beguiled Eve. 
C. - The snake becomes torpid during winter, I believe?

$F$. - Yes : it conceals itself in the fall, in some convenient spot, such as under logs, often in heaps of stones, and sometimes, I have reason to think, in the earth; for in ploughing late in the autumn, I once turned up a chequered snake: it was inert and dull, but not torpid.

C. - At what period of the year does it cast its skin?

$F$. - I believe that is the first operation performed, after its revivification in spring, and before it leaves its winter concealment. An intelligent neighbour informed me that once in turning over a heap of stones early in spring, before the snow had all disappeared, he discovered a snake in the very act of sloughing its skin; the skin was stripped off from the head to about the middle of the body; the displaced part lay around it in close folds or wrinkles: even the eyes were skinned. If I recollect aright, in Bingley's Animal Biography it is intimated that the snake crawls among the stalks of plants, in order that the skin may be rubbed off by friction, and that it is turned inside out, as we draw off a stocking. My neighbour's account appears far more probable: besides, it is supported by analogy; for it is exactly the mode in which all caterpillars slough their skins, as I have many times witnessed. The food of the snake is frogs, toads, lizards, and probably insects. I once killed a snake which I found in the field, (supposing then that it was poisonous,) by dashing it against the ground: and something protruded, which I supposed was its bowels, but on examination, I found it to be the pretty olive-spotted frog, with an orange-coloured belly (Rana Halecina?): it, too, was torn, but whether this was done by the snake, or by the shock against the ground, I don't know ; I suspect the latter, and that it had been swallowed whole, and probably alive. A friend of mine informed me that he once saw a snake of unusually large size, and determined to kill and open it; 
which he accordingly did, and found a very large green frog, which was dead of course, but unbroken. It seems impossible that so slender an animal as a snake can swallow or contain so large a creature as a frog, but the jaws, throat, and body, are capable of prodigious distension.

C. - I have read that the sloughs of snakes are an object of superstition with some Indian tribes, and are used in their pretended magical rites.

$F$. - They are also an indispensable article in the nests of some birds; perhaps from their softness, as they are extremely thin and smooth.

I have lately perceived the young deep green leaves of the Wild Leek (Allium Vincale) sprouting through the dead leaves on the ground, in the maple woods. This plant is greedily eaten by the cattle, probably because anything fresh and green is now acceptable to them; but if milch cows eat it, it gives a strong and unpleasant taste to their milk, so as sometimes to make it unfit for use. This flavour is in a considerable degree dissipated by slightly heating it as soon as brought in.

C. - I was much deceived last evening in a sound I heard : as I was standing in the field behind the house, about twilight, I heard what seemed to be the rattling of a thousand carriages on a rough road, about half a mile off. I could not think what it could be ; but on going towards it, I found it proceeded from the marshy spot below the barn, and on my approaching discovered that it was nothing more than the cackling and croaking of myriads of frogs. As I came pretty close, I could see one after another splash into the water, and the croaking gradually grew less and less until it altogether ceased. I had not left them long, however, before they tuned up their musical throats again, and 


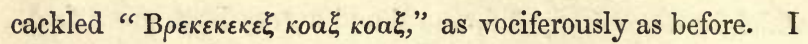
could not help laughing, to think how egregiously I had been mistaken.

$F$. - They have just awaked from their half year's sleep; and will now nightly serenade us with the same delightful sounds, for several weeks to come. Occasionally the Bull-frog (R. Pipiens) comes in with his bass, making a deep hollow sound, something like the short bellow of a distant bull. These sounds, with the whistling of the lizards, fill the air in the neighbourhood of the marshy places the whole night long; and are very annoying at first, but habit soon accustoms the ear to this, as well as to most other annoyances of a similar nature. That which is often repeated, except absolute pain, ceases to affect us with sensations either of disgust or pleasure; and becomes a mere matter of course, so as scarcely to be perceived. 
IX.

\section{MAY 10th.}

Belted Kingfisher.-Gold-winged Woodpecker.-Pileated Woodpecker. - Red-winged Starling. - Bald Eagle.-Meadow Lark.-Ferruginous Thrush.-Maryland Marmot.-Birch Stump.-Insects.-Grey-veined White Butterfly.-Spring Azure B.-Dog's-tooth Violet.-Tamarack. -EIm Blossoms.-Ova of Frogs.-Leather Plant.-Raspberry.-Black Cherry.--Red Cherry.-Bat.- Short-tailed Field Mouse.-Instance of maternal Care.

Charles. - I have been taking a walk this afternoon by myself ; my course has been down to Smith's mills, crossing the bridge, and following the river a little way ; occasionally straying into the woods, as I took my gun with me.

Father. - I perceive you have had some success in procuring birds.

C. - What is this bird? its head is too large to allow the form to be graceful ; but its colours, blue and white, are chaste, and even elegant.

F. - It is the Belted Kingfisher (Alcedo Alcyon): its habits are much like those of its more showy congener, the English kingfisher.

C. - I shot it near the mill: it was perched on the branch of a cedar which overhangs the water just below the falls, where the cliff is high and precipitous; I had some difficulty in securing it after I had killed it, for it fell in the water. It was probably watching for fish among the pools and eddies caused by the rocks.

$F$. - It generally frequents such situations: it no doubt 
finds its prey abundant, many fish being driven over the falls, and entangled among those rocky shallows below.

C. - I heard its sudden rattling cry two or three times, before I could get a shot at it. Is it migratory?

$F$. - I have never met with it in winter; and as our streams and rivers are fast frozen up at that season, I should think it impossible for it to subsist.

C. - I have obtained a specimen of a very beautiful bird, the Gold-winged Woodpecker (Picus Auratus), which was hopping about the ground, and the rails of the fence.

$F$. - In this respect it differs from the other woodpeckers; for they are very rarely, if ever, seen on the ground, and not often on the fence; whereas, this species is more commonly found in such situations than in any others. This, though it often rests perpendicularly, and climbs, like its brethren, yet more frequently sits on a bough, or on a rail, like other birds. He is very fond of ants, and to search for these is probably the business which so often brings him to the ground: he does not perforate trees so much as the others, though still he does a little business in that line.

C. - The common people here call it "Wickup ;" its common cry consists of one note repeated very rapidly, many times, so as almost to resemble a shake in music.

$F$. - I was once shown the nest of a Gold-wing; it was in the State of Alabama, where it is called the Yellow-hammer. The nest was in a hole in a decayed stump, about twelve feet from the ground; the hole was round and small, but widened within, and turned downwards. It contained four young ones, almost fledged. A boy took out one to show me, which he put in again, and for some time after, they kept up a singular hissing noise, sufficient to deter anyone from exploring their hole who was not acquainted with the origin of the sound. The colours of this bird are beautiful, without being gaudy. 
C. - I saw a still finer species, the noble Pileated Woodpecker ( $P$. Pileatus), with his black body, and white wings, and high conical cap of deep scarlet. He was stripping the bark from a dead spruce, in the black-timbered woods, and seemed to enjoy the sport, as he laughed a good deal at it. I wanted to spoil his tune, but could not get near enough to shoot him.

$F$. - The notes of the pileated woodpecker resemble the loud horse-laugh of a person with a cracked voice, gradually sinking, which makes the resemblance perfect; those of the Red-headed ( $P$. Erythrocephalus), are a cackling repetition of one sound. The pileated is not migratory, but is occasionally seen in winter; it is not however at all numerous at any season.

C. - On the willows and hazels in the marsh bordering the river, was a flock of pretty birds, all over shining black, except the shoulders of the wings, which are bright scarlet, edged with whitish. I shot two of them.

F. - It is the Redwinged Starling (Sturnus Predatorius) ; a bird much hated by the farmers of the neighbouring States, by whom it is called "Corn thief," on account of its appearing in countless myriads in the fields of Indian corn when it is soft, which it devours in immense quantities. With us, however, they do not assemble in such numbers as to be formidable; a few flocks, and those not numerous, are all that we usually see during the season.

C. - They had a singular kind of crowing sound, rather melancholy, and now and then opened their wings as they sat on the trees. There were several among them, whose plumage was black, mottled with white, which I take to have been females. —— These are all that I succeeded in procuring, but I saw several others that were new to me. One in particular I very much wished to obtain. At a very lonely part of the river, about a quarter of a mile 
below the falls, where its rocky course is bounded on each side by high cliffs, topped with thick evergreen woods, I saw sitting on the limb of an old hemlock that grew out of the side of the cliff, a very large eagle, of a dark brown colour, except the whole of the head, which was white. I suppose it was the celebrated Bald Eagle (Falco Leucocephalus), the emblem of America: it took to flight before I could come near it, and sailed down between the cliffs, till a bend in the river hid it from me, and I saw it no more.

F. - It was doubtless what you suppose it to have been; it is a noble bird, and is not altogether rare.

C. - Some pretty birds were running about the field at the margin of the river: the upper parts of the body were brown, mottled with black, the under parts bright yellow, except a black mark on the breast. They allowed me to approach pretty near, but I fired and missed my bird, when they all took to wing.

F. - That is the Meadow Lark, another visitant from the south (Alauda Magna): they are shot for the table, and are a delicacy. They are inuch larger than the larks of England, but resemble them in many of their habits. Their song is sweet.

C. - Early this morning, before I set out on my walk, I saw a bird, evidently a species of thrush, sitting on the top of a tree, singing with all his might, and with great sweetness of expression. He was of a bright red-brown above, and the under parts white, spotted with brown, like the songthrush of England. His attitude was singular; for he kept his tail spread out, and bent under him as he sat on the bough. I could easily have shot him, but he sang so delightfully that I had not the heart to do him a wrong.

F. - It is the Ferruginous Thrush (Turdus Rufus); and is a very prominent musician among the choir, which are just beginning to fill our woods with harmony. 
C.-But I have more game which you have not seen : I left it in the kitchen, but I will fetch it. It is a curious animal.

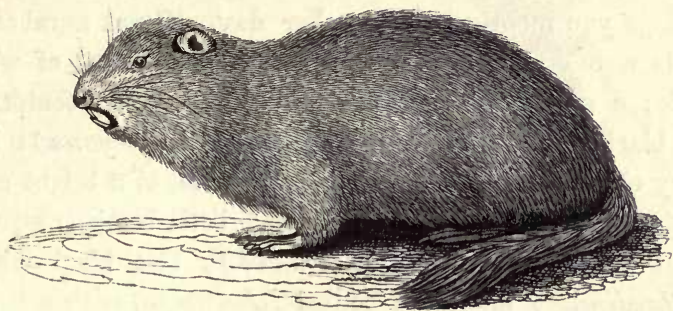

WOODCHUCK.

(Arctomys Monax).

F. - This is the Maryland Marmot (Arctomys Monax); it is common in the temperate parts of this continent. In some places it is called the Ground Hog, but here it is better known by the name of Woodchuck. It feeds on cabbage and other garden vegetables, young corn, \&c. and devours vast quantities, so that it is considered an injurious animal. He retires underground about the middle of September, and is generally very fat in spring. His burrows are long and cham. bered, and he sleeps in these even during the summer, taking care to make himself a soft bed, for he is very attentive to his own comfort. He cannot run very fast, and generally makes for his burrow if alarmed; but he is easily caught by a dog.

C. - Is the flesh good for food?

$F$. - It is often eaten, and I have partaken of it ; but the flesh, and especially the fat, has a rank and rather disagreeable taste.

C. - I shot it in the woods, more from curiosity to know what it was, than from any supposition of its being valuable. In entomology I have made some new captures: I found in the woods the stump of a very large birch, which 
had been cut down in the winter; the sap has flowed from it profusely, and is still flowing, and the whole top, and all down the sides, is covered with a thick coat of that pink mucilage you mentioned the other day. Great numbers of insects were crawling about this substance, several of which I took; a convex Chrysomela, resembling silver, sculptured with black curves and marks (Eumolpus Bigsbyana): it is a very elegant little beetle : another beetle, of a bright crimson (Cucujus Rufus); two or three little black ones, with scarlet bands (Ips Quadripunctata?); two black-winged Tenthredineta ; and a red-bodied Ichneumon, with a yellow scutellum (I. Devinctor?). I took a silver Chrysomela of the same species, from the very same spot yesterday; a singular coincidence. I have also captured several moths : four Geometra, and a Tortrix, none of which have much pretension to beauty. I have a very elegant little species of locust, the Spotted Fan-wing (Acrydium Ornatum): the thorax is elongated and tapers to a point, which reaches to the tail ; the wings are perfectly transparent, opening like a fan, and are very finely netted with delicate lace-work;

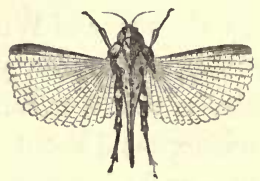

SPOTTED FAN-WING.

(Acrydium Ornatum.) they reflect the prismatic colours, like mother-of-pearl. On a pool by the road-side, I caught two species of Water-measurer (Gerris), very much like my former species, but both of these have wings, whereas the former is apterous in all its stages. I caught also a four spotted Ladybird (Chilocorus ? ) and a little Cur-culio in flight.

$F$. - I have been busily engaged to-day, sowing wheat, and have noticed some novelties. I took, crawling on the newly ploughed ground, the Copper-spot Carab (Calosoma Calidum), a large beetle, the elytra black, marked with rows of round 
hollow dots, which shine like new copper. A strong odour proceeds from it, resembling that of prussic acid, or almond kernels. It is not uncommon throughout the year, in meadows and ploughed fields. I also saw two new butterflies, the Grey-veined White (Pontia Oleracea), and the beautiful little Spring Azure (Polyommatus Lucia); these last were quite

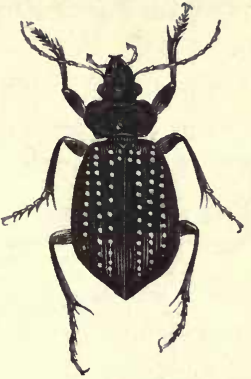

COPPER-SPOT.

(Calosoma Calidum.)

numerous, but confined to a small space of the road, and a part of the field adjacent : they are exceedingly playful ; chasing each other through the air, and though often alighting on the ground, remaining scarcely an instant before they are in flight again, flitting about over one particular spot, which they seem reluctant to leave. Notwithstanding they are so restless, they are not difficult of approach, and are easily caught. The colour of their wings, a delicate azure blue, is exceedingly brilliant.

C.- In the hard-woods, I observed several plants springing up through the fallen leaves of autumn, many of them having, in growing up, pierced through a dead leaf. They generally consist of one leaf, hollow or sheathed at the bottom, but some have another smaller leaf, appearing in the sheath of the first. Their colour is peculiar; they are of a polished green, with more or fewer brown spots, many of which run into each other, and cover a large part of the surface. A single stem springs from the leaf, surmounted by a very elegant drooping flower, of a bright yellow.

F. - It is the Yellow Dog-tooth Violet (Erythronium Amevicanum), which blooms abundantly in the beech woods. 


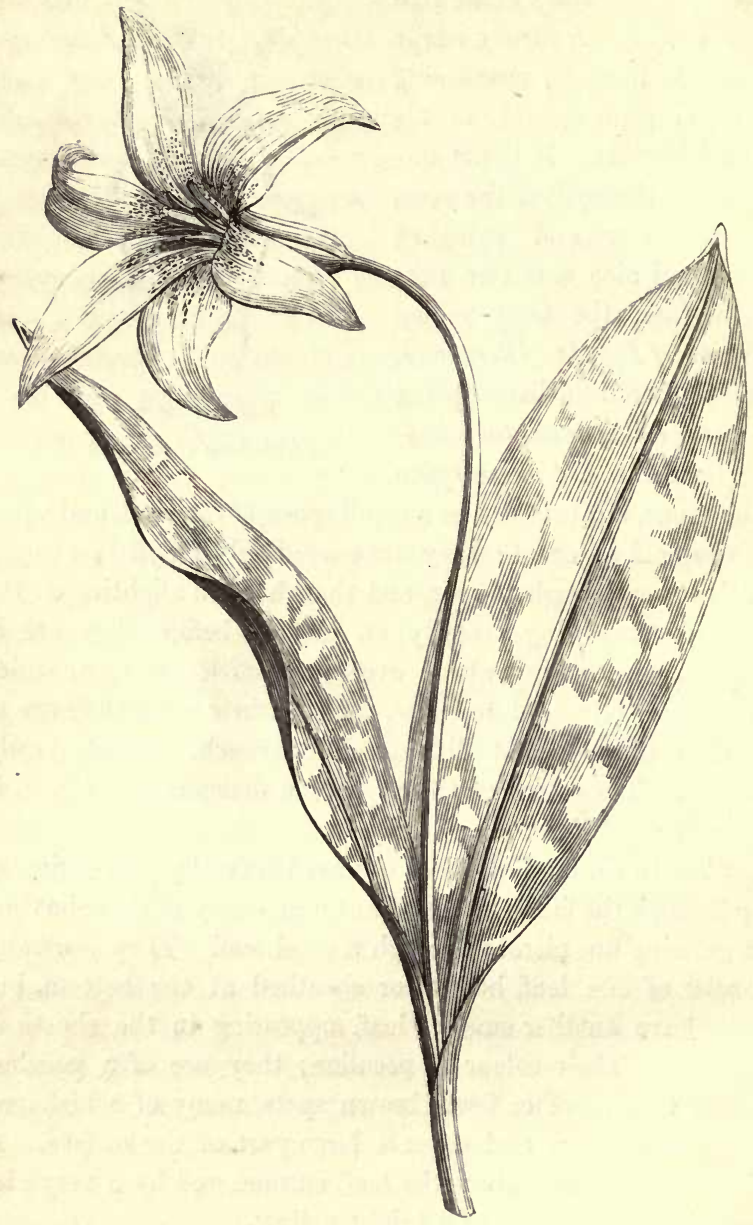

THE YELLOW DOG-TOOTH VIOLET.

(Erythronium Americanum). 
C. - I found on most of them, in the very bottom of the corolla, some little black beetles, with a red thorax. (Telephorus - ?)

F. - The leaf buds of the Larch or Tamarack (Pinus Pendula) are bursting; a deciduous member of an evergreen family.

C. - The tops of the elms are quite yellow: is this colour caused by the opening of the leaf-buds ?

$F$. - No: the elm has not yet begun to leaf; but it has been in full flower about a week. The blossoms are yellow and very small; from some trees they have already begun to fall, and are thickly strewn on the ground beneath. The seeds ripen and are shed in June, at which time they may be collected; and as the elm, if properly treated, would make an excellent hedge, it would be worth while for our farmers to plant the seeds for that purpose. It grows rapidly, and makes a strong shoot the first season.

C. - In standing water, I observed many masses of clear jelly-like substance, containing a number of small black globules.

$F .-T h e y$ are the eggs of frogs; they are all deposited at once, enveloped in this mass of jelly, which both serves as a protection to them, and keeps them from being washed away. When near the time of hatching, the young tadpole may be distinctly seen with a microscope in one of these eggs; but I suspect they are not yet sufficiently matured. The frog deposits its ova almost immediately after it revives from torpidity : we may always see these masses a very few days after we first hear their croaking.

C. - I found a shrub very numerous in the woods, covered with yellow flowers, very small, with thick downy envelopes. I have a twig of it; I was obliged to cut it off; for, small as it is, the bark was so tough that I could not tear it. 
F. - That is the Leather plant (Dirca Palustris), so called from the extreme toughness of the inner bark, which is so strong that the stoutest man could not break, by pulling, a strip of an inch in width, taken from the main stem. The bark is used as strings for many purposes, especially by millers, who collect great quantities for the purpose of tying their flour bags. The wood, when stripped of the bark, is remarkably soft and brittle, snapping with the slightest effort, almost like the pith of elder. Like the elm, it blossoms before leafing. It is here commonly known by the name of Wickaby.

C. - The leaves of the raspberry are opening. Is this plant a native?

$F$. - I believe it is : Eaton mentions it by the name of Rubus Idaus, among the native plants. It grows and spreads abundantly, so as quickly to overspread a large space of ground. I have never seen it in the primitive woods, but whenever a clearing is made, the raspberry appears. I think it is the most delicious of our native fruits ; fully equal, if not superior, to the garden raspberry of England : an unusual thing, for the advantage is almost universally on the side of the cultivated fruit. In Newfoundland, it also grows abundantly, and in the most unpromising situations, springing up from a mere bed of stones. As a weed it is troublesome, and not very easy to eradicate: mowing will, however, keep it down in grass land, and in tillage land we plough them up, and turn the bushes under the furrow. The stumps of trees that have been cut down, which we are obliged to leave in the ground for several years, but which give our fields so unsightly an appearance, are invariably surrounded by a clump of raspberry bushes; these seem privileged places. Another fruit-bearing plant, but of somewhat fairer proportions, is leafing; the Black Cherry (Prunus Virginiana). The cherry grows to a con- 
siderable tree; and has a spreading body, and a handsome outline, but its foliage is too thin to have that massy richness which gives so much beauty to many trees. Its wood is hard, of a fine grain, and susceptible of a polish, and from these qualities, and its colour, a dark red, it is in demand for furniture, which sometimes has no small resemblance to mahogany. The red cherry, whose fruit is very dissimilar in colour and flavour, is, I believe, a distinct species ( $P$. Borealis). Except by the fruit, they can scarcely be distinguished from each other: the red, however, rarely grows to any size.

C. - In coming home this evening, I saw a bat in flight: I should scarcely think there are yet moths enough abroad to support him.

F. - Though moths are his favourite food, I do not think he altogether confines himself to that diet, but occasionally makes a meal of other insects : and an entomologist of his skill and industry, no doubt, can manage to capture many specimens, even at this season.

C. - Under large stones and the like, I find many passages, turning in every direction, made in the surface of the ground, about half an inch deep: in some of them there is a great quantity of soft dried grass : as much as a man could hold in both hands, I have taken out.

$F$. - They are the burrows and nests of the Short-tailed Field-mouse (Arvicola Pennsylvanicus), a destructive little animal, which every farmer kills at every opportunity. In ploughing grass land, we frequently disturb them; and as they cannot run very fast, though they are nimble in creeping into crevices and under the clods, they very often suffer death. The farmer's animosity against them arises from their fecundity, and their appetite for grain and Indian 
corm, of which they destroy a great quantity. This animal is about four inches long, besides the tail, which is about an inch more; the head is roundish and blunt; the fur is thick and soft, the colour a kind of iron-grey on the back, the under parts light grey. They are very numerous. A friend of mine told me that once in the month of June, a mouse of this kind, whose nest he had exposed by turning over a large stone, was endeavouring to make her escape with three young ones which clung cleverly to their mother's back, holding with their teeth, and not retarding her progress in the least. His admiration of the maternal care of the old one was not, however, a sufficient inducement to prevent his killing the whole four. There is another species of Fieldmouse (Mus Leucopus?), much smaller, of a lighter brown, and with a tail considerably longer than the body. I have never seen more than one specimen of it, and that I did not preserve. 


\section{$\mathrm{X}$.}

\section{MAY 20th.}

Ricebunting. - Blackburn Warbler.-Canada Flycatcher.-Bay-breasted Warbler. - Purple Grakle. - Rusty Grakle. - Kingbird. - Yellowbird. - Scarlet Tanager. - Botfly. - Moths. - Carrion Beetles. Sparklers. - Reflections of Colour. - Poplars. — Curious Fact. - Balm' of Gilead. - Leaf-buds. - Thorn. - Hedges. - Birch. - White Birch. —Elm._Making Salts. - Height of Elms. - Uprooted Trees. - Leafing of Logs. - Rock Maple - Soft Maple._Oak. - Service. - Purple Finch. - Singular Dance. - Wild Gooseberry. - Willows. - Insects. - River Coatacook. - Indians - their warfare - war-whoop - domestic manners - religion - government — language — sufferings - anecdotes. - Evening Walk. - Perfume of Balm of Gilead.

Father. - Every day now increases our sources of pleasure and enjoyment. Nature now opens her stores so fast, that we have scarce time to look on one object before another is presented to our view, and in the multitude we doubtless overlook many altogether. The labours of agriculture; although by employing us in the fields and woods, they afford us opportunities for the observation of nature at this peculiarly interesting season, yet afford us little leisure to search for her more hidden operations, or even to duly mark those that fall under our notice. Very many interesting facts we cannot fail to observe; among which the successive arrival of one bird after another, from its hybernation in milder latitudes, is not the least worthy of remark.

Charles. - What species have you noticed since our last conversation on the subject? 
F. - On the fifteenth, I observed several little feathered strangers : the trees and bushes being still leafless, afford facilities for discovering birds, which a few weeks later we shall not possess. The first I noticed was that well-known bird, the Ricebunting (Emberiza Oryzivora), familiarly known to everybody here by the name of Bob Lincoln, from his call, uttered as he sits on a rail of the fence, or a branch of a tree, which much resembles the words "Bob Lincoln," but still more "Bob Linkling," whistled with a very peculiar intonation, the middle syllable being in a much higher note than the others. Yonder one sits on the fence now : do you note his call?

C. - Yes; he repeats his name very distinctly: as a stranger, he perhaps thinks it a point of politeness to announce himself. He is a pretty but singularly marked bird ; the whole of the under parts being deep black, and the back of his head and neck white, and his back being chiefly of the same colour, make a very curious appearance; the distribution of the colours being opposite to that of most other birds, which have the darkest tints above, and the lightest beneath.

$F$. - This is the male: the female has the back brownish, and the under parts dull yellow; and in the summer the male throws off his black and white dress, and becomes like his mate. I have never known them to do us any considerable injury, but in New England, and in the Southern States, they do great damage; in the former, by devouring the oat crop in summer, and in the latter, by the devastations they commit in the wheat fields in spring, and among the rice in autumn. For these reasons, and because his flesh is highly esteemed, no mercy is shown to him; but the immense flocks that appear are thinned by the combined guns of all the sportsmen in their vicinity.

C. - Has he no other notes but the "Bob Linkling ?" 
F. - Oh, yes ! his song is very pleasing; of which Wilson says, "Some idea may be formed of this song, by striking the high keys of a pianoforte at random, singly and quickly, making as many sudden contrasts of high and low notes as possible." I observe that they have a habit of suspending themselves in the air, and then coming gradually down, singing more and more rapidly till they alight, and in the moment of alighting, make a hissing, or sometimes a low guttural sound. They do not usually fly high, but sing in this rapid manner, hovering over a field. After having been several years in this country, on my return to England, hearing for the first time the skylark in the air, and turning quickly round and seeing the bird singing as it descended, my first impression was, "there is a Bob Lincoln."

C. - What other birds have you lately noticed?

F. - The Blackburnian Warbler (Sylvia Blackburnia) is one ; a little bird of great beauty: the whole upper parts are black, the black on the crown of the head, bounded and divided in the middle by lines of rich orange; a large white spot on the wing; the whole throat and breast rich fiery orange with black spots; the belly yellow. It is very rare in the United States, but here, I see some every spring; and in some seasons they are quite common: they are not very shy, coming around the house, and allowing a person to approach within a short distance, when in the woods. I saw a pair of them a few days ago, busily engaged in pecking the buds of a tamarack, probably searching for insects. Of its musical powers I can give no account, as I have never heard it utter a note.

C. - I have seen a bird somewhat like the one you describe, but its breast and belly were brilliant yellow. spotted with black, the upper parts dark coloured.

$F$. - I too have seen it, but cannot exactly determine whether it is the Black and Yellow Warbler (Sylvia Mag- 
nolia), or the Canada Flycatcher (Muscicapa Canadensis): as the former is represented as very scarce, it is probably the latter. Many of the warblers are marked on the under parts with different shades of yellow, and it is difficult from a casual sight of an individual or two in the woods, without opportunity for close examination, to determine with accuracy the species to which they beiong. I believe I am clear in mentioning the Bay-breasted Warbler (Sylvia Castanea) among our recent visitants, though $I$ do not know that I have seen more than one or two specimens. Many other warblers, marked with olive and yellow, are hopping about the bushes, but these colours are far too general in this family for me even to guess at the species.

C. - From the name, "warbler," given to this genus, I should suppose that they are noted for their song: is it so ?

$F$. - By no means : in general, the numerous species of this tribe are either silent, or have a few weak, simple notes. The word warble signifies to sing sweetly, but in a low weak tone of voice; and the notes of several of the Sylvia genus bear this character.

C. - Among a thicket of willows near Spafford's bridge, I noticed a flock of birds about the size of a thrush. At first, they all appeared of a deep black, but on a closer survey, I observed that it had a changeable gloss, and that the head was deep green.

F. - They are called by naturalists the Purple Grakle (Quiscalus Versicolor), but by farmers the Crow Blackbird. This is another of those species which assemble in immense armies, and attack the agriculturist in the tenderest part, his crops. I have seen large flocks in this country, but nothing compared to those clouds which are said to blacken the fields of our southern neighbours. The depredations of these birds, and others of similar appetites, seem chiefly committed on the maize, or "corn," as it is emphatically called ; 
but as very little of this grain is raised in the Province, we escape the ravages sustained by our less fortunate brother agriculturists in the south. There is a kindred species, hardly to be distinguished from this, the Rusty Grakle (Quiscalus Ferrugineus), visiting us about the same time: it has many of the habits of its congener, assisting in the destruction of the corn, though not in such countless thousands as the other. A large proportion of the individuals of this species are of a rusty hue, but this is not found in the full-grown male.

C. - There is a pretty bird with a black head, sitting on the topmost twig of that leafless bush just before us.

F. - That is the notorious Kingbird (Muscicapa Tyrannus); a bird well known throughout this continent, and I believe respected, wherever he is known. $\mathrm{He}$ is a bird of the most undaunted courage: during the breeding season, no bird of prey of any kind, no matter what its size or strength may be, can approach his territory with impunity. He sallies forth on the wing, attacks the intruder with vigour, and makes even the kingly eagle retire from his premises. The plumage on the head is frequently erected, and then shows a rich bed of brilliant flame-colour, at other times concealed. Like the rest of the flycatchers, he fixes on a prominent station, like that occupied by the individual just observed, whence he watches all around for bees, flies, and other insects: when he perceives his prey, he darts into the air, catches it with a snap, and instantly returns to his watch-post again.

C. - His slate-coloured back, and white breast, are very becoming; and his character is noble, as it appears to be in defence of his mate and young ones that all this courage is exerted. The service of banishing birds of prey more than compensates for the loss of a few bees.

F. - The Yellowbird (Fringilla Tristis) has been in 
summer plumage for several days. His appearance is now very beautiful and striking; the body being of a rich yellow, with the front of the head, wings, and tail of a deep black; and as they are by no means solitary, but fly in flocks, they cannot fail of being noticed by the most unobservant. Ha ! I see a stranger, still more showy in his appearance; the Scarlet Tanager (Tanagra Rubra); you may see him by getting on the fence, in this ploughed field, a few rods distant.

C. - I see him : he is indeed a beautiful bird. There is some resemblance in the distribution of the colours, between him and the Yellowbird; but where the latter is yellow, this is brilliant scarlet; both have the wings and tail black.

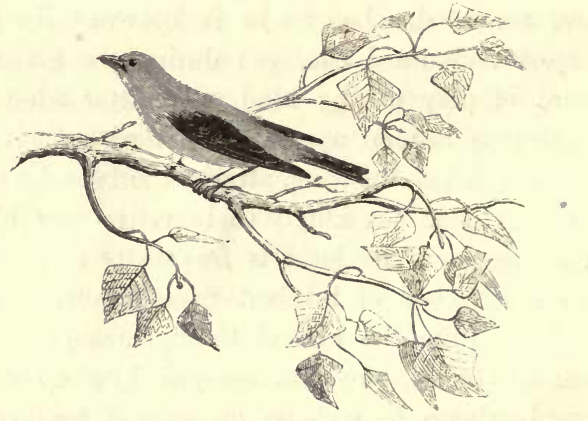

SCARLET TANAGER.

(Tanagra Rubra.)

$F$. - The tanager is more than twice as large as the yellowbird: the brilliancy of his colour makes him conspicuous, when the sun shines, at a great distance; and when seen near at hand, the contrast between the jet black and bright vermilion has a fine effect. His notes have not, I believe, any pretensions to be called a sorig; at least, I have never heard any, though I have seen them in considerable num- 
bers. The female is a kind of dull yellow-olive, a colour which the females of almost all our gaily coloured birds possess : probably to secure them from observation while performing their maternal duties.

C. - I picked up a few days ago, in the horse-stable among the ordure, a somewhat oval larva of a dirty white colour, encircled with rings of minute hooks. It is now become a pupa, not by throwing off the skin, but by the integument itself becoming more rigid : it is also a little altered in form, being cylindrical, and its colour is a shining chestnut brown.

$F$. - It is, no doubt, the Horse Gad-fly, or Bot (Gastrus Equi,) but it is not likely that you will raise it to the perfect state, unless you have covered it with damp earth. The Bot-fly deposits its eggs in summer and autumn, on those parts of the horse's body that he can reach with his mouth: a curious provision is made for the deposition of the egg; the oviduct of the female is capable of being thrust out to some length, and is composed of tubes, which slide one within another, like the tubes of a spyglass. When the fly is hovering around a horse, I have often observed this oviduct protruded, and turned up under the belly; if caught at this time, we find that an egg is already ejected, and lies at the very extremity, ready to be deposited. The slightest contact with the hair of the horse effects this, and the egg is left sticking to the hair. We frequently see the fore legs and shoulders of our horses almost white with the numbers of these eggs. In a short time they become ready for hatching, and the least touch of moisture, even a wet finger, will instantaneously cause the egg to burst, and the little maggot crawls and writhes about. As the horse frequently licks himself, hundreds of these eggs must be hatched, and the worms adhere to his tongue; and as many as escape the grinding of his teeth, go down with his food into the stomach. 
Here they have reached their destination; and here, or in the intestines, they thrive and increase in size until full grown, when in spring they are voided with the fæces, as the one you found. They are supposed by some to produce a painful, and sometimes fatal disease, to which horses are at this season subject; others, however, believe the presence of these insects to be even conducive to the health of the animal by their stimulating effects.

C. - I have taken several new moths within the last ten days, some flying in at the window at night: Noctuce and Geometra.

$F$. - Yonder is the carcass of a lamb, thrown out to putrefy, with no regard to the olfactories of passers-by. If your entomological zeal is sufficient to overcome your disgust at the scent, you may probably find some large and handsome carrion beetles under it.

C. - Oh, I don't much mind the smell if I can obtain any fine specimens. If you will stay here, I will examine it.

$F$. - Well, have you succeeded?

C. - Yes: there are multitudes of beetles of many different species crawling about it. Most of them were a black species of Sylph, the elytra covering the abdomen, except when the latter is elongated, the thorax broadly margined with pink (Thanatophilus marginalis): another species was numerous, much larger and handsomer, the elytra almost as long as the body, longitudinally ridged, and having a transverse row of red spots near the hind margin : the rest of the insect is black (Necrodes Surinamensis). There were numbers of Staphylinida, the Fish-beetle of Newfoundland (Staphylinus Villosus), the beautiful Goldtailed Rove-beetle (Staphylinus Chrysurus), and other smaller kinds. I also took a small black Hister (H. Harrisii), and a little lamellicorn beetle, with the thorax elongated into a projecting horn, and having another horn on the head (Pathophagus latibrosus). 
$F$. - These beetles answer the same useful purpose as the vultures and jackals of tropical countries : that of quickly removing putrid animal substances. The Silphida, in particular, are very useful in this respect: as soon as animal substances become fetid, these beetles throng to it from all quarters : whether the knowledge is derived from the sight, as in the case of the vultures, or from the smell, I do not know, but I suspect the latter. A curious practice prevails here, of throwing the carcass of a lamb, when one dies, into the limbs of an apple-tree in the orchard: it is true this instance is an exception, but the custom is a general one, though of the origin or object of it, I have not the most distant idea.

C. - The beautiful green Sparklers (Cicindela Sex-guttata), and a purplish species (Cicindela Proteus), fly about dusty roads. The former are of a most brilliant dazzling green, if the rays of light falling on them are reflected to the eye at an acute angle; but if it be obtuse, they appear of a deep and fine blue. The same phenomenon occurs in the brilliant colour of the Emerald Agrion of Alabama (Agrion Virginica), and Wilson notices exactly the same thing in the plumage of the Indigo-bird (Fringilla Cyanea). These Tiger Beetles, as they are called, are, I suppose, the most agile of all coleopterous insects; their legs are very long and slender, and they run with such swiftness, that they seem to glide along the ground rather than to crawl; and on the approach of a footstep they take wing with as much wildness as any fly, but only for a short distance, when they alight again. They can be caught only with a net, and it is a difficult matter even then.

F. - Many trees have burst their leaf-buds, and new ones are opening every day. Yonder poplar woods have a pleas- 
ing flush of green, the leaves being quite developed and open, but yet soft, small, and tender. The green is now of a very light and yellow cast, but after a while it will be much darker.

C. - The poplar seems to be the first tree that leafs.

F. - Yes : there may be others that burst their leaf-buds a day or two before it, but they are much longer before they acquire anything like foliage. I noticed the bursting of the leaf-scales in those woods about a week ago, but some near the village are more forward by several days. We often find a difference of many days in the leafing of trees of the same species in different situations, which, for aught we can see, appear equally favourable. The Poplars (Populus tremuloides, $\boldsymbol{P}$. grandidentata, $\boldsymbol{P}$. levigata, \&c.) are very rarely seen in the primitive forest: but if a clearing be made, and neglected for a few years, the ground will be covered with a new growth of trees, usually called " second growth timber," consisting almost wholly of poplars, provided the land be slightly disposed to wetness. The cause of this I cannot in anywise explain. It is not confined to the case I have mentioned: it has very often been observed that when forests are destroyed, they are succeeded by a spontaneous growth of plants of altogether different species from those which originally occupied the ground. How are they produced? From seed, certainly : but whence comes the seed ? has it lain in the ground for uncounted ages, waiting a favourable opportunity to spring up? I cannot tell; this is one of those mysterious things, which I am not at all adequate to unfold. I can only notice the fact.

C. - Is not the Balm of Gilead a species of poplar?

F. - It is : Populus Balsamifera is its botanical appellation. This tree affords a good example of the perules, or scales, which serve as a sheath to the bud in winter, and which protect the tender, unexpanded leaves within from 
the cold. That they may better do this, the perules in the Balm of Gilead, and in many other plants, are coated with a thick, clammy, resinpus substance, which may be scraped off with the nail, and which in this species has a fragrant smell. It seems probable that the hive-bee collects the substance called propolis, with which it stops the fissures and crevices of the hive, partly from the resinous perules of plants. Let us examine a bud from this Balm of Gilead; as the terminal ones open some time before the lateral ones, we shall find some unopened.

C. - Here is one.

$F$. - These two dark-brown convex scales are the perules; they are thick and tough; within them are two more, much thinner and paler, but still more coriaceous than the young leaves. Here are the leaves : how soft and small they are! they appear, however, much smaller than they are, for they are so folded up as to occupy the smallest possible space.

C. - I will try to unfold one, though it seems a very delicate operation. Are all young leaves folded up in the bud in this manner?

$F$. - I believe all are folded, but not all in the same manner. "It is found that the young leaves are constantly folded up in the bud in the same way in the same species of plants, but there are many different modes of this arrangement ; this is termed the vernation or foliation of the plant." The Balm of Gilead opens its buds at about the same time as the other poplars.

C. - I noticed a few days ago that solitary bush in the corner of the upper field beginning to unfold its leaves.

$F$. - It is a specimen of the native Thorn (Cratagus Coccinea); the leaves are shaped almost exactly like those of our English hawthorn, but the berries are much larger. This is not a very common plant here, though I know of several large shrubs within the compass of a mile : but near Quebec 
it is very numerous. The Heights of Abraham, and the sloping sides of the cliff are, in many places, so thickly clothed with thorn-bushes as to form almost impenetrable thickets.

C. - Could not this plant be introduced as a substitute for the hawthorn, in the formation of live fences or hedges?

$F$. - There is no doubt but it might. I have begun an experiment of this nature, but too recently to be able to speak with certainty of its ultimate success. I collected about a quart of the haws, from under the neighbouring bushes last autumn, and buried them in the garden a few inches below the surface; they will not, however, sprout until next spring. I also took the pains to collect about a dozen suckers and young plants, which I planted in a line last spring: many of them lived through the summer, and are now budding. There are many other plants which might be put to this purpose. The beech readily grows from seed, is very thick in branches, and may be easily dwarfed by cropping : it has the advantage of keeping its dead leaves through the winter, affording considerable shelter. It is said that after cider is made, if the pomace, that is, what remains of the pulp after the juice is expressed, containing the seeds, be strewn in a line and slightly covered with earth, a thick hedge of apple will spring up and prove very effective: all these, with the elm, are worth trying.

C. - The plum and apple trees in the orchard are likewise bursting their leaf-buds.

F. - So are the Birch (Betula Papyracea?) and Elm (Ulmus Americana). Both these trees grow to a majestic size, and are among the finest of our forest trees : the former is particularly abundant in wet and marshy lands, and is the companion of the resinous evergreens. It is considered a sign of poor land where it is plentiful. The outer bark of the birch is composed of many very thin layers, which 
may by patience be separated, and can be written on as easily as writing-paper. The outer laminæ are of a delicate cream colour, but as they approach the inner bark they become redder. These layers, when separated and divided into narrow strips, make an exceedingly soft and elastic bed, equal, if not superior, to a feather-bed; but great patience is requisite to prepare so large a quantity. The inner bark is about half an inch thick, of a crumbly, somewhat farinaceous nature : it is of a rather pleasant smell and taste, and of a bright orange colour, which it readily transfers to water. I have read that in times of scarcity, the rude inhabitants of northern Europe make a kind of apology for bread by pound. ing the inner bark of the birch. The buds have a similar smell, which is strong, but agreeable. For some time after the leaves are disclosed, they are covered with a fine silvery down, as you may observe : probably this down acts as a preservative against the effects of cold, both while within their perules, and afterwards while young and tender, for it soon disappears. The wood of the birch, when young, is yellowish white; when mature, the heart-wood, or all except the sap-wood (alburnum), is of a dullish red, which deepens by exposure; and is, when polished in furniture, \&c. of considerable beauty. In very old trees, the heart is nearly black, or rather of a deep bistre brown, and very brittle. The larninæ of the outer bark are used to form the very ingenious birch canoe of the Indians, being sewn together with deer sinews, and payed with resin. There is another tree of this genus, the Paper, or White Birch (Betula Populifolia? ?), which is said to be occasionally found in our woods : for instance, near the banks of the Masuippi river, on the west side. I have never met with it here, but have seen it in great numbers near the head of Lake Memphramagog, in Vermont. I have been told that the Indians sometimes travel through the country, making inquiries for this tree, for 
what purpose I do not know. It has a singular appearance : the bark is perfectly white, not glossy.or silky as the common Birch, but exactly like white paper, very smooth, but not shining; it readily peels in thin laminæ, but does not look so ragged as our tree. None that I saw were of large size, not more than six inches in diameter. I observed it in several other localities, usually on the slope of a hill, and near water.

C. - Is the timber of the birch applied to any useful purpose?

$F$. - It is often sawed into planks for tables, and many other articles of furniture, but is chiefly used as fuel, as it burns readily even when green, and makes a hot fire.

C. - Is there any difference in this respect?

$F$. - Oh, yes ; very great difference. Some woods, such as elm and the evergreens, especially hemlock, will scarcely burn at all when green, and when they do, make a very dull fire, smouldering away without flame. Maple and beech burn intensely, the former the most readily, and with the most flame ; but the latter, when half consumed, gives out the most intense heat, though there is little difference between these two. Birch ranks next, and then the ash, both white and brown : basswood and poplar can scarcely be consumed, except by gradual and slow smouldering, and that with the help of other fuel. All wood burns well when seasoned, or deprived of sap by drying.

C. - To what purpose is the wood of the elm applied?

$F$. - When young, it is often cut and quartered; that is, split through the middle into four parts, which are laid by to season. Few farmers have not a number of pieces of elm, white ash, and leverwood by them, to be brought into use whenever any small article is wanted, in which hardness must be combined with toughness, such as axe-helves, wheel-spokes, \&c. When grown, it is not used for any- 
thing that I know of, except by those who prepare salts of ley, for the manufacture of potash. As the elm yields a - large quantity of ashes when burned, in proportion to other trees, it is often felled by the salts-boilers.

C. - What is the process of making salts ?

$F$. - One man, or more commonly two, go into the woods with holders, and a kettle or large caldron; and make a kind of camp, very much like a sugar camp. As winter is the usual season of operation, they often make a rude hut, or some little protection from the cold. They commence their business by felling such trees in the neighbourhood as suit their purpose ; unless they have another object in view, the clearing of the land for cultivation, in which case they cut and burn indiscriminately all the timber, except such as is saved for some peculiar purpose, such as cedar for fencing, \&c. Having cut enough to begin, and divided it into logs, they pile them on one another by rolling them up an inclined plane, made by stakes from the lower logs to the ground: they then fill the interstices with dry brush, seasoned wood, \&c. and set fire to the whole, taking care to have sufficient wood that will burn to consume that which would not burn without assistance. The ashes are collected from time to time, and put into a holder, shaped like an inverted cone, with the bottom open; a little straw is placed over the hole at the bottom, a receiver placed beneath, and water poured on the ashes: the water filters through and runs into the receiver, having extracted the alkali contained in the ashes, which stains it of a dark colour, like that of brandy. This is called lye, or ley, and is boiled down till the water is evaporated and the alkali is left, which is the potash in a very impure state; it is of a black colour, and is called salts of lye. This is sold to those who keep a potashery, where it is cleansed from its impurities, I believe by burning in a furnace, and becomes the potash of commerce. 
The making of salts is toilsome and laborious, but is considered profitable, especially where it is carried on in conjunction with clearing. But to return to our elm. In June, the bark readily separates from the wood; and as it is very tough and leathery, it is often used (the dry furrowed outside being pulled off) to tie stakes together, between which boards are put as a fence.

C. - The elm grows to a great height; I know of several that I should think are not short of a hundred feet high. That solitary one on the top of the hill, near Barker's house, must be near that height. Divested of its neighbours, rising alone out of the open field, and stretching to so great a height without branches, it has a picturesque appearance.

$F$. - The large elms are often left standing in lonely majesty when a clearing is made : and their straight towering trunks, crowned at top with a small bunch of foliage, give them a character somewhat resembling that of the tall palms of southern regions, but without their feathery lightness. I suspect, however, that their uselessness pleads for their lives in the mind of the axe-man more strongly than their beauty. There was one in the field to the south of the house, more lofty than the one you have mentioned; and as it was much more insulated, and its top decayed and dead, except a small tuft of foliage on one of its limbs, it seemed as it stretched forth its withered arms, to be a stiking emblem of an aged patriarch, who has outlived all his companions, and is a stranger and a solitary in his generation ; in whom death is already struggling with life, and fast gaining the ascendancy.

C. - What became of it? for it is not there now.

$F$. - One Sunday morning last summer, we heard a thundering roar, a sound unlike any to which we were accustomed; we ran out of the house, but all was still around, and we could not imagine the cause. By and by we missed 
our aged Elm, and on going to the place found it prostrate ; the blast had come at length and laid it low.

C. - Is it not dangerous to leave trees in this manner, standing in the open field?

$F$. - Yes; the roots of our forest trees are very superficial, and the branches and foliage being all at a geeat height, the wind has a strong purchase, as it is called, and they are very liable to be overthrown; sometimes killing cattle and breaking fences. Even in the forest, when protected by their fellows, trees are often uprooted by the wind: ther we can see how very little below the surface the roots extend, forming, as the tree lies prostrate, a perpendicular wall of contorted roots, mixed with earth.

C. - We can see scores of these in every walk through the woods: the roots often extend to a great width, though to so little depth, and the wall, as you call it, is very high.

$F$. - So high that if the trunk be cut off close to the root soon after it has fallen, the weight of the roots will cause them to fall back into their original position. This is often done, as these roots are not only unsightly, but present great obstacles to cultivation after the land is cleared.

C. - I have observed that an elm log that was cut last autumn, is putting forth leaves as if it were still growing in the woods.

$F$. - That very often occurs; in our piles of firewood, cut during winter, you may see many logs during the ensuing spring and summer, not only budding, but actually putting forth leaves which attain considerable size. The sap contained in the log, supports and affords nutriment to the budding twig, for some time after the felling. In the same manner we observe that maple logs cut in winter, continue dry till spring; then the sap begins to flow freely, and the ends are running and dripping all day. By the way, 
I have not observed the progress of the maple in vegetation: here are some by the road-side; let us examine them.

C. - The terminal and lateral buds are both opened; the former seem to have been expanded some days.

$F$. - I supposed they were; the maple usually leafs at about the same time as the birch.

C. - How many kinds of maple are native?

$F$. - I believe some five or six species; but the Rock Maple (Acer Saccharinum) and the Soft Maple (A. Rubrum) are the best known, and the only ones that are of any note as trees. The Rock, or Sugar Maple is the most noble of our native trees : it grows to a great height, and is crowned with a dense mass of foliage at the summit; the trunk is generally straight, though often studded with projections and excrescences. When it grows in a clearing, with room for it to spread on every side, and when all its branches are exposed to the light, it is a tree of great beauty. It somewhat resembles the English oak, in its outline, its trunk, the form of its branches, and the massy character of its foliage - trees with broad sinuated leaves having this character in a higher degree than those whose leaves are more regular in their shape. Their colour is a fine green, changing in autumn to bright scarlet or deep crimson.

C. - We have seen its utility in producing sugar; has it any other use?

$F$. - I have already mentioned it as affording firewood of the best quality; and though as a sugar tree it is so valuable when growing together, yet as it is found scattered through all our upland woods, and as it is so very abundant, the greater part of our winter fuel is composed of this wood. Besides this, sound and healthy trees are often sawed into plank, which is used for many purposes. When a tree of this kind, or birch, or elm is found, which has a sudden curve or bend in the trunk, it is sawed into plank for the runners 
of sleds, which are curved up at one end to run on the snow. The wood is handsome, of a bright, changeable, satiny lustre, with many straight lines radiating from the centre outwards, across the grain; these are lustrous, and in one light look darker, and in another lighter than the rest of the wood: these are the medullary rays. It is used for the finer kinds of furniture, and when varnished, looks very beautiful ; it is hard and heavy, but it is not durable. Trees are occasionally found, the wood of which is filled with little knots or eyes, which make what is called curled, or Bird's-eye Maple, and which is much prized in cabinet work. This appearance is accidental, and does not indicate a different species. I have often seen logs of firewood which were curled, some less, others more; and sometimes the eyed part extends only a few inches, all the rest being as usual.

C. - Here is a Soft Maple : it is covered with little red blossoms, so thick as to hide the branches: how very beautiful it is, and what a delightful fragrance it diffuses around!

$F$. - The Soft Maple, whether in blossom or in foliage is, like its congener, a beautiful tree. It flowers several days before it leafs, and the blossoms individually considered are both handsome and fragrant: they grow in thick spikes or clusters on the twigs, and have a very rich appearance. This is a lofty tree, but with us it does not attain either the size or the height of the sugar maple. It very much resembles that species, but it may be distinguished from it by its trunk being more profusely marked with broad, pale yellow patches. In clearings, it usually divides at the ground, and takes the form of several small trees, growing in a clump; the bark in such situations is of a darker colour and smoother texture than when it grows in the woods. It affects marshy situations, the sides of rivers, brooks, \&c. but is not found with us in any great abundance. The wood is soft and too full of sap to make good fuel : indeed it will scarcely burn of 
itself. It is handsome, however, and is sometimes used for furniture. The bark of this tree, boiled with copperas, makes a fluid of an intense black, which is commonly used in the village schools as ink, but it never dries properly; and in damp weather the writing becomes glutinous and blots, after any length of time : it is also used in domestic dying. This tree is called indifferently, soft or white maple.

C. - Is no species of oak found here?

$F$. - I believe there is none nearer than the banks of Lake Memphramagog, about twenty miles distant: I have been told that the White Oak (Quercus Alba) grows there: and about Quebec I have seen oaks of several species. Throughout the United States, the white oak grows abundantly: I have seen it in Vermont and in Alabama, in both of which, and I believe in all the intermediate States, it forms a very prominent tree in the forests. Its general appearance is like that of the sugar maple.

C. - What tree is that in blossom yonder?

F. - It is the wild Service Tree (Pyrus Arbutifolia?) its profuse corymbs of white blossoms give it the appearance of a large snowball. Its fruit is about the size of a cherry, but more resembling a medlar in form : it ripens in August. The tree is not common with us.

C. - I see a beautiful little bird sitting on a bush yonder : it is of a dark crimson. Do you see it?

F. - Yes; it is the Purple Finch (Fringilla Purpurea). It has the power of raising the feathers of the head, as if it were crested, which it is continually doing. Wilson says it is of a tyrannical and domineering disposition : one beating and nearly killing two or three other birds with which it was confined, "driving them into a corner of the cage, standing on them, and tearing out their feathers, striking them on the head, munching their wings, \&c. - and even if called to, the aggressor would only turn up a malicious eye for a mo- 
ment, and renew his outrage as before." They are common here in spring, and the early part of summer; they probably spend the whole summer with us, but retire into the woods and swamps ; the female is olive coloured, as usual. I once noticed a curious trait in the history of this bird. One day, about the latter part of June, I observed two males and a female of the purple finch, hopping about beneath the window, and was amused by watching the motions of one of the males. He stationed himself close to the female, and looking at her, kept rapidly dancing from side to side, in the space of about a foot, with his wings widely extended and quivering, his crown feathers erected, singing all the time very sweetly; but so faintly were the notes uttered, as to seem to proceed from twenty or thirty yards' distance, though the bird was only three or four feet from me. The female took no part in the dance, but looked on very complacently, her crest being likewise somewhat erected.

C. - Did the other male take no part in the ceremony?

F. - No ; he hopped about, apparently minding his own business, and took no notice at all of the dancer.

C. - Here are some bushes of the wild gooseberry, which have begun to leaf; was this plant introduced from Europe?

$F$. - Oh no! many species of gooseberry and currant are indigenous to this continent. A Black Currant (Ribes Floridum?) is found here, which produces fruit much like the English black currant, but not so large; both the fruit and leaves have the same rank taste, but in a less degree. In the woods I have found Red Currants (Ribes Albinervium) scarcely to be distinguished from those of our gardens. Both these plants are rare; but this gooseberry (Ribes Cynosbati). is abundant about the edges of the forest, and in secondgrowth woods. It bears a middling-sized berry, deep red and sweet, but beset, as is the bush itself, with strong prickles, which make them somewhat formidable in picking 
and eating. In Newfoundland, a Red Currant (Ribes Ringens? ) is common, which is covered with hair, and has a very strong, unpleasant smell and taste. The stem and twigs, too, are thickly beset with brown hair.

C. - As we approach the river, the willows become abundant; their long shoots are quite green with the opening leaves.

F. - The Willows (Salix) of which there are forty species, natives of North America, leaf, like the Poplars, with great rapidity. They delight in marshy situations, and will not usually thrive except in the vicinity of water. Generally speaking, the willows have more the appearance of shrubs than trees, rarely growing to any considerable height, and commonly dividing at the root into many diverging branches; yet there is, on the road to Sherbrooke, within about a mile of that town, a willow, which is a lofty tree, being, I should think, not less than fifty feet in height.

C. - The Dayflies (Ephemera) fly now in the evenings: two of them, with dark wings, flew in at my open window last night, which, I see this morning, have sloughed their skins, and obtained perfectly hyaline wings. The Red and Yellow Sphex of Newfoundland (Nomada Americana) is now to be found; I saw one yesterday hovering about ploughed ground, and peeping into every little hole. Large dragonfly grubs are abundant at the bottom of brooks and ponds. I caught an Azure Butterfly (Polyommatus Lucia), with the upper wings having a broad border of black: from its distended abdomen, I supposed it was a female. Many beetles crawl about the grass and under stones, among which the Purple Carab (Carabus Catena) and the Copperspot (Calosoma Calidum) are numerous. In fact, insects of all orders have ended their winter's repose, and meet us at every step. 
$F$. - Let us stand still a few moments on the bridge, and view the scene. I love to stand here at this hour, when the twilight gives a mellowness to every object, and that indistinctness which has so pleasing an effect. I love to look on the calm and placid river, flowing in blackest shade beneath the tall overhanging woods on each side:-

"__ the dark, the silent stream,"

as Shelley beautifully says :- the line of light in the middle, where the sky is reflected between the woods on either bank, making the blackness of each side still more dense and obscure. Not a breath ruffles the surface; not a twig vibrates in the air; every sound and every motion seems stilled; nature appears to sleep in that calm repose which prevailed in this spot for centuries before the foot of the adventurous white man trod the soil. We seem to expect the face of the dark Huron to peep from the woods, or the canoe of the more chivalrous Algonquin to dart round yonder point; everything is in its primitive wildness : there is nothing to remind us of civilized man, save the bridge beneath our feet. The same silent river has flowed here for ages; the same woods have clothed its banks; the same beasts have hid in their recesses; the same birds have warbled among their branches; the same tiny flies have danced in the last light of evening, between the heaven above, and the reflected heaven below. Nature remains the same:-but where is the Red-man, whose noiseless tread once passed like the gliding of a spirit through these woods, or whose wild warwhoop broke the solemn silence, and made the forest ring? He has passed away, and left scarce a vestige behind.

C. - Do you know anything of the manners of the natives?

F. - Nothing from my own observation: I have seen but few, and they appeared to be little benefited by their inter- 
course with civilized man; they are a degraded race, very much like the gipsies of Europe. Perhaps I can give you some information respecting them, derived from sources to which you may not have had access. The Indians appear to have been originally divided into three great families, speaking languages so distinct, that no affinity can be perceived between them. All the numberless tribes into which the red men have been subdivided, may, with a few exceptions be assigned to these three families: the Algonquin, or Chippeway, the Dahcotah, and the Floridian. The Algonquin was the great race from which the Wampanoags, the Narragansetts, the Mohegans, the Pequots, the Ottawas, the Iroquois or six nations, and all the tribes which originally inhabited Canada and New England, appear to have sprung. These all speak dialects which can be traced to one great root, and in their habits and manners bear a great affinity to each other. I should rather use the past tense, however, as few remains of these powerful tribes survive. They fought for their hearths with a chivalric valour, and a determined perseverance worthy of a better fate; but the scalping-knife and the tomahawk have sunk before the musket and the bayonet. They were cruel and unmerciful in war, and cunning and stratagem were as highly esteemed as valour. The scalp, or skin of the crown of the head with the hair attached, was taken from a fallen enemy as a trophy, and highly valued: and so much honour was attached to the possession of these bloody spoils, that it is said a wounded Indian belonging to a retreating party, has been known to entreat his fellows to cut off his head, lest his scalp should fall into the hands of the enemy. In performing the act of scalping, the victor sets one foot on the neck of his disabled enemy, entwines one hand in his hair, and by a few slashes of the scalping-knife in his other, round the top of the head, is enabled to pull off the skin with the hair. Before the intro- 
duction of iron by Europeans, their hatchets were made of flint, and they used shells or sharp stones for knives. They stole upon their enemies with great caution; but when discovery was unavoidable, or concealmient no longer necessary, they uttered frightful yells, and the terrific war-whoop, to strike terror into their foes.

C. - Have you any idea of what the celebrated warwhoop was like?

$F$. - It is said to resemble the words " woach, woach! hach, hach, woach!" and I have been told by those who have heard it, that when two or three hundred Indians are shouting these discordant sounds, each one thirsting for blood, it is enough to appal the stoutest heart. Probably there is not so much in the sound itself, as in the ideas with which it is associated; the suddenness and unexpectedness of the attack, the stern and merciless character of the warfare, and often the horrors of night, and the uncertainty respecting the force of the enemy, have contributed to give to this war-cry that fearful character with which it has been invested by the whites. Prisoners were often taken, and put to death with horrible tortures, the sustaining of which, without any manifestation of pain, was indispensable in him who wished to bear the character of a warrior. They lived chiefly by hunting, and were well acquainted with the habits and retreats of the wild animals of the woods : they clothed themselves with the skins. They also cultivated the maize plant, or Indian corn, and from them the Europeans learned the mode. Instead of hoes, they used large oyster-shells, and the labour of cultivation was performed by the women; personal labour being considered beneath the dignity of a warrior and hunter. They had little knowledge of medicine; their jugglers were both physicians and priests : they used a few simples, and had some knowledge of rough surgery. A steam bath has often wrought surprising cures, and was a favourite remedy in 
most diseases. A small hut is made over a hole in the ground, and a number of red-hot stones are put at the bottom of the hole. The patient crawls in with a vessel of water, and closes the entrance; he throws the water on the hot stones, which fills the hut with a cloud of steam, and the man is thrown into a profuse perspiration. He then comes out, and instantly plunges into cold water; repeating the course several times, and ending with the steam bath. The medicine-bag, rattle, and juggling tricks of the priests were, however, the ordinary hopes of restoration.

$C$. - Had they any notions of religion?

$F$. - In this respect they were far before the refined nations of antiquity; for they held these important doctrines, the unity of God, the immortality of the soul, and a state of future retribution. It is certain these doctrines were tinctured by the prejudices of their habits and education: their paradise was a happy hunting-ground, where game was plentiful; their notions of vice and virtue were in many instances erroneous: thus an Indian prays that he may besome a great warrior, hunter, and horse-stealer; but it appears that these children of the forest acted, in general, in conformity to the light they had received, and were in many cases examples to us, who are partakers of a better dispensation. They were destitute of all government, except the influence which a strong mind exerts over a weak one; their chiefs were merely the bravest or most sagacious of their warriors, having no authority to make laws, nor power to execute them; but they were looked up to for advice, and led them in battle. Every man did what was right in his own eyes, and public opinion appears to have been the principal restraint on individuals. The chief was called a Sachem, or Sagamore ; he wore no badge of rank, and often possessed no more wealth than others. The Indian was indefatigable in the chase, unshrinking in war, but supinely indolent in peace; this indolence was an insuperable bar to 
improvement, as nothing but stern necessity could induce exertion ; and immediately their necessity was supplied, they returned to the same state of inaction as before. Yet they were not destitute of mechanical contrivance and ingenuity, for they invented the birchen canoe, an article which has elicited the approbation of all travellers. It is made of a frame-work of light tough wood, over which the papery bark of the birch is stretched; the pieces being sewed together with sinews, and the seams smeared with turpentine. It is water-tight, and so light that a man can carry it on his head: a white man would, on getting into one, tip it over: but the Indians manage them with great dexterity, and sometimes load them down to within an inch of the water. An American author says of the languages of these tribes, that " they are like no forms of speech known in the old world. They are wonderfully expressive, both defective and redundant, and are said to be difficult of acquisition. The verbs of the Dahcotah language appear to have no roots, and to be entirely irregular in their modifications. The nominative case neither precedes nor follows the verb, as in the languages of the old world, but is incorporated with it ; sometimes at the end of the word, sometimes in the middle, sometimes abbreviated, and sometimes entire. We have known traders fail to acquire it during a trial of thirty years. From the little acquaintance we were able to gain, we thought it a collection of phrases, with scarce the semblance of rule or order, and conclude that to be learned at all it must be learned by rote."

C. - Were not the red men treated with unnecessary cruelty by the first settlers of North America?

$F$. - There is no doubt they were; they were called " the heathen," and were often hunted and shot down like wild beasts. Some curious legends are preserved of these doings : some Indians of the Norridgewock tribe, who lived on the Kennebec river, near this province, were employed by some traders to draw a cannon into the fort, by means of a long 
rope. The Indians took hold of it, and seemed much amused with the sport; but the moment they were arranged in a straight line, the whites treacherously fired the cannon, and killed and wounded a great number. At another time, a man was chopping in the forest, and having cut a large log was engaged in splitting it: the wedges were riving the wood, and it had begun to open. Just then, a party of Indians suddenly appeared: though they showed no hostility, the woodman suspected their intentions, and at length asked them to help him in splitting the log. He told them to put their hands into the cleft, and pull against each other. As soon as they had got their fingers well in, he suddenly knocked out the wedges, and the Indians were all caught, like so many foxes in a trap. He then went for assistance, and secured (that is, most probably, killed) them all. They displayed considerable ingenuity in catching and killing animals : " they made traps by bending down young trees, which would spring, when touched, with force sufficient to raise a wolf or a bear. An English horse having strayed away was once caught in one of these traps, and sent sprawling and kicking, several feet into the air. The Indians, who had seen a horse but seldom, were afraid of his ' iron feet.' They shouted to him from behind their fence, 'what cheer, what cheer, Mr. Englishman's horse ?' but getting no answer, ran off and told the English they could find their horse hanging on a birch tree."

But the Indians are passing away; and except in the extreme north of our possessions, and in the southern American States, few are to be found east of the Mississippi. Westward of that river, and especially to the west of the Rocky Mountains, many tribes are yet to be found in primitive wildness. These, too, will recede before the mighty power of civilization; white men will ultimately reach to the Pacific; and where, then, will the poor Indian dwell? That it is better for the world at large, that this vast con- 
tinent should be peopled with civilized and Christian men, cannot be doubted; yet a benevolent mind cannot contemplate the fate of the red man without a pang of regret for the hardness of his destiny.

\section{"They waste us, aye, like April snow}

In the warm noon, we shrink away ;

And fast they follow, as we go

Towards the setting day :

Till they shall fill the land, and we

Are driven into the western sea."

But while we are talking of the Indians, the evening has waned into night; and were it not for the innumerable lamps above us, it would be quite dark.

C. - The evening is warm, and the air balmy and pleasant; the soft maple in flower on the bank of the river gives out a sweeter fragrance than before; but let us walk homeward.

$F$. - A walk in the evening at this season has always charms for me, and I often delight to protract it into the night '; the general quietness that prevails around, and the sight of those unnumbered glittering worlds, have a soothing and calming influence on my mind, and fit it for devotion.

C. - What delightful odour is that which is now diffused through the air? It is very different from that of the maple, but equally delicate and pleasing.

$F$. - It comes from the Balm of Gilead, near the house : by day it is not perceivable, but in the damp dewy air of evening, at this season, the tree diffuses this delicious perfume.-If one sense is delighted by day, another is charmed by night: how many sources of pleasure and innocent enjoyment has our good Creator opened for us!

" These are thy glorious works, Parent of good!

Almighty ! thine this universal frame,

Thus wondrous fair! thyself how wondrous then!" 


\section{XI.}

\section{MAY 25th.}

Spiders' Webs.-White and Red Death.-Violets.-Breeches Flower.Dandelion.-Plum Blossoms. - Humming-bird-its beauty, activity, habits-interesting Anecdote-peculiar mode of flight.-Scarlet Tanagers.-Crows.-Raven.-Black-poll Warbler.-Song Sparrow.Snow-bird.-Cat-bird.-Perfume from the Maple.-Leafing of the Ash -White and Brown Ash.-Native Fishes.-Shad-MaskilongeSturgeon-White Dolphin.-Seals.-Common Dolphin.-Capture of one.-Strange cetaceous Animal.-Caterpillars.-Orange Comma Butterfly.-Butternut.-Moosewood.-Basswood.-Red Currant.-Great horned Owl.-Striped Squirrel.-Red Squirrel-its playful tricks-agility.-Anecdote.-Other Squirrels.

Charles. - We can scarcely take a walk in the dewy morning without feeling our faces come in contact with the fine gossamer webs, which are stretched from fence to fence, and from tree to tree. They are so slight as to be invisible, except when the light is directly reflected from them, but the tickling sensation when they touch the face detects them in a moment. How does the spider manage to stretch his web through the air from one point to another so far distant, as he has no power of flight?

FATHER. - That is a very curious inquiry, and one which has given rise to much research and experiment, and much controversy; and yet it does not appear that the point is settled. Some maintain that the spider has the power of shooting out long filaments of silk in any direction, which are waved by the wind till they are entangled in some object; others affirm that the wind is necessary to produce these 
threads; that the spider ejects a little jet of glutinous substance, which the wind blows out into a thread; others again suppose that the spider fastens one end of its thread, and then patiently crawls down, we will suppose from the fence, along the ground, and up the opposite fence, taking care to keep the thread from contact with the surface on which it crawls : and when arrived at its chosen point, "hauls in the slack," as a sailor would say ; that is, tightens the web by pulling it in, and fastens the other end. These and other modes are said to be confirmed by actual observation, and probably they all are correct, different species having different habits ; and even the same species may not always be confined to one mode of operation.

C. - The network webs that are extended on bushes, between palings, \&c. are beautiful and curious, from the regularity and geometrical nicety with which they are constructed, the lines radiating from the centre like the spokes of a wheel, and the interstices filled with many concentric circles of the finest threads : and they are particularly beautiful in the early morning, when every thread is thickly studded with little sparkling gems of dew.

$F$. - They are so slender that one would suppose the slightest touch would break them, but the threads are elastic, and very strong in proportion to their size; they are sufficient to break the flight of small two-winged flies, and to detain them in their meshes. —_ Let us turn out of the road for a while into these beech woods, where many a flower "wastes its sweetness on the desert air." Here are two species numerous, besides the yellow dog-tooth violet, which is abundant. They are handsome flowers, and are much alike in every respect, except in colour, one being dark red, the other pure white, tinged with pink. Both have a corolla of three petals, three large heart-shaped leaves, a calyx three-parted, a style three-cleft, a seed-vessel three- 
valved and six stamens. These flowers are called by some of the Americans, the White and the Red Death: for what reason so ominous a name is given them, I am unable to determine. Their botanical appellations are Trillium Pictum the white, and Trillium Fatidum the red. Here

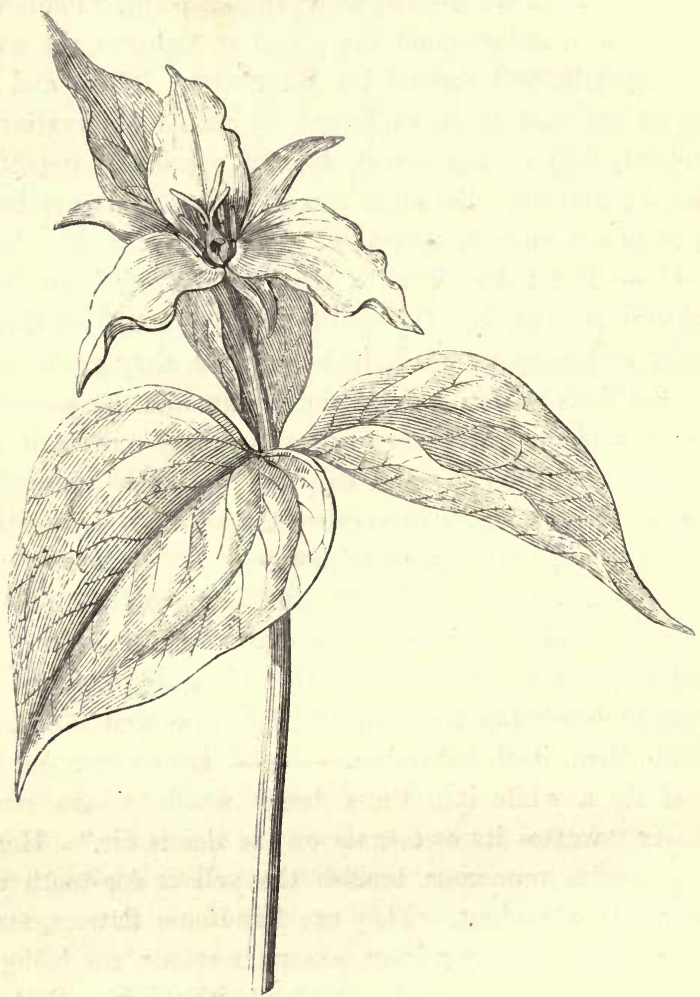

WHITE DEATH FLOWER.

Trillium Pictum. 
are violets of different species, some white, some bright yellow: we have also blue and tricoloured violets, like the pansy of our gardens, but smaller; these are not yet in blossom. None of them have the delicate fragrance of the little English violet. No less than thirty-one species of the

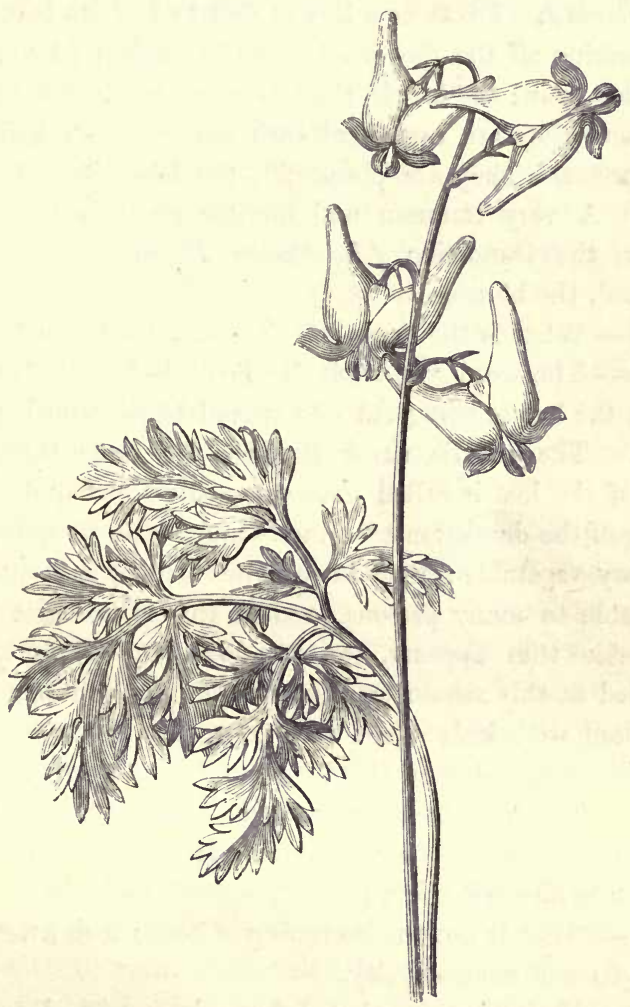

BREECHES FLOWER.

Corydalis Cucullaria. 
genus Viola are enumerated by Professor Eaton as indigenous to North America. I have seen one or two specimens of a delicate, lowly little flower, whose blossoms, hanging from a stem of about six inches in height, bear a resemblance to tiny pairs of breeches. They are white, the upper part or mouth of the corolla tinged with yellow (Corydalis Cucullaria). I was at a loss at first to find its leaves; for on breaking off the flower close to the earth, no leaves were attached to it : the fact is, the leaves spring directly from the root, and they are connected with the flower-stalk beneath the surface. They are pinnatifid, the lobes irregularly incised. A very common and humble plant is likewise in flower, the Dandelion (Leontodon Taraxacum); though despised, the blossom is pretty.

C. - What is the origin of the name, dandelion?

$F$. - The word was originally Dent-de-lion, that is, lion's tooth, the leaves being cut into curved teeth, pointing backward. The generic name signifies the same thing; this form of the leaf is called runcinate. In Newfoundland, the leaves of the dandelion are much sought after in spring, as a culinary vegetable ; their taste, when boiled, is peculiar, but agreeable to many persons, and as this is the first eatable vegetable that appears, the meadows and fields are frequented at this season by boys and girls, who in cutting up the plant with knives, cut up a great deal of the grass also, and do considerable mischief. Here it is not eaten.

C. - The plum trees are one mass of blossoms; let us look at them and enjoy their perfume. How loud the bees are humming amongst them!

$F$. - That is not the humming of bees; look attentively, and you will see a novelty.

C. - Ha! there is what I have long wished to see, a humming-bird sucking the flowers. There are two of them: let us take a closer view of them. 
$F$. - No, no: stay where you are, and remain quite still, and talk in a low voice; for on the slightest alarm, and their brilliant little eyes are glancing in every direction, they shoot off with the straightness and speed of an arrow. See how they hover on the wing, in front of the blossoms, quite stationary, while their long tongue is inserted, but their wings vibrating so rapidly as to be only visible as an indistinct cloud on each side.

C. - One of them has suddenly vanished, but I did not see him fly, though I was watching him.

$F$. - He has gone only about a yard: you may see him stationary again to the right of where he was before. These starts are so sudden and so rapid, that they are often lost to the sight.

C. - How very little and how very beautiful ! the body glitters in the sun with green and gold, and the throat is just like a glowing coal of fire. Now they rest on a twig; one of them I perceive has not the brilliant throat of the other.

$F$. - That is the female; in other respects her plumage is like that of the male. It is the Ruby-throated Hummingbird (Trochilus Colubris), and is scattered over the whole of this continent, at least to the latitude of 57 degrees north. It is the only species of the genus found in North America, except a species ( $T$. Rufus) which inhabits the coast of the Pacific, as far north as $61 .^{\circ}$

C. - Is it numerous here?

$F$. - Yes : in summer it is abundant; frequenting our gardens, for the tubular flowers, which it probes with its long bill and tongue, sometimes hiding its head in the corolla, and sucking with so much indiscretion as to be approached, and taken in the hand. It is particularly fond of the deep crimson flowers of the sweet-smelling Balm (Monarda Kalmiana), and will return to these after a few moments, even if 
repeatedly alarmed away. Last year, in the month of September, I was in the garden one morning, when a female humming-bird came, and began sucking the flowers. I immediately ran into the house for my insect net, but found that the bird was gone when I returned: I stationed myself, however, close by the balm flowers, holding the net up in a position for striking, that there might be no occasion for any previous motion if it should re-appear. I remained perfectly still, and presently the bird came again, hovering over the flowers, and probing them with its tongue within two feet of me, without any sign of fear. I dashed at it, and succeeded in capturing it. I carried it into the house, and held it in my hand, admiring its delicacy and beauty. It would lie motionless in my hand, feigning death, then suddenly dart off like an arrow towards the window, strike against the glass, and fall, and lie motionless as before. I at length killed it, not without regret; and having taken out the eyes and viscera, stuffed it with cotton, imbued with a solution of corrosive sublimate, which preserved it pretty well.

C. - I have read of humming-birds having been tamed, but I do not know whether they were of this species.

$F$. - The most interesting anecdotes of the ruby-throat which I have read, were published in a Quaker publication of Philadelphia, called "The Friend." The correspondent says, "Sometime in the seventh month of the present year [1834], one of my family caught a small humming-bird, which appeared quite debilitated for want of food. We presented it with some sugar and cream mixed together, which it sucked up with avidity; after which it was restored to liberty. In the course of a short interval, it again made its appearance, was taken in the hand, and a mixture of sugar made into the consistence of a syrup, was poured into the corolla of a trumpet honeysuckle, from which it eagerly extracted it. From that time forward it became quite familiar, 
and would come a dozen times a day, or more, to be fed. After fluttering a few seconds at the door or window to attract notice, it would alight on a neighbouring tree or rosebush, until its food was prepared for it; and then upon calling "peet, peet," it would dart in a straight line with the velocity of an arrow to receive it. We generally filled two or three tubes of the honeysuckle with syrup, which it extracted while on the wing, buzzing around the flower held in our hand, and inserting its bill, which was about three fourths of an inch in length, from which it protruded its tongue, at least half an inch longer, with which it sucked up the liquid. This generally sufficed it, but sometimes it did not appear satisfied, but would repair to its resting-place, and wait until the flowers were again filled, when upon being called it would return and finish its repast. But if after flying to its perch it wiped its bill upon the limb, we were then assured it wanted no more at that time; all the solicitations we could make would have no other effect than to hasten its departure. In the course of half an hour, it would be back again after more food, and if the member of the family to whom he applied was engaged, and not ready to attend to him, he would try over and over again to excite attention, by flying into different apartments of the house, and buzzing within a few inches. Peet's solicitations generally succeeded, as the younger branches of the family were delighted with attending to him. He appeared to be more fond of syrup when made thick, than any other food which was offered him. If it was too much diluted, he would fly to his resting-place, and wait until it was altered. We also at times gave sugar and cream, wine and water mixed with sugar, and once some honey obtained from a humble bee's nest, which he appeared to treat with great contempt. . Sometimes when he was fluttering around the flower held outside of the doorway, a stranger of the same species, having less confi- 
dence in human nature, would dart at the little fellow and drive him away, as if anxious for him to escape from so perilous a situation. But it only had a momentary effect on our little friend, as he would return with as confiding an assurance of safety as before. His little twittering noise and averted eye, as he momentarily withdrew his bill from the flower, appeared to say, 'surely thou wilt not hurt me.' After he had visited us every day so frequently for about three weeks, and been admired by numerous persons, he disappeared on the 11th of last month [August], being fed about the middle of the day, which was the last time that he was seen. As the wild humming-birds, which were quite numerous before, disappeared about the same time, it is probable he accompanied them to more southern regions. As we were on terms of the most friendly kind, it is hoped our little traveller will again revisit us, after he has finished his peregrinations among the flowers of the south, as it is very doubtful whether he will find them as sweet as he did the honeysuckles of Delaware."

C. - It is a very amusing account, and appears to have an air of strict veracity. I observe the darting flight spoken of; it resembles the motion of the dragon-flies more than that of birds.

$F$. - The flight of the humming-bird is like that of no other bird; it has a character peculiarly its own. When most birds fly, we perceive that there is an evident effort; that constant exertion, more or less, is necessary to support them in the air : their tendency appears to be to sink, which has to be continually resisted by muscular effort. The swallows, and some other tribes of swift and powerful flight, appear to skim at will through any stratum of the atmosphere without any tendency to rise or sink; but our little humming-bird seems just like a cork drawn under water; he seems all buoyancy, as if his natural place were above the clouds, 
and he had to struggle to keep himself in the lower air: he brings himself down to suck the flowers, then shoots away with a springy lightness like an unincumbered balloon when the cords are cut. It is more like the flight of a dragon-fly than anything else, but much more buoyant. The first that I ever saw were two males, that shot along just over my head one day in July, soon after my arrival here. From the peculiar character of their flight, and the sparkling brilliancy of their colours, I took them for large and beautiful insects, and it was not until I had seen more that I was convinced of my mistake.

C. - I have seen many Scarlet Tanagers lately in the ploughed fields and pastures ; yesterday they were very numerous, particularly in the orchard; there was scarcely a moment in which we might not see three or four within a few rods of each other. The Bob Lincolns are still more abundant; they sit on every fence, and utter their singular cry in every direction. Crows have been occasionally seen some time; but I have heard for about a week a sound from the summits of the forest, somewhat like their cawing, but much more soft and musical. I followed the sound to discover the authors, but could see nothing but crows not perceptibly differing from the common species.

F. - It is the common Crow (Corvus Corone); this change in its usually harsh note, takes place periodically at or rather just before the breeding season. They are selecting their mates, and fixing on a spot to build in, the top of some lofty elm or other tall forest tree. As soon as their nest is built, they become totally silent, and continue so until their young are flown, when they resume their usual mode of cawing. This is one of the few species which are common to both America and Europe. The Raven (Corvus Corax) occasionally sails over our heads, as he appears to visit nearly every country; but he is not a common sojourner with 
us ; or if he is, he must be generally mistaken for the crow, the chief difference being his superior size.

C. - I noticed a little stranger in the depth of the woods, which I have not seen before. Its head was deep black, wings and back dark, and all the under parts white; but it was very shy, so that I could not examine it particularly.

F. - Probably it was the Black-poll Warbler (Sylvia Striata), which occasionally visits this province, and even Newfoundland, where it is more common than with us. The nests of the Snow-bird and Song-sparrow (Fringilla Nivalis and $F$. Melodia) may now be found in great numbers; they both build on the ground, in a small hole, or in a tuft of grass : the former frequently chooses a hole in the side of a bank under a raspberry bush. They are easily discovered by the bird's flying away on the approach of man, and they are not very artfully concealed. - Have you in your rambles heard a bird whose cry resembles the mewing of a cat?

C. - I have not noticed any such. What is it like?

$F$. - It is a species of thrush; its colour is slate blue, deep on the upper parts, and light below. Its note exactly resembles the plaintive mew of a cat that has been hurt; it is very familiar, and when mewing in this odd tone, has various jerks and motions that are full as odd. It is called the Cat-bird (Turdus Felivox), and is very well known, but is not at all a favourite, though a very harmless bird.

C. - What a delicious odour fills the air from the maple grove.

$F$. - Yes ; the sugar-maple is in full blossom : its flowers are small and greenish white: their fragrance would scarcely be perceivable if smelt singly, but a grove of young maples, such as these, each one covered with blossoms, gives out a volume of perfume that indeed, as you say, fills the air.The leaf-buds of the brown and the white ash are expanding. 
The ashes are among the last trees that leaf, and the first that shed their leaves.

C. - The ash, when it grows in a clearing, has great grace and elegance, but it wants the massy character of foliage that distinguishes some trees.

$F$. - Its leaves being pinnate, give it a feathery kind of lightness, and its outline is graceful. The two species, White Ash (Fraxinus Acuminata) and Brown Ash (Fra. Sambucifolia) are much alike, but are distinguished by the buds, the bark, and the wood. The buds of the former are pale brown: of the latter nearly or quite black. In both, they are large and broad, and intensely bitter. The bark of white ash is deeply furrowed, and the ridges cross each other so as to give the spaces between a lozenge shape, or what is usually called diamond form: that of brown ash is much smoother, (though furrowed in old age,) the furrows are parallel and perpendicular; it is more inclined to a yellow cast, is more subject to be infested with bunches of moss, and may in some degree be peeled off in small thin plates, or laminæ. I have read in books much doubt respecting the cause of the distinction, white and brown, and the conclusion that it is from the superior lightness of colour in the bark of the former species. But not to mention that this is not so in fact, every Canadian farmer knows that it is in the roood of these two trees that this distinction is found; the whole heart of the brown ash is of a deep bistre brown, while that of the white ash is white from the bark to the centre. The wood of the latter is exceedingly tough and elastic, and is in much demand for hoops, chair-backs and bottoms, and any farming implements in which toughness is the chief requisite ; the grain is large and coarse ; it is capable of being torn into long strips, almost as thin as a wafer, which are interlaced for bottoms of chairs, and are very durable. The sapwood of the brown ash is tough, but not in the same 
degree, and the heart is brittle : this species is much more abundant, and is chiefly split into rails, which rank next to cedar for durability, but are far heavier and more difficult to handle. The white ash is very scarce as a tree of any size, and its value for the purposes named, and for sawing into plank, is too great to allow it to be used for rails; it is confined to upland, or what is called hardwood land, while the brown is most abundant in marshy ground, with the resinous evergreens and the birch.

C. - Yonder is a boy angling in the brook : do you know anything of the native fishes of our rivers?

$F$. - Very little indeed: and nothing of their natural history or specific characters. I have angled in the Coatacook, and caüght several small species, which bite very freely. Dace, trout, chub, lump-fish, and others, are names given to our most common river fish, whether correctly, I am not ichthyologist enough to determine. The Salmon is taken in our rivers: the Shad (Clupea Alosa), a fish very highly esteemed for its firmness and the delicacy of its flavour, abounds, I believe, in the St. Lawrence in spring; and the Maskilonge, (Esox Estor?) another fish of large size, of the pike family, is found in the lakes. On the bank of the Masuippi, about a mile above its junction with the Coatacook, is a spot where the land, after descending with a gradual slope, suddenly ends in rather a steep but grassy bank. At the very edge of this bank is a farm-house, and the owner has told me that he can sit at his door, and watch the sturgeon and other fish playing almost directly under him, over the pebbly bottom of the clear river. The Sturgeon (Acipenser Sturio) is very numerous just there; and is, I suppose, the largest fish we have, being several feet in length. They are long, slender, and angled, and covered with tubercles; the flesh is not much esteemed. They often leap from 
the water, several feet into the air. While on the subject of fishes, I may allude to the White Dolphin of the St. Lawrence (Delphinus Canadensis). In coming up that river in summer, I saw great numbers of them frolicking and leaping about, like their congeners, the dolphins and porpoises of the ocean, from which I could not see that they differed in any respect, except in being all over of a pure white. The $\mathrm{Na}$ tural History Society of Montreal offered a prize a few years ago for an essay on the Cetacea of the St. Lawrence, which was, I believe, handed in, but I have never had an opportunity of learning the information contained in it. Seals also often pop up their black heads in the same river.

C. - I have seen the common Black Dolphin (Delphinus Delphis) in shoals, while crossing the Atlantic. They are very amusing ; and as, when they come around a ship, they seem unwilling to leave her, we have plentiful opportunities for observation. They are in the habit of leaping out of the water, sometimes to the height of twelve feet, as I have seen, and while in the air their bodies are much incurvated. It is no matter how fast a ship is going, the dolphins play around her and under her bows, as if she were fast at anchor. Sometimes I have seen them quite clearly through the side of a wave, darting along with incredible velocity, and apparently without an effort, leaving behind them a wake of whitening foam beneath the water.

$F$. - They seem to revel in the storm: the prodigious leaps which they are so fond of making, appear to be made for no other reason than in mere wantonness, in the exuberance of their mirth. They are believed by sailors to indicate the direction of the wind, as it is absurdly supposed the wind will shortly be in that quarter from which the dolphins approach the ship. I have been present at the capture of two individuals, one of which was taken about midway between England and Newfoundland in the summer of 1832. It 
was just after dinner: a shoal of dolphins were amusing themselves under the bows, when our captain went forward, took his harpoon, and stationed himself on the bowsprit. He watched his opportunity, poised his weapon, and transfixed a fine fellow in the back. The animal rushed away with the speed of lightning, but the barb was fast, and so was the rope attached to it : the sailors hauled him to the surface of the water, where he tossed and plunged with amazing force, while the red life-blood gushed from his wound in torrents, dying the water all around. We were fearful of losing him; for one barb of the harpoon was out, and the point of the other was protruded through the skin: his hide must have been very tough, or his tremendous struggles would certainly have freed him from so slender a hold. After many trials and failures we at length got the bight of a rope under his huge tail, and another over his breast fins, and hauled him on deck, with the warm blood still spouting from his gaping wound. The mate, however, cut his throat, and he was dead almost instantly; but not before he had well lashed the deck with his muscular tail. I took an accurate drawing of him as he lay. He measured seven feet ten inches from the tip of the snout to the end of the tail : one foot four inches from the insertion of the back fin to the belly (that is, in perpendicular diameter); two feet four inches from tip to tip of the pectoral fins; the tail was two feet in width; the snout, from the tip to the angle of the eye, one foot. The blowhole on his forehead was very curious; it was circular, about an inch in diameter, and was closed by a valve. When it was cut open, we found that the orifice considerably enlarged a little below the surface, and was lined with a very soft black skin. The eye was of a transparent blue colour, and gleamed in some lights like the eyes of cats, \&c. The teeth were very small, regular, and beautiful ; those of the upper jaw fitting into the inter- 
stices of the lower. We found in his maw some beaks of squids (Sepia). Under the skin was a coating of white fat, an inch in thickness all over the body, and much thicker about the head; this was peeled from the flesh with the skin, and thrown into a cask to melt into oil. All the cetaceous animals having warm blood, would be likely to be chilled by the coldness of the water, as they have no outward covering, such as fur or hair. God has therefore protected them by a thick coat of fat, which is a poor conductor of heat: the effect of this is, that their blood is as hot as that of any land animal, if not more so. We ate part of the flesh of our game; it looked much like beef when raw, but was very dark when cooked: it was particularly tender, and " ate short," as it is called. I fancied it had something of the taste of reindeer venison, which I had eaten in Newfoundland. This was a male, and one of large size. The colour was bluish black on the back, lead colour on the sides and fins, and white on the belly. The other that I saw caught was in the Gulf of Mexico; the harpooning, the struggling, and the thumping of the tail were the same as in the former instance; but this was a much smaller specimen, measuring only six feet in length: it was a female. It had thirty-eight teeth on each side of each jaw, making one hundred and fifty-two in all; of this, too, I took a drawing. Whenever a dolphin is harpooned, the rest of the shoal vanish instantly, never staying to sympathize with the sufferer : indeed, sailors say that if one is wounded and escapes the harpoon, the rest immediately tear him to pieces with their serrated jaws, and devour him. I think it probable that some species of this tribe are yet undescribed. In going up the English Channel in 1832, when off the Devonshire coast, a large animal of the cetaceous kind suddenly appeared just under our bowsprit; it swam along for about ten minutes (the vessel going before the wind at about five 
knots,) as if to pilot us in our course, keeping within a few inches of the vessel's head, deviating sometimes a foot or so to the right or left. At length the captain prepared his harpoon, but before it was ready the animal had disappeared. It was about sixteen feet long, of a light grey colour, with a round bluff head. I could find no description of such a species.* B But where have we wandered? From the Masuippi to the St. Lawrence, from the St. Lawrence to the Atlantic, from the Atlantic to the Gulf of Mexico, from the Gulf of Mexico to the English Channel: a wide flight in a few moments! But let us return to our woods and fields.

C. - Several kinds of caterpillars are now to be found, which survive the winter; such as those of the Grey Kidney Moth (Polia — ? ), the Buff Leopard (Arctia Isabella), and others with which I am not acquainted. I caught two specimens of the Orange Comma Butterfly (Grapta C. Album?) a few days ago, a beautiful species. Some very pretty but small dipterous flies have appeared, with brilliant metallic thorax and abdomen, glittering with green and crimson gold (Sargus?).

$F$. - The Butternut (Juglans Cinerea) has begun to leaf: the buds of this tree much resemble those of the ast.es, but are larger, of a downy pale green, and they are not so regular in shape as the ash buds. The leaves are pinnate, like those of that tree, and on the whole there is considerable resemblance between the white ash and the butternut. This tree is considered an indication of the very best land we have; it is not abundant in this vicinity, though there are many trees scattered about: on the banks of the Coatacook, near Spafford's bridge, are several trees. The bark of this tree is used in dying: I believe it produces a snuff-brown colour; I know of no other value which it has

* Perhaps it was Beluga Leucas, the White Whale. 
except for its fruit, which is by no means equal to an English walnut.

C. - I notice the leaves of a shrub which grows abundantly in the upland woods; the common people call it moosewood. The leaves are large and heart-shaped, and much wrinkled.

F. - I know the bush well; it is a species of Guelderrose (Viburnum Lantanoides): the moosewood of botanists is a species of maple (Acer Striatum). This plant bears in autumn clusters of round berries, which are at first green, then bright red, and when ripe shining black. They are hard at first and astringent, but become farinaceous; they are not very pleasant, though some persons eat them. Its leaves expand very rapidly. The Basswood, or Lime (Tilia Glabra) is at length bursting its glutinous leaf-buds. This tree frequently attains a great height, but though its trunk is usually remarkably straight, round, and pillar-like, and its outline good, the foliage is never beautiful. The leaves are always corroded or distorted in some way, so that among many trees I have often vainly searched to find a perfect leaf, except such as were just unfolded. The cause of this I do not know, unless it be produced by minute insects: few caterpillars feed on the basswood, and as the tree is so common, their ravages could be easily discovered; whatever the cause, the effect is greatly detrimental to the beauty of the tree. The outer bark of this species is rough and stringy, the inner bark is viscid and sweet, the twigs and buds are likewise very glutinous when chewed; cattle are fond of them, and in severe winters, when fodder is scarce, it is common for a farmer to drive his stock into the woods of a morning, and cut down a basswood or a maple, on which they eagerly browse, and which proves nutritive.

C. - Is the wood of this tree of any service?

$F$. - It is extremely soft and white when green; when 
seasoned, it becomes of a light brown hue : it does not warp like the resinous woods, and is often sawed into boards for many purposes. The young trees are sometimes cut into poles, which are set up as rails for a temporary fence, but they are not at all durable. It is almost useless as firewood when green, being too full of sap. The basswood grows abundantly in this country, and is found in all situations, but most affects a low, and often a marshy soil.

C. - I observe the red currant bushes in the garden are putting out their leaves; and many other garden plants are beginning to shoot into active life (if vegetation can be called active); the bulbs of the Orange Lily (Lilium Canadense) are above the surface of the ground. What very large bird is that sitting on yonder hemlock. Is it an owl ?

$F$. - Yes; and one that is much oftener heard than seen; it is the Great Horned Owl (Strix Virginiana,) a

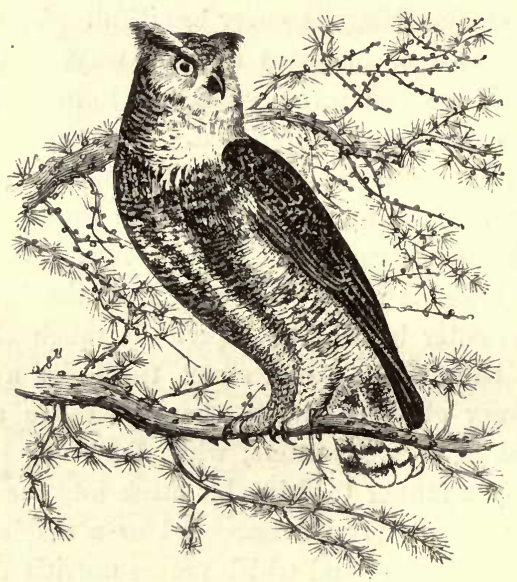

HORNED OWL.

Strix Virginiana. 
very fine species : it is a native of nearly the whole of North America, but is rarely met with here. Its voice is peculiarly loud and alarming: Wilson describes it in his usual happy manner: I have myself often heard it in the forests of Alabama, where in travelling through the swamps, covered with gigantic beeches and sycamores, entwined and tangled by the various species of briers and vines that hang in festoons from the trees, and amidst the evergreen bushes of the hystrix fan-palm, this "ghostly watchman" lifts up his hollow voice like a sentinel challenging the intruder. Through the afternoon, and especially as day wanes into evening, they may be heard from all quarters of the swamps; and in the deep solitude and general silence of these gloomy recesses, the cry is peculiarly startling. "Ho! ohó! ohó ! waugh ho !" is his call; the last syllable uttered with particular earnestness, and protracted for some seconds, and gradually falling. The whole is given deliberately, in a loud and hollow tone; and one can scarcely be persuaded that it comes from a bird. They call and answer to each other, and I have made one answer my imitation of his call. But it is at night that this delightful music is heard to most advantage: he sometimes makes a noise which Wilson justly compares to the half-suppressed screams of a person throttled, but I have heard this but seldom; the first appears to be his favourite song. There he goes; as he flies, you may observe how exceeding noiselessly he glides through the air: all the owls have this property; not a ruffle is to be heard: this arises from the very soft nature of their feathers; an owl is almost all feathers, and they are loose and unwebbed in most parts of the body, and offer little resistance to the air.

C. - What do they feed on?

F. - Small birds, field-mice, squirrels, and any animals that they can master. 
C. - The Ground Squirrel (Tamia Striata) is quite numerous now : it does not migrate, I believe.

$F$. - No: all our squirrels are residents, not sojourners here: I think the ground squirrel, however, retires to a burrow during the winter, and hybernates. I have never seen it, as I recollect, abroad during that season; but the Red Squirrel (Sciurus Hudsonius) may often be seen on a

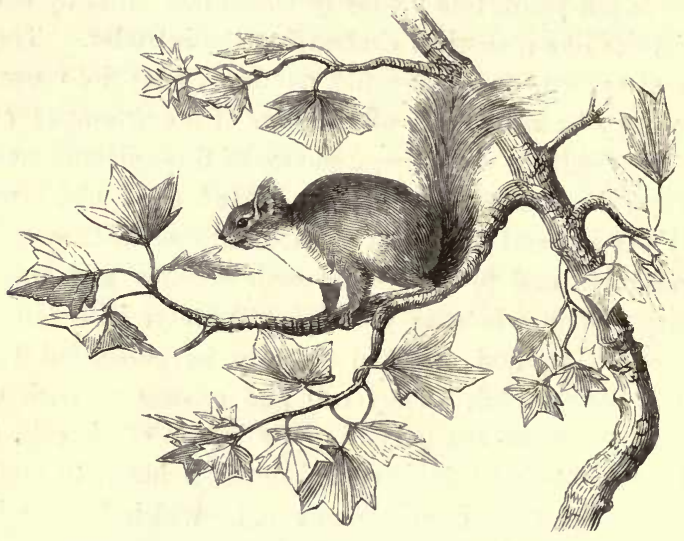

RED SQUIRREL.

Sciurus Hudsonius.

fine day at the foot of some beech or maple, and if disturbed he quickly runs to his hole under the snow.

C. - The striped or ground squirrel is a very pretty ani$\mathrm{mal}$ : it has not the roguish saucy familiarity of the red, and has little of the appearance of a squirrel. Its bright fawn colour is well marked by the three black stripes down its back and sides.

$F$. - He rarely if ever climbs trees, but is fond of playing bo-peep around old logs, or among a heap of stones, now and 
then poking out his head to take a sly peep at you ; then gone again. His note is a single chuck, uttered at intervals like the cluck of a hen : he is commonly known here by the name of the chipmunk.

C. - The red squirrel is a very fantastic little gentleman : he plays as many tricks as a monkey, and were it not that he is so fond of grain, and has such very loose ideas on the subject of meum and tuum, he would be a universal favourite.

F. - As it is, however, he is sorely persecuted with powder and shot, and even periodical hunts are made up, as a kind of frolic, in which men and boys eagerly join; any old rusty musket being a sufficient qualification. Two leaders choose sides, each alternately taking a man, till the whole are engaged, just as in cricket, \&c.: then they sally forth, and the party that brings in most squirrels is the victor; the whole then adjourn to some tavern, and have a dinner, to be paid for by the vanquished party. Notwithstanding all this, and the numbers that are shot about the barns in winter by vindictive farmers, they are not a whit less impudent or familiar, nor do they seem diminished in numbers. His jerks and motions are very amusing ; if you go under a tree where one is sitting, he sets himself firmly on the branch, flourishes his tail over his back, and looks fiercely at you, making a most angry chattering all the time, or rather a reiterated chirping; every now and then giving a start as if he had a mind to fly at you, jerking his tail too with a convulsive sort of motion. If you are pretty close to him, you may hear at every chirp, and simultaneous with it, a sort of low undertone of a mournful sound, something like the coo of a pigeon, but much shorter.

C. - How very nimble they are! they leap to a great distance, and run very swiftly: I have often chased them along the rails of the fence, I running on the road beside it; but 
though I ran with all speed, and though the squirrel had to run nearly double the distance, from the zigzag form of the fence, he would keep a-head of me. He is a cunning fellow too; for after running from rail to rail, he will often suddenly crouch down on one of the projecting ends where they cross each other, in hope of remaining unseen: I have often lost them in this way.

$F$.-Do you see that little grove in yonder bottom, exactly between our house and the village? There I once put the agility of a little rogue of a red squirrel to a pretty severe test. The trees are chiefly maple, cherry, and elm; all, or nearly all, though of considerable height, so slender as to be easily shaken with my hands. My little gentleman was enjoying himself on one of those trees, when as "his evil stars" would have it, I espied him. I knew that he would not leave the grove, and for a frolic I commenced shaking the tree violently, which put him at his wit's end: he ran from bough to bough, and at length leaped to another tree; this I instantly shook in the same manner, and so kept him flying from tree to tree sometimes at an astonishing distance, backward and forward through the grove, for more than half an hour, without a moment's cessation. He several times missed his hold, but always caught a bough in his fall, except once, when he came rather heavily on the ground from one of the topmost branches: he was instantly on his feet again, and up in the tree before I could come near him. I don't know whether he was tired, but $I$ was, and was fain to yield him the point, and leave him in quiet possession of his trees.

C. - Are there any squirrels found here besides the red and the striped?

F.- There are three others: the Grey (Sciurus Leucotis), the Black (Sciurus Niger), and the Flying Squirrels (Pteromys Volucella), all of them larger than these: but 
they are very scarce, and I know comparatively nothing of their economy. I once had a glimpse of a flying squirrel taking a long leap from the top of one tree to the top of another, in the forest; and I have seen one or two specimens of the grey species, which had been shot. The black has never fallen under my own personal observation: I know it only from the report of others, but have not the least doubt of its existence here. Many species are indigenous to this continent, but I am not aware that any others visit this part of Canada at least, than those I have mentioned. 


\section{XII.}

JUNE 1st.

Musquitoes.-Gallflies.-Moths.-Tiger Swallowtail Butterfy.-Black Swallowtail._Clouded Sulphur.-Black Skipper.-Other Insects.Elder.-Moosewood.-Wild Strawberry. - Beech - its bark-foliage roots-wood.-Leafing of Forest Trees.-Providence of God.-Tortoise-its manners-eggs.-Mushroom.

Charles. - I begin to feel the truth of your former observations respecting the virulence of the musquitoes: last night they were very numerous, and I was shockingly bitten by them.

Father. - Yes, they have begun to be troublesome, and we may now look for their nightly attacks, for three months at least, but not without frequent intermissions, or at least mitigations of their violence. We must bear it as we may.

C. - I yesterday picked up, lying on the ground, an irregular-oval, spongy gall, resembling a brown tuberous root, studded here and there with prickles : it contained very many regular cells, and pupæ of Gallflies (Cynips). I observed one little hole, which I enlarged, and tonk from it a little gallfly perfected, the first I had ever seen.

$F$. - The gallflies are generally small insects, but very curious in their economy: their power of so altering the course of nature, as to produce on plants apparent fruits and flowers, totally different from their ordinary productions, merely by means of an invisible puncture, is one that completely baffles all our researches, and shows us that, with all 
our boasted wisdom, we know nothing. There are very many species: the one you found is, I believe, produced on a species of Rubus (I think, the common raspberry). Another kind, very common, swells out the stem of a species of Solidago, Golden-rod, which is very abundant, into a round ball, spreading equally on all sides.

C. - I have taken two new moths lately, and three new butterflies have made their appearance since our last walk; the first of which is the beautiful Tiger Swallow-tail ( $\mathrm{Pa}$ pilio Turnus). This large and handsome butterfly is very

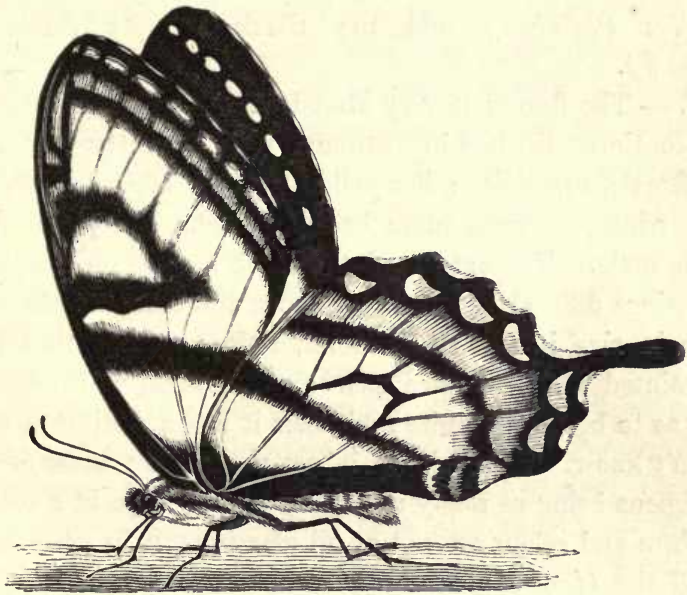

TIGER SWALLOWTAIL.

Papilio Turnus.

wild and difficult of capture; at least so I have found the specimens which I have seen, which are only two: I pursued them both, but succeeded in catching neither.

$F$. - They will be more familiar presently; or at least will be much more abundant, so that you will be able to 
secure as many specimens as you please. It is a wide-spread species, extending from Newfoundland to the Gulf of Mexico, and perhaps farther : in the State of Alabama it is common Another species, the Black Swallowtail (Papilio Asterius), is likewise found in Newfoundland and in the Southern States; in both of which I have found it numerous, and I have seen it mentioned in lists of New England insects, yet I have not met with it in this province. I should suppose, however, that it is a native, but probably, as in Newfoundland, only appears plentifully in particular seasons.

C. - The other butterflies were the Clouded Sulphur (Colias Philodice), and the Black Skipper (Thymele Brizo?).

$F$. - The former is very abundant through the summer, and continues till late in autumn : it is a pretty butterfly; the female, especially : her yellow-spotted black border, and pink fringe, is much more becoming than the plain black of the male. The extent of the black margin on the posterior wings differs much in individuals, and there is more variation in size in this species than, I think, in any that I am acquainted with. I once saw an individual which was so pale as to be nearly white : whether it was a distinct species, I don't know. The skipper is not numerous; three or four specimens being as many as I have usually seen in a season. Its form and colour are not at all pleasing: it has the habit of all the Hesperia, of jumping up and down in its flight over the herbage; whence these butterflies have derived the name of skippers. What other insects have you observed?

C. - I went out a day or two ago bush-beating among the willows, but the leaves were too young and small to afford me much success. I shook off a black Sawfly (Tenthredo), two green Waterflies (Perla Cydippe?), two $\mathrm{Ci}$ mices (Pentatoma — ? ), several Chrysomelida, with soft horn-coloured elytra (Crioceris — ? ), and another very 
little species, of a metallic purple (Phyllodecta Vitellina). I have also taken some more of the delicate Fanwing Locusts (Acridium Ornatum), another Tenthredo with netted wings (Lyda Circumcinctus?), one of the beautiful changeable crimson and green Elater, which is found in Newfoundland (Elater Metallicus?), a rufous Tipula, a pretty strawcoloured Pachyta with black spots, and a female Meloe Proscarabaus, the abdomen monstrously distended with eggs : it is all over of a deep steel blue.

$F$. - This is called the oil beetle, because, whenever molested, a round drop of bright yellow clammy fluid exudes from every joint, as from the Ladybirds (Coccinella). This species is rather common with us : I have taken it in the act of eating the leaves of the common Buttercup (Ranunculus Acris); there is a great disparity of size between the male and female: the elytra are exceedingly short in both.

C. - I found a small beetle, quite numerous on poplars, scarlet with black spots (Chrysomela 10-notata?); it resembles in shape, size, and colour, the ladybirds. Among stones I obtained a dingy specimen of the sculptured small bronze beetle of Newfoundland (Carabus _ ? ) ; and several purple and copper-spot Carabs (Carabus Catena, and Calosoma Calidum). I have also caught an Ephemera, with the tip of the wings clouded, and a Membracis with two prominences on the back.

F. - The Elder (Sambucus Pubescens) and the Moosewood (Viburnum Lantanoides) are both in blossom: the large white corymbs of the former are very fragrant, and are the constant resort of numbers of little flies and other insects.

C. - Windsor-beans and Scarlet-runners I see are above ground in the garden; but they were planted late. I observe the blossoms of the wild Strawberry (Fragaria Vir- 
giniana) abundant on those barren places in the pastures and grass fields, which will scarcely bear any grass. They seem almost confined to such places: probably where the grass is luxuriant, it chokes them out. .

F. - Here is the tardy Beech (Fagus Ferruginea) just beginning to open its leaf buds. This, and the brown ash usually contend which shall be the latest in leafing. The red beech is probably the most beautiful tree we have; its bark is remarkably smooth, of a pale blue colour, often marbled with large spots of white. Its leaves are of a graceful shape, of a deep glossy green; its general outline, when growing in a clearing, is often very round, and always beautiful, its lower branches spreading horizontally; and its foliage possesses that rich and massy character, common to the maple. It has the singular property of retaining a great portion of its leaves all through the winter, though they are sere and dry, as the leaves of other deciduous trees. The roots spread out to a great distance on the surface of the earth, and are generally very tangled and contorted; they often begin to diverge from the trunk some distance above the ground. In the forest, in which the beech holds a prominent place, the trunk is tall and straight, with a wide and branchy top : its twigs are slender, and minutely ramified : its buds are spindle-shaped, and long; and become much longer when they approach their expansion. The perules are coriaceous and tough, but thin, and are lined with a silky down. The leaves do not acquire their glossy appearance for a considerable time.

C. - What are the uses to which the wood of the beech is applied?

F. - It is a hard, close-grained, and firm wood, and is used for carpenters' tools, brushes, and many other small articles ; but the chief use we make of it is as fuel: a principal part of the firewood used in this country is beech, as it 
is very abundant, and burns well, and with a strong heat. Perhaps we use as much maple as beech, but these two form nearly the whole of what is consumed. The wood of the beech somewhat resembles that of the maple, but may be distinguished from it, by being redder, and by the medullary rays being broader and coarser in appearance; the ends of these form innumerable short dashes on the outer part of any section of the wood, which distinguish it from that of any other tree. It wants too the bright play of light that makes maple wood so beautiful. It is heavy in proportion to its bulk. When young, the sugar maple often bears great resemblance to the beech, before its bark has become furrowed, but the leaves in summer, and in winter the taper twigs and pointed buds, and an appearance of superior hardness in the bark of the beech, (which can be seen, but not described,) are a sufficient distinction. This tree grows to a majestic size and height, and its fruit affords sustenance to squirrels, and other wild animals.

We have now observed the gradual unfolding of the buds of all our forest trees: some, forward and fearless of late frosts, expand their incipient leaves or tender blossoms to the fickle sun of April; others, more sober and cautious, have suffered day after day to pass over, apparently uninfluenced by the increasing warmth of the solar rays; but all have at length yielded to the resistless influence of the genial spring; and greenness, the cheerful livery of the summer, will speedily envelope all the vegetable progeny of nature. Why one plant unfolds its leaves so many weeks before another, exposed to the same influences of light and heat, we cannot tell : we observe facts; but when we presume to inquire why these things are so, we are baffled and repulsed: in some cases we can penetrate to second causes, but the primary cause must be referred to the will of the Father of all ; who, we may be assured, appoints the seasons, and 
watches over the welfare of the meanest objects of His creation. He regulates with unerring wisdom, and with beneficent providence, the expanding of every leaf, and the unfolding of every flower; not a sparrow falls without His supervision, for "His kingdom ruleth over ALL!" What an encouragement is here for our implicit trust in His care, even as regards the comparatively trifling affairs of this life, " what we shall eat, what we shall drink, wherewithal we shall be clothed;" "seeing He clothes the grass of the field, and feeds the fowls of the air." And we are of far more value in His sight than these: if we do His holy will, and rely on Him by faith, we are raised above all anxiety, for Omnipotence and Omniscience itself is pledged to care for us : "Who is he that shall harm you, if ye be followers of that which is good?"

C. - Look ! what is this among the grass? it is a little Tortoise.

$\boldsymbol{F}$.- They are not uncommon in some of the brooks: there is a brook running through what is called the Robinson farm, on the banks of the Coatacook, near Spafford's bridge, where this species (Terrapene Clausa) is quite numerous. I have caught several at different times; if I should not rather say " found," for a tortoise is not a very difficult thing to catch. I kept one in the house for some days, where he was rather amusing: when touched, he would draw in his head and legs, and curl his tail so tightly to his body that my fingers could not pull it away: if left alone, he would gradually put forth his ugly, hawk-like head, but did not like to crawl if watched, contenting himself with merely looking out. If put into a room, however, by himself, he would soon take courage, and rattle over the floor with a speed I could not have anticipated from his uncouth appearance. He managed to get 
out of a box about a foot high, several times; but how he did it I don't know; for he does not seem at all adapted for scaling walls or crawling up a perpendicular. I bored a hole through the edge of his shell, and tied him with a string to the fence of the field, thinking he would there enjoy himself; but one day, I found my poor tortoise dead, killed, as I supposed, by the heat of the sun. Another that I caught, I fastened in the same manner to a stake by the side of a spring, giving him scope enough to immerse himself in it. I often found him, with his head and fore parts exposed, and the rest of his body in the mud, quite still, and apparently enjoying his situation; he lived in this way some time, and at last broke the string, and I saw him no more. I have never seen this species exceed the size of the one before us, about six inches in length of the upper shell. I once saw a tortoise taken in one of our streams, which was twelve or fourteen inches long; but I believe it was of a different species: I had no opportunity of examining it. They lay their eggs in the sand on the banks of the rivers, leaving them to be hatched by the sun's warmth. Farwell informs me that he has often been engaged in digging up the eggs of tortoises from the depth of a foot and a half in sand, and that once for a frolic, he boiled and ate some: they were about the size of sparrows' eggs, from which he says, he could not distinguish them in taste and appearance: they were covered with a brittle shell. He has seen the young on these warm sand-beaches, from the size of a dollar upwards. The eggs are to be found at about this season of the year.

C. - Here are some Agarics which look like Mushrooms; are they so?

F. - Yes; these are true Mushrooms (Agaricus Campestris), and very large ones: they are extremely scarce here: I do not remember ever having seen the mushroom 
here before, except in one instance, in which they were growing among the litter beneath the floor of a barn. The mushroom is distinguished by the colour of the gills being pink in young, and liver-coloured in old specimens, by the curtain beneath the head, by the solidity of the stem, and by the smell and taste. When fried or stewed, they are agreeable, but not very wholesome : they possess a remarkable resemblance to animal flesh, arising from the abundance of ammonia in their composition. 


\section{XIII.}

\section{JunE 10th.}

Beauty of Summer. - American Pearl-border Fritillary. - Yellowspotted Skipper. - Natural affinities of Insects. - Tiger Swallowtail. - Moths. - Sembling. - Star Cranefly. - Other Insects. - Tabanistructure of their Mouth - appetite for Blood - Distension. - Chigoe. - Termites. - Ticks. - Pearlfly. - White-bodied Cimbex. Passenger Pigeon - its immense Hosts - Beauty of Plumage. - Turtle-dove - its Notes. - Quivering of the Air. - River. - Evening Scenery contrasted with Morning. - Sleep of cold-blooded Animals. Barred Owl. - Firefly. - Use of its Light unknown. - Luminous Appearance of the Ocean. - Bottom of the Sea. - Singular Light once seen by the Author.

FATHER. - We may now say that summer is here in all its rich and gorgeous beauty: " the glorious summer time ;" a time which, to the naturalist, is like the opening of the gates of Eden. It is indeed delightful to walk forth and behold Nature in her majesty and loveliness ; - the glorious sunshine, the verdant field, the glittering insects; to feel the balmy and fragrant breeze; to hear the melody of the birds, as they glide among the leafy shades of the forest; to see the trees with their weight of massy foliage, fragrant with blossoms ; to observe the profusion, the almost excess of life and gladness, which pervades the vast temple of nature. Look at yonder maple woods: how rich an effect is produced by the contrast of light and shade! masses of the most soft and refreshing green, prominent in the bright sunshine, relieved by the dark sombre recesses which the eye 
cannot penetrate, while the leaves quivering in the air, seem as if each one were possessed of an individual life, and were frolicking in mirth and gaiety. The bushes and shrubs are studded with myriads of happy insects, of all sorts, merrily hurrying to and fro, and enjoying their brief but joyous span of life in the gladdening beam.

Charles. - It is indeed a scene of loveliness : it is almost worth a winter of frost and snow to witness such a scene. The apples in the orchard, and the wild cherry trees in the woods are now mere bunches of blossoms, so profuse as to quite hide the leaves. The fields of grass are brightly green, and enamelled with flowers, and the young grain is of a still richer and deeper greenness. The cattle in the pastures are beginning to acquire the sleekness consequent upon fresh and abundant herbage, and warm weather; and every thing speaks of happiness. The birds do not appear in such numbers, nor with so much familiarity as before, having probably domestic duties to attend to in the shelter of the groves; but the insect tribes are more and more numerous.

$F$. What new acquisitions have you lately made in entomology?

C. - The American Pearl-border Fritillary (Melitad Myrina), a very pretty little butterfly, much resembling M. Euphrosyne, has made its appearance. It is one of those Fritillaries which are marked, especially on the under surface, with spots having the lustre and polished metallic appearance of silver. Why is the name Fritillary given to this division of butterflies?

F. - Fritillarius signifies a chess or chequer-board, and the term is applied to this family, because a majority of the species composing it, have the upper surface of the wings, and sometimes the lower also, tesselated or chequered with black and tawny. This species, though small, is very 
elegant and beautiful; it is quite common, and is fond of settling on flowers, especially Syngenesia, by roadsides, \&c. where it may easily be caught. It continues with us till the latter part of September or October.

C. - Another little butterfly, but of humbler pretensions has likewise appeared. It is the Yellow-spotted Skipper (Hesperia Peckius).

F. - The family of butterflies known by the name of Skippers, have in the thickness and clumsiness of their bodies, as much resemblance to moths as to butterflies. I have sometimes amused myself by tracing the close affinities which exist between members of tribes, that appear at first sight widely different, and by observing the very minute gradations by which nature delights to step from one to another. Let us look at a few of these in the organs of flight; besides the thickness of body just alluded to, what a close resemblance of shape is there between the wings of the Hesperia and the Noctuce, so that when dead and expanded, it would not be easy for a young naturalist to tell whether the specimen were a butterfly or a moth. On the other hand, an equally close similarity exists between the Geometrce and butterflies: the delicacy of form and breadth of wing is the same; the butterfly flies by day, the geometra does the same; the butterfly erects its wings when at rest; nothing is more common than to see a geometra with closed erected wings: here we have resemblance in points, which are considered generic distinctions. How closely do the Hawkmoths approach the Phalana, through the subdivision Zygana! But for a far closer affinity, and between orders apparently very remote from each other, look at Lepidoptera and Hymenoptera. So exactly do many of the hawk-moths of the division AEgeria resemble hymenopterous flies, that even an entomologist may be deceived at the distance of not more than a yard. The transparent wings, often with 
opaline reflections of colour, the peculiar shape and relative proportion of the fore to the hind pair, the form of the antennæ, and even the colours of the body, and their arrangement in bands, are so exactly imitated, that every species of AEgeria seems to have its hymenopterous counterpart. I have observed in some, which possess the deep blue wings common to many of the Sphexes and Ichneumons, even the habits of those flies; the restlessness, the short flights, the frequent turns and starts, and even the flirting of the wings, which no one can have failed to observe in the larger Ichneumons. Again, see how close in the small hind-wings, and the ramification of the nervures, of the genus Psocus of Latreille, is the order Neuroptera brought to Hymenoptera. And when the hind-wings of this latter order are united to the fore ones by their minute hooks, it is not easy to perceive the difference between them, and the single wings of many in the order Diptera. "Thus does Nature laugh at our systems!"

C. - The Tiger Swallow-tails (Papilio Turnus) have become abundant: they have a very noble appearance in flight when compared with the meaner fry : they are seen a great way off, as they come dancing through the green lanes, and I do not now find them difficult of capture. Since this month began, I have obtained as many as twenty-five species of moths, which I had not seen before, of which seventeen are Geometra. The Streaked Hooktip, (Platypteryx Erosa?) Lemon Beauty, (Angerona Sospeta?) Pea Green, (Chlorissa Putataria?) and Grandee (Geometra Clemataria), are very elegant species, and the last-named is the largest Geometra I have seen here. The others of this division are not remarkable. A curious little Pyralis, the Rhinoceros Moth, (Herminia — ?) occurs now in clover fields : the palpi, which are very long, are recurved over the head like a horm. Three are Bombyces, the first I have 
seen of this division, and are all handsome : the Belle ( $S p i-$ losoma Virginica), a moth of soft, velvety, white wings, is become quite numerous; the Ruby Tiger (Phragmatobia Fuliginosa), an European species, I caught in a potato field just at night-fall. It laid several eggs in a box, which were hatched in about a week; the young caterpillars, which are hairy, eat the leaves of the dandelion. The other moth, the finest I have yet taken, is the Rose-breasted (Dryocampa Rubicunda), a female: the head is exceedingly small, and jaws (or sucker) altogether wanting. It is large and heavy, and very inert, not making the least attempt to fly, or even to crawl, when molested. I found it in the evening, on a large stone in the field.

$F$. - It is a rare species : the male is so much unlike the female, that you would scarce recognise it. It is much smaller and lighter of form, and not remarkable for inactivity ; and the wings, which are cream-coloured in the female, are in the male beautifully clouded with rose-colour.

C. - I put it and the female Belle Moth into sembling boxes to attract males, but though I kept them exposed in the field for several days and nights, no males came near that I was aware of : it may be that they were already impregnated, though in that case they would probably have deposited their eggs. It has been likewise unsuccessful with a female Tiger Swallow-tail which I reared from the pupa: hundreds are flying around, but not one comes near the captive.

$F$. - Sembling is not so likely to be successful with those species, whose females are active and lively, as with those which are dull and inert; therefore I am not surprised at your failure with respect to the Belle and the Swallow-tail; and perhaps the scarcity of the species may sufficiently account for it with the Rose-breasted moth.

C. - Wasps of different species are now very busy: some 
of them are large, and handsomely ringed with black and bright yellow (Vespa Marginata). The elegant Star Cranefly (Bittacomorpha Crassipes) I have observed slowly sailing through the air over a pool of water; the black and white legs extended at full length from the body like the radii of a star: it appears to be uncommon here. Two small but beautiful species of bee have appeared, vieing in the lustre of their colours with the brilliant Rubytails (Chrysis); one is of a smooth gilded green all over (Halictus Gramineus), the other has the abdomen polished crimson (Sphecodes Rubida). I netted a pair of handsome Ephemerce in coitu in the air, the wings elegantly spotted with brown. The larger species of Dragonflies (Libellulina) fly about, particularly on the banks of the river.

$F$. - What has become of the tuberous gall which you found a few days ago?

C. - About thirty little Gallflies crept out of it one morning, all alike, about half as large as a gnat, having a green thorax, and the abdomen of a metallic brown, with a long ovipositor. I had thought that galls produced only the true Gallflies (Gallicola), but experience has shown me that I was mistaken; for from one that I was keeping, differing, however, from the tuberous one, I had produced, a day or two ago, a dipterous fly, like a Musca, with mottled wings.

F. - The large Whameflies (Tabanus) are beginning to be troublesome to the horses and cattle: I have been told by surveyors and others, whose business leads them to penetrate the forests far from human settlements, that these large flies are so numerous and virulent that sometimes it is impossible to proceed. It is not uncommon for persons in such circumstances, to have their faces and limbs so bitten, as, with the venom infused, and the consequent irritation combined, to cause dangerous wounds or ulcers. I have never been attacked by them myself, nor have I ever known them to 
molest man in the open clearing in this country, except in one instance ; in which one of the little Clouded Whameflies (Chrysops Sepulchralis?) suddenly darted at the hand of my brother three successive times without alighting, inflicting a wound each time: it left hard whitish lumps, attended by severe pain. The mouth of these insects is a fine piece of mechanism: a fleshy case contains two spiny serrated needles, and two broad lancets, shaped like a knife, working laterally; these are to cut and enlarge the wound, and increase the flow of blood; within these is a fine tube enclosed in a separate sheath, through which the blood, probably diluted by some injected fluid (which causes the inflammation and pain) is sucked into the stomach. The palpi are short, straight, and fleshy, and being situated one on each side of the proboscis, guide and guard it from injury while piercing an animal. The whole apparatus, being little larger than the point of a pin, is well worthy of regard and admiration. I have taken the larger species from my horses, so full of blood, that the abdomen was swollen almost to bursting, and of a deep red colour. It appears that on such occasions, as well as in musquitoes, ticks, \&c. the vessels and intestines must be either disruptured, the blood flowing among the whole viscera, or else capable of such enormous distension, as almost to fill the whole body. That the bodies of some insects are eapable of very great enlargement, is proved by the Chigoe of the West Indies (Pulex Penetrans), the White Ant of Africa (Termes Fatale), and many species of tick. I have myself often seen in the Southern States, Ticks (Acarus Americanus) which, in their natural state, were not more than one eighth of an inch in diameter, and no thicker than writing-paper, swollen to the diameter of half an inch, and the thickness of an eighth of an inch, merely by the blood sucked from the body of some animal.

C. - The Golden-eyed Pearl-fly (Hemerobius Perla) is 
frequent amongst the bushes. I think there is no insect more elegant than this : the large wings so filmy and transparent, the delicate network tracery of the green nervures, and the graceful manner in which they close, the slender body, and the golden prominent eyes, are, I think, unrivalled. It is a pity that it gives out so disgusting an odour when handled.

$F$. - Have you ever observed the remarkable appearance presented by the eggs of this fly? Each one is elevated on a slender footstalk, as a flower grows on its stem, the lower end being attached to a leaf, or other substance. As they are often arranged in regular rows, and all of one length and thickness, they look very curious, and would hardly be suspected to be the eggs of an insect; they look somewhat like the capsules of some mosses. — A fine Hymenopterous fly, the White-bodied Cimbex (Cimbex 10-maculata) was lately evolved from pupa in my box : the larva of which, with some others, I took from willows in August last: it was pale green, with a blue band down the back. The perfect insect is not so large as a specimen I obtained in Newfoundland. The common Downy Cimbex (Cimbex Sylvatica) is becoming numerous: I perceive these flies are the same dull heavy creatures here as they are in that island, where I first became acquainted with them.

C. - Here is a large two-winged fly, crawling among the grass, which appears almost helpless and unable to use its wings : what is it?

F.-It is Coënomyia Pallida: I took one on the 13th of June, 1836, and another on the very same day the next year; this makes the third. They were all amongst the grass : one of them was in the act of emerging from the pupa when I took it: I have the pupa-skin still; it is large, and the hind segments have rings of spines; its colour is chestnut brown, and it much resembles that of a large moth. I have no doubt it is subterraneous in the pupa state. They all ap- 
peared thus dull and inert. In Say's American Entomology it is spoken of as a rarity: he says, "During the recent journey of Major Long's party to the source of the St. Peter's river, I obtained three individuals of this interesting species, the only one yet found in North America. They occurred in a small forest of scattered trees, where we halted at our dining hour, in the immediate vicinity of Wennabea's Sauk village on the Pecktannos. None were observed at any subsequent period of the journey." Say's figure is rather smaller than our specimens.

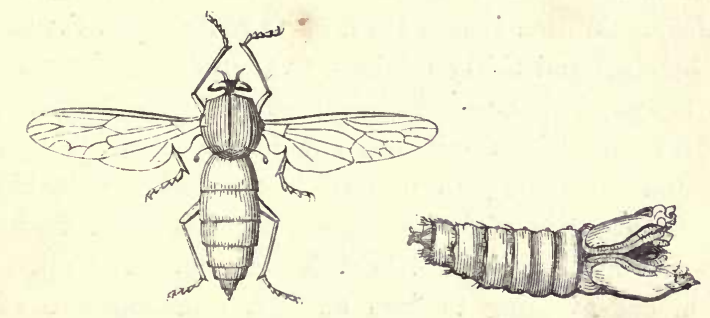

IMAGO AND PUPA-SKIN OF CÖNOMYIA PALLIDA.

C. - What birds are those flying so swiftly in a small flock?

F. - That is the celebrated Passenger Pigeon (Columba Migratoria), and the first flock I have seen this year. They do not appear to make their migrations, as birds in general do, to avoid ungenial seasons, but to obtain in abundance that food which is most suited to their wants : hence their appearances are very uncertain as to time. They are com- 
mon enough in this country every summer, but I have never seen anything like the innumerable hosts of pigeons that fill the sky in the forests of the west. Wilson and Audubon, each in his own felicitous manner, have described the comings and goings of these countless swarms; the eclipsed sun, the rushing roar, the crash' of broken trees as they alight, the report of fire-arms, the shouts of the people, the howls of the wild beasts, the eagles and vultures, the greedy hogs, and the unimaginable confusion and uproar attending such scenes as these. To give some idea of the abundance of these birds, both of these eminent naturalists have made a rough computation of the number contained in particular flocks seen by them. Wilson makes his flock to contain two thousand two hundred and thirty millions, two hundred and seventytwo thousand pigeons: Audubon supposes one billion one hundred and fifteen millions, one hundred and thirty-six thousand to have been contained in the flock seen by him; and the quantity of food necessary for this single flock to be nearly nine millions of bushels per day. The mind is lost in endeavouring to form an idea commensurate with these vast numbers; and this small, and apparently insignificant bird, may justly be considered one of the wonders of this western world. - There are two sitting on a limb of yonder beech; be cautious, and you have a fair opportunity of observing them.

C. - It is a very pretty bird: the slenderness of the body, and length of the tail, make it a more elegant bird than the tame pigeon, but there is a family resemblance; the prevalence of blue, and the changeable metallic gloss of the feathers, show its affinity.

$F$. - They are much sought after for the table, as the flesh is delicate, and many are killed during their sojourn with us: they fly, as.you see, very swiftly, and make very little noise with their wings. The sun shining on the flocks 
as they fly, from the changing lustre of their plumage, produces a fine effect. The eye of this species, as of all the pigeons, possesses a peculiarly soft and mild character, which, with their mournful and gentle notes, has perhaps contributed to make them the general favourites which they are. The Turtle-dove (Columba Carolinensis) is said by naturalists to be an inhabitant of Canada, or migratory here; and I suspect, from its general resemblance, it is often mistaken for the passenger pigeon: it is, however, smaller, and of more brilliant tints, and does not assemble in those immense flocks that the latter does, it being rare to see in summer more than two or three together. They fly with a loud whistling sound, caused by the vibration of their wings. In the South I have seen them abundantly, where their remarkably mournful cooings fill the woods all day long. The coo of the Turtle-dove consists of five deliberate syllables, not four, as Wilson has it, though the first is sometimes so low as to be unheard unless you are pretty near: the second is about five notes or tones higher than the others, which are all of one note. It is a very mournful, but not unpleasing sound; and being quite in character with the umbrageous solitudes of those majestic forests, has a soothing effect on the mind. They are fond of basking in the dusty roads when the sun shines, and are so tame that they will scarcely move from a horse's feet.

C.- There is that peculiar quivering in the air close to the ground, or the surface of any object, which we always see at this season; an appearance so exclusively associated with bright and warm weather, that the country people in some parts of England, have given it the name of " the summer."

$F$. - It is caused by the rarefaction and consequent rising of the air: the earth being heated by the sun's rays, gives 
out a portion of its caloric to the air at its surface, the strata of which, as they become heated, rise in little waves or ripples. The same thing may be seen around the pipe of a heated stove in our rooms, arising from the very same cause.

C. - Let us stay, and again admire the beautiful river, so calmly flowing : how brightly is the furnace-glow of the western sky imaged in the smooth mirror; every twig of the overhanging birches, every leaf of the quivering poplars, is perfectly reflected. Every now and then a trout snaps at some unfortunate fly, but makes so little splash that the receding circles scarcely break the surface. Clouds of gnats are dancing in the evening beam, and here is a little cluster of Ephemera, playing in mazy circles over the water which has just given them birth, and which will presently be their grave.

$F$. - There is a great difference between the feelings excited by the beginning and those by the termination of the day. In the early morning, the brightening twilight, the rosy east, the uprising sun, the dewy grass, the awakening birds, all contribute to give an exhilaration and a gaiety to the spirits, that impels us to shout and leap for mere joyousness of heart. - How different are the feelings at this evening hour! Although the setting sun is as bright as the rising, the sky as gorgeous, and the appearance of nature in most respects the same, yet there is an indescribable touching of sadness and melancholy, which comes over the spirit ere we are aware. Perhaps the difference exists more in ourselves than in the external world; perhaps there is an unacknowledged tinge of weariness, a feeling of vanity in the daily pursuits; or, perhaps, there may be an unconscious association of the departing day, with the passing away of all earthly things. 
C. - We had better return : for the musquitoes are beginning to dispel every trace of the romantic, with their very matter-of-fact bites. - I wonder whether these vermin ever sleep?

$F$. - They are active in their most congenial haunts at every hour of day or night ; though possibly, like sailors at sea, they keep "watch and watch ;" one set making fight while the other sleeps. But, seriously, I have often doubted whether any cold-blooded animals sleep, or at least whether they are not able to do without it, for long-continued periods at will. I have known fishes very remarkable and easily recognisable, keep under the stern of a vessel and about her rudder for many days together, while sailing through the ocean : if they had slept during that time, of course the vessel would have left them; and, besides, as there is no shelter in the ocean, without going down to unfathomable depths, I think if the smaller fish were to sleep, all exposed as they must be, they would inevitably fall an unresisting prey to those ravenous tribes which continually watch to devour them.

C. - There is a large bird flying across the road, just visible against the sky. Is it an owl?

$F$. - It is an owl, doubtless : from its size, though too dimly seen for certainty, I should take it to be the Barred Owl (Strix Nebulosa). It feeds on many small animals which roam abroad at night, and, as Audubon says, is fond of frogs. He is frequently seen in the afternoon, resting on some low limb of a tree, and will suffer a person to approach very close to him without troubling himself to move, and when he does slowly throw open his great wings, and betake himself to his silent flagging flight, he usually perches on another limb a few rods distant, whence he glares with his moony eyes at the intruder, as if in utter astonishment. 


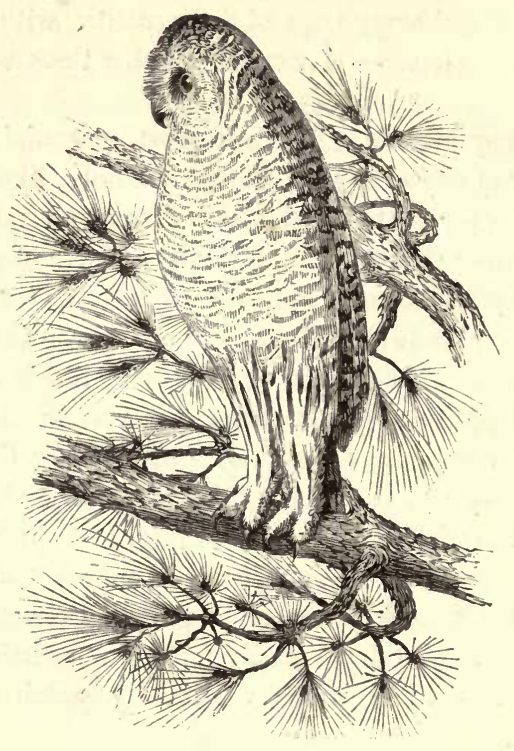

BARRED OWL.

(Strix Nebulosa.)

C. - What light is that before us?

F. - It is the Firefly (Lampyris Corusca); which illuminates our summer nights with its radiance. When I came up the country from the St. Lawrence, travelling late one evening, I first saw these pretty insects. The light, you see, is of a yellow colour, like that of flame, and very different from the blue gleam of our English glowworm: from this circumstance, I at first took them for candles in the woods, and though told what they were, at every one that appeared, the same idea would come across my mind, that it was some one in the woods, carrying a candle, until I became 
more familiar with them. Even now, if I see one suddenly, without having expected it, the impression momentarily recurs. They more frequently give out the light while flying, than when crawling or resting, though we may often observe the intermittent gleam as one crawls up a stalk of grass, or rests on the leaf of a tree. They fly slowly, and as they fly, emit and conceal their light with great regularity at intervals of two or three seconds : making interrupted lines of light through the air, gleaming slowly along for about a yard, then suddenly quenched, and appearing again at the same distance a-head. The insect is a pretty beetle, with soft elytra, of a light brown colour, marked with red, and handsomely striped : the light proceeds from the last three segments of the abdomen, which are of a delicate cream colour by day. At night these three segments are bright at all times, but at the regular intervals I have mentioned, they flash out with dazzling splendour. If this part be plucked off and crushed, many patches of brilliance occur for a few moments among the flesh, but they gradually die away. In summer evenings, they often occur in great numbers, especially over wet and marshy ground: I have seen the whole air, for a few yards above the surface of a large field, completely filled with them, thicker than the stars on a winter night; and, flashing and disappearing, every one moving about in their mazy evolutions, it is really a very beautiful sight: it is commonly believed these numbers precede rain. Notwithstanding their abundance, they are not often seen by day. They are usually known here by the name of lightning bugs.

C. - What can be the use of their light?

$F$. - That it has some end useful in their economy may not be doubted; but what that end is, we are entirely ignorant. It has been concluded and taken for granted that in a parallel case, that of the common Glowworm of England (Lampyris 
Noctiluca) its purpose is to direct the winged male to the wingless female. But it is surely forgotten that other insects have no difficulty in finding the females which are stationary, but that, on the contrary, they possess a peculiar power of discovering them, even when totally concealed from sight, as when enclosed in boxes, and even coming down chimneys, and beating against windows, to obtain access to them; on which power, the plan of taking males, called "sembling," is founded. And whether or not, the explanation of the phenomenon would not answer in this instance, where both sexes are winged.

C. - It is not without a parallel in other insects, such as some Elaters and Fulgorce; and in those very curious mollusca so abundant in the ocean, which make the ship's path a path of light and splendour. Have you ever observed these marine illuminations with any attention?

F. - I have not had any opportunity of making microscopic observations on them; but my curiosity and attention have often been excited by the appearances, and I have occasionally made some notes on their peculiarities. In crossing the Atlantic from Newfoundland to England, I have noticed three distinct kinds of light in the water, all visible at the same time. One was the cloudy, milky appearance of the sea under the stern and in the wake, just as if the ship had disturbed a quantity of chalk at the bottom : another kind consisted of an innumerable multitude of minute bright sparks, appearing at the sides of the vessel, and among the former cloudy light, though perfectly distinct from it. These two sorts appeared to be caused by the ploughing of the ship through the water, but the third sort was evidently quite independent of this cause. It may be described as broad flashes of light on the surface of the waves, coming and going like sudden fitful flashes of lightning. 
The first two are only seen in the vessel's track, and at the sides; but these gleams are seen as far as the eye can trace them, in every direction: they are much more rarely observed than the former. There was a confused swell when I made these observations, and some short waves; but they did not break. In a voyage to the Gulf of Mexico, I saw the water in those southern seas more splendidly luminous than I had ever observed before. It was indeed a magnificent sight, to stand in the fore part of the vessel, and watch her breasting the waves. The mass of water rolled from her bows as white as milk, with a luminous cloudiness, studded with those innumerable sparks of blue light. The nebulosity instantly separated into small masses, curdled like the clouds of marble, and soon subsided; but the sparkles remained. Sometimes, one of the brightest of these points appeared to burst into a small cloud of superior whiteness to the mass, and to be lost in the rest. Occasional flashes were seen on the dark surface of the surrounding sea, as some little wave would rise and break. The curdling of the milky appearance into clouds and masses, and its quick subsidence, were what I had never observed elsewhere. But how little do we know of the arcana of nature: this Iuminous property of the sea has doubtless attracted the attention of observant men in all ages, being seen on almost every shore; and yet what do we know of it? of its cause, of its nature, of its uses?

C. - The ocean is probably a world within itself; containing thousands of productions, that the eye of man has never seen. What numberless animals, shells, plants, zoophytes, may be supposed to lie on the undisturbed bed of the vast sea, where the sounding line of the mariner has never penetrated! How beautiful are Percival's lines on the tropical seas :- 
" The floor is of sand like the mountain drift, And the pearl shells spangle the flinty snow ;

From coral rocks the sea-plants lift

Their boughs, where the tides and billows flow :

The water is calm and still below,

For the winds and waves are absent there ;

And the sands are bright as the stars that glow

In the motionless fields of the upper air.

There with its waving blade of green,

The sea-flag streams through the silent water ;

And the crimson leaf of the dulse is seen

To blush like a banner bathed in slaughter.

There, with a light and easy motion,

The fan-coral sweeps through the clear deep sea, And the yellow and scarlet tufts of ocean

Are bending like corn on the upland lea.

And life, in rare and beautiful forms,

Is sporting amidst those bowers of stone,

And is safe, when the wrathful spirit of storms

Has made the top of the waves his own.

And when the ship from his fury flies,

Where the myriad voices of ocean roar,

When the wind-god frowns in the murky skies,

And demons are waiting the wreck on shore ;-

Then far below, in the peaceful sea,

The purple mullet and goldfish rove,

Where the waters murmur tranquilly

Through the bending twigs of the coral grove."

F. - I had almost forgotten to mention a very singular luminous appearance that I observed in Newfoundland about ten years ago. It was summer time: a few young men of us had been on an excursion from Carbonear to Brigus, in a pleasure-boat, and were now returning. The wind had died away before we had reached so far as Harbour Grace, and it had become a perfect calm; night was falling, and we had taken to the oars for some time, when a thick fog closed us in, and we lost sight of the land, just as we neared the southern point of Musquito: we were now bewildered, 
for though we had a compass on board, we had no light, and feared to row, not knowing our direction. Suddenly, we saw a bright red light, like the flame of a candle, near the surface of the water, in the fog, and thinking it to be the light of some fishing skiff, we rowed towards it ; but presently, we perceived it to be in motion; now receding from us, now approaching us with great swiftness; sometimes shooting round our boat, then whizzing away like a shot, until almost lost in the fog, then rapidly skimming along towards us again, so that we were lost in astonishment at its vagaries. We came near enough to see that there was no boat, nor any other visible substance but the flame itself, whatever its nature was. We at length dropped our anchor, and lay there till morning. I presume it was of a gaseous or phosphoric nature, though I cannot account for its motions.*

C. - It was a curious circumstance, and would have been alarming, if you had been superstitious. I have heard of balls of fire resting on mast-heads, yard-arms, and different parts of the rigging of vessels at sea in a gale of wind. Was the light you saw anything of that kind?

F.- I do not apprehend that it was : it appeared of altogether a different character of light: they are blue, pale, and indistinct; this was bright and red. I believe electricity is generally considered to be the cause of those appearances, and they only occur in contact with some substance: usually some projection. The ignis fatuus of the marsh has probably more affinity to it. I have often mentioned the circumstance to mariners, and others familiar with the sea, but have never met with any who was acquainted with the phenomenon.

* I have lately seen in the Magazine of Natural History (Vol. I. new series, 1837 , page 548 , et seq.) several papers attributing the light called ignis fatuus to winged insects. It has struck me that the appearance above noticed may have had a similar origin; in which case its motions would be no longer unaccountable. - P. H. G. 


\section{XIV.}

\section{JUNE 20th.}

Purple-banded Wakerobin. - Buttercup. — Red Clover. — Cedar Bird. Singing Birds. - Night Hawk - its singular manners. - Appearance of Forest. - Straightness and Nakedness of Forest Trees. - Process of clearing Land. - Ornamental Trees. - Gloom of Forest. - Age of Trees. - Tenacity of Life. - Pearl-crescent Fritillary. - Chequered Skipper. - Small Copper. - Banded Purple - its Caterpillar and Chrysalis. - Caterpillar of Forked - of Orange Comma. - Moths. - Twineyed Hawkmoth. - Depredations of Mice. - Congregations of Butterflies. - Voracity of a Bug. - Other Insects. - Decay of Trees, \&c.

Father. - Will you roam with me through the woods for an hour or two, that we may see if nature has any novelties to offer us?

Charles. - Very willingly : but it appears to be rather a dull time in every department except entomology : insects are numerous enough; but the birds seem to have all deserted us, and the trees manifest no change, except a greater depth and density of foliage.

$F$. - Here is a striking plant, the Purple-banded Wakerobin (Arum Atropurpureum); the leaves and spathe are handsomely striped with longitudinal bands of deep purple. You have probably been familiar with the Spotted-Wakerobin (Arum Maculatum), which grows in some parts of England.

C. - Oh, yes! it is abundant in some of the lanes near Wimborne and Blandford; at school, we used to gather them for the beautiful, crimson, pillar-like spike of flowers, sitting in state beneath its canopy; for which reason, probably, they 
are called "lords and ladies." They have a most putrid odour, when the flower fades.

F. - The root of the different species of Arum is fleshy and tuberous: it is highly acrid and even poisonous when raw; but heat dispels this quality, as it does in some other vegetable substances; and when cooked, it contains a farinaceous nutriment. This species of ours is sometimes called Indian turnip, and is said, when boiled, to taste like cassava.

C. - The Buttercup (Ranunculus Acris) begins to show its familiar yellow blossom in the fields: is it a native?

$F$. - I think it is probable that the seed has been introduced among grass seeds from Europe. It is a plant perfectly useless to man, cattle uniformly rejecting it: yet it no doubt answers some purpose of utility in the great economy of Creation, and the chain would be imperfect without it. But we may observe another field plant blossoming, which is of essential service to the agriculturist: I refer to the Red Clover (Trifolium Pratense), the general cultivation of which is undoubtedly one of the greatest improvements of modern husbandry. It yields an abundant crop of herbage, fit for mowing, to be cured as hay, or to be fed to stock when green, called soiling. It opens the soil, and by the rotting of its roots admirably fits it for the succeeding crop. Our American farmers here are prejudiced against it as hay, pleading that it becomes hard and dry; but the cause of this is obviously their mismanagement. Clover should be cut just as it comes generally into full blossom, at which time it possesses more nutriment than at any other; but it is usually sown here with Timothy (Phleum Pratense), which produces the best hay when cut in ripe seed. This grass does not blossom till the middle of July, at which time most of the clover has ripened its seed, and become dry stalk, almost worthless as hay. But our haymaking does not usually commence till late in July, when timothy is in the best 
state for cutting, but clover completely sacrificed. The latter should be sown separately, and cut at a much earlier season, and would then bear a very different character.

C. - Is clover a grass?

$F$. - In agriculture, nearly all plants whose herbage is used for food for domestic cattle are so called; but in botany it is a papilionaceous flower, and when examined it is a very pretty one. What is commonly called a clover blossom is in fact a collection of many flowers closely united: the corolla contains much nectar or honey, and this is very sensible to the taste, if we suck the basis of them individually. The blossoms are much frequented by bees, butterflies, and other insects, on this account; and a bee-hive placed near a clover field will not lack honey. It is thought that honey gathered principally from clover is of a peculiarly agreeable flavour. White Clover (Trifolium Repens) is not sown with us, yet it springs up abundantly by the road sides; but the seed has doubtless been introduced. It is not suited for hay, but forms very excellent pasturage, and is more durable than the red species.

C. - There is a very elegant little bird on a stake of the fence, with a high pointed crest.

F. - It is the Cedar Bird (Ampelis Americana); and a very pretty little stranger it is: it is remarkable for the smoothness and glossiness of its plumage, which is chastely but not brightly coloured. Its chief singularity consists in some curious appendages to the tips of the quill feathers, which look exactly like bits of red sealing wax. It is an inoffensive bird, and a general favourite, but with no pretensions to song.

C. - What has become of our bright-feathered friends that charmed us by their beauty and their song a short time ago ? It is three weeks since I have observed the scarlet tanagers, or any of the warblers. 
$F$. - The spring is the chief time for the singing of birds : it appears to be connected with their pairing, and the rearing of their young. When these duties are performed, our little musicians become silent : a few sing in autumn, but very few indeed during the heat of summer. They have not left the country, however; they have merely retired from view into the recesses of the woods and swamps. I saw some of the warblers in a cedar swamp yesterday: I believe they were the Bay-breasted Warbler and Canada Flycatcher ( $S y l$ via Castanea, and Muscicapa Canadensis). The finches are much more familiar; the Purple Finch (Fringilla Purpurea) yet remains with us; the Goldfinch (Fringilla Tristis), the King-bird (Muscicapa Tyrannus), and the sparrows, are still hopping about the fences; and the Redwings (Sturnus Predatorius) and Grakles (Graculus) are occasionally seen.

C. - Last evening, as I was returning from the field about sunset, some rather large, dark birds kept flying over my head, sweeping along with great swiftness: they had a pale spot on each wing. Their wings were long, and they flew like swallows, with great power of wing. Now and then, they uttered a short harsh scream.

F. - They were Night Hawks (Caprimulgus Americanus): they screech in the air every evening from sunset till after darkness has closed in. They are spread over the whole of the United States, in some of which they are called the bull-bat, partly from their resemblance to bats, as they flit along in the twilight, and partly from another circumstance, which is very peculiar. In the evenings, the males amuse themselves by mounting on the wing to a great height, then suddenly dropping down perpendicularly, head foremost, like a lump of lead; they bring themselves up with a turn before they come to the ground, then mount, and precipitate themselves again. While in the act of descending, they suddenly utter a hollow booming sound, which may be heard at 
a great distance, and has some resemblance to the bellow of a bull. It is supposed that the sound is caused by the air rushing into their capacious open mouths, as into the top of a barrel. They feed on moths and other night-flying insects, and are rarely seen by day.

C. - Is the Whip-poor Will (Caprimulgus Vociferus) an inhabitant of this part of Canada?

$F$. - I have been told that it has been sometimes heard, but I have never heard nor seen it myself, and at all events, it must be considered a very rare visitor.

C. - Our neighbour here is clearing some forest land.

$F$. - Observe the remarkable appearance of it: if we look at the forest at the edge of an old clearing, yonder field for instance, we see it green and leafy to the very ground; but if we look at it where a portion has been recently cut away, a very different aspect is presented. We see nothing but tall, slender, upright stems of different sizes, with scarcely a leaf, except at the top, where there is a small and scanty surface of foliage, quite out of proportion to the height of the trees: the eye can penetrate a long way into the gloomy depth, as there is no foliage to intercept the vision; nothing but this host of straight grey sticks. There is certainly a little underbrush, on the ground, but it is meagre, and extends only to the height of a very few feet, consisting of a few scattered shrubs.

C. - What is the cause of this remarkable manner of growth?

F. - The want of light; without which there is no foliation: those trees which grow on the edge of the forest shoot out side-branches into the light, and bushes and shrubs spring up, which are profusely covered with leaves. But those that spring up within, continue to shoot upward and upward, until they reach the top of the forest (the only situation in which they can reach the light), before they shoot 
out any permanent branches. If the leading shoot of a young tree growing alone be broken off, the tree ceases to grow much higher, but sends out many ramifying boughs; but a young forest tree in similar circumstances acts differently; another shoot is sent out, which becomes the leader, and carries up the perpendicular, and this after the tree has attained a considerable height and circumference, as I have seen in many instances. It is this circumstance of growing

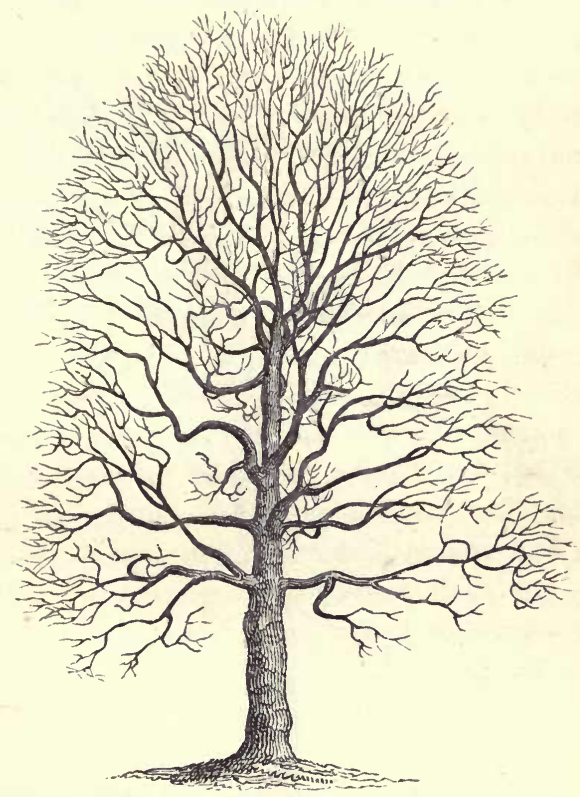

MAPLE (Acer Saccharinum) IN A CLEARING.*

* There is an apparent incongruity in representing trees naked and leafless in the middle of June, but the object was to illustrate the mode of ramification, on which the appearance alluded to in the text depends. 
so tall without lateral branches, that makes forest timber so valuable, for wherever a branch grows, there is a knot in the trunk.

C. - Will you describe the process of clearing land?

$F$. - Our neighbour having just got his "crops" into the ground, is clearing this for next year. He begins by cutting with a heavy bush-hook, the shrubs and slender saplings, which are then piled in large heaps : the axe follows, and cuts down the young trees, the larger ones being left for the pre-

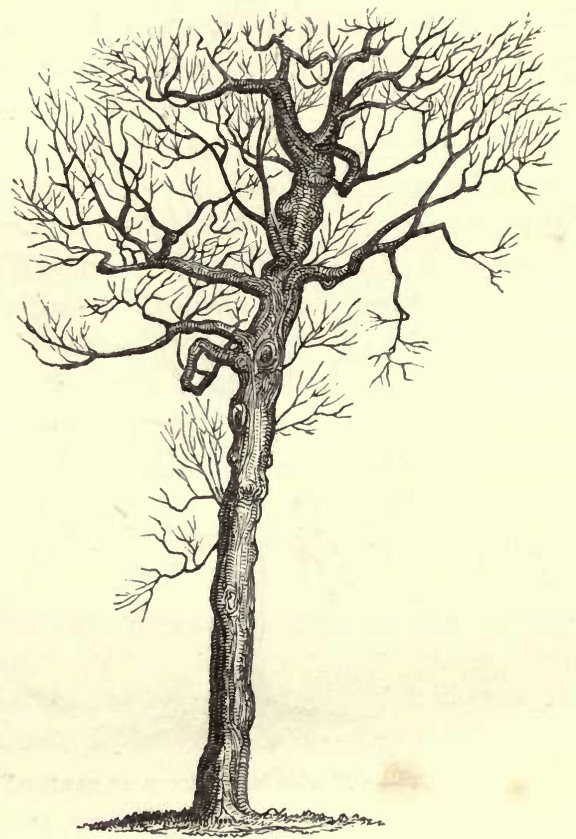

MAPLE (Acer Saccharinum) IN THE FOREST.*

* See figures of the Elm, pp. 14, 15. 
sent; the felled ones are cut in lengths, and piled with the limbs on the brush heaps. All these have been cut quite close to the ground, so that the stumps may offer no obstruction to the harrow : all being piled, nothing remains but to fell the large trees, which is done at about two feet from the ground, the stumps being permitted to remain till the gradual decomposition of the roots allows of their extraction: a work of years. The trunks of the trees are now chopped into lengths, those which are useful for fencing placed by themselves to be removed, and the remainder, by the efforts of oxen with chains, and men with levers, are piled one upon another, and the tops thrown into heaps as before. In this state everything remains during the summer, exposed to the burning sun of July, August, and September, which dries up a good deal of the moisture, and makes the heaps fit to burn. In the fall, advantage is taken of a dry time to put fire to the logs and brush, which burn rapidly, and are usually consumed, with the exception of some remnants of the $\log$ heaps, which are piled together for a final burning. The running of the fires over the ground kills every vegetable, and the fertilizing ashes make the whole in good order for culture. The plough is not put into the ground for some years, until the small stumps and roots have decayed: it is merely harrowed over, the virgin earth being soft and mellow, and grain is sowed with grass seed. After the first crop, it remains in grass for several years. Such is the ordinary practice, slightly varying, according to circumstances.

C. - Are no young trees ever left for ormament?

$\boldsymbol{F}$. - Were it possible to do so, they would be anything but ornamental; for a young forest-tree is nothing more than a very tall hop-pole with a few leaves at the top: but the fires would be sure to kill them, if such were spared by the axe and hook. Ornamental trees must, in general, be 
planted, or spring up spontaneously; and this sufficiently accounts for what travellers think so strange in a forest country, the general want of trees about the homestead, roadsides, \&c.: farmers in general being too much employed to pay attention to planting for ornament.

C. - Let us walk into the forest.-What a sombre gloom prevails; the more striking, as contrasting with the bright sunlight we have left. Scarce a ray here and there can penetrate through the leafy canopy, that almost fatigues the eye to look up to it. Yet that is the most cheerful part of the scene; for there the leaves, so brightly green, are dancing and sparkling in the light; while we, far below, are in shade.

F. - The gloom and solitude of the interior of the forest have invariably a solemnizing influence on my mind: an awe like that which one feels amidst the timeworn pillars of an ancient cathedrai ; which these grey and moss-grown trunks greatly resemble.

C. - How old do you suppose these large elms to be?

$F$. - I cannot tell: probably they were rearing their slender stems years before Jacques Cartier explored the St. Lawrence, or even before the chivalrous Genoese launched his frail bark on the grim Atlantic. The concentric circles around the heart of a tree are, however, believed to give a correct estimate of its age, one being made every year: we can count the rings in some of these logs that have been felled.

C. - I have counted one; an ash of about eighteen inches in diameter, which has but one hundred and sixty circles.

$F$. - I chose this hemlock log, about two feet in diameter : if this be a true criterion, this tree must be three hundred and ninety-five years old, which carries us back to a period fifty years before the first voyage of Columbus. But what is this? what is the age of the largest tree in these forests 
to the celebrated Baobab of Adanson, or the Cypress of Decandolle, both of which are believed to be nearly as old as the deluge? The former is in Senegal, the latter in Mexico.

C. - Does a tree invariably die when it is cut down?

$F$. - Oh no: the stump often sends out fresh shoots, which are remarkable for the vigour of their growth, and for the great size of their leaves. I have seen an ash stump throw out a shoot six feet long in a single season, with the leaflets eight inches in length; and maples in a similar proportion, with leaves near a foot in diameter. These fresh shoots and suckers often cause the farmer much trouble, by springing up in ground that he has cleared. If deprived of their leaves in July or August, however, the stock will die; and so it will if the tree be cut down at that season. Very large trees do not usually send out new shoots after being cut down, under any circumstances, or at any season.

C. - Butterflies of several kinds are now numerous on sunny days, especially about the borders of the woods; but very few are to be found actually within the forest. I have noticed the appearance of several new species; the first of which was the Pearl-crescent Fritillary (Melitaa Tharos), a pretty little fly, with the tawny wings marked with yellow and black; the female differs so much from the male that I took it for a distinct species, till further observation showed me their identity. A rather pretty little Skipper, the Chequered Skipper, (Pamphila Paniscus?) has also appeared, but $I$ have taken only a single specimen.

$F$. - It is very rare.

C. - Another species would be perhaps the most splendid butterfly we have, if its size corresponded with its beauty: I mean the Small Copper (Lycana Phleas) which now occasionally flits about the roads. The richness of the glowing flame-coloured wings is worthy of admiration, and the under 
surface is very delicate : and I do not see that it is less beautiful because it is diminutive; though if it were as large as a Swallow-tail or a Camberwell Beauty, it would strike the attention more readily.

$F$. - There is often considerable diversity in the vividness of colour of different individuals of the same species of butterfly or moth ; one being much more beautiful than another; in the same individual, however, one wing in general
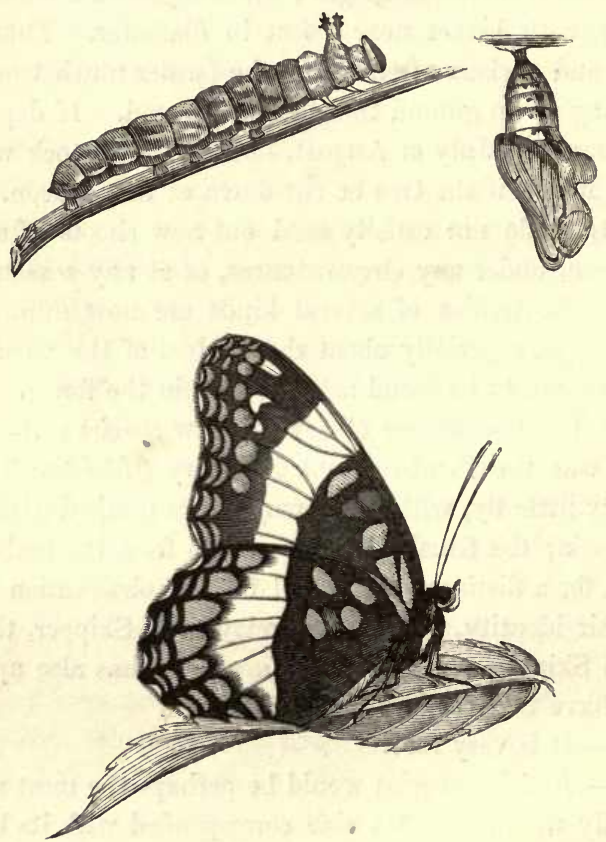

LARVA, PUPA, AND IMAGO OF THE BANDED PURPLE.

(Limenitis Arthemis.) 
exactly corresponds with the other, its fellow. But I once took a Small Copper in the month of September, which had a very apparent difference in the colour of the wings; the left fore-wing being much lighter on both surfaces than the right, though neither was defaced in any degree. It was resting on a stalk of grass, and was unwilling to fly, the weather being cold with misty rain. It was unusual to find a butterfly abroad in such weather. In the same month, one that I had taken laid nine eggs; they were small, nearly round, flesh-coloured, appearing under the magnifier covered with indentations.

C. - I took from an elm tree, on the leaves of which it was feeding, a large and handsome caterpillar, mottled with white and greyish green, with two spinous horns on the second segment, and two prominences on the fifth. It went into pupa on the 15 th, suspended by the tail ; the chrysalis has a remarkable prominence on the back.

$F$. - It will continue in the pupa state about a fortnight, and then produce the Banded Purple Butterfly (Limenitis Arthemis).

C. - I have also obtained a caterpillar of the Forked Butterfly (Vanessa Furcillata), and two or three of another kind, spinous, greenish, with a flat white back: they were feeding on the common nettle.

F. - They produce the Orange Comma. (Grapta C. Album?) I perceive a moth, of the division Bombyx, has been produced from the cocoon of a yellow, hairy caterpillar, which I took from a poplar tree at Quebec, on the 30th of last July: it spun its cocoon in a corner of a box a few days afterward, so that the moth has been nearly eleven months in pupa, a most unusual while. It is an unnamed species.

C. - I have had some Bombyces evolved this week, from cocoons produced by caterpillars, which I obtained last autumn. The Buff-Leopard (Arctia Isabella) and the Muff 
(Lophocampa 'Tesselaris) are pretty moths; the Brindled (Biston Hirtarius?) is plain and more sober. And I perceive this morning that a beautiful, but rather small Sphinx has crawled out of the earth in one of my breeding-boxes, in which the caterpillar buried itself in September. It very much resembles the Eyed Hawk-moth (Smerinthus Occellatus), but the eye-spot has two pupils. I do not think, however, that this character, the double pupil, is constant, though it has given the specific name; for in breeding two individuals, whose larvæ were taken together, in nowise distinguishable from each other, one of the perfect moths had two blue spots, and the other only one, in these ocelli. They were exactly alike in every other respect: it is the TwinEyed Hawk (Smerinthus Geminatus). The wings are not deflected, but stuck out at an angle of about $45^{\circ}$ horizontally from the body, the second pair being concealed beneath the fore ones; they are kept in almost constant vibration : the tongue or sucker is very small. Besides these which I have bred, I have taken many other species: two pretty Bombyces, the Snowy (Spilosoma - ?) and the Panther (Spilosoma Acria), both of which flew into my room at night: the sexes of the latter differ from each other, the hind wings of the male being deep yellow, those of the female pure white, both spotted with black; some Noctuce, among which I may mention the Angleshades (Phlogophora Meticulosa); this I shook from a willow in bush-beating: among the Geometra, the minute but pretty little Orangeband, (Pyralis ?) and some of the Veneer moths (Crambus) among the Tiner.

F. - I found two large hairy caterpillars of a dark greyish colour, about a week ago, feeding on the leaves of a tall herb, provincially called Indian Wickup (Epilobium Latifolium); they have since spun dark brown cocoons. They 
belong to the beautiful Royal Tiger Moth (Arctia Virgo), and remain in the pupa state about four weeks.

C. - I must tell you of a sad misfortune that has befallen me : a rascally mouse has managed to find access to my setting-board, and destroyed a good many insects, some of them valuable ones; eating the bodies, and leaving the mangled and scattered wings.

$F$. - Mice seem pretty fond of insect diet, for they will always commit these depredations at every opportunity: I have myself suffered from the same cause.

C. - Look ! what a congregation of butterflies on that little muddy spot ! and all of one species, the Clouded Sulphur (Colias Philodice). I should think there are near twenty within a square foot.

$F$. - This species is very fond of assembling in such places to assuage thirst, but other butterflies have the same habit: I once saw fifteen of the Tiger Swallowtail (Papilio Turnus) in a space not exceeding a foot square; and my brother soon after counted fifty-two of the same fine species together; besides many more which were hovering about the spot, on the wing. See; here is an instance of tyranny and rapine, though on a small scale. A large flat Bug (Pentatoma) has caught an unfortunate caterpillar, and plunged his sucker, or rostrum, into its body ; this rostrum is usually bent up under the breast; but now it is extended straight from the head, holding the caterpillar at the end of it. Observe how fiercely he holds on, and won't let me take it away from him. All the bug tribe are carnivorous, and live by sucking the juices of other insects, and sometimes of larger animals. I have succeeded in rearing plant bugs to the perfect state, by supplying them with house-flies, which I maimed and threw into the box.

C. - I have caught, near the river, one or two Day-flies 
(Ephemera Cognata?) of very large size, mottled with black and yellow, having only two anal setæ. In coming up the river St. Lawrence last summer, many of this fine species flew on board below Quebec; and the exuvia of the pupæ were floating down the river in myriads. Some pretty beetles have occurred in my late researches: a small black Cerambyx, with curved marks of bright yellow on the elytra; (Clytus — ? ) a Buprestis, with rough elytra of a bistre brown; the upper part of the abdomen brilliant green, only visible when the elytra and wings are expanded; the under side coppery (Odontomis Trinervia); a Leptura, with the fore part of the elytra scarlet, the rest black (Nephropis Canadensis); I have observed, also, the Green Triangle Dragonfly (Gomphus Vulgatissima), the Greater Clouded Casefly, (Limnephilus - ?) and the little Scorpion-fly (Panorpa Fasciata); the abdomen, in the males of this genus, terminates in a large thick knob, containing a pair of pincers, like a crab's claw; this it generally carries turned up over its back. The brilliant little Green Rubytail (Chrysis Cyanea) appears about the posts and walls of houses ; the delicate Green Waterfly (Perla Cydippe) flies about the margins of brooks and rivers; and I have noticed a specimen of the Inlaid Casefly, (Phryganea - ?) which appears to be a rarity.

F. - We are drawing near the edge of the woods, as you may perceive by the increasing light: we will go out, and return home.

C. - Walking in the forest would be much more pleasant if it were not so much encumbered with logs, roots, and fallen trees. Sometimes we break our shins against them, or stumble over them; at another time we step on one, and tread into a soft mass of dust and rubbish, instead of a hard log, as it appeared. 
F. - "Nulla fronti fides" here: the bark of trees will often seem perfectly sound, when the interior is, as you observe, become a mere mass of dust, utterly gone to decay. This is owing to the greater abundance of carbon in the bark than in any other part, which resists putrefaction. The bark of the birch, in particular, appears almost incorruptible. We see here an example of that continued round of decay and renovation which pervades all created, or, at least all organised, bodies. The seed falls from the tree; it shoots up a tender twig; it grows upward, drawing continual supplies of nutriment from the earth by means of its increasing roots ; the slender stem slowly, but surely expands in height and thickness, till it has become a mighty tree ; it continues erect, and apparently vigorous, for centuries: but time, edax rerum, at length prevails over its giant frame: and by imperceptible, but ceaseless attacks, robs it of life. The frost rends, and the rain rots the heart; the moss and the lichen fix themselves on its outside; the winter gales blow; and the majestic, hoary veteran bows to the blast, and descends with a rushing roar that shakes the earth. There it lies : the process of decomposition now goes on unresisted by the living principle; many agents complete the work, and at length the place of its bed is marked but by a slight, a very slight elevation of the soil. It has reverted to the same earth from which its own sustenance was first drawn, and now its elements are forming the sustenance of other trees, to perform the same round again, as long as earth shall endure. 


\section{XV.}

\section{JULY 1st.}

Transformations of Insects - local Habits. - Baltimore Fritillary. - Large Sphinx. - Silver-spot Fritillary. - Tawny-edged Skipper. - Moths rearing winter Pupæ. - Mould - Puff-balls. - Curious Beetles. - Hemerobius. - Dragon-flies. - Day-flies ; - other Insects. - Giant Waterfly. - Buprsetis. - Raspberry. - Wild Strawberry. - Poke. Sandpiper. - Blue Iris. - Redtop Grass. - White-throated Sparrow. - Large Moth.

Charles. - Perhaps one of the chief pleasures of natural history, especially entomology, is the perpetual novelty and variety we find in it: we are meeting at every turn with new and interesting facts: the endless diversity of habits, locality, structure, form, colour, to be found in insects, is such a source of pleasure, as effectually prevents us from feeling weariness or melancholy. It seems almost a contradiction in terms, for a naturalist to be in low spirits : everything he sees tends to enrapture and delight him. Among these things, one of the most pleasing is the observation of the various transformations to which insects are subject: the same individual, Proteus-like, taking new forms and presenting new objects of examination to our admiring eye. - The caterpillars of the Forked and Orange Comma Butterflies, which I took a few weeks ago, have both become pupæ, and the chrysalis of the Banded Purple (Limenitis Arthemis) has produced the butterfly, an insect of remarkable beauty: the contrast of the white, orange, and deep 
changeable purple, is very fine. It has already become quite numerous, especially near the little brook that crosses the road below the maple grove: this place, from some cause which I am not aware of, is a very favourite resort of many species of butterflies.

Father. - I have noticed the same fact, having seen species there that I had not met with anywhere else ; and on a fine summer day many kinds are always thronging that

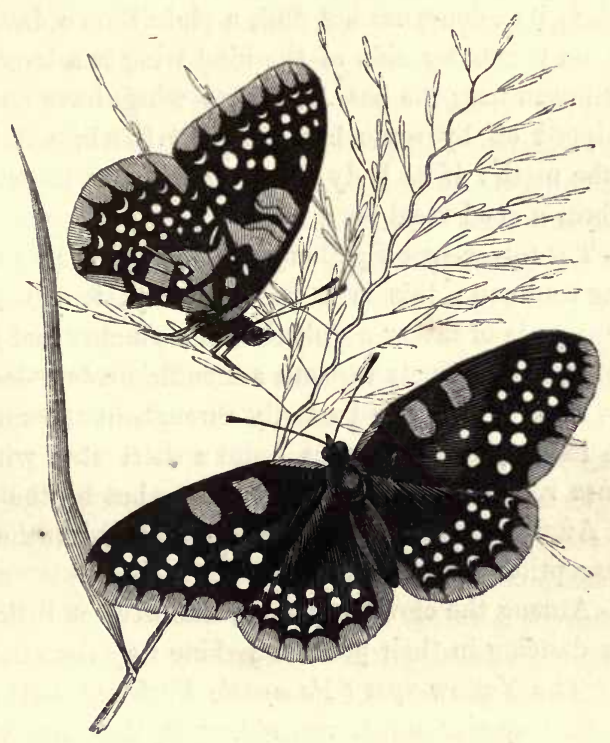

BALTIMORE FRITILLARY.

(Meïtca Phaeton.)

lane. I caught, a day or two ago, in that very spot, a beautiful little butterfly, the Baltimore Fritillary (Melitca Phaeton). It is the first specimen I have ever seen in 
this country, and may well be called rare. It is elegantly marked with the Baltimore colours, black and orange, with round spots of white.

C. - Here are two wings of a very large moth, that I have just picked up from the ground by the side of the road.

$F$. - They are the two left wings of a Sphinx, and of a remarkably large species: the insect must have measured four inches and a half in extent of wing. I have never met with the species; its colours are but dull, a plain brown drab ; but you. see, on the under side of the hind wing is a large cloud of dull crimson near the base.* These wings have no doubt been snipped off by some bat, or night hawk, which had caught the moth : if its body corresponded with its wings, it would form a good meal for a bat.

C. - The Silver-spot Fritillary (Argynnis Aphrodite?) is becoming common: this is a fine butterfly, for though its upper surface is of rather a dull tint, the number and beauty of the bright silver spots beneath are sufficient to redeem it.

$F$. - It is a common butterfly throughout the summer; but the Banded Purple makes quite a short stay with us; it becomes very numerous all of a sudden, but by the beginning of August they have all disappeared, with the occasional exception of a straggler.

C. - Among the clover blossoms, hundreds of little Skippers are dancing in their peculiar jerking way from flower to flower. The Yellow-spot (Pamphila Peckius) is abundant, and another species much resembling it, the Tawny-edged Skipper (Pamphila Cernes). Two new Bombyces were evolved a few days since from caterpillars taken last fall; one of them is very pretty, the Silver-spotted Buff (Pygara

* It is not described in Dr. Harris's recent monograph of the American Sphinges. 
Gibbosa). I have obtained several new species of Noctuce, among which is the Gamma Moth (Plusia Gamma), so common in England, with Geometre, Tortrices, and Tinece; two of these last, belonging to that very elegant division called Veneer Moths (Crambus), and another to a division of very minute moths, (Microsetia?) known by their burnished metallic appearance.

$F$. - You have been fortunate in rearing your winter pupæ.

C.-Yes ; I have scarcely lost one out of a great number that I wintered. I pursued a plan that you recommended; late in the fall, after the Bombyces had all spun their cocoons, I buried the breeding-boxes in the earth, very lightly covering them. In the spring, as soon as the ground was free from frost, I dug them out, and have been rewarded for my trouble, by some fine moths. On first opening the boxes, all the inside was clothed with a fine white downy mould, nearly an inch high, but impalpable.

$F$. - I was induced to recommend that plan, on account of my own failures : in the preceding winter, I had upwards of fifty pupæ, chiefly Bombyces, which I kept in their boxes in a dry cupboard. - In the spring, I had scarcely a single imago out of that number, the pupæ being dead and dry. I then considered that to be successful, I must adhere more closely to their habits in a state of nature: we usually find the cocoons of Bombyces in the spring, on the ground beneath large stones, boards, \&c., where the earth affords them the moisture necessary to life, and the snow probably secures them from congelation. For this reason, I advised you to bury them lightly; and it seems the result has answered my expectations.

C. - The appearance of the mould struck me as being curious. I know it is a vegetable production; but how could its seeds have found access into my shut boxes? 
$F$. - The propagation of mould is one of the most curious subjects in vegetable physiology. The seeds or germs of the future plants are supposed to be continually floating in the atmosphere, and do not spring up till a suitable degree of heat and moisture developes their vegetative power.

C. - The Puff-balls, so common in our pastures, are singular things.

F. - They do not look much like plants, either when the inside is a soft green mud, or when it is become ripe, and resembles a lump of fine sponge, dipped in a box of impalpable snuff. If these atoms of dust be the seeds of the plant, as is supposed, it is surprising to me that the land does not become completely covered with them, instead of being scattered, as they are, here and there, half a dozen on an acre.

C. - Are they considered pernicious by agriculturists? or is any effort ever made to check their increase?

$F$. - Not that I am aware of : our farmers here do not think them injurious, except inasmuch as they are useless encumbrances, and draw nourishment from the soil: the evil is not of sufficient extent to alarm the farmer's fears. I believe their presence is considered, with what truth I know not, an indication of land whose fertility has been exhausted, as they do not infest the soil when in a high state of cultivation.

C. - Here are two curious insects, with the fore wings black, with two orange bands, and very thick pectinate antennæ: what are they?

$F$. - I have been puzzled by them myself; having even doubted to which order they should be referred; but further observation showed me that they are beetles, with flat and very flexible broad elytra (Lycus Reticulatus). I have found another species, of about the same size, one-third of an inch in length, and resembling it in every respect, except 
that the elytra are half orange and half black, or very deep blue. As in this case, they are deeply furrowed, and the hind wings are smoky black (Lycus Terminalis).

C. - As I was roaming on the bank of the river yesterday, near the bridge, I caught a large black Hemerobius, the wings banded and spotted with white (Hermes - ?) Great numbers of Dragon-flies were flying over the water, many of them in coitu, in the form of a circle, having a very singular appearance. Towards evening, I noticed several Day-flies (Ephemera), dancing in the air above the river. I observed that they alternately fluttered perpendicularly upwards for about ten feet, and then sunk down with closed erect wings; the anal bristles held perpendicularly and diverging: then they would flutter up and sink again; continuing these motions over one spot, till I left them.

$F$.- The Brush-footed Bee (Megachile Willughbiella) and the Green and crimson Elater, (Elater Metallicus?) both natives of Newfoundland, I have observed here lately. There are not nearly so many species of insects common to that country and this, as I should have expected from their proximity. It is stated by Linnæus, if I mistake not, that twelve degrees of latitude make almost a total change in the insect species; but probably much difference is also caused by the situation of a country : for instance, between the coasts of an island, as Newfoundland, and an inland region, as this part of Canada.

C. - A lad gave me, yesterday, a Water-fly of very large dimensions, measuring about three inches and three-fourths in spread of wing. It is of a dusky colour, and the nervures of the wings are of the same; its claims to notice are only its enormous size, as compared with other species of the genus, for it has no beauty. It is Pteronarcys Regalis. 


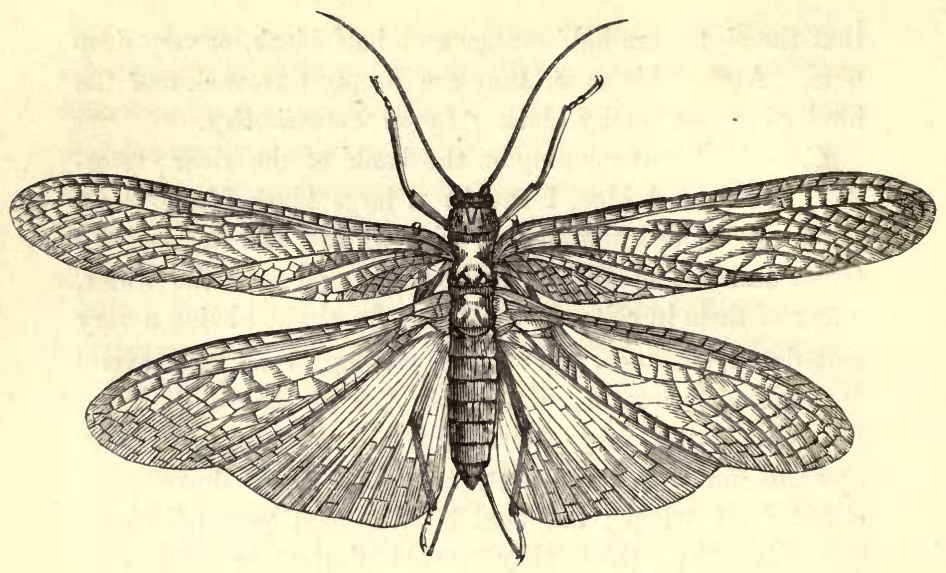

GIANT WATER-FLY.

(Pteronarcys Regalis.)

F. - I have taken a very large species (Pteronarcys Proteus) at Sherbrooke, near the junction of the Magog River with the St. Francis; but I have not any specimens now. It is not, however, near so large as yours, but resembles it in colour.

C. - A handsome Buprestis (Stenuris Divaricata) is now occasionally seen; chiefly on trunks of trees, rails of the fence, \&c. The Buprestis, I believe, inhabits wood in its earlier stages, which accounts for the perfect beetle's frequenting such situations, having, perhaps, just emerged into daylight from its long imprisonment; or, perhaps reconnoitring for the purpose of laying eggs, for a new generation. This one has the upper parts metallic brown, the under parts shining coppery ; and the elytra, which are sculptured, terminate in lengthened points or tails. I have taken a larger species (Anoplis Rusticorum). 
F. - The genus Buprestis is remarkable for the general beauty of its species; most of them being characterized by a metallic brilliancy of colour. We have several species here. I have lately observed two species of Coccinella, which I have seen in Newfoundland, but which appear to be scarce here; one is the beautiful Scarlet Ladybird, (Coccinella 5 -notata?) so very common there ; the other is the Banded Ladybird. (Coccinella —?)

C. - The Wild Raspberry (Rubus Ideus) has been in blossom about a week; and on some bushes I perceive the fruit is beginning to form. The Wild Strawberry (Fragaria Virginiana) is ripe, and quite abundant : it is of a pleasant flavour, but far inferior in size to the cultivated species. Here is a rather handsome plant; do you know its name?

$F$. - It is commonly called the Poke, and its root is considered by the common people as poisonous. Its botanical appellation is Veratrum Viride. It has not the slightest resemblance to the plant called Poke in the south (Phytolacca Decandria). This plant resembles some of the large liliaceous plants ; it dies to the root every year, and in the spring sends up a large bulb of broad, lance-oval leaves sheathing each other: the leaves have deep plaits running their whole length, like a half-closed fan. From the centre shoots a stalk sometimes three feet high, bearing a spike of small plain greenish flowers at the top; as you see, for it is now in blossom: these are succeeded by dry seed vessels, which open and drop their seeds. The plant is most common in the black swampy earth of the evergreen woods, and does not often grow in clearings, except by the side of pools of water in low grounds, as here. The flowers have no beauty, but the large leaves give it rather a noble appearance.

C. - What pretty little bird is that, running along with such nimble feet on the bank?

$F$. - I believe it is one of the Sandpipers (probably 
Tringa Semipalmata, or T. Pusilla); this numerous tribe is so much alike in general appearance, that it is not easy for a common observer to know the species, without an accurate examination and comparison. A few may be seen every summer, just at this spot, but I have never met with them in any other. The land here is low; scarcely above the bank of the river, which flows close beside the road on one hand ; and on the other is a large pond and marsh ; the latter clothed with willows, bushes, and rushes. The road, you observe, is raised up, like a causeway; yet in spring, when the river is swollen by the melting of the snows, it overflows .this part of the road, and, with the adjacent pond, makes the surrounding meadows look like a miniature sea. On the sandy banks of this pond the little sandpipers run to and fro, picking up worms, insects, and small testacea. They run very fast, but do not readily fly, and when they do, it is only to a few yards, alighting again immediately. Many plants and animals seem in some degree peculiar to this spot; though no doubt there are many other situations having the same character and equally congenial to their habits, where the same species may be found. A large and handsome flower, the Blue Iris (Iris Versicolor), haunts this place; the beautiful blossom may now be seen capping the curious sword-shaped leaves.

C. - What a light and feathery appearance a field of grass has at this season! To what is it owing?

F. - The Red-top Grass (Agrostis Vulgaris), of which this field is chiefly composed, is now in flower: the blossoms of this grass grow in a large loose panicle, the anthers project from the glumes, and it is they that cause this downy lightness.

C. - I have several times heard in the woods a very sweet but singular note, the author of which I cannot discover. It consists of six notes deliberately uttered, the first 
low, the other five about four tones higher, and all alike, so clear, and shrill, and musical, that I have been quite charmed with the sound. The higher notes are something like the strokes on a small silver bell, and are frequently shaken or trilled.

F. - I have heard the notes hundreds of times, both here and in Newfoundland, where it is very common, and have had very great curiosity to know the author. They usually proceed from the thick.woods, and the bird is too shy to allow approach : one day, however, I heard it proceeding from one of the plum trees in the orchard; I crept cautiously to the spot, without disturbing it, until I arrived directly under the tree, within a few feet of the bird, which, while my eyes were fixed on it, whistled its sweet but simple song. It was the White-throated Sparrow (Fringilla Albicollis); a pretty bird, the upper parts spotted, like most of the Sparrows, with bay, brown, and black, the head handsomely striped with white and black, and the under parts white. I have never seen the bird since. Its song, though heard at all times of the day, is chiefly uttered early in the morning, and in the evening; and even sometimes continued till darkness has spread her curtain over the earth, at which time it has a pleasingly solemn effect.

C. - Did you see that very large moth that just darted along, over our heads?

F. - No: but I have seen several lately, in the dusk of the evenings, of very large size, but too indistinctly to identify them: they are no doubt Saturnice, and would be a noble addition to your cabinet; but it would be vain to pursue them at this late hour, as they are almost instantly lost in the darkness. - Now you have an opportunity of seeing an assemblage of Fireflies, which I described to you a 
few days ago. Cast your eyes over yonder meadow below the road, and observe the millions of bright sparks dancing there, and over the river.

C. - It is indeed a sight to be admired: I can compare it to nothing that I have ever seen. It is something like the stars on a clear winter's night, but the redness of the sparks, the regular emission and concealment of light, and the continual mazy evolutions which every one performs, give it quite a unique and singular, and certainly a most beautiful, appearance. 


\section{XVI.}

\section{JULY 15th.}

Climate.-Thundershower.- Subsequent Freshness.-Fog.-Agricultural Productions.-Weeds.-Canada Thistle.-Burrweed.-Spurry.-Blue Bird.-Baltimore Oriole--Humming Birds.-Dewberry.-Raspberry. - Timothy Grass.-Indian Wickup. - Orange Lily. - Fox-coloured Sparrow.-Orange Comma Butterfly.-Pearly Eye.-Eyed Brown.Compton Tortoise.-Remarkable variety of Forked Butterfly.-Banded Purple.-Dragon Moth.-Cœrulean.-Pink Arches.-Twin Gold-spot. -Clouded Cream.-Spotted Lemon.-Drab Plume.-Caterpillar of Vapourer, - of Grey Comma Butterfly.-Dragon Fly.-Hoof Boletus.Toad Beetle--its Larva and Pupa-Habit of counterfeiting Death.Skunk-its fetid Odour-Mode of Emission-Habits.-Blue and Gold Cerambyx.-Black and Yellow Whame-fly.-Punctured Beetle.Sweet-scented Milkweed.-Resort of Insects.-Dandelion. - Scattering of Seeds.

Charles. - What a strange climate is ours! a climate of extremes. A few months ago the thermometer was down to $30^{\circ}$ below Zero: now it is ranging from $90^{\circ}$ to $100^{\circ}$ above: showing an annual range, that perhaps scarce any other part of the world can equal.

Father. - It has been very hot lately; and the cloudless atmosphere, through which the sun darts the full blaze of his beams, makes the heat in the open air exceedingly oppressive, almost too hot to labour. But the thunderstorm of last evening cooled the air, and laid the dust, which rose before in choking volumes. 
C. - I never before saw rain anything like it: the large hail preceding it; then the shower itself, coming down in dense sheets, and the drops so large and heavy! why, the roads, with all their thick beds of dust, in five minutes were mere water-courses. And how vivid the lightning! coming from no particular point, but appearing to fill the sky with one blaze, followed in quick succession by deafening roars of thunder, dying away and taken up again in repeated echoes! It was quite appalling.

$F$. - A great evil needs a strong remedy : a gentle rain would not cool the air sufficiently to be attended with any lasting benefit; nor would it have wet the earth to such a depth. But the change in the air is chiefly caused by the sudden restoration of the equilibrium of the electric fluid, which had been destroyed by the great heats. After the storm had ceased, a more beautiful scene, though not so terrifically sublime, was presented by the lightning, which continued to play in the clouds around the horizon, after the thunder had ceased to be heard, and the sky over head had recovered its azure serenity. Long after sun-set, the horizon was ever and anon lighted up with brilliant flashes, sometimes cleaving their zigzag path apparently through a dense cloud, then shining behind, and round the edge of a black mass of cloud, which was shown in full distinctness and dark outline.

C. - I have often seen in summer evenings, gleams of lightning around the horizon, unaccompanied by thunder : it is called by some people, "summer lightning ;" does it differ in its nature from that which is followed by thunder?

F. - I believe not: the cause of the thunder's not being heard is, as I suppose, nothing more than its distance : light being visible at an incomparably greater distance than sound is audible. We sometimes see summer lightning at evening, even when the horizon-sky seems perfectly clear and cloud- 
less : in that case I presume we do not see the flash itself, but the illurnination of the atmosphere consequent on it; the reflection in the sky, as it is called ; the clouds containing the electricity being beneath the horizon, and therefore invisible.

C. - What an exhilarating freshness and purity there is in the air, this morning; similar to that which is perceived on mountain summits, or any great elevation.

$F$. - For this we are indebted to the trees and plants around us : all vegetables give out oxygen by day, the lifegiving part of the air we breathe ; but after the excitement of a thunder-storm, it is evolved in much greater profusion, which has a refreshing and enlivening effect on animal spirits.

C.- How delightfully fresh and green the trees and herbage look! the leaves are yet sparkling with the raindrops: see the long, seedy grass bowing its heavy head under the weight of moisture; what a silvery appearance it has! it is almost ready for the scythe.

$F$. - Let us climb this hill, whence we may look down on the lowlands and bottoms. - I should have rather said, we can look towards them; for I perceive they are hidden by a dense film of mist or fog, that lies upon them.

C. - What is the cause of its covering the land so partially?

$F$. When the rain fell last night, the earth had been heated to a considerable extent: much of the water was evaporated, and rose in invisible vapour, but now that the morning air is cool, the vapour is condensed, and falls in the form of a thick fog upon the low lands. Often during a season of dry weather, if we stand on a hill at early day light, we may trace the river through all its circuitous windings through the forest, (though no part of it is visible,) by the belt of white fog which hangs over it, but which is 
quickly dissipated by the beams of the sun. This phenomenon only occurs during the hottest part of summer.

C. - The farmer begins to see some promise of a reward for his exertions : the potatoes have been in blossom for several days, and so have the peas; oats and wheat are coming into ear. At a short distance beyond Sherbrooke, I saw a field of wheat in ear, as early as the 6 th of this month.

$F$. - A field of potatoes in blossom has, in my opinion, a very fine appearance, from the rich luxuriance of the vegetation; the dark green hue contrasting with the delicate lilac blossom. The regularity of the rows adds to the effect, if they are kept clean and free from weeds; but this is a difficult task, and requires a great deal of attention and labour.

C. - What are the chief weeds we have to contend with ?

F. - I have already mentioned the Canada Thistle (Cnicus Arvensis); but even that vile plant is not so bad as the Burrweed (Galeopsis Tetrahit), which is spreading over our fields, and ruining our farms. This is a vigorous plant, growing from a creeping root, which is, I believe, perennial ; though the plant is annual : it has a tall branchy stem, and leaves like those of a nettle; it bears a pretty white labiate flower, succeeded by large burrs or seed-vessels, covered, when ripe, with hard, sharp prickles, defying the touch. It produces seeds in most prolific abundance, which are unfortunately scattered before our grain is cut; and as it spreads from the root as well as the seed, there appears no way to eradicate it, but pulling up every plant. But in doing this, the root often breaks, and leaves a part in the ground, to become the progenitor of a new stock of weeds. Besides this, wherever this spinous weed grows with wheat or other grain, a great deal of the latter is obliged to be wasted, as it cannot be reaped; for no man can put his hand into a bed of burrweed with impunity. In short, 
though unknown a few years ago, it is now spreading with alarming rapidity, and laughs at our efforts to control it. Another pernicious weed is likewise becoming an object of some attention; though it has not yet attained the notoriety of the former. I allude to Spurry (Spargula Arvensis), so abhorred by some of our farmers, that they have given it the name of " devil's gut." It has a long, but very slender stem, trailing on the ground, with nodules about an inch apart, at each of which the stem forms an angle. The leaves and flowers are inconspicuous; the seed-vessels are numerous, globular, and about as large as peas: the stems trail a long way from the roots, and twine and entangle one with another. It chiefly infests new land; but I suppose the seed has been imported with other seeds from Europe. There, I have understood, it is sometimes sown for the sake of its herbage, which affords an abundant and nutritious food for cattle. These three are the worst weeds that infest our crops: we have many others; but they do not spread so rapidly as these, and can in some measure be kept under.

C.-Oh! what a beautiful bird is on that apple tree : his back is bright azure blue, and his breast reddish brown.

F. - That is the Blue Bird (Saxicola Sialis). It is not very common with us, but is a universal favourite wherever it appears. I have seen it here as late as the month of October, and have no doubt that it arrives from the south pretty early in spring, though I have not met with it at that season. It appears to frequent the clearing more than the forest, and to be rather familiar with man, and of a mild and confiding disposition. In the south I have seen them abundant ; but cannot add anything to Wilson's very minute and accurate account of their economy. His simple stanzas in honour of this pretty bird are so beautifully feeling, that I need make no excuse for repeating them to you. 
"When winter's cold tempests and snows are no more, Green meadows and brown furrow'd fields reappearing, The fishermen hauling their shad to the shore, And cloud-cleaving geese to the lakes are a-steering;

When first the lone butterfly flits on the wing, When red glow the maples, so fresh and so pleasing;

$\mathrm{O}$ then comes the blue-bird, the herald of spring, And hails with his warblings the charms of the season.

"Then loud piping frogs make the marshes to ring,

Then warm glows the sunshine, and fine is the weather;

The blue woodland flowers just beginning to spring,

And spicewood and sassafras budding together:

$\mathrm{O}$ then to your gardens, ye housewives, repair,

Your walks border up, sow and plant at your leisure ;

The blue-bird will chant from his box such an air,

That all your hard toils will seem truly a pleasure !

" He flits through the orchard, he visits each tree,

The red-flowering peach, and the apple's sweet blossoms ;

He snaps up destroyers wherever they be,

And seizes the caitiffs that lurk in their bosoms;

He drags the vile grub from the corn it devours,

The worms from the webs where they riot and welter;

His song and his services freely are ours,

And all that he asks is in summer a shelter.

"The ploughman is pleased when he gleans in his train,

Now searching the furrows, - now mounting to cheer him ;

The gardener delights in his sweet simple strain,

And leans on his spade to survey and to hear him ;

The slow ling'ring schoolboys forget they 'll be chid,

While gazing intent as he warbles before them,

In mantle of sky-blue and bosom so red,

That each little loiterer seems to adore him.

"When all the gay scenes of the summer are o'er,

And autumn slow enters so silent and sallow, And millions of warblers, that charm'd us before,

Have fled in the train of the sun-seeking swallow ; 
The blue-bird, forsaken, yet true to his home,

Still lingers, and looks for a milder to-morrow, Till forced by the horrors of winter to roam,

He sings his adieu in a low note of sorrow.

"While spring's lovely season, serene, dewy, warm,

The green face of earth, and the pure blue of heaven, Or love's native music has influence to charm,

Or sympathy's glow to our feelings is given,

Still dear to each bosom the blue-bird shall be ;

His voice, like the thrillings of hope, is a treasure ;

For through bleakest storms, if a calm he but see,

He comes to remind us of sunshine and pleasure !"

C. - Wilson had the true naturalist's enthusiasm: he appears to have lived in a world of birds, and to have viewed them in the light of intelligent and companionable beings : his earnest defences of their characters, and his frequent eulogia on their moral excellencies, prove this. They are certainly very fascinating little creatures. — A few days ago I saw a very showy little fellow, dressed in deep black and orange : his tail, in particular, was bright orange at the sides, and black down the middle: he was flying about the end of an outhouse in a garden.

F. - It was either the American Redstart (Muscicapa Ruticilla), or the Baltimore Oriole (Oriolus Baltimorus); your description applying pretty equally to both: but I rather suppose it might be the latter, for I have heard Americans speak of the Gold Robin as being found here, by which name they distinguish the Baltimore; though I have never observed it myself in this country. This bird is remarkable for its skill and ingenuity in the manufacture of its nest, which is pensile, hung at the end of a bough or twig, a bag of thick strong felt, about six inches deep, made of tow, flax, hair, wool, \&c. according to Wilson. I have no doubt of its being an inhabitant of this province, as it is spread over the 
whole of the United States; and I have myself seen it in Newfoundland.

C. - Red currants in the garden are ripe: and many garden flowers are now blown; which form a great attraction to the humming-birds. I see the brilliant little meteors glancing to and fro, very often; and stopping to suck the deep crimson flowers of the balm; the tail bent down, the wings vibrating, and the head almost buried in the corolla; yet not easy to be surprised.

$F$. There is a delicious berry now abundant in the woods, growing on a very low plant, scarcely rising above the ground: it is called here the Dewberry (Rubus Procumbens). In appearance it is much like the berry of that name in England, but is superior in taste, being of a pleasant tartness.

C. - Yesterday I found, in walking, some wild Raspberries ripe (Rubus Ideus); I think they equal in flavour your description of them. See : here are more.

$F$. - From this time forth, they will be daily ripening: and bushels will rot upon the ground for want of being gathered; although large quantities are collected, and either eaten as they are, or made into an excellent conserve. The bushes are extremely numerous on every road-side, and almost in every field, growing in the corners of the fences, springing up abundantly in ground recently cleared, and "burnt over ;" and invariably forming a great bush around every dead stump, or neglected $\log$ : so that we have no lack of this delicious fruit: and from its great abundance it is really no inconsiderable addition to our comforts. The strawberries are going out of date, but the raspberries are more than sufficient to supply their place.

C. - Timothy Grass (Phleum Pratense) is now in flower : the anthers look like little fragments of dust on the green 
heads: a field of timothy, or, as the people here call it, "herd's grass," has not the beautiful appearance which one of Redtop (Agrostis Vulgaris) has.

F.- Perhaps not, but it is more profitable; generally producing a greater weight of nutritive matter to the acre; and this is a subject to which a farmer is much more alive than their respective claims to beauty. Here is a fine flower, which possesses far greater pretensions than either of the grasses: it is vulgarly called Indian Wickup (Epilobium Latifolium); its leaves are large and lanceolate, and its tall and elegant pyramidal spike of pink flowers, continuing in blossom till late in autumn, would form no mean object in a garden. Long before the upper buds are blown, the lower flowers have yielded their place to long narrow pods, having a partition down the centre, and bearing winged seeds. This plant is common in Newfoundland; but not in such abundance as here: with us it frequently covers a large space of ground. The caterpillars of the Panthermoth (Spilosoma Acria), Royal Tiger (Arctia Virgo), and I believe of some other moths, feed on its leaves. Another handsome flower, the Orange-lily (Lilium Canadense), is now, and has been for some time, in bloom: the brilliant colour and the graceful drooping of the bell-shaped corolla, entitle it to our admiration. It grows commonly here, particularly in meadows near the river.

C. - Have you seen a thick-set bird, shaped like a sparrow, hopping about, of a bright rust-colour, slightly mottled with dusky brown? I saw three or four of them a few days ago on the ground, at the edge of the maple woods.

F. - I have not met with it here; but I am very familiar with the bird, as it is in Newfoundland one of the most common species. It is the Fox-coloured Sparrow (Fringilla Rufa); in its manners fearless and familiar, resembling 
the European house-sparrow. - What is new among the insect tribes?

C. - An Orange Comma Butterfly (Grapta C. Album?) has been evolved from the chrysalis in my possession, having been in pupa only seven days. I saw in the woods a few days ago, a very beautiful butterfly, which was new to me: I pursued it, but it alighted on the trunk of a tree, far up, out of my reach. Presently afterwards, I saw it again, or else another of the same species, which I succeeded in cap-

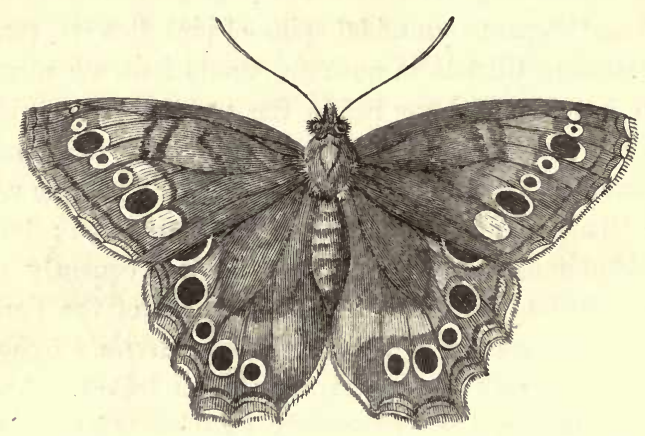

PEARLY-EYE.

(Hipparchia Andromacha.)

turing, and found it to be the Pearly-eye (Hipparchia Andromacha); the under surface is particularly beautiful.

F. - It is indeed a rarity. Say, if I mistake not, mentions it as being confined to the Southern States; and I have seen it in abundance there, but never have heard of its being found here before. In the south, I have known one frequent the foot of a particular tree for many days ; whence he would sally out on any other passing butterfly, either of his own or of another species, and after sundry circumvolutions, retire to his post again. Sometimes one of the same species, after 
having had this amicable tussle, would likewise take a stand on a neighbouring spot, and after a few minutes both would simultaneously rush to the conflict, like knights at a tournament, wheel and roll about as before, and each return to his Qwn place with the utmost precision, and presently renew the combat with the same result,-for very many times in succession.

C. - Another butterfly of the same sub-genus has appeared, the Eyed Brown (Hipparchia Transmontana).

$F$. - This is likewise described by the American naturalists as very rare, and as found only beyond the Rocky Mountains; but with us it is extremely numerous during the latter part of summer and autumn. The female is much larger and handsomer than the male, the eye spots being more distinct; but both are pretty. All the Hipparchiæ fly in a jerking dancing manner, alternately opening and closing their wings, usually not far above the ground or herbage: in this respect somewhat resembling the Skippers (Hesperia); but when alarmed, they vastly increase their speed.

C. - That large and fine butterfly, the Compton Tortoise (Vanessa $J$. Album), begins to appear, particularly in the grove-lane; it was one of the first butterflies we saw in the spring; but since that time I have scarcely seen an individual until lately.

$F$. - It cannot be said to be common at any season; but in the latter part of summer and autumn it is more frequent than at any other time. The individuals we now and then see in early spring are, no doubt, such as have been so fortunate as to survive the severities of winter: the same may probably be said of all the Grapte and Vanessa which appear at the same season. The Grey-veined White, Clouded Sulphur, and Spring Azure, are, I presume, but recently evolved from pupa when we see them. 
C. - On the public road, near the village of Compton, I caught a new butterfly, which exactly, even in the most minute particulars, agrees with the Forked (Vanessa Furcillata) in the hinder wings, and the under surface of all; but the first pair on the upper surface are black, with only a row of small, indistinct, and undefined red spots in place of the broad orange band: the bright fulvous spots on the front margin are wanting.

$F$. - It is probably not a distinct species, but only an accidental variety of $V$. Furcillata; or what is sometimes called a lusus naturce. The Banded Purple (Limenitis Arthemis) is beginning to grow scarce; but about ten days ago I observed as many as sixteen of this species crowded together on an old log by the road side; so close together as to be almost touching in every part.

C. - I have been out in the fields and borders of the woods lately, in the evening twilight, mothing, with some success. A large Bombyx, the Dragon-moth (Hepialus Argenteo-maculatus), was quite numerous; belonging to that division of moths called Swifts, or Ghost Moths : and I was surprised and pleased to observe the striking similarity, not only of shape and general appearance, but also of manners, to the English species of that family. They continue in one place, dancing from side to side on the wing, just above the herbage, within the space of a yard or two. A large female which I caught, on being pinned, began to eject her small white eggs with great rapidity, driving them to a considerable distance. Another time I heard a fluttering at the bottom of a raspberry bush, and on looking down saw a large insect: I threw my net over it, and on holding it up to the light, found that I had captured a fine female Twin-eyed Hawk-moth (Smerinthus Geminatus). I folded the net around the handle, and instantly ran home with the prize; but what was my chagrin 
on arriving, to find that it had escaped through a hole in the net ! I have obtained specimens of between thirty and forty new species of moths, of which I shall only mention such as are remarkable for beauty:-The Cœrulean (Ctenucha L $a$ treilliana), a pretty, rather slender Bombyx, has a golden yellow head, and the thorax and abdomen silky skyblue : the wings are of a purplish black. A Noctua, the Pink Arches (Thyatira Scripta), is one of the most delicately beautiful of the small moths that I have ever seen.

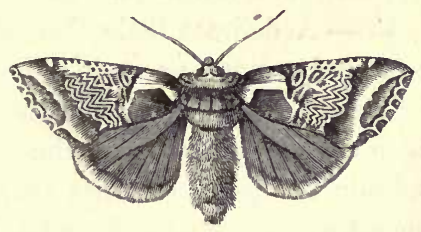

PINK ARCHES.

(Thyatira Scripta.)

F. - They are both rather common: the former I observed numerous about Quebec, particularly on the Heights of Abraham.

C. - The rich Twin Goldspot of Newfoundland (Plusia Iota?) is not uncommon; nor the Clifden Beauty (Xerene Albicillata) and Spotted Lemon (Angerona Sospeta), the last a bright-coloured little species, one of which laid a number of oval, green eggs while in my possession. I have also taken several specimens of a delicate Pterophorus, the Drab Plume. I have obtained many caterpillars lately by bush-beating; among which are two quite young ones of the Tiger Swallowtail, feeding on Basswood (Tilia Glabra); they are bluish grey at each extremity, and white in the middle; also several of the Vapourer-moth (Orgyia Antiqua), from Ash (Fraxinus Sambucifolia), Choke-cherry (Prunus Serotina), and Willows (Salix). From the Wild Gooseberry (Ribes Cynosbati), I took several spinous caterpillars, which are light-coloured, with dark transverse spots. One of them has since suspended itself by the tail, and 
become a chrysalis of a drab hue, tinged with green in some places; the pointed projections of the head curving towards each other.

F. - It is the larva and pupa of the Grey Comma (Grapta C. Argenteum), and will probably attain the perfect state in a few days.

C. - A delicate little Dragon-fly (Agrion — ? ) with a red body, may be seen in some numbers on fine days, sailing slowly over the spring in the pasture, occasionally resting with erect closed wings on the weeds and grass : and I have taken a still prettier species near the village, with the abdomen banded with black and bright sky blue alternately: (Agrion Puella). These are elegant little creatures.

$F$. - One would suppose that they are incapable of any long continued exertion; they appear so frail, and fly so languidly. Yet this may not be the case. Once, in coming through the Gulf of Florida, on a calm afternoon, on looking over the side of the ship, I was surprised to see close to the surface of the water, a little Agrion, much like the first you described, now and then alighting on the side of the vessel, then flitting off, and playing over the surface. We were then twenty miles from the nearest land, and the ship had not been within ten miles of land for many days, having been last lying in Mobile Bay, many miles from the town. At length it alighted under the counter of the ship, and I did not see it again.

C. - What are these curious excrescences growing on the bark of this old stump?

F. - They are a species of Fungus (Boletus Igniarius), called the Hoof Boletus, from a resemblance which they often bear in shape to a horse's hoof: they may be seen from the size of a walnut to a foot or more in diameter, varying in 
colour, above, from dull white to bright polished brown, like mahogany. They grow on many trees, but seem chiefly to affect the birch : they are also very frequently found on the underside of upturned roots. From the elevated ridges on the surface, forming parts of concentric circles parallel with the edge, it would appear that they grow not by gradual increase of the whole, but by additions to the outer margin. Let us examine the structure of one of them, which we shall find very curious. The upper part is of a tough leathery consistence, often becoming hard and woody ; the under part consists of a congeries of long capillary tubes, parallel with and close to each other, fixed on the under surface of the pileus or covering, and proceeding downwards at right angles to it. These tubes, though minute, are so straight, that if you cut off a piece of this part, and hold it up towards the light, slowly turning it, the light will suddenly flash through them, when the orifices come opposite the eye, as through a spy-glass. This mass of tubes is elastic, and capable of taking up and holding a large quantity of water, like a sponge. This Boletus constitutes the food of some beetles; if we examine more, we may probably find some.

C. - Here are some; they are monstrously ugly; they are nearly square, of a dark earthy brown colour, and covered with rough, irregular prominences and depressions. Some of them have two projecting incurved horns on the thorax; others have only slight prominences in their place.

$F$. - From their roughness, colour, shape, and sluggish motion, I call them Toad Beetles (Bolitophagus Cristatus): when molested, they draw in the antennæ and legs, and lie as if dead; and certainly in that position it would require an experienced eye to tell that they were living creatures at all.

C. - Here are some large hollows in the porous part of 
the fungus, containing white maggots, and one or two pupæ : do these produce the beetle?

$F$. - Yes : for I once reared one of these pupæ to the perfect state; the toad-beetle was produced on the 19th of August; I had taken it in pupa on the 5 th ; how much longer it had been in that state, I have no means of ascertaining. The habit which some insects have of counterfeiting death, is a singular and inexplicable one. Very many genera of beetles have this practice: when they are touched or disturbed, they suddenly draw in their antennæ and palpi, and gather up their legs and feet close to the abdomen: some species have hollows in the abdomen, in which the legs lie on such occasions; and that so closely, one part fitting in with another, that the eye can scarcely discover them, the whole appearing a smooth surface. The antennæ are generally hidden beneath the clypeus, or shield of the head; but those of most of the Curculionida, which are situated on the end of a long rostrum or snout, have the first joint much elongated, at the end of which they can be doubled up, the two portions lying parallel with each other, and so close to the side of the rostrum as to be invisible. It has been said that insects on these occasions will allow themselves to be roasted to death over a fire without moving, but my own observation does not agree with this: I have invariably found that the application of heat caused them to sprawl out their limbs pretty quickly. It may, however, be different in some instances.

C. - Has any motive been assigned or conjectured for this habit?

$F$. - It is thought that it may be for the purpose of escaping detection; as the projecting limbs, and still more the motion of insects often cause them to attract notice, when otherwise they would be overlooked. It is true they do not feign death unless they are actually touched, but 
they may often be accidentally touched by birds, \&c. before they have been observed. Yet nineteen times out of twenty I should think this artifice would fail to deceive the sharp glance of an insectivorous bird. The manis, armadillo, and hedgehog, when alarmed, roll themselves up into a ball : but in so doing they protect their vulnerable parts, exposing only a surface of sharp spines, or a coat of mail, which effectually secures them from injury. But I do not know that the beetle is a whit better defended from violence, by having its limbs wrapped up, than before. Besides, many other genera, and those fully as subject to attack, are not provided with any such stratagem. On the whole, I cannot but think that the end to be answered by this artifice is unknown to us at present; but that it is intended for some useful purpose, and that such object is actually accomplished by it, the acknowledged power and wisdom of God forbid me to doubt.

C. - Do you not perceive a strong rank smell?

$F$. - Yes : I have smelt it some time : it is the odour of a skunk (Mephitis Americana), a small animal of the weasel tribe. Its colour is black, with a white stripe down each side; the tail is large and bushy. The fur of this animal is very soft and valuable; but its powers of defence are so great that it is seldom molested. These consist wholly in the ejection of a peculiar fluid, so intolerably offensive, that neither man nor beast can withstand it. It pervades the whole atmosphere to a great distance around, and where the animal has been killed, the odour continues to be diffused for many weeks. I once contracted a greater intimacy with this creature than I desired: I did not then know its powers. He was rather a pretty fellow to look at, but he did not by any means improve on acquaintance. It was standing but a few feet distant from me, on the other 


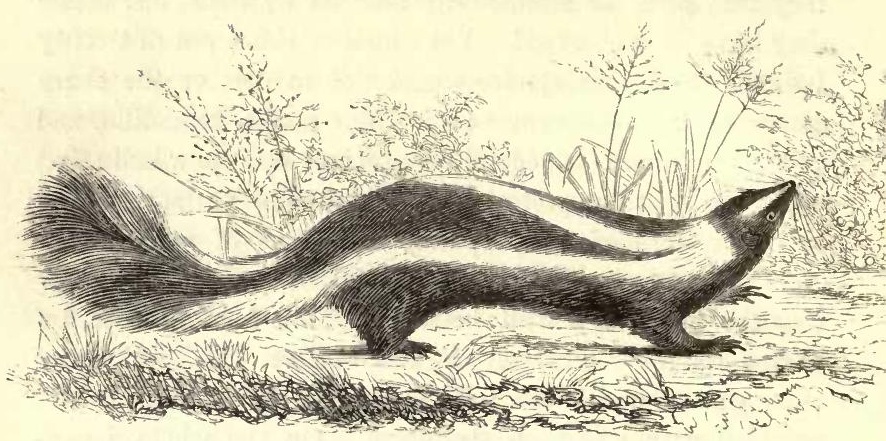

SK UNK.

side of a low fence. It did not attempt to run, but stood looking away from me, without any appearance of fear, its tail elevated over its back. I did not molest it, but looked at it with curiosity and pleasure, when suddenly a jet of this singular liquid was darted through the air from it, over my face and breast. For some moments the effects were insufferable; the smell is unlike other smells; not altogether fœetid, but so pungent and overpowering as to cause a sensation of fainting. I left the scene at once, but wherever I came, I brought the odour with me. By repeated washings I removed it from my face, but no washing could free the bosom of my shirt from the abominable taint. Some of the neighbours told me that nothing would remove it, but burying the garment for twenty-four hours in the earth : this I did, but to make assurance doubly sure, left it there several days; on taking it up the smell was eradicated, but the mildew had taken hold of it, and spoiled it. Since then I have avoided intruding on the privacy of a skunk. I have been told that they frequently haunt cellars, but do not emit the offensive liquid unless irritated: that they are fond of 
being caressed, and may be tamed without any bad smell attending them; but I should think them dangerous pets, for a house in which the odour is emitted, is rendered uninhabitable for a long time. I have likewise been informed that if the animal be suddenly seized by the tail, and held up in the air, it has not the power of ejecting this fotor, and may be killed without trouble or offence; but this I give only on the report of others. It lives on birds, and other small animals; and often makes great devastation among the poultry.

C. - I have just taken a pair of large and very handsome beetles crawling up a tree : the head and thorax and half the elytra are of a brilliant blue; the fore-half of the elytra, rich golden yellow: the joints of the antennæ are large and conspicuous. Is it a common species?

F. - It is the Blue and Gold Cerambyx (Desmocerus Cyaneus), and is described and figured in the "Naturalist's Library," where it is said to be a native of India. It is by no means uncommon with us through the autumn. The colours of this large and showy Cerambyx remind me of a very large species of Whame-fly (T'abanus Affinis?), which I caught in the act of sucking my horse's blood: it was altogether black, except three or four segments of the middle of the abdomen, which were bright orange yellow. I noticed, also, at the same time, another species of the same tribe, strange to me, which was black, with white triangles down the back (Tabanus Zonalis?).

C. - I picked up, while you were speaking, this pretty little Cicindela ; it is dark sea green, covered with punctures.

F. - It is rare and curious : I believe it is Elaphrus Intermedius, not a Cicindela. Here is a bed of plants, which will be the means of increasing your entomological cabinet; as it is a constant resort of many species of insects, by night and day. This is the Sweet-scented Milkweed (Asclepias 
Syriaca), a beautiful and fragrant flower. I have observed the first appearance of its blossoms for two years on this day. It usually grows in large groups or beds; and is a tall plant, as you see, with large broad oval leaves; when broken, a white glutinous fluid exudes, whence it, with other plants, has acquired the name of milkweed. The flowers which, as you perceive, grow in large close heads, are very curious in their structure: the order to which they belong is "known from all others by the single character of its grains of pollen adhering together within a sort of bag, which occupies the whole of the inside of each cell of the anther; and when it falls out, sticks to glands of a peculiar character occupying the angles of the stigma." Besides this, the anther and the stigma adhere firmly to each other. A large Sphinx, the Zebra Hawk-moth (Sphinx Kalmia), resorts to these flowers in considerable numbers, during the warm evenings; and many smaller moths. The Zebra Hawk I have invariably found as soon as the milkweed is blown, but at no other time, and on no other flowers. You may, no doubt, see some there this evening, soon after the sun has set. The flowers of this plant are succeeded by large spindle-shaped pods, (that is, thick in the middle and pointed at each end,) about three inches long, containing many rows of flat round seeds, lying imbricated one upon the other, attached to a pithy substance that runs through the centre, the placenta; to each seed are affixed long silky filaments of down, which, when ripe, act the part of wings to convey the seeds on the wind, and scatter them in different directions.

C. - Many plants have downy seeds : those of the common dandelion (Leontodon Taraxacum) are very regularly and beautifully arranged.

$F$. - The modes by which the seeds of plants are transported about, are exceedingly various, and well worthy of attention: and perhaps none are more so than those of syn- 
genesious plants, most of which have a downy egret, as the dandelion, thistle, groundsel, \&c. I do not know a prettier sight than a dandelion seed floating along beneath its feathery plume on a gentle breeze: now erect, now lightly waving to one or the other side, yet still keeping its position, like the car of a miniature balloon; till at length it slowly descends, and fixes itself in some crevice of the earth, there to be nourished, far enough from its parent flower. Some seeds have attached to them a broad thin blade, (samara,) as the ash, maple, \&c. which forces them obliquely through the air, instead of perpendicularly : others are jerked to a distance by a peculiar mechanism in the seed vessel : others are carried to distances in the stomachs of birds, their vegetative power increased, rather than destroyed, by the process of digestion. All show a power at work, to which the wisdom of man is foolishness. 


\section{XVII.}

\section{AUGUST 1st.}

Zebra Hawk-moth-its resemblance to a Humming-bird.-Grey Hawkmoth.-Beautiful Noctuæ.-Eggs and Larvæ of Zebra Hawk.-Diurnal Insects. - Conops. - Six-spotted Blue Hawk-moth.-Great spangled Fritillary.-Camberwell Beauty.-Archippus Butterfly.-Clouded Sulphur.-Canadian Pearl-fly.-Humble-bee Hawk-moth.-Scarlet-fly.Sheep Gad-fly.-Horse Gad-fly._Humble Bees' Nest.-Hay-making.After-grass.-Meadow Frog.-Bull Frog.-Toad.-Tree Frog.-Jerboa - Becomes torpid in Winter.-Field Locusts.-Rattling Locust.Wasps' Nest.-Hair Grass.—Virginian Deer-its Grace and BeautyWide Locality-Timidity-Artifice.

Charles. - I have found the blossoms of the Milkweed (Asclepias) very productive of lepidopterous insects. The large Zebra Hawk-moths have been very numerous: I caught on one evening eight, and on another seven of them, and saw many more. What a very striking resemblance exists between these hawk-moths and the humming-birds! their straight, arrowy flight, their sudden arrest in front of a flower, the rapid vibration of their wings, the insertion of their long tongue, the glancing of their bright eyes, their loud hum, their jealous alarms, and even the shape of their bodies, and their size, are so exactly a counterpart of the Ruby throat, that at first one is tempted to think it is actually a humming-bird protracting his nectar-seeking excursions into the night. Among these flowers, almost immediately after sunset, we hear a loud humming, and looking to the 
spot, see the large moth suspended on the wing in front of a blossom; presently one is seen in another direction; then another, and another; and the small moths begin to swarm, and hurry from flower to flower, seeming to increase with the increasing darkness, until the eye fails to follow them, but still dimly sees the swift-winged hawk-moth, directed by the more acute perception of the ear. They are large and thick, though of a graceful shape, and possess considerable muscular strength; I have had them actually within my fingers, yet have failed to hold them, as they have forced their way out by the mere strength of their wings. On almost every one that I caught, there were little soft clubshaped filaments, about one-sixth of an inch long, projecting from the head, generally from the eyes: do you know what they are?

FAtHer. - They are parts of the milkweed blossom, which adhere to the head of the insect, when eagerly sucking the nectar, and come away with it. I was much at a loss myself when I first observed them, but having seen the same substances, in the south, attached to the heads of Swallow-tailed Butterflies (Papilio) which I had taken in the act of sucking an allied species, the Orange Milkweed (Asclepias Incarnata), I had no longer any doubt of their origin. They are the little bags of pollen, that I mentioned before, which are found within the anthers.

C. - Among these I have taken another species, somewhat resembling them, but not nearly so pretty, the Grey Hawk-moth (Sphinx Cinerea); this appears rare. I have netted also some very beautiful Noctua, the Twin Goldspot, (Plusia Iota?) the Gold and Silver, (P. Festuca?) the Green Gold ( $\boldsymbol{P}$. Chrysitis?), and the Spangled Orange (-?); the last two exceedingly splendid: the Royal Tiger Moth (Arctia Virgo), a handsome Bombyx, is become common. 


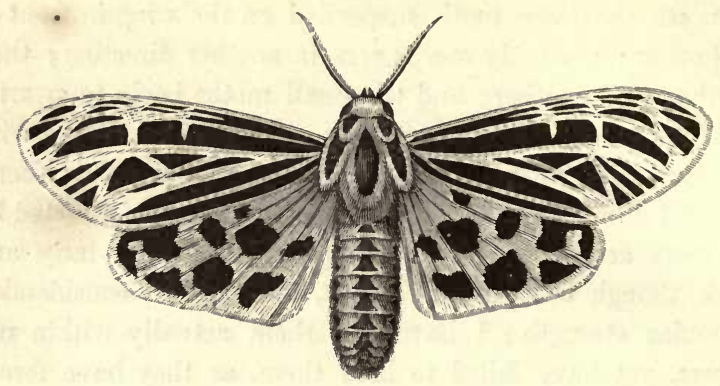

ROYAL TIGER-MOTH.

(Arctia Virgo.)

$F$. - The lustre of the spots and marks on many moths and butterflies, rivals the glitter of the precious metals: the silver spots on the wings of the Spangled Orange moth are exactly like those on some of the Fritillaries.

C. - Some of the Zebra Hawk-moths, which I enclosed in a box, laid several eggs, which were round, rather flat, pearly white, of about the size of a small pin's head. They were not deposited all in a place, like those of a Phalcena, but singly, all about the box, slightly stuck on. In about seven days they produced the young caterpillars, which, when hatched, were about one-fourth of an inch long, all white, except the anal horn, which was black, straight, and half as long as the body. Not knowing their food, I tried them with a great variety of leaves, and at length found that they would eat those of the ash ; and I afterward found a solitary egg of this kind attached to the leaf of an ash tree. I suspect the caterpillars would have very materially altered in form and colour, as they became mature; but I had not the satisfaction of proving this, as every one died in a day or two after being hatched. 
$F$. - Have you examined the Milkweed by day, as well as in the twilight of evening?

C. - Yes ; I have found it on sunny days swarming with insects of all orders ; many day-flying moths frequent it, and different species of flies and bees. I took from it a dipterous fly, very much resembling a Sphex in shape; the abdomen clubbed, or subglobular, and joined to the abdomen by a slender petiole: the head is large; and the mouth has a projecting tube, like that of a gnat (Conops Rufipes?). I also took a little Cerambyx, black, with bright yellow curves on the wing cases (Clytus - ?): and a pretty little Sphinx, the Six-spotted Blue Hawk-moth (Alypia Octomaculata). But it is chiefly the resort of crowds of butterflies of almost every species that is now about; but more particularly the Fritillaries; of which a large and handsome species is numerous, the Great Spangled Fritillary (Argynnis Cybele).

F. - This much resembles the Silver-spot (Argynnis Aphrodite), and for a long time I supposed it to be the female of that species; but having seen the latter in coitu, I am convinced they are two distinct species: the Great Spangled being distinguished from the other by its superior size, brighter tint of colour, and by the less number of black spots on the wings.

C. - I have seen the Camberwell Beauty (Vanessa $A n$ tiopa) about, within a few days. This noble butterfly has not been seen before, to my knowledge, since the first days of spring. The Tiger Swallowtails have disappeared about a fortnight. A Grey Comma (Grapta C. Argenteum) has been evolved from the chrysalis I mentioned to you, having been in pupa thirteen days. I saw, the other day, a very fine butterfly, the Archippus (Danais Archippus); the largest species I have yet seen. It fluttered along slowly 


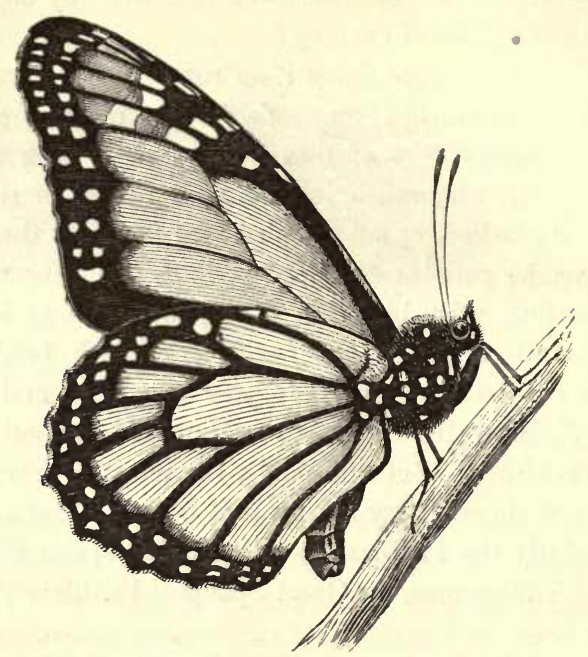

ARCHIPPUS.

(Danais Archippus.)

and fearlessly, often alighting very near me, so that I at length caught it.

F. - This fine butterfly is said by the American naturalists to be unknown north of Virginia; it is rather rare here; though I have seen as many as half a dozen in a season: in some seasons, however, I have not met with one specimen. They often fly at a great height in the air.

C. - We spoke some time ago of the habit which some butterflies have of congregating together. I observed, a few days ago, on the public road, great numbers of the Clouded Sulphur (Colias Philodice) in flocks of eight or ten, pitched on the patches of wet slushy mud; they were so closely 
set together as to make yellow spots, visible a long way off. These little flocks continued at intervals for some miles.

F. - A very large species of Hemerobius, the Canadian Pearl-fly (Chauliodes Pectinicornis),* was given me yesterday : it measures three inches and a half in spread of wing: the jaws are curved and sharp; the antennæ strongly pectinate; the wings tinged with pale brown, the nervures spotted with black; they are netted, but the cross nervures are few. I caught a pretty Sphinx, busily hovering over some

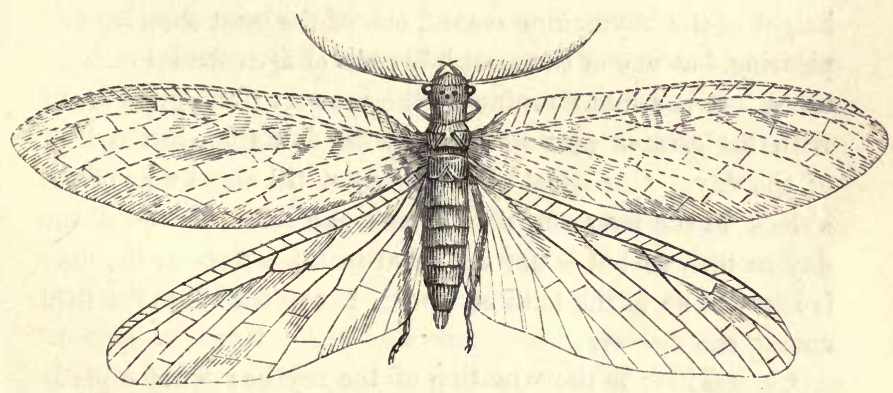

CANADIAN PEARL-FLY.

(Chauliodes Pectinicornis.)

tubular flowers in a friend's garden, during the heat of the day; the Humble-bee Hawk-moth (Sesia Pelasgus); the wings are reddish brown, with hyaline disks. It is rare, as I have never met with it before.

C. - Two or three specimens of a curious Musca ( Tachina - ?) have occurred lately: the abdomen is large and round, of a scarlet colour, covered with strong upright spines or bristles. I have also taken the Sheep Gad-fly

* This fine insect, I should state, the only living specimen I ever saw, was not taken in the neighbourhood of Compton, but at Quebec, on the 30 th of July, 1835. 
(Estrus Ovis); and the Horse Gad-fly (Gastrus Equi) is quite common. In hoeing potatoes lately, I laid bare a curious scene of domestic economy. It was a Humble-bees' nest, about an inch below the surface of the earth, and contained two bunches of yellowish oval sacs, each containing a pupa; about a dozen in all. Twenty or more bees of different size and appearance, but I suppose all of the same species (Bombus Terricola?), flew about, very much alarmed at the destruction of their household.

$F$. - All our neighbours are now very busy; it is the height of the haymaking season, one of the most cheering and pleasing, but one of the most laborious of agricultural occupations. It is a fine morning for the mowers ; the grass is cut with far greater ease while wet with dew than in the heat of the day. Our usual plan is to mow till about nine or ten $o^{\prime}$ clock in the forenoon, then spread and turn it: and if the day be fine, so hot is our sun, that in the afternoon the hay is ready to go to the barn or stack. Let us walk into the field among the mowers.

C. - There is the whetting of the scythe: what a peculiarly rural sound that is! how connected with pleasant fields, snug cottages, merry peasants, and bright "skies. How beautifully smooth and green the closely shaven meadow looks, from which the hay has been cut and raked: very different from the pasture, where many brown heads and coarse tufts and rank weeds destroy the uniformity of the appearance.

$F$. - The short young grass which escapes the scythe, is very agreeable to cattle, and we always turn our stock into the fields immediately after mowing; a practice which I believe does not so generally prevail in England, where the ground is usually so level and smooth, that the scythe goes very close to the surface. In our rough fields, much grass is left in the hollows, and about stones, stumps, \&c. which the scythe cannot reach. 
C. - I see several frogs hopping about among the grass.

F. - Yes : this species, the Meadow Frog, (Rana Halecina?) is fond of lurking in the long grass, whence the mower disturbs it: it is very handsome, if we are divested of that nursery prejudice which looks on every reptile as ugly and abominable ; its limbs and upper parts are whitish with large irregular spots of dark olive-brown, and the whole under parts are bright orange red. I have never seen it near water.*

C. - What is this curious circular organ, like a round scale, on each side of the neck? I observe it in all frogs.

$\boldsymbol{F}$. - That is the organ of hearing. Frogs have no external ear, but this round membrane which you see, is the tympanum or drum of the ear, tightly stretched over the auditory canal.

C. - What other species of this genus have we?

F. - There is the great Bull-frog (Rana Pipiens), so called from its deep hollow voice, resembling the short bellowing of a bull; it is of a fine green, spotted with black. It resides chiefly in water, and may often be seen sitting in a shallow pool, with its muzzle just out of water ; continuing in the same position without the slightest motion for hours together. Then, I believe, there is another smaller species, inhabiting the marshes, of a dusky brown colour, but whether this is the young of either of the others, I am not certain. (Rana Clamatis?)

C. - I have seen in the summer evenings a large toad in the garden, and near the house, covered with large reddish brown warts and excrescences, adding by no means to the beauty of its appearance (Bufo Cognatus). Its solemn look as it sits upon a stone, sucking in its throat, and

* I am almost sure this is not Halecina, but I cannot find in Dr. Harlan's paper on the Reptiles any other to which it bears any resemblance, though it must be found in New England.-P. H. G. 
its awkward attempts at hopping when it moves, do not tend to render it a general favourite, any more than its personal beauty.

$F$. - These are all the species that I can mention as common; but there is another which I suppose to be quite rare, or, at least, seldom met with. About this time last year, I saw on a raspberry bush a small frog, about an inch and a half long; as near as I can recollect, it was of a pale brown or drab colour ; it was very active, leaping from leaf to leaf. It attracted my attention by its unusual situation, and by the tenacity with which it clung to the leaves, always adhering where it alighted, without any struggling or falling off, however inclined the surface might be. I caught it, and observed that the ends of the toes were furnished with round, dilated, membranous suckers; from which circumstance I have since discovered that it was a Hyla, or Tree-frog (Hyla Versicolor). While I was holding it in my hand, it leaped to the bush; and though I searched long and anxiously, I could not again find it. I did not then know that they generally adhere to the lower sides of the leaves and branches, which may be a reason why they are so seldom seen.

C. - See, see! there is a little animal leaping like a kangaroo through the grass.

F. - It is the Canadian Jerboa, or Deer-mouse, as it is called here (Gerbillus Canadensis); and a beautiful, agile little creature it is. It is of a bright fawn colour above, and pure white beneath: the hind legs are much longer than the fore ones, and it usually moves by long leaps, as that which you have just seen; I believe, however, they put their fore feet to the ground when not disturbed: the tail is very long. They are often seen in mowing and in reaping: I have 
known them caught in June, and as late as the last of September. A friend of mine, once working in his field, felt something between his trowsers and his thigh, which proved to be a deer-mouse, having run up his leg; he caught it, and gave it to me. It appears to become torpid during winter: my friend, Mr. H. Bill, has informed me that once, when digging up earth to cover a potato pit, he exposed two deermice in a little cavity, about eight inches below the surface of the ground: they were stiff and motionless, but were sleek, and did not appear dead. He carried them into his house, and in the warmth they revived. There was no appearance of a nest, nor any hoard. It was late in the season, as the ground was partially frozen : probably in the month of November.

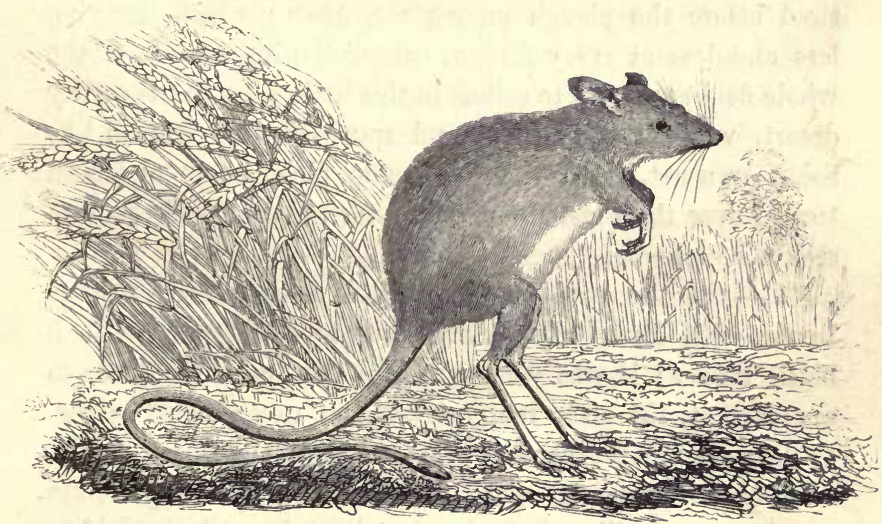

DEER-MOUSE.

(Gerbillus Canadensis.)

C. - I perceive a large green grasshopper abundant among the grass, which I have not observed before.

F. - This is more properly a Locust: I believe those 
Grylli with straight wings, having long setaceous antennæ, are generally called grasshoppers; and those with short stout antennæ, locusts; those whose wings are flat on the back, and lap over each other, are called crickets. None of the species are usually seen in the perfect state much before this season: those which are met with, among the herbage, are in the earlier stages. This field locust is a clumsy, thick species, and its motions are rather heavy. It is extremely numerous in our grass fields, and probably the aggregated individuals in one field consume no small quantity of herbage. In ploughing round a triangular piece of green sward, I have been amused, as I gradually drew near the end, to observe the hosts of these field locusts crowded together on the constantly diminishing little spot of grass in the centre. They would not stay on the furrow, but continually retired before the plough among the grass; which, growing less and less at every furrow, caused the inhabitants of the whole field gradually to collect in this little oasis in the earthy desert, where they kicked, and sprawled, and leaped, like fishes in a net, until the inexorable ploughshare at length turned over their last fragment of turf, and obliged them to seek a new home.

C. - On the road to Compton, I have noticed a large locust, with dusky elytra, and bright yellow wings with a black border; it was very watchful, not permitting me to approach it, till after many trials and much manœuvring. It flies short distances, and often remains stationary on the wing over a particular spot; and while on the wing, makes a noise exactly like that of a watchman's rattle in miniature.

F. - I know it well, and call it the Rattling Locust. (Edipoda Sulphurea?) It is singular to observe the predilection which some insects have for particular places. A spot on the road to the village, at the foot of a hill, a little 
beyond Spafford's bridge, is the "beat" of this Gryllus. I have occasionally, but rarely, seen a straggler in other places; but there, on every fine day through the autumn, they are almost sure to be seen and heard, season after season. You may drive them before you a few yards, but they will not go far, neither are they willing to leave the road; they will presently find means to slip by you, back to their boundary again.

C. - Why have the mowers left yonder little plat of grass uncut, with a stone in the centre?

$F$. - That is not a stone, although it looks so much like one, as you would find to your cost if you planted your foot on it. The mowers have cut as near as they durst approach to it, for it is a Wasp's nest (Vespa Marginata), and full of very irascible and formidable subjects, who are not to be assaulted with impunity. These large round nests are generally attached to a stone, often nearly covering it, and cannot easily be distinguished from it. They are made of a tough whitish paper, manufactured by the wasp, of the minute particles which she abrades from weather-beaten wood, and agglutinates with saliva, spread out into this thin form. This nest consists of several layers, convex above, and projecting at the edges to shoot off the rain from the comb within, which is made of the same substance, and contains young and pupæ. You may observe numbers of the wasps coming and going, and crawling busily about the nest, the entrance to which is beneath the edge: they are yellow, with black bands.

There is a curious grass now in flower, the Hair Grass, (Trichodium Laxiflorum), remarkable for its delicacy of form ; it is a tall species, and much branched, but scarcely thicker than a hair. See, here are tufts of it ; but it is most abundant in the field by the bridge, affecting a low moist situation. It said to be valuable in an agricultural view. 
C. - There is some animal in the oat field: don't you see its brown back above the tops of the grain?

F. - Ha! it is a Deer (Cervus Virginianus); they often come out of the woods to feed on the standing grain at this season : but it is not very usual for them to come in the daytime. Let us approach cautiously, and we may get a view of it without alarming it. They are very fond of salt, and I have been told that farmers sometimes sprinkle a little about the place where they have been seen, so that if they return and find the salt, they may be induced to repeat their visits to the spot, while the farmer lies in wait with his rifle.

C. - It has taken the alarm. How jealously it looks round! and now, there it goes off to the woods. How graceful its motions are! it does not run, but proceeds by light bounds :-now it is lost in the forest. It is a doe, as it has no horns.

$F$. - This species is found from the St. Lawrence to the Gulf of Mexico. - I once saw a young tame one in the State of Alabama, which was allowed the range of a large field, and would often come to the house, and prance about the lawn. I could not help admiring the beauty of the animal, and the grace of every motion. It would approach me if I stood quite still, stretching out its pretty head, and taper neck, towards my hand; but it was so extremely timid, that at the slightest stir, its whole body and every limb would start, and on the least motion it would bound away, then stop, and turn, and look again. When standing still, it would be continually starting in this way, and when it trotted or walked, it lifted its little feet so high, and bent its slender limbs as if motion itself were a pleasure. It would occasionally stand a few moments, with one fore-leg bent up, the hoof nearly touching the belly. Its long and graceful ears were almost ever in motion, now directed forwards, now backwards, now erect, to catch the slightest sound. The large swimming black eye 
reminded me of the descriptions of that of the gazelle, which I should think can scarcely be superior in beauty and softness. It usually carries its neck upright, and there is a fairy lightness and elegance in its whole appearance, which make it the prettiest of pets.

I have been informed by a neighbour that he once shot a deer, which was running up a very steep hill : after receiving the ball, it continued to run twenty or thirty yards, when it gave a vast bound sideways, and dropped dead. On examination, the ball was found to have passed through the centre. of the heart. It is no uncommon thing for deer, when pursued by scent-hounds, to leap aside from their course into a thicket, in hopes of lying concealed till the dogs pass by. They are said to shed their horns in spring, and to have an additional prong ( $I$ believe to a certain limit) every year. During summer the horms are small, and covered with a velvety skin.

C. - It seems a pity to kill such gentle, inoffensive animals, as their occasional trespasses are not worth mentioning.

$F$. - I have known as many as seventy deer killed at a single hunt, in the south: this appears to me a useless waste; the dominion over the inferior animals being given to man for the supply of his necessities, or for his protection : certainly not for the wanton destruction of animal life. But " might makes right" is too often the maxim acted upon, if not acknowledged. 


\section{XVIII.}

\section{AUGUST 16тн.}

Decayed Trees. - Remains of Insects. - Musty Chafer.-Smooth Chafer. -Julus.-Touch-me-not.-Indian Hen.-Sand-wasp.-Evolution from Pupa of Insects with petioled abdomens.-Beautiful Contrivance.Red Fox. - Green Grasshopper. - Furbelow-moth.-Green Comma Butterfly. - Sirex. - Y ellow-belted Hawk-moth. - Lizards. - Minute Day-flies. -Violet-tip Butterfly. - Sphinx Caterpillar. - Sex of Larvæ and Pupæ.-Fine Echo._-Snakehead.-Wild Chocolate.-Chokecherry. - IndianWickup._False Sunflower-Mullein. - Rainbow.

Charles. - Yesterday morning, I took an early walk to the maple woods, where I spent an hour very pleasantly. There was a large but quite decayed tree, which I almost pulled down piecemeal. The trunk was pierced with many holes, and in nearly every hole were the remains of a Sirex, almost gone to dust, except the crustaceous skin; a large black and yellow species, resembling $S$. Gigas. I found remnants of many kinds of beetles, some too far gone to be identified; but I recognised a Buprestis, and a shining red beetle. (Platycerus Placidus?) There were several oval cases, as large as pigeon's eggs, containing the exuviæ of beetles, and in one I found a lamellicorn, complete but decayed. I afterwards took from an elm a living beetle of this species (Gymnodus Rugosus), which in size and shape much resembles the Rose Chafer (Cetonia Aurata), but is of a dark reddish brown colour: the elytra rough and striated. A strong and offensive musty smell came from it; and it made a slight creaking sound when held in the fingers. 
FAtHer. - I lately caught an allied species, but considerably larger, of a smooth shining black, but like it in other respects (Gymnodus Drakii). It was in the dusk of the evening, when it came buzzing round the verandah, and at length alighted at my feet. But go on with your forest researches.

C. - I found, in another rotten tree, several specimens of a large Julus, or " thousand legs," three inches long, and a quarter of an inch in diameter: it is of a dark purplish red, slow of motion, and, when touched, coils itself up in a circular form, the head in the centre.

F. - This insect (Julus Marginatus) is considered by the American inhabitants as being highly poisonous if taken into the stomach: I have been told of instances in which a person has accidentally bitten one, and has hardly escaped death.

C. - There were many groups of a pretty flowering plant, bearing numbers of hanging blossoms, shaped somewhat like a cup, with a long curved tube at the bottom, of a bright yellow, with red spots. Hearing a loud hum, I looked round, and saw a beautiful Humming-bird poising itself before these flowers, inserting its bill for an instant, then whisking to another like lightning; while I stood motionless, it approached and sucked flowers within a yard of me, but on the least motion it was off to a distance.

F. - The flower is the Touch-me-not (Impatiens nolitangere); it grows in considerable quantities in wet situations, both in woods and in open places. It is a favourite resort of the Ruby-throat, numbers of which may be seen about a cluster of these flowers on almost every bright warm day. They do not blossom much before this period. 


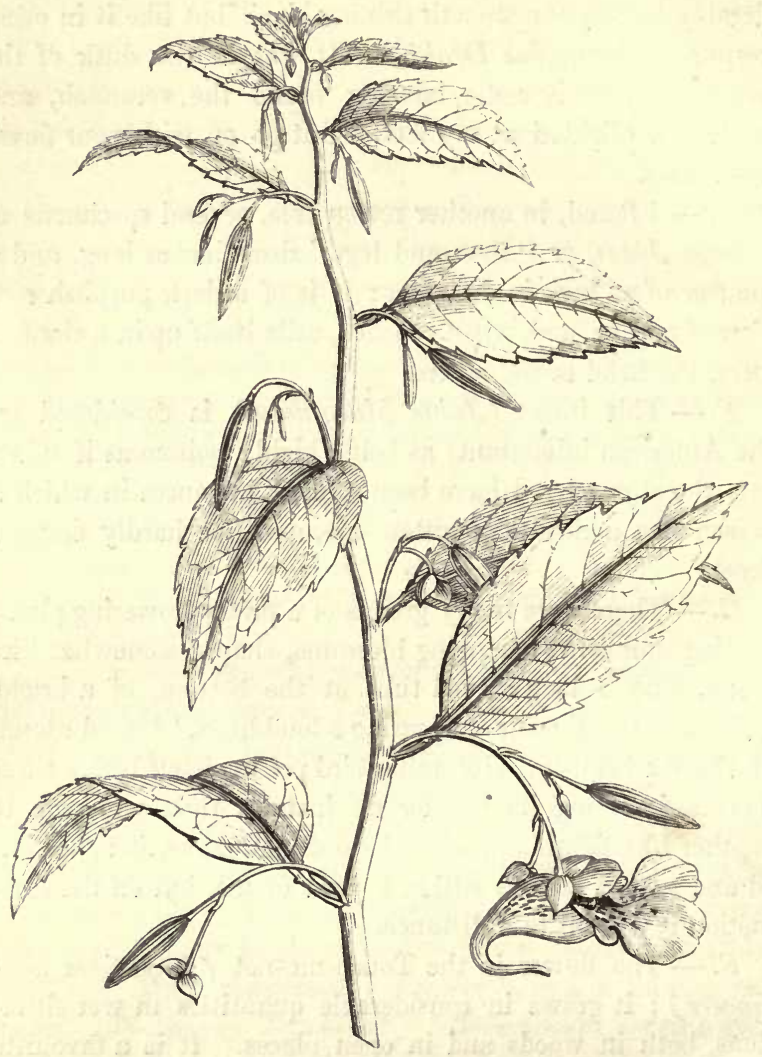

TOUCH-ME-NOT.

(Impatiens noli-tangere.)

C. - I observe a singular bird on the top of that scathed hemlock: do you know what it is? 
F. - It is the Indian Hen, or American Bittern (Ardea Minor). It looks very small; but when its wings are extended, it measures nearly three feet and a half from tip to tip, and three feet from the bill to the toes : it is, however, of a slender form; the neck and legs being long, but the body small. The head is remarkably flattened, and gives the bird a very singular appearance: the feathers of the neck are long and loose, and capable of being erected: the general colour is dark brown, spotted with yellow, on the back; and yellowish, spotted with brown, on the belly. As you see it

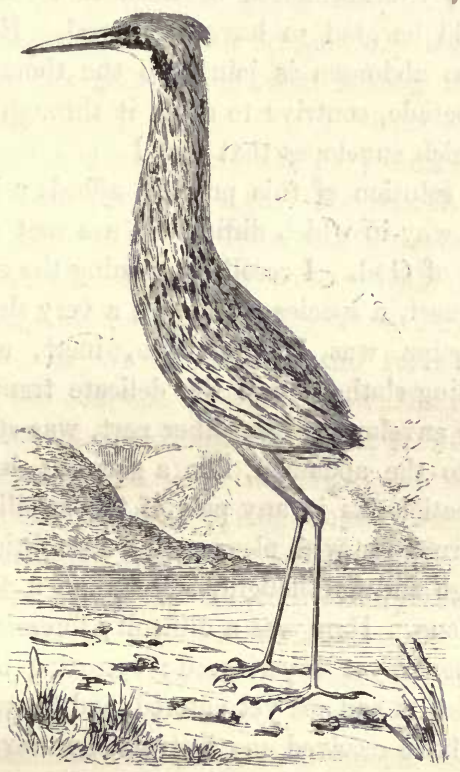

INDIA HEN.

(Ardea Minnr.) 
now, the long neck is drawn back, the head resting between the wings, its usual mode of reposing; but it frequently pokes out its neck to see what is going on. It flies with a flagging motion; and as it slowly rises to flight, and unfolds its great pinions, we are startled to see such an expanse of wing displayed by what we had supposed so small a bird: it chiefly frequents marshes. A species of bittern is found in Newfoundland, which I suppose to be this kind.

C. - I lately saw a fly, which closely resembles the common Sand-wasp (Ammophila Sabulosa), but is a little smaller. A great difficulty has occurred to my mind with respect to the transformation of these and similar insects, which I should be glad to have explained. How do those insects, whose abdomen is joined to the thorax by a long and slender petiole, contrive to draw it through the narrow pupa skin which envelopes that part?

$F$. - The solution of this problem affords a beautiful instance of the way in which difficulties are met and obviated in the works of God. I recollect opening the earthy cocoon of a Sphex's nest, a species which has a very slender petiole: the white pupa was lying within, inert, and wrapped in its swaddling clothes; and the delicate transparent skin, which closely enveloped every other part, was stretched from the thorax to the abdomen, like a garment, being as wide around the petiole, as in any part of the swelling abdomen. This sight struck me with pleasure and admiration; it proved creative design and forethought, better than a dozen lectures could have done. Here was a diffieulty foreseen, which the insect had never yet experienced; occurring in a state of being on which it had not yet entered, and for which it could not possibly have received any instructions, having been immured from the egg, nay, from the ovary of the parent, within a very close and dark prison, without the slightest communication with the external world. It was removed by a re- 
markable deviation from ordinary circumstances, a contrivance beautifully simple, yet perfectly adequate to the end required. Does not the conviction come at once, unsought, irresistible, like the light of noon upon the open eye, that there was a contriver, an intelligent maker? And who is he but God?

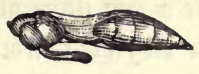

THORAX AND ABDOMEN OF A HYMENOPTEROUS PUPA.

C. - Yonder goes a red fox, crossing the road just before us : he does not seem in a great hurry, leisurely leaping along with light bounds, and occasionally stopping to look at us. - He has gone out of sight among the young trees in the swamp.

$F$. - The fox does not appear very numerous with us, though it is now and then seen. Richardson considers our Red Fox a distinct species from the European, under the name of Canis Fulvus ; but there is so little difference, that Cuvier, a high authority, considers it as only a variety of that species. In Newfoundland, the furriers distinguish three kinds, the common Red or Yellow, the Patch or Cross Fox, of a brindled colour, and the Black or Silver Fox, very rare and valuable. A short time ago I saw a fox, which a young man had taken in spring from a litter that he had found; he said that it was at that time quite black; when I saw it, it appeared to me very closely to resemble the Cross, or Patch Fox. He was an amusing little fellow, very shy and coy: he was chained to a post, and allowed to run under the house : when I went to see him, it was difficult to entice him out; as it appeared, though familiar enough with his friends, he was averse to making acquaintance with strangers ; however, his master, by means of a bone, induced him to appear, while I peeped at him round a corner of the 
house. He was playful, but did not appear much short of his full size, though not one season old. I was sorry to hear a few days after, that some malicious person had killed poor Reynard, from spite to his master.

C. - Does the Fox extend far over the continent?

$F$. - Yes; it is found in high northern latitudes, and as far south as the Gulf of Mexico at least; how much farther I am unable to say. In the south, it is hunted with much avidity by sportsmen, where I have been told of a curious instance of that cunning, for which the animal is proverbial. When pursued through the forest, he will often make for some tree which grows in an inclined position, run up the trunk, and then leap off to a considerable distance, in order to break his trail, and put the hounds at fault.

C. - Here is a green Grasshopper, with long legs and large wings : it resembles the great green species of England.

F. - This species (Phyllopterus Myrtifolius?) is not uncommon in autumn, flying about willows and bushes; but it does not often alight on the ground. The ovipositor is broader than that of the species you named, and much curved upward. A much smaller and more delicate species, (Locusta_-?) quite a little one, of a bright green, with very long ovipositor, may be found occasionally among the grass at this season. The ringing crink of some species now begins to be heard at evening, and continues through the night, with such unceasing pertinacity, as to drive sleep from the eyes of a stranger; yet habit reconciles us to this, as it does to other evils, to so great a degree, that it is, in fact, after a little while, unheard, except when the attention is directed towards it.

C. - I have lately had a new Noctua evolved, the Furbelow-moth (Calyptra Libatrix); it is likewise an English species : its colours are very delicate and beautiful. The Green Comma Butterfly (Grapta Progne?) is beginning to be numerous. 
F. - A fine male Sirex, with red abdomen (Tremex Columba) I met with in the woods a few days since; I also saw a winged specimen of the Great Ant of Newfoundland Formica Pubescens?), and the Falcate Crane-fly (Pedicia ?) so common in that country. It is rare here.

C. - Are the insects which are resting on this potato plant, wasps?

$F$. - No ; if you examine them closely, you will see that they are Lepidoptera, unlike as they appear. They are a small species of Sphinx, the Yellow-Belted Hawk-moth. (Egeria - ?) I have myself often mistaken them for wasps, as the resemblance is very striking; the alternate black and yellow belts of the abdomen, the shape, the mode of holding the wings horizontally extended at an acute angle with the body, are decidedly waspish. These I have taken in some numbers, chiefly on the willow and the potato; and two other species somewhat resembling them, I have met with, but very rarely (but one specimen of each) ; the White-Belted and the Gold-Belted Hawk-moth, the latter larger, and much brighter, and more beautiful. I am not certain, however, that these two may not be varieties of the firstnamed. The Gold-belted laid in my box a great many shining, kidney-shaped, dark red

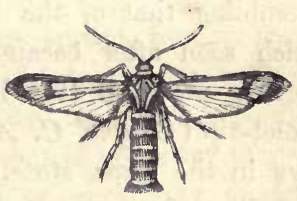
eggs. The economy of this di- GolD-BeLted HaWK-моTH. vision of the Sphinxes is pecu(Ageria - ?)

liar; the caterpillars are whitish, and usually feed on the pith and wood of trees or shrubs, emerging into daylight only as the perfected moth. They are often destructive to fruit trees, by their insidious and hidden attacks.

C. - I have just turned up a stone, and found under it a small, pale-reddish Lizard, which moves slowly; there is 
something disgusting in these slimy, sluggish lizards, which does not appear in the agile kinds that live among the leaves in the woods, and dart along like lightning on our approach.

$F$. - I have taken a pretty kind (Salamandra Rubra?) in watery situations; dark red on the back, with bright spots; the belly orange red with dark spots: it swims nimbly and gracefully.

C. - A few nights ago, as I was writing near an open window, a number of very minute Dayflies (Ephemera) not half as large as a gnat, flew in, attracted by the light, and grovelled on the table and paper before me. They did not seem capable of rising again, but spun round here and there ; they kept on flouncing down upon the paper one after another for some time, so that it was not an accidental thing, for the actions of all were the same.

$F$. - Minute flies, I have noticed, will often grovel about a bright surface, such as a book, \&c. by candlelight; probably not aware of the obstruction until they feel it.

C. - About the beginning of this month, I found feeding on the hop, a large, reddish, spinous caterpillar, somewhat resembling that of the Painted Lady (Cynthia Cardui), which soon after became a gilded chrysalis. It has this morning produced that large and handsome Butterfly, the Violet-tip (Grapta C. Aureum), after having been eleven days in the pupa state. Here is a young sphinx caterpillar, feeding on a willow; it is rough, light green, with yellowish slanting stripes. I presume it is the larva of the Twin-eyed Hawk-moth (Smerinthus Geminatus.) Is there any means of ascertaining the sex of a caterpillar?

$F$. - The sex of insects is not developed until they attain the imago state; but I have been able to determine in some instances the future sex by the size of the caterpillar, particularly of moths belonging to the division Bombyx. I have never discovered the eggs in the body of the larva, 
but nothing is more common than to meet with them in the pupa, sometimes hard, round, and substantial. In the pupa state of moths having pectinate antennæ, we may often discover the sex by examining the form of these organs, which is easily done by the lines and wrinkles of the pupa: the males have them much broader and larger than the females; the shape and size of the abdomen, too, is often a sufficient distinction while in this state.

C. - I was much pleased lately at discovering a fine articulate echo in our orchard-field, near the first of the large elms in the road. It repeated five syllables with distinctness by day, and probably in the still calm evening would repeat more.

F. - Echoes formerly were subjects of much wonder and admiration: many fanciful and poetical theories were made by the ancients to explain thern: they are now, however, well understood. Sound consists of undulations or waves in the air, diffused in every direction from the producing cause, as the circles on smooth water are spread from a stone dropped into it. It is also capable of being driven back on meeting with any impenetrable body, as a ball rebounds when thrown against a wall. All that is necessary to produce an echo is an intervening wall, or other body, at right angles to the course of the sound, without any intermediate object to break or destroy it. Such is the case in the one you mention; the centre or focus is on a rising hill : at the distance of two or three hundred yards, is the end of a large barn, exactly at right angles to the direction. The necessity of this position is shown by the fact that if you go a yard to the right or left, the echo is destroyed; so it is if you go higher up the hill or come lower; in the former case, the sound would be reflected lower than your position, in the 
latter, higher, in neither case reaching you; the angle of reflection being always the same as that of incidence. The number of syllables returned depends on the time occupied in pronouncing them, and the distance; varying, however, to some extent, from the state of the atmosphere.

C. - What flowers are these, growing in this marshy place beside the road?

F. - The first is called the Snake-head (Chelone Glabra), from a fancied resemblance which the flower bears to the head of a snake or a tortoise. It is a large and handsome labiate flower, and the number of white blossoms, growing in a tall spike, something resembling the Foxglove, gives it a striking appearance. - Here is another plant peculiar to wet soils, being found chiefly in marshes, and at the edges of brooks and ponds. It is called Wild Chocolate (Geum Rivale), from a supposed resemblance of the roots to that substance in taste. The root is long, horizontal, and somewhat thick and solid; it is of a purplish red colour externally; has an aromatic flavour; and, being astringent, is often dug up, washed, and boiled, for the relief of diarrhoa, a complaint to which strangers coming hither are subject for some time. The decoction I have proved to be efficacious, and it is not an unpleasant drink. The flowers are not conspicuous for beauty, of a dull reddish brown; but the seeds are very curious, being terminated by a bent hooked tail or awn, which, as well as the receptacle and most of the plant, is hairy. — The Choke Cherry (Prunus Serotina) is ripe: here is a bush on which the fruit is abundant; taste it.

C. - It is sweet and pleasant; but so very astringent that it well deserves its name of choke cherry; it dries the mouth and throat like the cones of the spruce or oak galls. The glossy scarlet fruit is very beautiful.

F. - In yonder patches of Indian Wickup (Epilobium 
Latifolium) many of the pods have opened, and show the cottony down attached to the seeds, which makes it unpleasant to approach them on a windy day, the down being so fine as to penetrate the mouth and nostrils, being borne along in clouds.

C. - Are not these large Sun-flowers some that have degenerated from gardens?

$F$. - No : much as they resemble them, they do not even belong to the same genus: this is the false Sun-flower (Helenium Autumnale), a native of this country. The disk is smaller in proportion to the rays, than in the Sunflower. Here is another fine, but very common plant, the Great Mullein (Verbascum Nigrum); its leaves are of a very soft and spongy character : its height is commanding, and its bright yellow flowers, spotted with scarlet, possess great delicacy and beauty. Some people have a notion that the leaves of this plant, strewn over grain, will prevent the depredations of mice, but I believe it is unfounded.

C. - See yonder bright rainbow; the "bow in the cloud!"

$F$. - There is, perhaps, no natural object more beautiful than a perfect rainbow, backed by a dark cloud, when the sun is low. The real or principal rainbow is always attended by another more faint, outside it, in which the colours are reversed, the violet being outward. But I once observed one which was treble. It was at sea in winter time: the colours of the bow were remarkably vivid, and within the main bow was another adjoining it, the prismatic colours recurring in their proper order, and not reversed: the violet was succeeded by red, orange, yellow, \&c. till it ended in violet; in fact, making one broad bow, containing two sets of colours. The inner set was fainter, but quite 
perceptible, the red and green particularly. I am not optician enough to explain it; perhaps it may have been nothing strange, but I never saw it before or since. The outer arch was reversed, and at the usual distance. 


\section{XIX.}

\section{SEPTEMBER 1 st.}

Black Bear-its Food-Appetite for Pork-Andecote-Mode of Fighting -Depredations on the Indian Corn-Farmer's Revenge. - Wolves. Everlasting. - Mallow. - Cherries. - Fire-weed. - Sumach. - Wild Gooseberry.-Canadian Blackberry.-Bugs on Fruit.-Needle Ichneumon.-Thistle.-Fields of Grain.-Harvesting Wheat.-Cradling.Frosts.-Climbing Buck-wheat.-Tints of Foliage.-Pigeons,-Larva of Tiger Swallow-tail-Of Muff Moth-Of Puss Moths.-Curious Caterpillar with clubbed Hairs-Other Caterpillars-Of Camberwell Beauty-of Twin-eyed Hawk-moth.-Black Sirex.-Fire-fly.-Fulgora. -Black Crickets.-Cicadæ.-Singular Forms of Insects.

Charles. - A woman came running to our house last evening, about twilight, almost dead with fright, saying that a bear had run out of the woods at her, close by our bridge, and pursued her some distance up the hill; and some few minutes after, a neighbour going down the road to the mill, smelt a bear pretty close to him, which was probably the same individual.

Father. - Several Black Bears (Ursus Americanus) have lately been seen in this neighbourhood: they do not in general attack a man, unless rendered desperate by hunger; but it is said they will pursue women or children. An instance lately occurred, in which a man, perceiving a bear lying in the road, was rash enough to dismount from his horse, and attack him with the butt-end of his riding-whip; but, as might have been expected, he met with a formidable antagonist, and had nearly suffered for his temerity. He, 
at length, after much struggling, managed to kill the beast with a stout club, which he providentially met with.

C. - The flesh of the bear is eaten, I believe?

$F$. - Yes : the hams, in particular, are much esteemed; a large bear will weigh five hundred pounds, and some have been found of even greater weight. Their skins are thick and warm; and, dressed with the hair on, are much in request for lining sleighs, as buffalo robes.

C. - Does our bear feed on flesh?

F. - Not wholly ; indeed it appears to be less carnivorous than the Ursus Arctos of northern Europe, and less ferocious. His chief food seems to be of a vegetable nature, grain, fruits, and roots. He has an appetite for pork, however, and occasionally makes a visit to the farmer's hog-sty for the purpose of cultivating an acquaintance with the grunting inhabitants. Some years ago, one of our nearest neighbours was aroused in the night by a commotion in his hog-pen ; suspecting the cause, he jumped up immediately, took his gun, and saw a bear in the act of getting over the fence with a fine hog, embraced very lovingly in his forepaws. The man fired (while his wife held a light), and killed the intruder. It is difficult to hurt a bear with any weapon but fire-arms; he fights with his fore-paws like a cat; and so watchful is he, and so expert at warding off every blow that is made at him, that it is next to impossible to strike his head, the only part in which he is vulnerable; for you might almost as well batter a feather-bed as the body of a bear, so encased and shielded by an enormous layer of fat. In our climate, he becomes torpid during winter, generally choosing for his hybernaculum, some large hollow log, or a cavity beneath the root of an overthrown tree. The species is numerous in all the wooded parts of this continent, even to the shores of the Gulf of Mexico. In the southern states, he commits depredations on the 
farmer's fields of maize: when the corn is in that milky state called " roasting ears," so prized for boiling and eating as a table dish, like green peas, or roasting whole on the cob, the bear manifests a singular unity of taste with the farmer, and devours and treads down a large quantity, as he finds no difficulty in climbing over the zig-zag rail fence. I have been told that he repeats his nightly visits to the same field; and, what is singular, always, on such occasions, mounts the fence, night after night, at the same spot where he got over the first time. The planters take advantage of this regular habit, by fastening to the fence a heavily loaded gun at such an angle that it shall point at the bear's breast as he rises on his hind legs. The identical crossing place is easily known by his great tracks in the soft earth. A stick is attached to the trigger, and this is made fast, at right angles, to a transverse stick resting on two forks about breast high, a few inches outside the fence. The bear rears up to put his forepaws on the rails, and in getting over presses with his breast against the transverse stick, which drives back the trigger, and poor Bruin instantly receives the reward of his dishonesty. The bear is one of those animals called plantigrade; that is, he rests the whole sole of the foot on the ground, not walking on tiptoe, as a cat or dog does, which gives him a somewhat heavy, shambling gait, though he contrives to get along with considerable speed. He makes a peculiar kind of sniffing, or whistling sound, and diffuses a rank odour, per ceptible at some distance.

C. - The wolves are again beginning their autumnal depredations; one was seen a few mornings ago, crossing one of our fields at dawn of day, and their dismal howlings are to be heard at night.

$F$. - But let us see what Flora has to offer us. Here is a simple plant, the Everlasting (Gnaphalium Margaritaceum); it should be a type of constancy, for it never 
changes; it is abundant in our grass fields, and is of course stored with the hay, but when "fed out" to the stock in winter, the blossoms of this Gnaphalium have precisely the same appearance as when they are growing in the field. Cattle reject this as well as many other weeds, occurring in our rubbishy hay.

C. - The Mallow (Malva Sylvestris) is now in flower, with its pretty blue blossoms; there is a plant growing vigorously near our house, the only one I have seen. The round flat seeds we used to call, when children, cheese-cakes.

$F$. - These are not the seeds, but a compound fruit, called a carcerule, containing the seeds. The fruit of the Wild Black Cherry (Prunus Virginiana) is now ripe, as well as that of the Red (Prunus Borealis). They are about the size of currants ; the latter are pleasantly sour, of a bright crimson; this variety is indigenous to Newfoundland: the former are rather larger, less acid, but have a bitterness of flavour that is not pleasing; no doubt both might be greatly improved by cultivation. Wild fruits, which are naturally sour, are more susceptible of amelioration than others ; as the tendency of culture, light, heat, manure, \&c. is to increase their sweetness; but fruits naturally sweet, become insipid.

C. - What is this tall plant, with deeply notched leaves?

F. - It is a species of Groundsel, called Fireweed, or Crenate Milkweed (Senecio Hieracifolius): the leaves are runcinate, the segments pointing backwards; the flowers, which are just blossoming, are small and plain, resembling those of common groundsel. A thick milky juice exudes from the leaves and stem when broken, which speedily acquires consistence, and becomes a highly elastic substance, resembling Indian rubber. It springs up abundantly in rank luxuriance on newly cleared land, after it has been run over by fire, whence it has obtained the name of Fireweed. 
C. - I have seen a shrub, lately, bearing thick clusters of small berries of a brilliant scarlet, on the ends of the twigs : the leaves handsomely pinnate.

F. - That is the Sumach (Rhus Typhinum): it is somewhat rare here; it keeps its handsome spikes of berries all the winter, whence it is cherished as an ornamental shrub; the berries are extremely acid. Sumach is used in tanning the finer kinds of leather. _— The Wild Gooseberry (Ribes Cynosbati) is ripe; the fruit is dark, dull red, very sweet, but armed with formidable spines. You may have observed at the edge of yon willow and poplar woods, a thicket of brambles, consisting of long tall shoots so closely entangled, and so beset at every point with exceedingly sharp and strong spines, that there is no penetrating it. It is called here the Blackberry (Rubus Hispidus): the fruit is sweet, but dry, and rather insipid; and by no means worth the pain and toil of procuring it.

C. - The wild raspberries are now in full ripeness and flavour; the bushes are crowded with them. Numbers of bugs, shaped like a tortoise, with a convex back (Scutellera), and other kinds, resort to them; and we often take these into our mouths with the fruit; but the horribly pungent smell and taste soon discover to us the difference between a bug and a raspberry.

F. - I once saw a largish Cimex (Coreus Ordinatus?), which, when molested, suddenly ejected so powerful an effluvium, that the water ran out of my eyes, and they smarted as if an onion had been cut under them. This power is, I suppose, their means of defence.

C. - Here is a curious Ichneumon; it is of a polished black, the abdomen is very long, the first five segments being each one third of an inch in length.

F. - It is the Needle Ichneumon (Pelecinus Polycera- 
tor) ; its flight is rather heavy and slow; the sting or ovipositor is concealed, but the last segment of the body is pointed, and when held in the hand it strives to wound, by striking blows with the

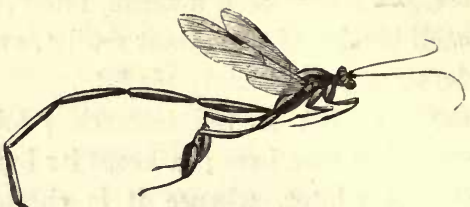

NEEDLE ICHNEUMON.

Pelecinus Polycerator. point of the abdomen : it is capable of giving a slight puncture, attended with only a transient smart. The long abdomen is usually carried in a curve, the end bent under : the hindmost shanks (tibice) have a remarkable swelling. It is found from Canada to Alabama, but does not appear to be numerous anywhere.

C. - The down of the Canada Thistle begins to be borne about on the wind, filling the air at intervals with clouds of the little feathery aëronauts; especially when a flock of the brilliant little Yellow-birds (Fringilla Tristis) are busily engaged in a bed of these plants, pecking away at the downy heads, to get at the seeds beneath, and dispersing whole hosts of the egrets at every touch. On those flowers of the thistle which have not yet ripened, the Pearl-border Fritillary (Melitaa Myrina) is numerous, frisking to and fro, and opening and shutting its tessellated wings in the sun.

$F$. - Here is a sight which ought to open the heart with gratitude : our fields of ripe golden grain; the bright-yellow feathery oats, waving lightly in the breeze, which plays over their changing surface, as over a summer sea ; the more sober-coloured and heavier, but not less valuable, wheat, the "staff of life ;" the buckwheat, a plant having considerable claims to beauty, with its deep green, heart-shaped leaves, 
not yet withered and scorched by the frost, and its pretty little white blossoms; the bristling barley; the full pods depending from the tangled peas; all the object of the farmer's hopes, and the end of his ceaseless labours. "Thou crownest the year with thy goodness, and thy paths drop fatness. They drop upon the pastures of the wilderness, and the little hills rejoice on every side. The pastures are clothed with flocks; the valleys also are covered over with corn; they shout for joy, they also sing."

We have begun reaping wheat, as you see: when there is an anticipation of bad weather, we have a mode of protecting the grain which, I believe, is not adopted in the upper province, for want of which much is sometimes lost. We put ten sheaves together, six to stand against each other, in three pairs, and a single one at each end; then we take the two remaining ones, the largest having been selected for this purpose, and opening the heads, draw them, ears downward, over the ends of the standing ones, so as to meet each other in the middle, covering all like caps (as indeed they are called). The projecting ears and straws of the caps shoot off any rain, and protect the insides of the sheaves from moisture. The caps are kept in their place, by a few of the longest ears on each side of one being brought round the other in a band, and tied. In fair weather, the bands are untied, the caps taken off, and the sheaves opened a little with the hand to admit the sun; all being ready to put up again in less than a minute. This whole bundle is called a stook.

C. - I see a labourer cutting wheat with an instrument called a cradle-scythe; what advantage has this mode over reaping?

F. - Many farmers doubt of any ; the grain is cut much more quickly, but as it has to be raked together in bundles; and to be bound by hand, there is little ultimate saving of labour, and perhaps even this is counterbalanced by the num- 
bers of ears which are necessarily left on the ground, and the irregularity of the sheaves. We have been favoured this season; the protracted fair weather allowing of a general ripening of the corn before the severe autumnal night-frosts, which I have known to occur as early as the 12th of August ; killing the grain when yet in " the milk," blighting the hopes of the farmer, and causing in many parts of the country distress little short of actual famine.

C. - We have had some frosts already; but not of sufficient intensity to injure plants, for even the delicate scarlet beans in the garden are not withered.

$F$. - I have heard it asserted by an intelligent practical friend, who has passed many years of sagacious observation in this country, that grain may be gradually inured to a severity of cold which would kill it if it were exposed to its violence without any such preparation. For example, if frosts come, light at first, but every night gradually increasing in intensity, a heavy frost may be then sustained without any injury; whereas if a frost of the same severity had come suddenly, after mild weather, the grain would have been inevitably killed. I cannot give any personal opinion on the matter, nor am I physiologist enough to debate the probability of such a variation; his opinion is drawn from observation of facts, not from any theoretical principles.

C. - I see in the field, among the grain, a slender, climbing plant, whose leaves resemble those of buckwheat: the seeds are of the same shape, of a deep shining black, enclosed in a light skin; the flowers are small, and pale pink. It climbs spirally around the stalks of wheat, and is not uncommon.

$F$. - It is a wild weed; a native plant of the same genus as Buckwheat (Polygonum Convolvulus?). Do you observe that the elms are beginning to put on their yellow autumnal dress ; and that patches of crimson begin to appear 
among the foliage of the maples ? an earnest of that splendid livery which will clothe all the forest in a few weeks.

C. - What birds are those which are hovering in a cloud about yonder field of buckwheat?

F. - They are the common Passenger Pigeon (Columba Migratoria); they devour a great quantity of that grain, in seasons when they are numerous with us. It is, I believe, the only mischief we sustain from them; and the gun takes ample revenge.

C. - While the leaves of the trees are yet green, I am diligent in beating them for lepidopterous caterpillars: I have had much success in obtaining these lately, some of which I will mention to you. I have taken several of the fine green velvety caterpillars of the Tiger Swallowtail (Papilio Turnus), with violet spots on the body, and two eye spots. It spins a bed of silk so tightly stretched from one edge of a leaf to the other as to bend it up, so that a section of it would represent a bow, the silk being the string. On this elastic bed the larva reposes, the fore parts of the body drawn in so as to swell out that part, on which the eye spots are very conspicuous. I have taken it from willow, poplar, and basswood, but chiefly from brown ash. Before it spins its button and suspending girth, it gradually changes colour to a dingy purple. The chrysalis is brown, with many darker blotches. The caterpillars of the Muff Moth (Lophocampa Tesselaris) are also numerous on ash, willow, poplar, and apple trees; these are very pretty, covered with a thick, soft, long fur generally bright yellow in the middle, and black at each end; but in many the yellow, and in others the black, predominates, to the almost total exclusion of the other colour. They spin oval cocoons, slight and thin in texture, being in a great degree composed of the hairs of the caterpillar ; these are found attached to the under sides of stones, \&c. in spring. I find caterpillars of that division called 
Puss-moths (Cerura), of all ages, on the willows ; some recently hatched, with the double tail sticking out in the air unreasonably long; some larger, the tail much shortened, handsomely coloured with bright green and brown; others of the same size, differing in having the back white; they spin close cocoons, abrading particles of the wood from the box in which they are kept, and mixing them with the silk.

$F$. - One of these produces the Griseous Moth (Cerura Hastulifera).

C. - A little warty caterpillar, of a bright pellucid green, feeds now on the apple tree, which spins a cocoon in an angle, and produces the Apple Moth (Tethea__? ). I took, from a rose-bush, a handsome and singular caterpillar, black, with large oval spots of bright yellow down the back: from every segment proceeds a hair on each side, which is dilated at the end into a stout knob. Do you know it?

$F$. - I have taken it likewise from the hop, but never succeeded in rearing it. I once took from an ash, a small caterpillar, black and white, with two or three knobbed hairs, projecting over the head; this afterwards moulted, when the whole back became brown, and the clubbed hairs proceeded from each segment, as in this species; I suspect it might have been the present, in an earlier moult.

C. - In beating willows, a very beautiful and large caterpillar, of a bright green, with circles of short bristles, proceeding from orange-coloured tubercles, resembling that of the fine Emperor Moth of England, fell into my umbrella, but was unfortunately killed by the fall. It was no doubt that of Saturnia Luna. I found suspended from a stalk of Golden Rod (Solidago), one of the large spinous caterpillars of the Camberwell Beauty (Vanessa Antiopa); it was just ready to become a chrysalis, which it accordingly did soon after, on the floor of its cell ; for I had disengaged it from its button of silk, from a curious desire of seeing whether it would 
spin another, but it did not attempt it. The caterpillar was dull black, with large red spots down the back; the chrysalis brown, with rusty marks; neither of them handsome.

$\boldsymbol{F}$. - I lately observed a larva of the Violet Tip Butterfly (Grapta C. Aureum) attached by the tail to a growing stalk of grass, and, of course, hanging parallel to it, as yours just mentioned: one would suppose they would prefer to hang from a horizontal plane.

C. - From the willows, I have lately obtained many of those handsome caterpillars which produce the Twin-eyed Hawk-moth (Smerinthus Geminatus), in different stages of growth. When full grown, they are very rough, pale green, with diagonal light-yellow stripes on each side: the anal horn is small, curved, and blue; the head has two yellow stripes down it. In some that sloughed their skins, I observed that for some time before the moult, the new head was seen bulging out the neck; and these yellow lines on it appeared distinctly through the skin. One that I took from the same trees, differed from the others in this particular, that it had two rows of reddish purple spots on each side, one of which contained the spiracula ; but for this, they were exactly alike; I doubt it is not specifically distinct. One of the largest is, this morning, become a pupa, not very large, naked, deep brown. Many other kinds of caterpillars have occurred: I have described only the more remarkable. The plan of shaking or beating branches of trees over an umbrella is a most productive one, yielding to the practical entomologist a great number and variety of species, that might otherwise elude his keenest research.

F. - Going to the village a few days since, I made an addition or two to my stock of entomologic lore. Standing in a house there, I observed a large insect, flying backwards and forwards before the door, and on going out succeeded in catching it with my hand; it proved to be a female of the 
Black Sirex of Newfoundland (Sirex Juvencus). Then, in the evening, returning after dusk, I found among the grass by the road-side, a flat grub, much resembling an Oniscus; from which proceeded a spark of greenish light, by which I discovered it. I suppose it was the larva of our summer fire-fly (Lampyris Corusca).

C. - Your speaking of fire-flies reminds me of a small Fulgora that I have lately taken (Otiocerus _ ? ) ; our specimen, however, has none of that luminous radiance which characterises the fine foreign species, the Peruvian and Chinese Lantern-flies. It is a pretty little insect; the head is curiously elongated, the wings are very delicate, transparent whitish, with a pink stripe through them; but what is most remarkable, the antennæ are triple on each side.

F. - The ugly Black Crickets (Acheta Campestris) now begin to swarm about the fields, especially under stones: except in colour, they strikingly resemble the house cricket. We find many little frog-hoppers, with prominent thorax; but here is a singular species which I have just caught, (Membracis Belligera?) having the thorax projecting like a curved horn, far over the head. - How wonderful the variety in form alone, which appears in insects! what strange shapes, endlessly diversified, we see every day, which would command our constant admiration, but that their minuteness makes us in some measure blind to their peculiarities ! Yet no variation of form is made, we may be assured, without some determinate and wise purpose, not only proposed, but effected. 


\section{XX.}

\section{SEPTEMBER 10th.}

Excursion to the Bois Brule.-A "Slash."-Indian Wickup.-Old Mill.Fruits and Berries.-Aphis.-Scarlet Stoneberry.-The Brule.-Swamp Plants.-Indian Cup.-Character of the Woods.-Origin of this place. -Return by another Route.-Arched Lane.

Father. - A few days ago, I accompanied a friend to a singular place, of which I had often heard, and about which my curiosity was excited. It is the Bois Brule, a large tract of land, lying at no great distance, but so hidden in the recesses of the woods, and so out of the way of any travelled road, that it is not often visited, except by the trapper.

Charles. - I should have liked to be with you; but, as it is, you would gratify me by a brief account of your walk.

F. - We proceeded up Bradley's Brook, on the steep bank of which I found a thistle in flower, with crenated leaves (Cnicus Altissimus?) which I have not observed elsewhere. The first quarter of a mile lay through a very rough slash,

C. - Excuse the interruption; but what is a slash?

$F$. - Sometimes a person wishes to cut down the timber from a piece of land, when he has not time to trim the trees, pile the brush, or cut the logs ; he, in that case, fells all the trees, letting them lie promiscuously on the ground, as they fall ; this is called a slash, and the plan is chiefly followed in the thickly-timbered evergreen swamps. After the trees 
have lain for a longer or shorter period, exposed to the influence of the sun, at some convenient time fire is put among them, which often consumes the principal part, and the remnant is collected, and re-burned. Such a labyrinth of fallen timber we had to penetrate, climbing over the trunks, and scrambling through the dry branches of the prostrate trees, often falling through ; and, to make the matter worse, these were concealed by the tall Indian Wickup (Epilobium Latifolium), with which the ground was absolutely covered; and as the long seed-pods were just bursting, our every movement dispersed clouds of the light downy cotton, which, getting into our mouths and nostrils, caused us considerable inconvenience. Presently we descended the steep bank, and walked, or rather scrambled, up the rocky bed of the stream, by means of the stones which were above water; though, as they were wet and slimy, we occasionally wetted our feet. Thus we went on, sometimes in the stream, sometimes among the alders and underwood on the banks, for about a mile and a half. We were much surprised in going up this brook, about a mile up, at coming upon a ruined building, which had been erected over the stream at a craggy fall, of which the timbers had fallen down, and some of them had been carried a considerable distance downwards by the freshets. I supposed it must have been a mill, but wondered at its situation, so far from any road. I have since been informed that it was a saw-mill which had been built by Messrs. Spafford, and that there was a good road to it, which went through what is now P. Barker's south-west field; but being now overrun with bushes and young trees, this road had escaped our notice. The mill has been disused nearly twenty years. On the borders of the brook, I met with the seedvessels of the Touch-me-not (Impatiens noli-tangere), the handsome subconic scarlet fruits of the White and the Red Death (Trillium Pictum, and T. Fotidum), the large um- 
belled bright blue berries of Smilacina Borealis, and many others. In pressing through the brush, we got our clothes bedaubed with a nasty substance, which we discovered to proceed from thousands of the Aphis Lanata (?) which we had crushed; they were so thickly clustered round the branches of the alders as to make a solid mass, half an inch thick, covered with ragged filaments of white down. The insects were much larger than most species of this genus, of a lead-gray colour. We were getting nearly tired of the ruggedness of our path, when we suddenly came upon a new and very good bridge across the brook, made of round (that is, unhewn) logs, which connected a good broad path, from which the fallen trees and incumbrances had been cleared away, and which had evidently been used for the purpose of drawing out mill-logs in winter, with sleds. As its course seemed to be nearly parallel with that of the brook (about south-west), we preferred pursuing it, as being much more pleasant and easy of travel. The sides of the road were lined with the stumps of large spruces and hemlocks, which had been felled the previous winter; and the road itself was strewn with the chips of the axemen. The course lying through a cedar swamp, the ground was mossy, and in some places wet; here the Scarlet Stoneberry was abundant, as well as the berries mentioned before. The former (Cornus Canadensis) is a low and pretty plant, having a white flower, resembling that of a strawberry, and four large oval green leaves on the ground. At present they were crowned with the little cluster of bright red berries, which were ripe, and we ate many : they are farinaceous and agreeable. This plant is common in Newfoundland. I found an Orchis, consisting of two very large oval leaves, deeply plaited, but it had no flower. — We continued to follow this path till it appeared almost interminable, though its tedious uniformity made it seem longer than it really was, as I suppose 
we did not walk more than a mile and a half on it, when I perceived by the increasing light among the trees that we were approaching a large opening.

We now pressed eagerly on, and found that we had reached the borders of the Brule, which was not a clearing, as I had expected, but was covered with a stunted and ragged growth of moss-grown spruce, from eight to twelve feet in height, exactly resembling the small woods of Newfoundland, on the borders of the large marshes. I found also the same plants that inhabit such situations in that country, and which I now saw for the first time in Canada. The ground was covered with the same spongy moss, with shrubs of Indian Tea (Ledum Latifolium), Sheep Laurel (Kalmia Angustifolia), Swamp Laurel (Kalmia Glauca), and other Newfoundland plants. The last two are there called Gould; they bear bunches of pretty little pink flowers, nearly circular, the stamens radiating very regularly, and their anthers forming a circle within the edge of the corolla:- the first, whose leaves, bent downwards at the edge, are thickly clothed on the under surface with a close yellow fur, is often infused and drunk as tea : the infusion is bitter, but is relished by many. I also recognised numbers of another old acquaintance, an exceedingly curious plant, the Indian Cup, or Pitcher Plant (Sarracenia Purpurea): the leaves of this plant have their edges united together, each one forming a deep and capacious cup, always filled with water, not, I think, collected rain, as is generally supposed, but distilled from the marsh, through the pores of the plant: minute flies and other insects are often found drowned in these natural reservoirs. The leaves are sometimes green, but more commonly dark red, always with the nerves ramified in an infinite number of red veins over the surface; their bases are erimson, each one partly sheathing the next, but this part is usually concealed among the moss. From the bed of leaves 
arises an upright stem, about eighteen inches high, bent at the top, bearing a somewhat leathery flower, of five reddish petals; the stigma of the pistil is dilated into a broad convex shield, almost concealing the interior of the corolla. - But

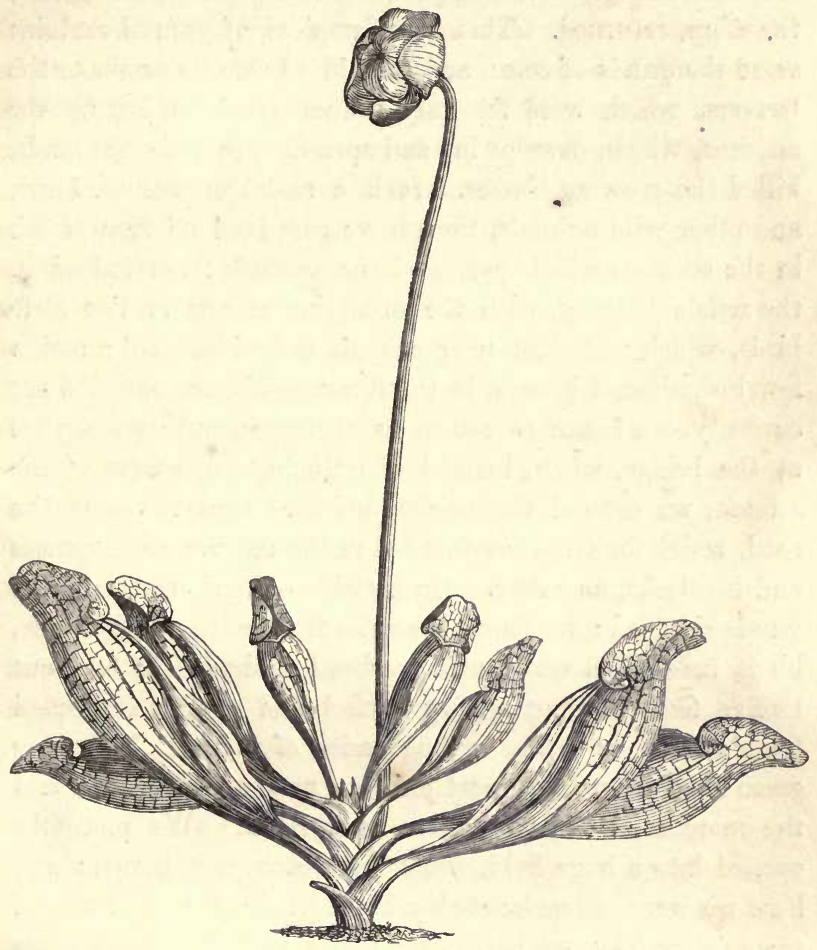

INDIAN CUP, OR PITCHER PLANT.

(Sarracenia Purpurea.)

to proceed. The road by which we had approached did not enter the Brule, but merely touching its edge, went straight 
on, entering the tall woods on the other side, and emerging, as I understand, about a mile farther, into the stage road from Compton to Hatley. We penetrated a few rods into the Brule, to see if there were any clearing, but could perceive no change in the ugly, dead, half-burnt spruce; and, therefore, returned. This singular piece of ground contains some thousands of acres, and is said to owe its origin to the beavers, which were formerly numerous, damming up the streams, which, overflowing and spreading over the flat lands, killed the growing timber. It is a resort of wolves, bears, and other wild animals, though we perceived no sign of life in the stillness which pervaded the solitude; nor indeed in the whole journey, with the exception of one or two little birds, which were not near enough to be identified; and a few insignificant insects, in the forest. - Having satisfied our curiosity, we began to return as we came, until we arrived at the bridge, when, instead of retracing the course of the stream, we crossed the bridge, and continued to pursue the road, which for some distance led us through towering spruces and hemlocks, as before. On a sudden the character of the woods changed : we found the sides lined with young maple, birch, beech, \&c. which met overhead at the height of about twelve feet, forming a very perfect and regular continued Gothic arch, or rather a long series of arches. This long green avenue was the most pleasant part of our walk; and the more so, as it was quite unexpected. We presently opened into a large field, which had been just mown; and here we were rather laughably bewildered: the place was a terra incognita; we had never before seen it, nor could we recognise any object, so as to guess at our "whereabouts." There appeared to be no outlet through the woods by which the field was environed:- in one part was the skeleton of an old log-house, without a roof; and a portion of the field was planted with potatoes. We at length saw a path through 
these potatoes, on which we walked till we came to the brow of a hill, from whence we perceived familiar objects. It commanded an extensive view : the beautiful and winding Coatacook was at our feet, with its bridge, Smith's mills, and all that neighbourhood; beyond a broad belt of the forest was visible Tildon's tavern, and the road leading from Hatley to Sherbrooke, and the forest again behind all. We now left the path, taking a short cut over the hill, coming down by Bradley's mill, and so home, much pleased, notwithstanding the little disagreeables, with our excursion. 


\section{XXI.}

\section{SEPTEMBER 20th.}

Autumnal Frosts.-Threshing Buckwheat in the Field.-Grinding. Butterflies. - Humming-bird. - Fading of the Leaves of Trees. - Brown Ash.-OtherTrees. - Seeds of White Ash.-Crimson Beetle.-Beetles in Earth.-Warblers. - Finches.-Rough Caterpillars of Geometraof Buff-leopard Moth - of a large Sphinx - handsome one from Willow - very beautiful one of Saturnia Polyphemus. - Summer Duck. - Hooded Merganser. - Anecdote of a Brood of Black Ducks. Waterfowl. - Migration of Aquatic Birds. - Bryant's Lines to a Waterfowl.

FATHER. - The autumnal frosts have now cut off the increase of many of our plants. The beans and potatoes are turned black, the leaves and stalks looking as if they had been plunged into boiling water; that part of the buckwheat, which is not yet cut, is of a rusty brown colour; pompions and squashes, and many garden plants and flowers, are destroyed:- the wheat and oats were happily ripe before the frost, so as to be beyond the reach of injury.

Charles. - What are those men about in yonder field?

$F$. - They are threshing buckwheat on the ground: we have some slovenly customs, and this is one of them. When this plant is ripe, the grains are so tenderly attached to the branches, as to be shaken off by a very slight shock; especially in the heat of the day, when the stems are brittle from dryness. On that account we usually mow this plant early in the morning, ceasing as soon as the dew is evaporated. Notwithstanding this precaution, a great quantity of grain is 
lost in this operation, and in that of turning it to dry in the sun when cut. As I have said, the drier it is, the more seeds are shed, so that in carting and removing it to the barn, very much is unavoidably wasted. To obviate this in some degree, many farmers thresh it on the ground where it grew, either on a moveable flooring of boards, or on the bare earth, though of course much earth and dirt must be mixed with it.

C. - Do not the seeds that remain on the ground spring up in the succeeding summer?

$F$. - So much so, that a good crop may be obtained from merely this unintentional sowing. But this fact, the diffculty of getting the soil clear of the plant, is, with many, an objection to the raising of it, notwithstanding its productive return. If, however, the land be stocked down with grassseed at the time buckwheat is sown, it will be rather an advantage than an injury; as whatever plants might spring the succeeding year, would of course be mown down with the grass, before the seed was perfected, and tend to increase the herbage, cattle being very partial to the plant. It is an annual, so that one mowing would effectually eradicate it.

C. - Is this grain ground in the same manner as wheat?

$F$.- Yes; but in a separate hopper: it is bolted, and what remains consists of two parts, the three-sided brown husk, and a pale yellow skin, which enveloped the flour; the latter is called the bran; mixed with boiling water, it forms a glutinous, bitterish mass, which is eagerly devoured by hogs, and proves nutritive. The husk is thrown into the mill-stream as totally useless. The American housewives chiefly use buckwheat flour for making pancakes, eaten piping hot, and agreeable to many palates.

C. - Though the nights are frosty, the days of this month are very pleasant ; the sun has much power yet, and many Lepidoptera are abroad enjoying it. Vanessa Antiopa, and the different species of Grapta, in particular, are numerous 
and active. I was much surprised to see the Banded Purple again (Limenitis Arthemis), on the 4th of this month, after it' had so long disappeared: but I conclude it was only an occasional straggler, or one of an unusually late hatching.

$F$. - The Ruby-throat humming-bird, not deterred or driven away by our frosts, is still courting the remaining flowers. He will soon, however, take his departure for a sunnier region.

C. - I have observed that the Black Cherry leaves are turning yellow.

F. - The Brown Ash is the first tree that feels the effect of the season: it cannot withstand the breath of winter. The very first hard frost that comes denudes the ash, not only causing its leaves to fade and become yellow, as those of other trees, but blackening and shrivelling them up, so that they fall in showers, with the least breath of wind. Most of the ashes are already as bare as in winter.

C. - The ash is about the last that leafs in spring: can any parallel be drawn between the times of the expanding and the fading of the leaves of forest trees?

$F .-$ No; they show no regularity in this respect. The ash, butternut, basswood, and beech, leaf about the same time, very late in the season: the ash and the basswood fade early; the former first of all ; but the butternut maintains its foliage late, and the beech continues brightly green, long after many other trees are faded. The maple is late in expanding, but it fades gradually, and loses its leaves neither very late nor very early, - about the same time as the birch, which also leafs with it; but the elm, which leafs likewise at the same time, is denuded long before either. The poplar and willow leaf early and fade late: the black cherry leafs and fades early; and the tamarack buds very early, and remains braving the autumnal storms the latest 
of all the deciduous trees. But the close alliance of this tree with its evergreen congeners, may account for this.

C. - About a week ago, I saw a White Ash (Fraxinus Acuminata) which was thickly covered with seeds, dropping them very fast; the ground underneath was strewn with them. The seed is curiously enclosed in the end of a long, flat wing. - Here is a specimen of the beautifully coloured Crimson Beetle, crawling on this stump. It is of a singular shape, being so thin and flat.

F. - It is a Cucujus (C. Rufus); it is not uncommon, crawling on logs, trunks of trees, beneath bark, \&c. In ploughing now, we often turn up the soft, inert, Chestnut Chafer (Rhizotroga Fervens), the Copper-spot (Calosoma Calidum), and the Purple Carab (Carabus Catena), and other beetles. Most of the soft-billed, insect-eating birds, the pretty warblers, \&c. are now gone from us : it is true they have been withdrawn from our observation for some months, but they were occasionally seen. Owing to this habit of retirement, it is difficult, without very close research, to note the time of their departure; but we find that most species appear in the State of Pennsylvania, on their southern migration, during the months of September and October; from which we may conclude that they leave our land a little before that time. Many of the seed-eaters, the Fringillæ, \&c. remain, however, with us. Have you procured any more lepidopterous caterpillars lately?

C. - I have obtained some; but the season is becoming too far advanced for much success in bush-beating. Many large geometric caterpillars are found on the willows, near three inches long, and as thick as a goose-quill, very rough, and full of knobs and irregularities, mostly dark brown; they take a firm grasp of the branch on which they rest, with the two anal pairs of feet, and rear the rest of their 
bodies up into the air in a stiff attitude, which they maintain a long time without the slightest motion, so as to have a very close resemblance to a knotty twig. They become a naked pupa, with a mucronate tail, without any spinning.

$F$. - I suspect one of these, for there are different kinds much alike, produces that large and beautiful Geometra, the Grandee Moth (Geometra Clemataria); but I have never reared it.

C. - The hairy larvæ of the Buff-leopard Moth (Arctia Isabella) are numerous among grass and bushes. Their hair is close, but rather short and stiff, all black, except on the three middle segments, which are rust-red. They undergo the change to pupa within a cocoon. A few days ago, before the frosts had denuded the brown ash, I shook from one of these trees a large and beautiful caterpillar of a Sphinx, larger and thicker than those of the Twin-eyed Hawkmoth. It was smooth and velvety, light pea-green, with slanting white stripes, and triangular red spots on the sides; the anal horn was rough, green and pink: the fore parts much more slender than the hind.

$F$. - I have seen a representation of this larva, in a fine collection of coloured drawings, made by Mr. Titian R. Peale, of Philadelphia, an eminent and zealous lepidopterist ; but I could not ascertain to what moth it belongs.

C. - Mine went beneath the earth in its breeding-box in due course; but after a few days I accidentally discovered that it was dead, with a large hole in its side, the viscera corrupted. My suspicions are strong against a dipterous larva which I had turned up in the ground; a long, white, cylindrical fellow, with a taper head, which I put into the same box, not suspecting any danger.

F. - Many of the subterraneous dipterous larvæ are fierce and ravenous, and often prey upon caterpillars. You have bought wisdom by experience. 
C. - A caterpillar of very singular appearance, I shook from a rough-leafed willow. It was about two inches and a quarter long, very soft, the belly flat like that of a leech; all smooth, except a tuft of white hairs on each segment at the edge of the belly; the head downy. The colour was light grey, beautifully mottled and chequered with black; the third segment was separated from the second and from the fourth by bands of bright orange, which appeared only when it crawled; the whole under surface was mottled with black and tawny. It has since spun a slight cocoon. Perhaps it was a Catocala. But the largest and most beautiful caterpillar that I have yet seen, is one of the great Satur. nia, which I found about a week ago, resting on a Choke cherry bush (Prunus Serotina). It is of a most brilliant light green, nearly transparent; each segment of the body rising into two roundish humps, each ending in a little bright yellow tubercle, bearing two or three short hairs; two rows of similar tubercles run down each side, which are joined by a diagonal yellow line on each segment, just behind which are the spiracles, which are scarlet. The head and legs are light brown; the anus is terminated by a line of purplish brown. It is rather inactive, and slow of motion. Its length, when crawling, is two inches and a half, and its diameter about half an inch.

$F$. - It is the larva of an exceedingly large and fine moth, (Saturnia Polyphemus).

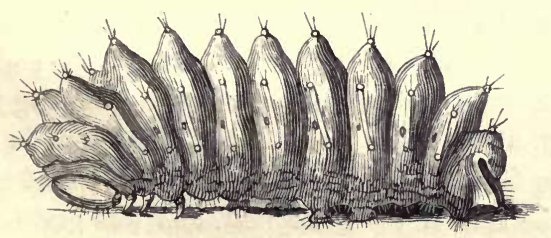

LARVA OF SATURNIA POLYPHEMUS. 
C. - A few days after, I took another not quite so large, from an elm: I perceive they eat the leaves of either plant indiscriminately. They are now spinning cocoons. I met with a large Dragonfly (EAshna), handsomely spotted and banded with bright grass-green, on a brown ground : I caught it in my hand.

$F$. - Here we open on the smooth river. Do you see those two birds flying along under the bank, close to the water's edge?

C. - They are ducks, by their straight, swift, but very peculiar flight, and by the whirring of their wings. $D_{0}$ you know of what particular species they are?

$F$. - I suspect them to be the lovely little Summer Duck, or Wood Duck (Anas Sponsa), which haunts the borders of our wooded streams. This is the most beautifully ornamented of any species of duck that I am acquainted with. Its hanging crest, and its beautiful colours, have made it a favourite in Europe, where it appears to be half naturalised. I am little acquainted with our water birds, but I think it probable that in our lakes and rivers most of the fresh-water ducks that inhabit the United States may be found. One of our neighbours shot on the Coatacook, where it runs through the meadows, a few days ago, a summer duck, and some Pied ducks, as he calls them, with sharp pointed bills, but which, from his description, I take to have been no other than the Hooded Merganser (Mergus Cucullatus). The same person has told me of an attempt he once made to rear a brood of wild ducks of some sort, which he calls the Black Duck (possibly Anas Obscura). About the end of May he found a black duck sitting on a nest, containing ten eggs ; happening, at the same time, to have two hens in his yard contending for the possession of one nest, he placed the duck's eggs by the side of the hen's nest, and was gratified to observe that one of the hens took to them. In due time the 
ducklings were hatched, and grew well through the summer. One night, in October, he heard them making a great tumult, and flying about; and determined on securing them in the morning: when morning came, however, he could find only three or four, which he caught, and clipped their wings : the others had got away, but one of them was seen on the river for some days. Before this, they had manifested the native wildness of their disposition, roaming to a distance : he once thought he had lost them, having missed them for some hours ; and suspecting that they might have got into a brook which runs through his farm, and joins the river a short distance, in which direction they had last been seen, he went to a little sand-beach, which, in such case, they must have crossed, and there he found their tracks; by following which he discovered them in the brook, the old hen terribly alarmed on the bank, and loudly calling them out.

C. - The ducks, in general, appear to be inhabitants of a cold climate.

$F$. - By the thickness of their plumage, which is remarkably soft and compact, they are protected from the effects of the inclemencies to which they are exposed. There is probably no warmer covering in nature than the soft, close, downy plumage of waterfowl, resisting the transmission and consequent abstraction of the animal heat, most effectually. Accordingly, we find them abundant in the high Arctic latitudes, during the short summers; the species being, in many instances, common to the northern regions of both continents. This fact, the community of species of Arctic birds, seems a strong argument in favour of the existence of a polar continent, or archipelago of islands, which would allow these birds food and rest during their summer excursions across the Pole, suppose from Spitzbergen to Melville Island. The geese, it is true, are capable of long flights; but the freshwater ducks, though of swift wing, do not appear to be com- 
petent to a long-continued flight, such as across the narrowest part of the Atlantic; though the distance from the Ferro Isles to Iceland is probably not more than three hundred miles. But this is merely a conjecture, and perhaps a groundless one.

C. - I presume you know Bryant's fine stanzas "To a Waterfowl."

"Whither, midst falling dew,

While glow the heavens with the last steps of day,

Far through their rosy depths dost thou pursue

Thy solitary way?

Vainly the fowler's eye

Might mark thy distant filght to do thee wrong,

As, darkly painted on the crimson sky,

Thy figure floats along.

Seek'st thou the plashy brink

Of weedy lake, or marge of river wide,

Or where the rocking billows rise and sink

On the chafed ocean-side?

There is a Power whose care

Teaches thy way along that pathless coast, -

The desert and illimitable air,-

Lone wandering, but not lost.

All day thy wings have fanned,

At that far height, the cold thin atmosphere ;

Yet stoop not, weary, to the welcome land,

Though the dark night is near.

And soon that toil shall end;

Soon shalt thou find a summer home, and rest, And scream among thy fellows; reeds shall bend

Soon o'er thy sheltered nest. 
Thou 'rt gone ; - the abyss of heaven Hath swallowed up thy form : yet on my heart Deeply hath sunk the lesson thou hast given, And shall not soon depart.

$\mathrm{He}$, who from zone to zone, Guides through the boundless sky thy certain flight, In the long way that I must tread alone, Will lead my steps aright. 


\section{XXII.}

\section{OCTOBER 1st.}

Beautiful Hues of the Forest in Autumn.-Cause of the fall of LeavesLeares as Manure -Parasites on Leaves.-Butternut.-Shrew.-Bulrushes-Singular downy Heads-Used to make Beds.-Wild GeeseMigration. - Vegetation of a Head of Grass. - Snow in September. Crimson Underwing. - Fire-flies.-Brood of Bugs. - Beetles. - Caterpillars.

Father. - How gorgeously is the forest now adorned with the most splendid colours! our woods in autumn have a glory that perhaps no part of the old world can boast.

CharLes. - I had often read of the splendour displayed by the American forests in autumn, but the reality exceeds my expectation. Every part of the woods is glowing in an endless variety of shades : brilliant crimson, purple, scarlet, lake, orange, yellow, brown, and green; and looking from this hill over the tops of the trees, as far as the eye can reach, the same bright hues are to be seen; the shadows of the passing clouds, playing over the vast surface, now dimming the tints, now suffering them to flash out in the full light of the sun; here and there a large patch of sombre evergreens, making the dark parts of the picture:- the whole forest is become a gigantic flower-garden.

$F$. - By far the greatest proportion of the more glowing colours is the production of the sugar maple, and other species of the same genus; the leaves of these display all shades of red, from deepest crimson to bright orange; which generally occurring in large masses, not in individual detached leaves, 
prevents anything tawdry or little in the effect. On the contrary, when the full beams of the sun shine on them, the warm and glowing colours possess a great deal of grandeur. The poplar leaves often assume a crimson hue; the elm, a bright and golden yellow; birch and beech, a pale, sober, yellow ochre; ash and basswood, different shades of brown; the tamarack, a buff-yellow. The beech, the ash, and the tamarack, do not, in general, bear much part in this glittering pageant; the ash is mostly leafless at the time, and the glory has passed away before the other two have scarcely begun to fade. Indeed, the glossy green of the beech is perhaps more effective than if it partook of the general change ; and even the gloomy blackness of the resinous trees, by relieving and throwing forward the gayer tints, is not without effect. This beauty is not shown to equal advantage every year : in some seasons the trees fade with very little splendour, the colours all partaking more or less of dusky, sordid brown; early frosts seem to be unfavourable for its developement: and even at its best it is a melancholy glory, a precursor of approaching dissolution, something like the ribbons and garlands with which the ancient pagan priests were accustomed to adorn the animals they destined for sacrifice.

C. - What is the cause of the fall of leaves?

$F$. - The severity of the weather is doubtless the cause of the death of leaves, since we find that only those survive the winter which are protected by a resinous varnish, as the fir, laturel, \&c. But the fall of the leaf does not necessarily follow its death, for if a branch be cut off from a tree in full leaf in the midst of summer, the leaves will not be shed; they will dry up and become brittle, but it will be found that their connexion with the stem is as strong, and their hold as tenacious as when they were in vigour and greenness : so that we must look to other causes for the denuding of a tree. Every bud is formed in the axilla of a previous 
leaf, or the angle made by the foot of its stalk and the branch : all the summer this bud continues very small and inconspicuous, but by the autumn it has increased so much as to force apart the junction of the old leaf with the stem, and separate it by an articulation which did not originally exist there, but which has been gradually formed since the developement of the leaf. Its footing being destroyed, it either falls in obedience to the laws of gravity, or but waits the passing breeze to convey it to its grave.

C. - Would not forest leaves make a good manure?

$F$. - In favourable situations, such as where they have accumulated in great numbers, and where the ground is sufficiently open to allow of the passing of carts, \&c. I have no doubt they might often be applied with profit. I have myself collected some quantities, and applied them in the proportion of about sixteen loads to the acre, with good effect ; they readily decay, and contain much fertilising matter.

C. - The beautiful coloured foliage, I perceive, does not look so perfect when you examine it leaf by leaf, as it does viewed from a little distance as a whole: numberless scratches, spots, and discolorations deface the surface, which were altogether invisible before. I have often observed round black spots on the surface of leaves beginning to decay ; maple leaves, I see, have them plentifully.

$F$. - It is a species of fungus which parasitically fixes itself there, and draws its support from the substance of the leaf, thus forming a rapid agent in its decomposition.

C. - The fruit of the butternut is now ripe, and falls from the tree. It resembles the walnut of Europe, but is much inferior.

$F$. - The nut is not in its best condition until it has lain some time to dry, and the frosts of winter have matured it. Then its taste is agreeable; but its shell is hard to break, 
and what is commonly called the fruit, (but is botanically a seed,) is so divided by the internal cells of the shell, as to be much less in bulk than the walnut, and difficult to extract. It is best cracked by holding it perpendicularly on a stone, and striking the base with a hammer, when the shell generally flies in pieces without crushing the seed.

C. - Here is a little strange-looking mouse, lying dead.

F. - It is not a mouse; it does not even belong to the same order; this is a Shrew (Sorex Brevicaudis?) belonging to the order Ferce, whereas the mouse is placed in Glires. I believe this genus is the smallest of the Carnivora, to which its teeth claim affinity; its usual food is, however, insects, worms, \&c. It is not commonly seen here. This has probably been killed, and rejected by one of the house cats. - Have you ever examined any of that large patch of bulrushes (Typha Latifolia) which grow in the bottom of this field? it is difficult to get at them, as it is a complete bog all around, but they are so curious that they repay the trouble of obtaining them. The thick cylindrical head appears like a fine, but very closely set brush, radiating from the axis or stalk, which it covers for about six inches. On picking out a lump of what we may call the bristles of this brush, we are surprised to see that we have a handful of the softest down, that which before was not bigger than one's thumb, now, on being freed from the stalk, filling one's hand; and the hiatus made by the loss is filled up by the expansion of the remainder, so completely as scarcely to be perceivable. In short, the whole head is composed of this very expansive down; and I am told that poor persons sometimes collect quantities of it to make beds, which are said to be soft and elastic.

C. - Yonder goes a flock of Wild Geese (Anas Cana- 
densis) on their aërial voyage from the frozen regions of Boothia Felix to the "Father of Waters," Chesapeake Bay. I have observed several other flocks lately, all pursuing the same southerly course.

$F$. - What a mysterious instinct is that which impels these and similar birds to seek, at a certain season, over thousands of intervening miles, such apparently inhospitable climes, to remain but a few weeks, then to retrace the same journey! And this, year after year, with such undeviating uniformity, "knowing the times and the seasons." What is the motive of so toilsome a pilgrimage? Is it to procure food? one should suppose that the sedges and grasses of our coasts, our marshes, our rivers, the shell-fish of our beaches, and the worms of our meads, would afford these birds fully as abundant and as suitable food as the regions of Hudson's Bay. Do they seek those impenetrable recesses for the sake of bringing up their young in security, their jealousy being of so ultra a character, that the very possibility of intrusion is intolerable? Or is their blood of so high and heated a nature, that they cannot bear the temperature of our summers? What do we know, with all the researches of modern science, concerning the nature or causes of migration in general? It is a subject yet enveloped in much darkness, which we are not able to penetrate. "Doth the hawk fly by thy wisdom, and stretch her wings towards the south?"

Here is a curious specimen of vegetation; this was a sheaf of timothy grass, which was reaped with others about a month ago, to be threshed for grass seed, but this one being overlooked has lain upon the ground ever since. The warm rains of the past month have caused the seed to germinate; and now, see what a host of little straight green sprouts arise from every stalk, and what a matted mass of fibrous roots is the underside, which has lain on the earth! 
C. - Notwithstanding a few pretty smart frosts, we have had some very pleasant weather lately; and though the days are warm, the midges, musquitoes, and such like pestiferous insects, have ceased to molest us.

$F$. - In the autumn of 1835 , though by no means a cold season, we had, on the 30th of September, a fall of snow, which continued without intermission throughout the day; so that in some places in the neighbourhood it stood on the ground to the depth of fifteen inches. We were dismayed with the anticipation of an early and severe winter, but the snow vanished almost as rapidly as it had fallen, and the winter did not set in for many weeks afterward, though it proved unusually severe in December and February.

C. - I caught lately in the house, a fine Noctua, the Crimson Underwing (Catocala_-?); and on the 25th ult. late in the evening, I saw several fireflies in the grass at intervals, but none in flight : one, which I secured, proved to be a larva. — Oh! look what a family of young bugs on this decaying stick; some in larva, others in pupa: the abdomens of all are scarlet. How closely they are congregated together !

$F$. - I have often discovered broods or nests of this kind, and invariably find them thus associated together : I suppose they are the young of a small species, which is black, with a scarlet transverse line on the thorax, and two scarlet spots on the scutellum (Cydnus Bilineata?). A few days since, I took, on a dunghill, a Staphylinus, which I had not met with before: the head horn coloured; thorax and elytra brown and black, mottled; abdomen silveryblack, with a tawny central line, the fourth and fifth segments grey (Staphylinus Chrysocephalus?). A little black Chafer is numerous, the thorax projecting like a horn over the head, much more prominent in some than in others 
(Pathophagus Latibrosus). I presume caterpillars have disappeared.

C. - I have obtained only one worth note, for some time; a large plump one, shaped like that of the zigzag moth, delicately varied with white and pink, procured from the sugar maple. Few remain now. 


\section{XXIII.}

\section{OCTOBER 16th.}

Indian Summer.-Peculiar Weather-Supposed Causes.-Lepidoptera.Freezing of the River.-Winter Wren.-Wasps.-Nest of Leaf-cutting Bee.-Moths.-Snake.-Insects on fallen Leaves.-Pearlfly.-Grakles. -Ignorance of Natural History hurtful to the Farmer.-Anecdote.Crossbills.-Day-flies._Caddis-flies.-Torpidity.-Blue Bird.-Frozen Apples.-Effect of Frost in loosening Leaves.-Beech Nuts.-Fruit of the Maple-Of the Birch-Ash-Basswood.

Charles. - The weather, for a few days past, has been delightful, and more like summer than autumn: if it were not for the nakedness of the leafless trees, we might easily fancy ourselves removed a month or two back in the calendar.

Father. - Have you not noticed, since this warm weather commenced, a peculiar haze around the horizon, a mistiness in the atmosphere, which is not common in summer? there is an indistinctness about distant objects which, in ordinary weather, are clearly seen; the sun is "shorn of his beams," and the air appears filled with a light thin smoke. This characterises the "Indian summer," a very remarkable phenomenon, and peculiar, I believe, to North America. It never appears till after the summer has yielded to cold weather, and generally follows a series of wintry days, and often pretty severe frosts. It is hailed with pleasure when it comes, as a slight and brief relaxation from the horrors of 
winter ; for in our frigid clime, we are glad of any shortening of our winter of half the year. I do not know that this little mimic summer ever fails of its appearance, though in some seasons it is much more brief in its duration than in others. Sometimes it continues, a course of beautiful and serene weather, for two or three weeks; at others, we have only as many days, hastily snatched from the sway of Boreas, just to remind us of balmier times.

C. - It is a pleasant variation, and as curious as it is agreeable. Pray what is the cause of the phenomenon?

$F$. - I believe no adequate cause has yet been assigned, though many conjectures have been hazarded. Some have supposed the heat and mist to be evolved by the fermentation of those immense masses of vegetable matter, leaves of trees, wild herbage, \&c., which are deposited at this season, over the vast forests and wildernesses of this continent. But it appears to me that fermentation would take place to a much greater extent in the ensuing spring than in the autumn, the heat of that season being likely to have a greater effect on these masses, especially after their having been saturated with moisture from the melting snows, which have lain upon them through the winter. Others conjecture that the heat and haze are caused by the fires which at this season are kindled on almost every farm to consume logs, brush, \&c., after the drying of summer. This cause, at first sight, seems very incompetent to the production of so general an appearance; but the burnings appear to be very widely spread, and I have myself observed at other times, when large brush fires have been burning in the neighbourhood, that the smoke will be diffused and rest in the air for several days, if there be no wind, causing an appearance very similar to the present. Still, however, I incline to think that it owes its origin to natural, rather than to artificial causes.

C. - The lepidopterous insects seem glad to avail them- 
selves of this intermission of winter, for they are sporting joyously in the sunshine; the moths are hurrying to and fro among the leafless bushes and dead weeds, and even butterflies, more emphatically children of the sun, are enjoying the Indian summer. I have seen the Compton Tortoise, and Camberwell Beauty (Vanessa J.Album, and V.Antiopa) about the house and orchard: and the Violet Tip (Grapta C. Aureim), and Clouded Sulphur (Colias Philodice), are quite numerous. Indeed, I had a specimen of the former, (the Violet Tip) produced from the chrysalis in my nurseboxes, this very morning.

$F$. - Ice was formed about the margins of the Coatacook a week ago, but the warm weather since has melted it. The edges of a river always freeze some time before the centre, on account of the greater stillness, the attraction of the banks resisting the current, and preventing it from having that force which it has in the middle. For a parallel reason, bends or sudden turns in a river are often dangerous, when all appears covered with solid ice; the eddies formed in such places tending to prevent the freezing.

C. - There is a wren hopping about the logs at the edge of that swamp. What a cunning little fellow he looks, creeping about with erected tail! he seems the very essence of activity.

F. - I suspect it is the Winter Wren (Sylvia Troglodytes), which Wilson supposes to be the same with the common European wren; but I judge only from the season, the other species leaving for the south much before this time. All the wrens are too much alike to determine the species without actual examination.

C. - Yonder goes a large wasp with black and yellow rings: it is late for wasps to appear; but I suppose the new summer has revived it from its torpidity. Looking at the 
nest, which we found in the hay field in mowing time, I found the wasps benumbed and unable to fly, as it was one of those cold frosty days, a week or two ago.

$\boldsymbol{F}$. - I found, a few days since, in a cavity in a piece of timber, several of the thimble-like cases forming the nest of the Leaf-cutting Bee (Apis Centuncularis); they were made of round pieces cut out of rose leaves, most snugly compacted together; the thimbles fitting each into the other, and each containing a maggot.

C. - Would they have produced the perfect bee this season?

$F$. - No, I should think not; but it is probable, as the maggots were considerably grown, they would have gone into the pupa state, if left undisturbed, and have produced the imago early in spring.

C. - I have taken some new moths lately, particularly a beautiful Geometra, and some pretty Noctuce.

F. - A friend of mine told me that he observed, about five days ago, in a potato field, a young snake of the common chequered kind (Coluber — ? ). It was about six inches long, and as thick as a tobacco pipe; it was very active, and darted out its tongue quite vigorously. I have not met with any myself for many weeks.

C. - These heaps of fallen maple leaves are quite teeming with life: here are great numbers of the little crimson-striped Froghoppers (Tettigonia Quadrivittata), hopping about right merrily; and some of a green species, still more minute (Tettigonia Mollipes). Here is also one of those fan-winged locusts, with the thorax elongated into a sharp spine, reaching to the anus, whose delicate net-work wings reflect every tint of the rainbow (Acrydium Ornatum). And this reminds me of another very delicate insect, the little Pearl-fly (Hemerobius Fasciatus?), which I found last evening on a wall within the house. Several flocks of black 
birds have been hovering and alighting about the ploughed fields all day, and yonder is a large flock now. Are they Grakles?

$F$. - There is no doubt but they are: from what I can distinguish, I judge them to be the Rusty Grakle (Gracula Ferruginea), which are searching for worms and larvæ of insects, on which they probably depend for subsistence as much as on grain. They will soon retire to the south, as they are migratory. It is stated by Bonaparte, in his Ornithology, when treating of the Great Crow Blackbird (Quiscalus Major), a closely allied species to this, that "when the first European settlements were formed in North America, the havoc made by these birds [the Grakles] and the Troopials, in the grain fields, was so great, that a premium was given for their heads. Their destruction was easily effected, as they are not shy, and are more easily approached as their numbers decrease; but the evil which resulted from exterminating so many of these birds was as unexpected as irremediable. The corn and pastures were so devoured by worms and insects, that the inhabitants were obliged to spare the birds, in order to avert a scourge which had been previously unknown." How short-sighted is man! and into what disastrous calamities would he plunge himself had he but the power, as he has too often the will, to alter the decrees and arrangenents of Providence! To no man is the study of natural history of more practical benefit than to the agriculturist, that he may learn what are his real enemies, and how to distinguish friends from foes. I once saw a gentleman of wealth and intelligence in the South busily engaged in picking off from his cotton and destroying the Ladybirds (Coccinella). On my inquiring the reason, he informed me that the cotton was infested with hosts of Plant lice (Aphides), and that they were produced from these beetles. He was confirmed in this opinion by the two being 
always associated together: wherever the lice were, there was the ladybird. He was quite astonished when I informed him that the aphides constitute the regular and sole food of the ladybird, which seeks them out and devours them continually; and that he had been promoting the breed of a pernicious insect, by blindly destroying another race, which God had appointed to keep them down.

C. - Our friendly little winter visitants, the Crossbills (Curvirostra Americana), are come. I observed a flock of them yesterday, hopping about, behind the house, where the washings of the kitchen are thrown. They were all in mottled plumage.

F. - They are northern birds: I do not conceive that they breed even in this latitude, but retire to their native regions of snow and ice, the solitudes of Hudson's Bay, in summer. Perhaps we may consider, with respect to all birds that seek cold latitudes in summer, that those are their natural regions, from whence they are driven by the inclemencies of winter to seek a temporary shelter with us, but return to those countries again as their homes; which may be as delightful to their feelings as the tropical islands to the Birds of Paradise.

C. - Here are some little flies flitting along: I have caught one, and find it to be a delicate Day-fly (Ephemera). Flies of this genus appear early in spring, and continue all the summer through; that is, a succession of them; for they are proverbially short-lived. The Caddis-flies (Phryganea), however, seem to have a much longer range; perhaps the longest of all insects, except some of the Muscida, and a few beetles ; for they flit to and fro in the woods, before the earth has put off its mantle of snow, and withstand the approaches of winter for some time, if I may judge from last fall, when I used to observe Phryganece in the evenings until November was considerably advanced. 
F. - The frogs have not yet retired to their dormitories beneath the mud; to spend their half-year in sleep, or a state still nearer death than even sleep itself. A curious state is that of torpidity! in which the respiration, digestion, circulation, and all the vital functions are suspended for so long a time, and yet, that time being past, resume their sway with the same precision and regularity, as if they had never been intermitted. We may say of these animals that their life is all summer : since during winter they can scarcely be said, with propriety, to live at all. - Those little dancing motes, the Tipulidan Gnats, are playing over the brooks, and may occasionally be noticed in the sheltered woods, in fine days, even in the depth of winter. They must have a great power of resisting the effects of cold.

C. - I saw a flock of Blue-birds (Sylvia Sialis), a few mornings ago, perched on the fence of the garden, close to the house. It was a cold morning, and they might have been attracted by the hope of picking up some of the minute crumbs and scraps, \&c., which might be lying about : for I suppose insectivorous birds can upon occasion feed on farinaceous substances, such as bread, \&c.

$F$. - The severe frost on the night of the 4 th spoiled my store of apples, by freezing most of them on the trees. The effect of frost on this fruit is singular; the pulp of the apple seems to be all turned to juice, which may be squeezed from it in abundance at every pore, after it is thawed: I suppose the cellular texture has in some measure been broken and destroyed by the expansive power of the frost, so that the juices which before were held in minute cells now lie loose as it were among them, like a saturated sponge. They very soon rot, but it is said, that if they are pressed immediately, they are as suitable for making cider as unfrozen apples. A very slight covering will often protect fruit from the effects of frost: I have known a number of apples to be preserved 
from injury by merely a linen cloth thrown loosely over them, while others lying in the same chamber, and beside them, but uncovered, were hard frozen.

C. - On the morning succeeding that frosty night, I was amused to observe the leaves falling from the trees: at every stir in the air, which was very still and calm, they descended in showers. Our old butternut in particular, I noticed; it had been in almost full leaf, but the crisped and brown foliage fluttered down in a continual stream, so that in an hour or two it was almost completely leafless. I never saw so great a change in so short a time.

$F$. - A change nearly, though not quite as great, was made in the general woods; most of the deciduous trees are now bare; even the poplars are turned, and fast defoliating. The ground in the hardwood forest is now covered with sere leaves, and strewn with beech nuts. These are numerous this year, affording a plentiful supply to squirrels, mice, blue jays, \&c. Squirrels mostly remain within the woods, in winters when nuts are plentiful, and fare well; but in seasons of scarcity they come very short; many resort to the farmer's barn, and live by theft, and often die by the avenging gun, but very many more are starved to death : so that after a season in which the beech-mast has failed, we see but few squirrels for several years. The fruit of the beech is called by botanists a glans; it is at first tightly enclosed in a strong and tough envelope, covered with flexible prickles : this is the cupule, a form of the involucrum; its bracts are four, enclosing two triangular nuts, which face each other; they resemble the chestnut in some particulars, but are much smaller, and the angles are sharper: like it the kernel or seed is enclosed in a shining coriaceous pericarp or shell, of a dark brown colour. The bracts separate when sufficiently ripe to allow the nut to fall to the ground, but occasionally an empty cupule, and sometimes an unopened one, is found 
on the ground. The nuts are sweet and agreeable, but are too small to be worth the labour of collecting. Among them are great numbers of the fruit of the sugar maple: it is a samara, and very much resembles the wing and thorax of a large hymenopterous insect: the wing being full of longitudinal veins adds to the likeness: they usually grow in pairs, and might be taken for a pair of wings, but that the thorax is likewise double. This part is hollow, and contains the seed, the cotyledons of which are green, smooth, and long-oval: these, though more than an inch in length when unfolded, are so curiously convoluted and wrapped together, as to occupy a space little larger than the head of a large pin; and this too is enclosed in a skin. Its taste is like that of the beech nut. The seeds of the birch are very small and flat, inserted beneath the scales of cones much like those of the pine family: like the seeds of most forest trees, they are almost confined to the topmost branches. The fruit of the ash is long-oval, thin, and flat; it is a samara: the seed runs through the middle, but towards the lower end. One of the most curious of our forest seeds is that of the basswood: you may see one yonder slowly descending through the air : it whirls round horizontally with great rapidity, as it falls, as if on an axis or pivot. Take it up and examine it: here is a long lance-oval leaf (bractea) transversely bent in the middle : from the angle on the under side proceeds a slender stalk, at the end of which is fixed a round body like a pea, which looks, as it descends, as if it hung by a thread from the leaf-like wing. This contains the seed. 


\section{XXIV.}

\section{NOVEMBER 1st.}

Clear bright Weather of Autumn unlike that of Summer. - Beautiful Forms of Frost. - Hoar Frost on Grass. - Skeleton of Leaves. Migratory Birds. - Tamarack. - Insects. - Autumnal Flow of Sap. - Resort of Butterflies. - Firefly. - Crinking of Grylli. - Carab. Moths. - Ichneumon. - Snake.-Frogs.-Ruffed Grouse-its mode of Flight - Food, \&c.

FATHER. - This is a delightful day; the air is clear, fresh, and bracing; the sunshine is bright and unclouded; yet how totally unlike summer! its character is exclusively its own, but yet we cannot readily tell in what it consists; we feel and see intuitively the great difference, but do not at first see what causes it. The pleasant breeze, the bright blue sky, the warm sun, are the same ; the ground dry and hard with frost, has the same solidity and appearance as if parched with heat;-yet if we consider minutely, we shall find its peculiarity consists in the stillness that prevails; there seems to be a general death pervading the woods, the fields, and even the very air. If we call or shout, our voices seem unnaturally loud, and a hollow echo is all the sound returned; then the same deathy stillness prevails again. In summer the woods are full of little twittering musicians, glancing from bough to bough, which, even when they do not sing, continually, by their unceasing activity, break the still silence. The quivering leaves, with the light ever glittering through 
their green transparency; the hum of bees; the crinking of grasshoppers ; the arrowy flight of the dragon-fly ; the brightwinged butterfly; the little pearly moths hurrying from bush to bush; and the thousands of little insects, too minute for enumeration, almost too minute for vision, which throng the air, reflecting tiny flashes of light in every direction from their filmy wings, make the summer full of life and joyousness. Now, all this has ceased: the fields are deserted by the husbandman; no insects flit to and fro ; no leaves glitter in the sun;-now and then the quick rattle of the red squirrel is heard, or a few crows caw as they sail over the woods, or a blue jay raises a discordant scream as he flies from one tree-top to another, or the black-capped titmouse twitters a few moments from the branches of some thick balsam, or a sere beech-leaf slowly rustles to the ground;but all these are casual interruptions, only heard at intervals, and seem to make the intervening silence still more dead.

Charles.-The solitude, however, is not unpleasing; the brightness of the sun and the freshness of the morning air prevent anything like a tendency to melancholy.

$F$. - How extremely beautiful are all the forms of congelation! whether we examine the filmy star-like flakes of snow; the needles shooting across the surface of freezing water; the curled and fantastic leaves traced upon the window-pane; the curious spongy masses of columnar ice formed among the furrows of ploughed land, or the delicate hoar frost on the lowly herbage; each forms a volume in itself, and each is a monument of skill and wisdom. Look at this stalk of grass : how elegantly is it decorated! a thick series of white crystals, like glassy feathers, stand out at right angles from the stalk, radiating in every direction, and extending not only all up the main stem, but even to the remotest extremities of the panicle. 
C. - What is the cause of these crystals called hoar frost ? or, rather, in what manner are they produced?

$F$. - They are never found except after those nights in which the floating vapours are condensed and precipitated in the form of dew : a cold stratum of air resting on the earth, freezes the minute drops as they are deposited, and they shoot into these slender crystals. Hoar frost is frozen dew : its delicacy is owing to the minuteness of the drops.

C. - Here is the skeleton of a maple leaf, which has been macerated in water till the substance has been dissolved, leaving nothing but the veins. What a labyrinth of network is here!

$F$. - The veins or nervures of leaves are not put out at random, but ramify in a perfectly regular arrangement, differing very widely in different plants. This mode of arrangenient is important, as upon it the form of the leaf depends. In the maple, you see several main veins running from the junction of the leaf with the foot-stalk, and proceeding to the points or lobes of the leaf; these send out smaller side-veins, and these finer still, till such an immense number of ramifications is produced as we here see. When perfect, the interstices were filled with a cellular green substance, called parenchyma, enclosed between two transparent skins. But all this has disappeared, and left only the framework, a specimen of lace of nature's own manufacture.

C. - The Robin (Turdus Migratorius), the Snow-bird (Fringilla Nivalis), and the Sparrows, (F. Melodia, \&c.) appear to have retired to the south: they were to be seen almost every day, up to about a week ago, but since that time I have not seen them.

F. - There is much more difficulty in observing the departure of migratory birds than their arrival: as the first 
sight of a species naturally strikes the attention, and makes a stronger impression on the mind, than the ceasing to see it. We can scarcely arrive at any very definite data on this subject, without the tedious process of making a list, and marking the species that we have seen day by day. The birds that you have mentioned, however, being more familiar, are more readily missed than those which remain in the bosom of the woods, and only occasionally fall under our observation.

C. - The poplar and the balm of Gilead have now become almost leafless, and the tamaracks have put on their bright yellow dress. - As we look over the adjacent valley, we can easily trace the patches of tamaracks, wherever they occur, and even individual trees; the bright colour strongly contrasting with the sombre hue of the other coniferce, among which they grow. It does not appear to be a common tree with us, though on the borders of the river there are some patches of considerable size. - The tops of the hardwood forests have a reddish appearance, the terminal twigs of several species having that colour, particularly those of the maple and the basswood.

F. - We may consider the "Indian summer" as over: the present agreeable day being altogether of a different character. It has been a protracted one, lasting to the frosty night of the 28th, in which a slight shower of snow fell. Many occurrences worthy of notice marked the mildness of the time; among which, not the least remarkable was the appearance of Dragon-flies (AEshna), which I observed hawking about up to the 27th. The Winter Moth (Cheimatobia Vulgaris), and little Autumnal Case-fly, (Phryganea —?) both Newfoundland insects, have also appeared, but these are rather indicative of cold weather than of mild.

C. - A young maple tree was cut down a week or two ago; from the stump of which the sweet sap exuded just as 
it does in spring from stumps of the trees felled during winter. This showed, what I was not previously aware of, that there is an ascent of sap in autumn as well as in spring. The weather was very similar to that considered favourable to the flowing of the sap in spring,--slight frosts at night and pleasant warm days. But I was going to allude to another curious circumstance: this stump was thronged day after day by great numbers of insects, busily engaged in sucking the saccharine juices which exuded. Besides beetles, bugs, ichneumons, and multitudes of flies, of various kinds, there were many Noctuce and butterflies (chiefly of the Camberwell Beauty and Violet-tip species; the former of which was quite numerous).

F. - I observed the larvæ of the firefly shining in the grass as late as the evening of the 22nd of October. It may be possible we have more than one luminous species of Lampyris : this is a subject worth some examination. Perhaps, what I have supposed to be larvæ, may be an apterous species, allied to the glow-worm of Europe. Mr. Knapp, in his Journal of a Naturalist, mentions the appearance of the glow-worm about the end of September, as unusually late; and that in the mild climate of England. It is true our brief return of summery weather may have re-vivified these beetles, so far as to induce them to emerge from their hybernacula, as well as the butterflies and dragonflies, which have lately appeared: the last, especially, seem as exclusively summer insects as the fireflies.

C. - I observed a winged Aphis in the house a few days ago: and the crinking of the Grylli has not yet ceased, for I have heard it at intervals, since we have been abroad to-day. I have within a few days met with several groups of a very beautiful little Carabus (Agonum Cupripenne); at first sight you would hardly know it from the polished brown sort that runs so swiftly among gardens, which, from their 
rank smell, children call foxes; but these have the elytra of a brilliant crimson, that changes to as bright a green, if the light falls on it from a different angle.

$F$. - Here are two other insects of different orders; a pretty Tortrix, and a large female black Ichneumon, which emits a strong and peculiar smell. But the effects of the late weather are not confined to insects: three days ago I was surprised to see a full-grown Chequered Snake swiftly gliding over the fallen leaves, beneath the maple grove: the frogs, too, are still to be seen in the marshy pools and springs.

C. - Ha! what is that?

$F$. - It is a partridge, the Ruffed Grouse of Wilson ( $T e$ trao Umbellus). It remains with us, I believe, all the year, and at this season frequently skulks about old logs, near the borders of woods, where it might lie concealed, if it would keep its own counsel; but an approaching footstep flushes it, and off it goes, with a loud whirring noise that is quite startling: its flight is widely different from the silent motion of the Owls. It is a large and handsome bird, mottled with various shades of brown and black; and the delicate flavour of the flesh is equal to its beauty. It is in excellent condition at this season, having fed on mast, berries, \&c. ; but though common with us, it is not much pursued. Our farmers are by no means sportsmen : if a partridge were to come to their doors, I suppose they would kill it, but in general the destruction of a few pigeons when eating their buckwheat, or a few grakles at their corn, is the height of their attainments in this way. The partridge, or pheasant, as it is called farther south, breeds with us : I have frequently flushed the coveys in July and August : they will suffer you almost to tread on them before they will fly; but then they fly fast and far, before they alight. 


\section{XXV.}

\section{DECEMBER 1 st.}

Uses of Winter. - Our Feelings an insufficient Criterion of Temperature. - Cause of this. - Thickness of Animals' Coats in Winter. - Effects of Change of Climate. - Hair of Caterpillars. - Termination of Agricultural Occupations. - Butchering. - Freezing of Carcases. - Hybernation of Reptiles. - Case-flies. - Podurce - various Modes of Locomotion. - Freezing of the River. - Winter Condition of Fishes. Subaqueous Sensations. - Reflection from the Surface of Air. - Yellow-bird. - Canada Jay. - Downy Woodpecker. - Blind Prejudice. Tempest in the Forest - its Effects. - Grandeur of God.

FATHER. - The rains of autumn have now fairly yielded to the frosts of winter : our long season of cold weather has set in :-

"And skies their wintry sternness wear."

Charles. - How dreary and desolate an appearance the face of Nature now presents? no longer smiling in loveliness either in forest or in field. The trees, stripped of their rich foliage, stretch their naked and contorted arms abroad, like gaunt skeletons ; the streams and brooks, where the sunbeams played in the sparkling waters, are sealed up and still; and the verdure of the field is exchanged for a wide and unbroken waste of snow; and animate nature is as dead and silent as inanimate: nothing mores but the tops of the leafless trees in the wind: nothing is heard but the sighing of the gale through the boughs. Oh! I do not love winter: it is cheerless and depressing: give me the 
smiling spring, or the glorious summer, with their thousand gladdening accompaniments, that make our blood dance, and our hearts leap!

$F$. - But it would not do for summer to last always. Nature requires a season of comparative rest, as well as of action. Important purposes in vegetation are fulfilled in winter, which, though they are unseen, are not unfelt in their consequences; juices are elaborated and modified; recently developed parts acquire strength and consistency; and plants are prepared to shoot out fresh buds, the rudiments of another verdure. Yet winter is not altogether cheerless; by searching we may yet find a few subjects worthy of investigation, and capable of affording amusement and instruction to the mind; nature is never barren of lessons of wisdom, to him who possesses a mind willing to receive them.

C. - The wind blows keen, although, when we set out, the thermometer indicated rather a mild temperature. How is this? why shall one day to our senses be quite warm, and the next keenly cold, though the mercury stands at the same degree on both? I know it is caused by the presence or absence of wind, but I do not see why the wind should have so sensible an effect on our feelings, and yet make no corresponding alteration in the state of the thermometer.

F. - Our senses do not give us a true estimate of the real temperature of the atmosphere. Cold is not a positive quality : it is merely a negation, the absence of heat : the sensation of cold is caused by the animal heat being abstracted from the surface of our bodies faster than it can be generated internally. It is the property of heat to equalize itself by passing out of one body which has more, into another in contact with it, which has less, until the temperature of both is alike: but some substances abstract heat more rapidly than others, whence they are called good conductors of heat. 
These facts being premised, we see the cause of the difference between our feelings and the height of the thermometer. When the temperature of the atmosphere becomes colder, the surrounding air abstracts the heat remaining in the mercury, until the instrument and the atmosphere are exactly alike. After this, it may blow a hurricane without affecting the thermometer, for wind being nothing but motion communicated to air, no more heat is abstracted, as it has already been equalized. But a living body has a power of generating heat, which passes in due course into the circumjacent air: if the air be still and undisturbed, the portion immediately around us becomes in some degree saturated, as it were, and no longer abstracts the heat so fast ; perhaps not so fast as it is generated, in which case we feel the sensation of warmth. But let the air be put in motion, and the stratum of heated air which enveloped the body is blown away, and new and cold portions are every moment brought in contact with it, which, abstracting the heat faster than it can be generated, cause a sensation of cold that increases in proportion to the force of the wind; that is, to the rapidity with which fresh particles are presented to the surface. This too explains the use of clothes: they keep, but they do not make us warm: they are made of substances which conduct heat slowly, and so maintain a stratum of heated air around the body, parting with the heat less readily than it is re-supplied.

C. - I suppose the thickness of animals' fur in winter answers the same purpose: I observe the horses and cattle have their coats much thicker than in summer.

$F$. - Yes; that is an admirable ordination of Divine Providence, for the comfort of the inferior animals. No sooner does winter approach, than the coat of our domestic creatures (and I believe the wild ones too), which before was thin and sleek, becomes thick, shaggy, and somewhat erected, and partakes more of the nature of fur than of hair: 
in spring, when its purpose is answered, and when it would be no longer an advantage but an encumbrance, it is shed in thick matted masses, and got rid of by rubbing, \&c. the coat becoming thin and smooth as before. A similar change takes place in those animals which are clothed with fur in summer; on the arrival of cold weather, the base of the fur is filled with a very thick and soft down, like that of birds, which disappears in spring, as may be seen in the hare, racoon, \&c. It is the same if we alter the climate of any animal : the hair of the dog becomes wool or fur in very cold climates, and the wool of the sheep becomes hair in torrid ones. It is this circumstance that makes the furs of cold regions so much more valuable than those of warmer ones; the texture is thicker, softer, and more downy; the same species which produces fur at Hudson's Bay producing little else than hair at the Gulf of Mexico.

C. - Here is a caterpillar of the Buff leopard Moth (Arctia Isabella), coiled up in an auger-hole in this maple tree: he too is probably protected from the cold by his tufts of thick bristly hair.

$F$. - Perhaps so : and yet I am not quite certain that animal heat is generated by insects, or that they need external covering. - All the operations of agriculture have now ceased: the digging out of the potatoes was the last of the processes belonging to the crops of last season; which was generally completed two or three weeks ago. The potato is perhaps the greatest blessing which America has given to the world; its consumption is already spread over the civilized world, and its cultivation is yearly extending, on both continents.

C. - After the potatoes are stored, you begin to plough for next year.

$F$. - Yes, and before: immediately after harvest, we plough at intervals when the weather will not admit of any- 
thing else. Our season for preparation in spring is so short, that we are anxious to open as much land as we can in the fall, before the frosts set in and render it impracticable; we therefore plough early and late, both stubble land and greensward. Besides this, the effect which the severe frost of winter has on ploughed ground, in expanding, pulverizing, and rendering it mellow, is so great an advantage as we spare no exertions to obtain.

C. - What occupies the farmer's attention when the frozen ground will no longer permit him to plough?

$\boldsymbol{F}$. - He then kills his fatted cattle and hogs, either for market or for domestic consumption : this is a business of a good deal of bustle and activity, and attended with no small merriment and congratulation from one to another; the number, weight, fatness, and description of animals butchered, forming inexhaustible subjects of conversation for some time after. Some, especially of the pork, is salted down, but a good deal of the beef and mutton, and part of the pork, is kept throughout the winter, perfectly sweet and fresh, by being frozen in carcases. Many sled-loads of frozen sheep, pigs, \&c. may be seen during the season, going to market, so hard and solid that they can be divided only by the axe or saw. The lean part of meat, when frozen hard, is more difficult to saw than oak plank, and makes a quantity of saro-dust. If much mild weather occurs in the winter, the meat thaws, and these repeated thawings and freezings deprive it of much of its juices, and make it rather dry.

C. - All the cold-blooded animals seem to have retired to their winter quarters.

$F$. - The reptiles have, no doubt: on the 16 th of November, I saw some young frogs dart from the bank and dive amongst the mud of a spring, which was the last time I ob- 
served them; and I suppose, as a fall of snow took place. during the ensuing night, most of those which remained active retired on that day. A few insects, however, are still to be met with; I found a living Case-fly (Phryganea) on the surface of that snow I have mentioned, on the morning after. it had fallen, and small Musca and Tipula still fly about the woods, and in sheltered situations.

C. - Here are some hopping atoms, on the surface of the snow on the road side. I observe they are a minute species of Springtail, of a dark bluish grey colour.

F. - This tribe of insects, the Springtails (Podura), minute and insignificant as they appear, have not been too mean to be the exclusive object of one instance of the inventive wisdom of the Deity. These little creatures have a mode of progression peculiarly their own, and differing widely from that of any other animal I know of. The tail terminates in two setæ, or bristles, which are usually bent up under the belly, but when the insect wishes to move, these fly out straight, and by the elastic force, throw the insect forward by a vast leap. Whether the spring is kept bent by muscular effort, and flies out of itself when relaxed, or whether its natural and unconstrained position is bent, and it is driven out by an exertion, I cannot affirm. It is singular that this species generally appears on the surface of snow, just after it has fallen; whence coming, I know not.

C. - I have observed several other species : one swarms on little pools of water in summer, sometimes so thickly as completely to hide the water, showing only a surface of black dust, resembling a parcel of gunpowder. Another, a little larger, and lighter in colour, abides in crevices of posts, and particularly of hot-bed frames, in spring.

$F$.-The different modes by which locomotion is performed, constitute a very curious subject of investigation : they are far more varied than cursory observers would suppose. Some 
animals proceed by running, as the horse, the partridge, the Cicindela; - some by leaps, made by the elastic force of the hind feet, as the kanguroo, the jerboa, the frog, the grasshopper, the flea; by a spine entering into a cavity with a jerk, as the Elaters ; by a bifurcated anal spring, as the Podura just mentioned;- - some by flight through the air, performed by very different organs, the feathered wings of the swallow, and the skinny flaps of the bat, the transparent filmy wings of insects, the lengthened fins of the flying fish, the cottony down of the Aphis Lanata, the airy gossamer of the spider:- some hop, as the sparrow; some walk, as the crow:- some move on the ground, by alternate extension and contraction of muscular rings, as the earthworm; by imbricated scales, as the snake; by a sucker at each extremity, as the leech ; by an application of all parts of the under surface to the ground, as the snail:- some swim through the waters, by means of fins, as fishes; by an ejected stream of water, as from a forcing pump, as the grub of the dragon-fly; by a serpentine motion of the abdomen, as that of the Ephemera; by oary feet, as the Dytiscus and Notonecta; by the impulse of the tail, as the lobster; by contraction and dilatation, as the Medusa: - some glide on the surface of the water, as the water-measurers, and some spiders :some float on the surface, as the waterfowl and the Portuguese man-of-war (Physalis): - and some slowly change their position by the projection of a muscular tongue-like organ, as the cockle, and some other Testacea. Here is great variety; but doubtless there are many other contrivances for the same end, with which I am unacquainted. 
C. - The Coatacook is now frozen over, and I suppose will not open again before spring. Do the fishes become torpid? or how do they sustain the severity of the season, when the water is covered with " thick ribbed ice?"

F. - I apprehend that fishes in general do not become torpid, and I do not know that any species does : the temperature of the lower parts of the water probably does not differ in a very great degree, at the different seasons of the year. The very ice that is formed at the surface contributes to preserve the equality of its temperature, and we know that as long as it remains fluid, it cannot be lower than $32^{\circ}$ of Fahrenheit, whatever that of the air may be. There is another question, however, which may be raised: fishes cannot subsist, any more than terrestrial animals, without an absorption of oxygen; when the connexion of the water with the external air is cut off by a solid crust of ice, will they not sooner or later arrive at a point, when the water will part with no more of its oxygen? That this is not an imaginary difficulty is proved by the fact, that fishes in a bowl of water placed beneath an exhausted receiver, soon die, although the water still contains much oxygen, or it would no longer be water, but hydrogen gas : though perhaps it refuses to part with any more. I once saw in Newfoundland a case in point: a little brook had been enlarged in one part into an oval fish-pond, containing perhaps two hundred square feet, in which the water commonly lay about eighteen inches deep ; a few trout lived in this little pool, that usually continued open in the middle, through which the brook ran; but one severe winter it was quite frozen over, and the fishes in the ensuing spring were found to be all dead. In the case of this river, however, the edges always communicate with the air, the ice breaking by friction, so that a stick may often be thrust down between the bank and the ice; and were it otherwise, it would seem that the vast supply of 
fresh water continually flowing down beneath the ice would afford oxygen enough to support the comparatively few fishes that inhabit it.

C. - I should think a life under water must be a dull kind of existence, confined to a very limited sphere; for I suppose their senses can give them very little, if any, information respecting the world above them.

$F$. - I am not so sure of that; as we can distinguish objects clearly in pure water, when the rays from them strike our eyes in a direction perpendicular to the surface, or nearly so, it is not improbable that fishes may be able to see with some distinctness those objects in the air, which are immediately above them; such as the trees on the bank, the insects. and birds that fly over the water, the blue sky, clouds, sun and stars : though of the green face of the earth they must of course be as completely ignorant as we are of the caves of ocean. Here, however, they have variety enough, and I should not think their life dull for lack of objects, though it is doubtless a very different world from ours. I have sometimes tried to picture to myself the scenery of the water, but can form very little idea of it: the bottom is probably as plentifully clothed with vegetation as many parts of the land, and contains hills and dales, rocks, and caverns, and bright sands, in profusion. There is an interesting fact, which is familiar enough to the fishes, but of which you are probably not aware. It is, that the surface of air which touches the water possesses the power of reflection as perfectly as that of water; but of course in the opposite direction: so that could we stand under water and look obliquely towards the surface, we should see every object beneath reflected from it; the diversified bottom, fish swimming, floating weeds, \&c. would be as truly imaged, if the top were smooth and unruffled, as the skies and trees are on the surface of the still pond, Any one may prove this, by filling a glass 
tumbler with pure water, and putting therein a few waterinsects, or any substances that would float just beneath the surface: a globe containing gold fish is a good illustration, and the illusion caused by the fish's occasionally coming up and meeting its image has a pretty appearance. Of course, the observer must look through the side of the glass, obliquely up to the surface.

C. - Yonder are two little birds singing on a cherry tree.

F. - Their song and their colours show that they are Yellowbirds (Fringilla Tristis), but in their sober winter plumage. It is very late for these birds to be here; I should think they would hardly retire at all, since they have deferred it so long. - The Canada Jay (Corvus Canadensis) is quite numerous now : it appears with us about the middle of October, hopping about in fields and pastures, and at the margins of woods. Wilson appears to have had a very slight acquaintance with this species; it is by no means a bird of solitary habits, almost always appearing in parties of three or four: neither does it, with us, confine itself to "unfrequented shaded retreats," as his informant reports, but, on the contrary, seems to be a saucy, familiar, fearless bird, often coming about the house, and playing about till one gets very near it. In Newfoundland, where they are common, they live in the woods, but are very often found in the paths, feeding on the crumbs of bread, droppings, \&c. which are met with in frequented places. A winter or two ago, there were several Canada jays that used to come and play about some fir trees on the banks of the Masuippi, close to a village school, unterrified by the uproar of the boisterous boys. I observed a party of them a few days ago, around 
the house, paying particular attentions to a sheep-skin which, having been recently taken off, was spread on the fence close to the house to dry. They hopped upon it, close up to the window, where I was looking at them, tugging at the bits of fat which remained on the skin, large pieces of which they tore off, and swallowed. I then observed that the white on the crown, chin, throat, \&c. is of the purest and brightest tint, and not "a dirty, brownish white," as described by Wilson. These birds, from their carnivorous habits, are here called by the common people "Carrion-birds ;" in Newfoundland, it is known as "the Jay." But the wind is rising and the clouds indicate an approaching storm: we had better return.

C. - There is a little bird hopping about the trunks and branches of those willows: he has all the appearance and manners of the woodpeckers. I presume it must be the little Downy Woodpecker (Picus Pubescens).

$F$. - Yes : it is a pigmy species, scarcely larger than a warbler; a woodpecker in miniature, yet in every respect a very complete representative of his tribe. He very strongly resembles his brother, the Hairy Woodpecker (P. Villosus) in everything but size: the present is not so common as that species, but has received in common with it the ridiculous name of "Sapsucker," a name which is undeservedly, slanderously, affixed to these useful birds, throughout the whole of the United States, from Canada to the Gulf of Mexico. That they bore our apple trees is undoubtedly true ; but it is for the purpose of dislodging the hidden maggot, which is rioting unseen on the juices of the tree; and it is as just to accuse the woodpecker of the injury which the tree sustains, as to accuse the surgeon who probes the wound for the purpose of extracting the assassin's ball, of inflicting the wound, and of being himself the assassin. But preju- 
dice is, I fear, too inveterate, and too deeply rooted, to be removed by reason.

C. - Hark to the wind! how it howls and whistles shrilly through the tops of the trees, like a close-reef gale through the shrouds and ropes of a ship at sea. Now it sinks to a hollow moan, then sings again, uttering sounds which one might fancy those of an immense Eolian harp. The leaves fly from those few trees which still retain any, and the long grey moss streams from the tops of the scathed hemlocks, stretching far out upon the blast, like signals of distress.

F. - Ha! do you hear that crashing roar? Some mighty tree has bowed to its destiny. We are in danger until we can get out of the proximity of the forest. Yonder is one prostrate across the road, which has fallen since we passed an hour ago: see how it has crushed the fence, and torn up the ground of the field on the opposite side! There thunders another! they are falling now on every side; and the air is thronged with pieces of bark, shreds of tree-moss, and broken branches, descending. It is appalling to hear the shrieking of the gusts, and the groaning of the trees as they rock and chafe against each other, while they toss their naked arms about, as if in agony.

C. - Now we are out of immediate danger, we may breathe more freely. But see! here is another scene of devastation; the wind, acting with full force on these rails, has laid the whole fence prostrate with the road, for nearly the whole length of the field. And look at yonder haystack; the gusts of wind insinuate themselves under, near the top, and tear off great bunches of hay, which go sailing over the fields.

$F$. - It is well these tempests do not often occur; for they do much mischief, unshingling, and sometimes blowing 
down houses and barns. - How great is the power of God! who can arm with such resistless force an agent so impalpable, so invisible, as the air: 'so that a substance which in ordinary circumstances is not only pleasant and innocent, but absolutely indispensable to the continuance of our existence, may become the swift messenger of our destruction. Well may we say with Elihu, "with God is terrible majesty!" 


\section{XXVI.}

\section{DECEMBER 31 st.}

Drifted Snow.-Inconvenience of intense Cold little felt-Effects more external than internal. - Frozen Feet of Poultry. - Semi-congelation of Water. - Sleigh-riding.- Occupations of Winter. - Tending Stock. - Threshing. - Cutting Fuel - Rails. - Brown Creeper.-Grubs of Beetles. - Winter Gnat. - Snow-bunting. - Yellow-birds [Pine-finch, note].-Gleam of the Woodman's Axe. - Arvicola. - Insects.-Hippobosca. - Blue Jay. - Size of Trees. - Structure of Trees. - Death by Girdling. - Excrescences. - Close of the Year. - Conclusion.

Charles. - What curious and beautiful forms the drifted snow assumes! here it lies in gentle undulations, swelling and sinking; there in little ripples, like the sand of a sea beach; - here it stands up like a perpendicular wall; there like a conical hill :- here it is a long deep trench; there a flat overhanging table; but one of the prettiest sights is that which is presented by a lumber-shed hung with cobwebs, after a drift. The snow in greater or less masses has attached itself to the cobwebs, and hangs from the rafters and walls, and from corner to corner, in graceful drapery of the purest white; but of such fantastic shapes, as we don't readily see.

Father. - The heavy masses of snow which rest on the flat horizontal boughs of the spruces and hemlocks after a fall, are striking and beautiful: but these must be gently deposited, or they will not rest ; they are not drifted; a very slight wind is sufficient to shake them off. 
C. - We have had some severe weather during this month, yet I have not felt nearly so much inconvenience from the intensity of the cold, as one would expect from the temperature of the atmosphere. There seems to be something enlivening and bracing in our air, which prevents our becoming so much affected by it.

$F$. - Our cold weather is generally clear and uniform, and our bodies become inured to its severity. After having spent many winters in Newfoundland and Canada, I passed one in the State of Alabama. I had congratulated myself on the thought that now I should not know cold weather; that * after Canada, the winter of Alabama could be nothing to me. But I found that slight frosts, and wet windy days, interrupted by warm ones, seemed to me almost as cold to the feelings as the severity of Canada. Before the winter was over, I sailed for England, and although the thermometer was on only one day as low as $36^{\circ}$, I felt the inconveniences of extreme severity, my feet becoming covered with the wellknown annoyances called chilblains, and my whole frame shivering with cold: this was, no doubt, owing to the sudden transition from a climate of $76^{\circ}$ to that of $36^{\circ} .-\mathrm{We}$ here find the intensity of the cold as much manifested by collateral circumstances as by our bodily sensations. The creaking of the snow beneath our feet : the adhesiveness of doorlatches, or any metal, to our hands, if there be the slightest moisture on them; the clouds of steam which pour from our mouth and nostrils when we breathe; the accumulation of frosted leaves on the windows of rooms in which great fires and close stoves are kept; the fringe of ice round the edges of our pillows and blankets, from our breath having frozen while we slept ; the piercing pang felt by the lungs on suddenly emerging from a warm room, and inhaling the cold air ; the pricking sensation in the cheeks ; the whitening of the whiskers, hair, and eyebrows; the icicle at the nose; 
the freezing together of the tips of the eyelashes, during the momentary twinkling of the eye; - these warn us of the real state of the atmosphere, and of the danger of remaining long exposed, even when it does not feel very unpleasant to the senses.

C. - We yesterday found one of the fowls in the barn in an awkward predicament: it was lying on the floor, unable to stand : and on taking it up we perceived that both feet were frozen hard, so as to be perfectly stiff, and chinking, when struck, like stones. We brought it to the house, and put it to lie with its feet in a bowl of cold water, where it remained very contentedly for a considerable time, until its feet were thawed, and they seemed perfectly restored.

$F$. - They are for the present, but after having once been frozen, they are peculiarly liable to a recurrence of the accident, and rarely survive the winter.

C. - I observed a curious circumstance a short time ago: I had taken a bowl of water into my room to wash my hands, but something delaying me, it remained for an hour untouched. Then, when I dipped my hands in it, it was perfectly fluid, and altogether free from any incipient crystals of congelation; but in an instant it became a semi-solid mass, filled with minute particles of ice.

$F$. - I have often observed the same fact, and at one time mentioned it to my friend, Mr. W. C. St. John, of Harbor Grace, Newfoundland, whose acquaintance with the science of chemistry led me to ask him for an explanation. He told me that, as "water cools below $32^{\circ}$, the particles of it approach one another; but in consequence of its being still, i.e. unagitated, those particles, although they approach, remain equidistant from each other: - that is to say, the repulsive power (alias, the matter of heat) and the 
attractive power acting equally upon every individual particle, no set of particles can overcome that repulsive force, so as to form themselves into a new arrangement, viz. into an angle of $60^{\circ}$. Therefore, the water remains in a fluid state; but as soon as it becomes agitated, the equilibrium is immediately destroyed; the motion, which is impressed on the particles, is the means of bringing some of them nearer to some than to others. A union is the consequence; and when two particles are thus united, of course their sphere of attraction is enlarged, and other particles will be soon drawn into contact, and that soft, half fluid, half solid mass, is the result." Sorne time after, he showed me the following passage in Parkes's Chemical Catechism, not as attempting a solution of it, but showing that the fact had been noticed before : "If, when the air is at $22^{\circ}$, we expose to it a quantity of water in a tall glass, with a thermometer in it, and covered, the water gradually cools down to $22^{\circ}$ without freezing, though $10^{\circ}$ degrees below the freezing point. Things being in this situation, if the water be shaken, part of it instantly freezes into a spongy mass, and the temperature of the whole instantly rises to the freezing point." The question has difficulties which are still unexplained.

C. - There go the sleighs! how merrily they slide along with their jingling bells! I think there is no motion, not even that of a swift boat upon a smooth sea, so pleasant as the riding in a sleigh on a bright sunny day, or moonlight night. Protected from the cold by the warm bear-skins, or buffalo robes, we glide noiselessly along, and see the fences and trees shoot by us, without a jolt or shake to remind us that it is ourselves who are moving; while the tinkling of the bells on the horse's neck pleases the ear, and all is gratification! Oh! it is the beau ideal of travelling!

F. - Sleighing-time is a season of general festivity : most farmers possess these vehicles; and as the agricultural ope- 
rations have now ceased, and they are not immediately pressed with work, some time is devoted to excursions of friendship and pleasure; and even the travelling which business requires is made an agreeable recreation.

C. - How do the farmers employ themselves during the winter season generally?

$F$. - The feeding and tending of their cattle and other stock, a daily employment, consumes much of the short days, and the supplying of the immense fires which we are compelled to keep up, makes considerable inroads upon the residue. The grain is threshed, and cleaned, and carried to market, with other produce. - After this, or at intervals, the greatest portion of the winter's labour is performed in the forest, in felling and splitting cedars for fencing-rails, cutting hardwood for the twelvemonth's supply of fuel, (which, with the drawing it to the homestead on large sleds, forms no small part of a winter's work,) and cutting and drawing logs for the saw-mill. So that no part of a Canadian farmer's time can be considered without employment, though in winter he does contrive to snatch a few days from toil, to devote them to amusement.

C. - I see a little bird creeping up the perpendicular trunk of a maple tree; it looks just like a mouse in size, colour, and manners : is it a species of Nuthatch?

F. - No: our Nuthatches are all of a light blue colour above; this is the Brown Creeper (Certhia Familiaris), a bird much resembling that family in appearance and habits, but with a slender curved bill. It does not appear to be common with us, or if it is it must be very shy, as I have seldom seen it. It crawls about the trunks and limbs in every direction with great agility, in search of small insects, which are lodged in crevices of the bark, and similar situations. 
C. - In cutting up a partly decayed birch tree a few days ago, I found it bored with long cylindrical passages, in several of which I found white flat grubs, with large brown heads, and six feet; in one I found a Buprestis alive, a dark brown species with lighter marks. The larvæ probably belonged to this species.

F. - I should not think that our little Certhia can capture such insects as these, its bill not being at all calculated for boring; these constitute the appropriate prey of the Woodpeckers, whose sharp, steel-like bill tears away the wood, and digs into their hidden recesses ; the bird perceiving, by unfailing instinct, the direction in which they lie concealed.

C. - I have lately seen the Winter Gnat (Trichocera Hiemalis), with pretty plumose antennæ, playing in the windows of our house.

F. - Yonder is a flock of Snow Buntings (Emberiza Nivalis) in their white winter plumage. They are not uncommon, though in some winters I do not recollect having seen any : they fly in flocks, and often flit about the orchards and barn-yards : when a flock of them is perched on a tree, their bright plumage in the sun presents a very beautiful appearance, looking like a number of silver ornaments sparkling among the boughs : they also show to advantage in flight, seen against a black, clouded sky, full of snow and storm ; at which time they are very active. They are restless birds, never long in a place, and when one moves, all follow. In Newfoundland, they are rather common.

C. - Yesterday, a flock of Yellow-birds (Fringilla Tristis) was hopping about the barnyard and house at intervals all day, picking up oats, and seeds of grass and weeds.

$F$. - I have seen several flocks in the woods, and about the borders, lately, flitting from tree to tree, and twittering 
their sweet, but weak song.* _- Some weeks ago I found a mammal, which I cannot find described in Dr. Godman's American Quadrupeds, and which may possibly be unknown. I took it for a species of Arvicola, resembling the common short-tailed field-mouse, but with a shorter tail, and the head much rounder and more bluff; the ears were large ; it was of a dark iron-grey colour. It had probably been caught by a cat, for it was lying dead on the earth, near the house. It may possibly be Arvicola Hudsonius, or perhaps a Geomys.

C. - I see, at a great distance, at the margin of the forest, a sudden bright gleam of light recurring at regular intervals of two or three seconds. Do you see it? or do you know what it is?

$\boldsymbol{F}$. - It is a woodman chopping; he is too far off to be distinguished among the bushes and underbrush; but every time he lifts his axe above his head, the polished steel reflects the sun's light, and makes those fitful flashes. It has a singular appearance, unconnected, as it seems, with any apparent cause.

C. - The insect world I have found to be not altogether so shut up from observation as I had imagined. On Christmas-day, I took a walk into the woods; and examining the stump of an old decayed hemlock, I found in it two minute Chrysomelida, a small black Cantharis, and two specimens

* At the time of making the observations on which the above remarks are founded, I had no doubt at all that these were Yellow-birds, from their mode of flight, song, colour, and manners. But I have since been induced to believe that they might perhaps have been the Pine Finch (Fringilla Pinus), a winter bird ; and which, I find by reference to Wilson, has a very remarkable resemblance to the yellow-bird in all these respects, particularly in note and plumage. The same remark will apply to the observation made in XXV. December 1st. page 345. P. H. G. 
of a pretty Ichneumon, which is shining black, except the middle of the antennæ, the scutellum, one ring of the abdomen, and the anus, which are yellow. These were inert and torpid, but soon became lively on exposure to warmth. I took among the wool of a sheep, near the roots, among which it insinuated itself forwards, backwards, and sideways, so nimbly, that I could with difficulty get hold of it, a smali apterous Hippobosca. I also observed, suspended from the wall of a house, a chrysalis of Vanessa Antiopa.

F. - The Blue Jay (Corvus Cristatus) continues as numerous and as noisy as ever. His harsh screaming voice may be heard above that of all the other feathered inhabitants of our groves, all the year through. A beautiful bird he is, with his bright violet, white, and sky-blue coat, long tail, and pointed crest ; and by his airs and grimaces he appears to have no mean idea of his own personal attractions, and probably he may think his voice as charming as his plumage, as he so continually gives us the benefit of his music. He appears to tyrannise over his brethren occasionally. I once: saw, in the south, a blue jay in close and hot pursuit of a summer Red-bird (Tanagra Estiva), and Wilson records a parallel incident. He has other notes, besides his common loud squall, some of which are difficult to recognise. In the clearing, the parties of these birds, for they are hardly numerous enough to be called flocks, generally fly high, and alight about the summits of lofty trees; but in the woods, particularly in spring, they as frequently choose a lower altitude. They are wary, and rather difficult of approach.

C. - These tall, but comparatively slender elms, remind me of an observation that struck me on my first entering a Canadian forest; that the trees, individually, are by no means of that gigantic size that my fancy had pictured them. The general height of the forest does not perhaps fall short of my expectations, but though the trees are most 
of them of good size, I have seen none of those giants which one would look for in a primeval forest.

$F$. - I have made the same reflection; I have read of very enormous trees occasionally occurring in the woods of Upper Canada, but in this province, certainly, they do not generally surpass mediocrity. The largest boles with us appear to be those of elm, birch, and hemlock, none of which I have seen that would measure more than five feet in diameter, at about a yard from the ground. I have heard of large logs of white pine, but the trees of this valuable species have been all cut away in this neighbourhood. Possibly, in other parts of the province, the timber may grow to a larger size, but I have never heard such a fact hinted.

C. - What is the cause of the coarse furrows and corrugations of the bark in many trees?

$F$. - Let us examine the structure of a tree: here is a recently-cut maple log, which will serve our purpose. We perceive several manifest divisions, the exterior of which is the bark; this, however, is not homogeneous in its texture; the outer part is called the rind or epidermis; in some, as the birch and beech, this is thin ; in others, as the maple, elm, and basswood, it is thick, dry, and rough ; in others, as the ash and spruce, it is scaly. The inner part is the liber, or true bark; and is the seat of life in the tree, the origin of the new buds; in some trees it resembles the rind in appearance, as in the maple, but in others is widely different, and may be separated, as in the elm and birch. It appears that the bark does not increase so rapidly as the wood of the tree, the increasing diameter of which forces and tears apart the rind, causing these furrows; which process is well exemplified in the stringy rind of the cedar, which is torn into lozenge-shaped divisions, like the meshes of a net. In many trees the outer layers of the rind are being continually thrown off by exposure to the weather, and their place as constantly 
supplied by the outer layers of the liber, so that however diverse in appearance, it appears that the structure of these two is alike. In the beech, fir, \&c. I conceive the epidermis is not thrown off. Beneath the bark, we perceive the wood, which likewise consists of two parts ; the outer is the alburnum, or soft wood; the interior, the duramen, or heartwood; the latter is usually darker in tint, and more compact in texture. These parts are composed also of strata or layers, which are very visible, as each layer exhibits two structures, the inner side of it being composed of cellular tissue, the outer of ducts and woody fibre; they do not increase in size, but a new one is formed every year, between the liber and the alburnum. If we strip the liber from a tree in June, we find that it readily separates, and that a mucilaginous fibrous substance is deposited between it and the trunk, which appears to form a layer of alburnum on one side, and a layer of liber on the other. In the centre of the tree we see a ring, or a section of a tube, called the medullary sheath, or corona, whence proceed radiating lines to all parts of the circumference, forming, when the tree is split, those shining satiny bands, so beautiful and conspicuous in the maple, beech, and birch. These are medullary rays, and serve to connect the medullary sheath with the leaves; the water taken up by the roots passing up the spiral vessels and ducts of the sheath, through the rays into the leaves. Within the corona is the medulla, or pith, which is composed of cellular tissue slightly compressed: it never increases in diameter after it is formed, and therefore its bulk depends not on the size of the tree, but in some nneasure on the size of the twigs; the ash, butternut, elder, \&c. which have thick large twigs, having more pith than the maple, beech, or elm, whose twigs are slender. In some full grown trees, its presence is indeed scarcely to be distinguished, the cells having been gradually filled up by the juices of the tree. 
C. - Why does a plant die if its bark be cut round?

$F$. - Because the vegetative life resides in the liber, and if this be divided, as in girdled trees, so that the upper part has no contact with the lower, no more buds or leaves can be put forth, these being produced from the inner surface of the liber. But if it be divided in part, that side of the tree whose connexion is unbroken will continue to flourish, while the portion immediately above the separated bark, withers and dies, as may be seen in a hundred instances in our forests.

C. - I have often wondered at the huge globular excrescences that stand out from the trunks of some trees, such as the maple, but more especially the birch ; sometimes as large as a hogshead. Do you know the cause of them?

F. - I do not, accurately; on being cut, they present the regular structure of wood, surrounded by bark, but remarkably twisted and gnarled in the grain : in the centre is always some cavity or defect. I suspect they are either a diseased growth of the tree, like wens in animals, or the accumulated layers of ages around the base of some broken limb.

But we have finished a year; the seasons have completed their annual course, since we commenced our wild woodland rambles ; many subjects of interest have fallen beneath our observation; many phenomena, more or less obvious, have occurred to our notice, calculated, I trust, to make us wiser and better. If they have tended to enlarge our information, to increase our cheerfulness, to calm and elevate our minds, to enforce a merciful consideration towards inferior animals, to open before us a wider display of the power, wisdom, providence, and benevolence of Him who is essential Love, - why, we have not wasted our time. But we have seen but a small portion of the mysteries of nature ; inexhaustible stores yet remain to be unlocked; interesting and 
unexpected facts, hidden from the unobservant, are continually disclosed to him who walks through the world with an open eye. We may possibly undertake another course of investigations similar to the one just concluded; new beauties will present themselves to our admiring gaze; no season is so barren but that it possesses charms, either inherent or associated, peculiar to itself; and every clime affords ample opportunities for the prosecution of these studies. "Day unto day uttereth speech, and night unto night sheweth knowledge: there is no speech nor language, where their voice is not heard." These, too, "declare the glory of GoD," and these "shew forth His handy-work." This fact cannot be too strongly impressed : it should never be forgotten that we must not rest in the creature, but be led up to the Creator; and not only perceive His hand, but fear Him, trust in Him, and love Him. 


\section{GENERAL INDEX.}

A.

Agarics, 86.

Ants, 61, 64, 279.

Apple, 140, 327.

Ash, 16, 168, 306.

Aurora Borealis, 46 .

B.

Balm of Gilead, 17, 138, 157.

Basswood, 14, 175.

Bat, 127.

Bear, black, 285.

Beaver, 43.

Beech, 14, 140, 186.

Beetles, 5, 78, 84, 106, 184, 224, 230, 232, 272, 319, 334 .

Carrion beetles, 76, 136.

Whirlbeetle, 102.

Purple Carab, 107, 150, 185, 307.

Crimson beetle, ]22, 307.

Silver beetle, 122.

Copper-spot, 122, 150, 185, 307.

Tiger-beetles, 137.

Oil-beetle, 185.

Toad-beetle, 251.

Blue and gold beetle, 255.

Birch, 16, 73, 140.

Blackberry, 289.

Blackfly, 100.

Bluebird, 241, 327.

Bois brule, 297.

Boletus, hoof, 250.

Bot-fly, 135.

Buckwheat, 290, 304.
Bulrush, 317.

Bunting, rice, 130, 167. snow, $54,83,354$.

Butchering, 340.

Buttercup, 87, 185, 211,

Butterflies-

Tiger Swallowtail, 183, 194, 223, 249, 293.

Black Swallowtail, 184.

Clouded Sulphur, 184, 223, 247, 262, 323.

Grey-veined White, 123, 247.

Archippus, 261.

Pearl-border Fritillary, 192, 290.

Pearl-crescent Fritillary, 219.

Baltimore Fritillary, 227.

Silver-spot Fritillary, 228.

Great spangled Fritillary, 261.

Green Comma, 84, 96, 278.

Orange Comma, 174,221,226,246.

Grey Comma, 250, 261.

Violet tip, 280, 295, 323, 334.

Camberwell Beauty, 96, 261, 294, $305,323,334$.

Forked, 107, 221, 226, 247.

Compton Tortoise, 96, 247, 323.

Banded Purple, 221, 226, 248,306.

Eyed Brown, 247.

Pearly Eye, 246.

Copper, 219.

Spring Azure, 123, 150, 247.

Black Skipper, 184.

Chequered Skipper, 219.

Yellow-spotted Skipper, 193, 228.

Tawny-edged Skipper, 228.

Butternut, 16, 73, 174, 316. 
C.

Caseflies, 86, 224, 326, 341.

Catbird, 168.

Cedar, 12.

Cedar Bird, 212.

Cherry, black, 16, 126, $288,306$. red, $127,288$. choke, 282.

Clearing, 216.

Clover, 87, 211.

Coatacook river, 91, 151, 202, 323, 343.

Creeper, 353.

Crossbill, common, 53, 326.

white winged, 52 .

Crow, 86, 167.

Currants, 149, 244.

\section{D.}

Dandelion, 162, 256.

Dayflies, 85,150,196,224,231,280,326.

Deer, Virginian, 22, 270.

Deermouse, 266.

Dewberry, 244.

Dolphin, white, 171. black, 171.

Dragonfly, 79, 196, 224, 231, 250, $310,333$.

Duck, summer, 310. black, 310.

\section{E.}

Eagle, bald, 120.

Echo, 281.

Elder, 112, 185.

Elm, 14, 101, 125, 140, 144 .

Emigration, 108.

Evening, 15], 202.

\section{F.}

Finch, pine, 53, 355, (note.) purple, 148, 213.

Fir, balsam, 7, 10.

Firefly, 204, 235, 296, 334 .

Fishes, 170, 203, 343.

Flowers :-

Coltsfoot, 112.

Dogtooth Violet, 123.

White and red Death, 159, 298. Grouse, ruffed, 86, 335.
Flowers :-

Violets, 161.

Breeches-Flower, 162.

Orange Lily, 176, 245.

Purple Wake-robin, 2] 0.

Indian Wickup,222,245,282,298.

Poke, 233.

Blue Iris, 234.

Scented Milkweed, 255, 258.

Touch-me-not, 273, 298.

Snake-head, 282.

Wild Chocolate, 282.

Sunflower, 283.

Mullein, 283.

Everlasting, 287.

Mallow, 288.

Fireweed, 288.

Stoneberry, 299.

Swamp Laurel, 300.

Pitcher Plant, 300.

Flycatcher, Pewit, 112.

Canada, 132, 213.

Foot-marks in Snow, 32.

Forest, appearance of, 214. gloom of, $6,218$. autumnal splendour of, 314 .

Fox, red, 277.

Freshets, 103.

Frog, piping, 94. meadow, 114, 265.

bull, 116,265 .

tree, 266.

cackling of, 115.

ova of, 125 .

hybernation of, 327,340 .

Frost, effects of, 3, 45, 292, 304, 327, 331,350 .

G.

Gadfly, 76, 264.

Gallflies, 182, 196.

Golden Eye, 54.

Goose, Canada, 76, 317.

Gooseberry, wild, 289.

Grakle, purple, 132, 213. rusty, 133, 325.

Grass, 211, 234, 244, 269.

Grasshopper, 278.

Grosbeak, pine, 52. evening, 93. 
H.

Hare, American, 54.

Harvest, 290.

Hatley, view of, 105.

Hawkmoths-

Twin-eyed, 222, 248, 280, 295.

Zebra, 256, 258, 260.

Grey, 259.

Six-spotted Blue, 261.

Humble-bee, 263.

Belted, 279.

Haymaking, 264.

Hemlock, 7, 9.

Hop, 90.

Humming-bird, 162, 244, 273, 306.

I.

Indian Hen, 275 .

Indian Summer, 321, 333.

Indians, 151 .

J.

Jay, blue, 54, 90, 356 .

Canada, 54, 345 .

K.

King-bird, 133, 213.

Kingfisher, belted, 117.

L.

Lark, meadow, 120.

Leaf, skeleton of, 332 .

Leather-plant, 125.

Leaves as manure, 316.

Leek, wild, 115.

Ley, salts of, 143 .

Lichens, 8, 65 .

Light, singular marine, 208.

Lights, Northern, 46.

Lizards, 279.

Locomotion, various modes of, 341 .

Locust, field, 267.

rattling, 268.

fan-wing, 122, 185, 324 .

Luminosity of ocean, 206.

Lynx, 41.
M.

Maple, sugar, 13, 73, 146, 168, 215. soft, $73,147,157$.

Marmot, Maryland, 121.

Martin, purple, 104.

Maskilonge, 90, 170.

Masuippi river, 54, 92, 170.

Midget, 100.

Mists, summer, 239.

Moose, 22, 56 .

Moosewood, $175,185$.

Moss, 66 .

Moths, 51, 193, 235. Buff-leopard, 78,174,221,308,339.

Muff, 97, 221, 293.

Panther, 97, 222, 245.

Brindled, 222.

Streaked Hooktip, 194.

Lemon beauty, 194.

Pea-green, 194.

Grandee, 194, 308.

Rhinoceros, 194.

Belle, 195.

Ruby tiger, 195.

Rose-breasted, 195.

Snowy, 222.

Angleshades, 222.

Orange-band, 222.

Veneer, 222, 229.

Silver-spotted buff, 228.

Gamma, 229.

Royal tiger, 245, 259.

Dragon, 248.

Coerulean, 249.

Pink Arches, 249.

Twin Goldspot, 249, 259.

Clifden Beauty, 249.

Spotted Lemon, 249.

Drab Plume, 249.

Vapourer, 249.

Gold and Silver, 259.

Green Gold, 259.

Spangled Orange, 259.

Furbelow, 278.

Griseous, 294.

Apple, 294.

Green Emperor, 294.

Eyed Emperor, 309.

Crimson Underwing, 319.

Winter, 333.

Mould, 229. 
Mouse, field, 32, 127.

Muscles, 76. unknown, 355.

Mushroom, 189.

Muskrat, 44.

Musquito, 99, 203.

\section{N.}

Nighthawk, 213.

Nuthatch, 59.

o.

Oak, white, 148.

Orford mountain, 87.

Oriole, Baltimore, 243.

Otter, 41.

Owl, snow, 54 . horned, 176. barred, 203.

Owl's Head, 87.

P.

Pigeon, passenger, 199, 293.

Pine, white, 7.

Pitcher-plant, 300.

Poplar, 16, 75, 138, 333.

Puff-balls, 230.

Puma, 39.

R.

Rainbow, 283.

Raspberry, 126, 233, 244.

Raven, 167.

Red-poll, 90 .

Reindeer, 22.

Robin, 96, 332.

S.

St. Francis river, 92.

Sandpiper, 234.

Saw-whetter, 92.

Seals, 171.

Seeds, 328.

Service, 148.

Shrew, 317.

Silver thaw, 19.
Singing of birds, 82 .

Skunk, 253.

Slash, 297.

Sleighing, 352.

Sliding banks, 103.

Snake, chequered, 113, 324, 335.

Snow, blueness of, 4 . beauty of, $30,32,349$. crystals of, 26. opacity of, 3. uses of, 30 .

Snow-bird, 82, 168, 332.

Sparrow, fox-coloured, 245. song, $82,168,332$.

tree, 54 . white-throated, 235 .

Spiculæ, floating, 2.

Spiders, 158.

Springtails, 341.

Spruce, 7, 8.

Squirrel, black, 180. flying, 180 . grey, 180. ground, 178. red, $32,178,328$.

Starling, red-winged, 119, 213.

Strawberry, 87, 185, 233.

Sturgeon, 170.

Sugaring, 67.

Sumach, 289.

Summer, 191, 201.

Sundog, 50.

Sunset, 45 .

Swallow, barn, 91, 98.

T.

Tamarack, 7, 11, 125, 333.

Tanager, scarlet, $134,167$.

Tempest in the forest, 347 .

Thistle, Canada, 105, 240, 290.

Thorn, 139.

Thrush, ferruginous, 120 .

Thunder-storm, 238.

Titmouse, 23,54 .

Toad, 265.

Torpidity, 62, 327 .

Tortoise, 188.

Trees, form of, 13. roots of, 145 .

age of, 218. 
Trees, decay of, 225.

fading of, 306,315 . size of, 356 . structure of, 357 . ornamental, 217.

Turtle-dove, 201.

$$
\text { W. }
$$

Warbler, Blackburn, 131. bay-breasted, 132, 213. black-poll, 168 . black and yellow, 131 .

Wasps, 195, 269, 323.

Water, semi-congelation of, 351 .

Waterflies, 79, 224, 231.

Weeds, 240, 288, 292.

Whame-flies, 196, 255.
Whip-poor-Will, 214.

Willows, 75, 150.

Winter, uses of, 337. occupations of, 340 . of $1837-8,31$.

Wolf, 33, 287.

Woodpecker, gold-winged, $5,118$. red-headed, $5,119$. hairy, $4,346$. pileated, 5,119 . downy, 5,346 . northern, 5 .

Wren, winter, 323. Y.

Yellow-bird, 86, 133, 213, 290, 345 354. 


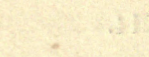




\section{SCIEN'TIFIC INDEX.}

A.

Acarus Americanus, 197.

Acer Saccharinum, 13, 73, 146, 215.

Rubrum, 65, 146.

Eriocarpon, 73.

Striatum, 175.

Acheta Campestris, 296.

Acipenser Sturio, 170.

Acrydium Ornatum, 122, 185, 324.

Egeria —? 193, 279.

Eshna —? 310, 333.

Agaricus Campestris, 189.

Agonum Cupripenne, 334.

Agrion Virginica, 137.

Puella, 250. ? 250 .

Agrostis Vulgaris, 234, 245.

Alauda Magna, 120.

Alcedo Alcyon, 117.

Allium Vincale, 115.

Alypia Octomaculata, 261.

Ammophila Sabulosa, 276.

Ampelis Americana, 212.

Anadonta? 76.

Anas Clangula, 54.

Canadensis, 76, 317.

Sponsa, 310.

Obscura, 310.

Angerona Sospeta, 194, 249.

Anoplis Rusticorum, 232.

Antilope Furcifer, 22.

Aphis Lanata, 299, 342.

Apis Centuncularis, 324.

Arctia Isabella, 78, 174, 221, 308, 339. Virgo, 223, 245, 259 .
Arctomys Monax, 121.

Ardea Minor, 275.

Argynnis Aphrodite, 228, 261.

Cybele, 261.

Arum Atropurpureum, 210. Maculatum, 210.

Arvicola Pennsylvanicus, 32, 127. Zibethicus, 44.

Hudsonius? 355.

Asclepias Syriaca, 255, 258. Incarnata, 259.

B.

Betula Papyracea, 16, 73, 140. Populifolia, 141.

Biston Hirtarius, 222.

Bittacomorpha Crassipes, 196.

Boletus Igniarius, 250.

Bolitophagus Cristatus, 251.

Bombus Terricola, 264.

Bombycidæ, 221, 229.

Boreus Hyemalis, 51 .

Brachynotus Bennettii, 78.

Bufo Cognatus, 265.

Buprestidæ, 5, 224, 272, 354.

Byrrhus Varius, 107.

C.

Calosoma Calidum, 122, 150, 185, 307.

Calyptra Libatrix, 278.

Canis Nubilus, 34 .

Lupus, 34 .

Fulrus, 277.

Cantharis —?. 355 . 
Caprimulgus Americanus, 213. Vociferus, 214.

Carabidæ, 24, 84, 185.

Carabus Catena, 107, 150, 185, 307.

Catocala —? 319.

Cerambycidæ, 5, 224.

Certhia Familiaris, 353.

Cerura Hastulifera, 294.

Cerrus Virginianus, 22, 270.

Alces, 22, 56.

Tarandus, 22.

Wapiti, 22.

Chauliodes Pectinicornis, 263.

Cheimatobia Vulgaris, 333.

Chelone Glabra, 282.

Chilocorus —? 122.

Chionea Araneoides, 51.

Chlorissa Putataria? 194.

Chrysis Cyanea, 224.

Chrysomelina, 24, 84, 122, 184, 185, 355.

Chrysops Sepulchralis? 197.

Cicadellæ, 78.

Cicindela Sex-guttata, 137.

Proteus, 137.

Cimbex 10-maculata, 198.

Sylvatica, 198.

Cimbicidæ, 74 .

Clupea Alosa, 170.

Clytus —? 224, 261.

Cnicus Arvensis, 105, 240.

Altissimus ? 297.

Coccinella 5-notata ? 233.

Coccinellidæ, 185, 233, 325.

Coënomyia Pallida, 198.

Colias Philodice, 184, 223, 262, 323.

Coluber —? 113, 324.

Columba Migratoria, 199, 293.

Carolinensis, 201.

Colymbetes - ? 85.

Conops Rufipes? 261.

Coreus Ordinatus? 289.

Cornus Canadensis, 299.

Corvus Corone, 86, 167.

Cristatus, 90, 356.

Corax, 167.

Canadensis, 345 .

Corydalis Cucullaria, 161.

Crambus, 222, 229.

Cratægus Coccinea, 139.

Crioceris Collaris? 84.

Ctenucha Latreilliana, 249.
Cucujus Rufus, 122, 307.

Culex, 99.

Curculionidæ, 252.

Curvirostra Leucoptera, 52. Americana, 53, 326.

Cydnus —? 97. Bilineata, 319 .

Cynips, 182.

Cynthia Cardui, 280.

\section{D.}

Danais Archippus, 261.

Delphinus Canadensis, 171. Delphis, 171.

Desmocerus Cyaneus, 255.

Dirca Palustris, 126.

Dryocampa Rubicunda, 195.

Dyticidæ, 342.

E.

Elaphrus Intermedins, 255.

Elateridæ, 5, 24, 185, 231, 342.

Elephantopus Scaber, 78.

Emberiza Nivalis, 83, 354.

Oryzivora, 130.

Ephemeridæ, 85, 150, 185, 196, 202, $224,23 \mathrm{l}, 280,326,342$.

Epilobium Latifolium, 222, 245, 282, 298.

Erythronium Americanum, 123.

Esox Estor? 170.

Eumolpus Bigsbyana, 122.

F.

Fagus Ferruginea, 14, 186.

Falco Leucocephalus, 120.

Felis Concolor, 40.

Canadensis, 41.

Formica Pubescens, 65, 279.

Formicidæ, 61 .

Fragaria Virginiana, 87, 185, 233.

Fraxinus Acuminata, 16, 169, 307.

Sambucifolia, 16, 169, 249.

Fringilla Arborea, 54 .

Pinus, 53, 355.

Melodia, 82, 168, 332.

Nivalis, 82, 168, 332.

Tristis, $86,133,213,290,345$, 354. 
Fringilla Linaria, 90.

Vespertina, 93.

Cyanea, 137.

Purpurea, 148, 213.

Albicollis, 235.

Rufa, 245.

G.

Galeopsis Tetrahit, 240.

Gallicolæ, 196.

Gastrus Equi, 135, 264.

Geometridæ, 97, 122, 136, 194.

Geometra Clemataria, 194, 308.

Geomys — ? 355.

Gerbillus Canadensis, 266.

Gerris — ? 107, 122 .

Geum Rivale, 282.

Gnaphalium Margaritaceum, 287.

Gomphus Vulgatissima, 224.

Grapta - ? 84, 305.

Progne? 96, 278.

C. Album, 174, 221, 246.

C. Argenteum, 250, 261.

C. Aureum, 280, 295, 323 .

Gymnodus Rugosus, 272.

Drakii, 273.

Gyrinus Eneus, 102.

H.

Halictus Gramineus, 196.

Helenium Autumnale, 283.

Hemerobius Perla, 197.

Fasciata, 324.

Hepialus Argenteo-maculatus, 248.

Hermes —? 231.

Herminia —? 194.

Hesperidæ, 193, 247.

Hipparchia Andromacha, 246.

Transmontana, 247.

Hippobosca —? 356 .

Hirundo Americana, 91, 98.

Purpurea, 104.

Hister Harrisii, 136.

Humulus Lupulus, 90.

Hyla Versicolor, 266.

Hypnum —? 66.
I.

Ichneumonidæ, 24, 97, 122, 356.

Impatiens noli-tangere, 273, 298.

Ips Quadripunctata, 122.

Iris Versicolor, 234.

J.

Juglans Cinerea, 16, 73, 174.

Julus Marginatus, 273.

Jungermannia —? 66 .

$\mathrm{K}$.

Kalmia Angustifolia, 300. Glauca, 300 .

L.

Lampyris Corusca, 204, 296, 334.

Noctiluca, 205.

Ledum Latifolium, 300.

Leontodon Taraxacum, 162, 256.

Lepus Americanus, 54.

Libellula, 79, 196.

Lilium Canadense, 176, 245.

Limenitis Arthemis, 220, 226, 248, 306.

Limnephilus —? 224 .

Locusta —? 278.

Lophocampa Tesselaris, 97, 222, 293.

Loxia Enucleator, 52.

Lutra Canadensis, 41.

Lycæna Phleas, 219.

Lycus Reticulatus, 230.

Terminalis, 231.

Lyda Circumcinctus? 185.

M.

Malva Sylvestris, 288.

Medusæ, 342.

Megachile Willughbiella, 231.

Melitæa Myrina, 192, 290.

Tharos, 219.

Phaeton, 227.

Meloe Proscarabæus, 185.

Melolontha? 61.

Membracis —? 185.

Belligera, 296.

Mephitis Americana, 253.

Mergus Cucullatus, 310. 
Microsetia —? 229.

Monarda Kalmiana, 163.

Mus Leucopus? 128.

Muscicapa Nunciola, 112.

Canadensis, 132, 213.

Tyrannus, 133, 213.

Ruticilla, 243.

Muscidæ, 60, 78, 97, 326, 341 .

\section{N.}

Necrodes Surinamensis, 136 .

Nephropis Canadensis, 224.

Noctuidæ, 84, 136, 193, 229.

Nomada Americana, 150.

Notonecta, 342 .

\section{O.}

Odontomis Trinervia, 224.

Edipoda Sulphurea? 268.

Estrus Bovis, 76.

Ovis, 264.

Omalium ? 76.

Ophion Luteum, 107.

Orgyia Antiqua, 249.

Oriolus Baltimorus, 243.

Ostrya Virginica, 66.

Otiocerus —? 296

P.

Pachyta - ? 185.

Pamphila Peckius, 193, 228.

Paniscus? 219.

Cernes, 228.

Panorpa Fasciata, 224.

Panorpidæ, 51.

Papilio Turnus, 183, 194, 223, 293.

Asterius, 184.

Parus Atricapillus, 23.

Pathophagis Latibrosus, 136, 319.

Pedicia — ? 279.

Pelecinus Polycerator, 289.

Pentatoma ? $184,223$.

Perla Clio, 79.

Cydippe, 184, 224.

Phleum Pratense, 211, 244.

Phlogophora Meticulosa, 222.

Phragmatobia Fuliginosa, 195.

Phryganidæ, 78, 86, 107, 224, 326, Quercus Alba, 148. 333,341 .
Phyllodecta Vitellina, 185.

Phyllopterus Myrtifolius, 278.

Physalis, 342.

Phytolacca Decandria, 233.

Picus Auratus, 5, 118.

Erythrocephalus, 5 .

Villosus, 4, 5, 346 .

Pileatus, 5, 119.

Pubescens, 5, 346.

Varius, 5.

Carolinus, 5 .

Tridactylus, 5 .

Pinus Strobus, 7.

Canadensis, 7, 9.

Nigra, $7,8$.

Alba, 7 .

Balsamea, 7, 10.

Pendula, 7, 125.

Platycerus Placidus, 272.

Platypteryx Erosa, 194.

Plusia Gamma, 229.

Iota? $249,259$.

Festucæ? 259.

Chrysitis? 259.

Podura, 341.

Polia —? 174.

Pœderus Riparius, 84.

Polygonum Convolvulus, 292.

Polyommatus Lucia, 123, 150.

Pontia Oleracea, 123.

Populus Tremuloides, 16, 75.

Balsamifera, 17, 138.

Dilatata, 75.

Grandidentata, 138.

Lævigata, 138.

Prunus Virginiana, 16, 126, 288.

Borealis, 127, 288.

Serotina, 249, 282, 309.

Pteromys Volucella, 180.

Pteronarcys Regalis, $23 \mathrm{I}$.

Proteus, 231.

Pterophorus —? 249.

Pulex Penetrans, 197.

Pulmonaria, 66 .

Pygæra Gibbosa, 228.

Pyralis - ? 222.

Pyrus Arbutifolia, 148.

Q.

Quiscalus Versicolor, 132. 
Quiscalus Ferrugineus, 133, 325.

Major, 325.

R.

Rana Halecina? 114, 265.

Pipiens, 116, 265.

Clamatis? 265.

Ranunculus Acris, 87, 185, 211.

Rhizotroga Fervens, 106, 307.

Rhus Typhinum, 289.

Ribes Floridum, 149.

Albinervium, 149.

Cynosbati, 149, 249, 289.

Ringens? 150.

Rubus Idæus, 126, 223, 244.

Procumbens, 244.

Hispidus, 289.

S.

Salamandra Rubra, 280.

Salix, 75, 150, 249.

Sambucus Pubescens, 112, 185.

Canadensis, 113.

Sargus? 174.

Sarracenia Purpurea, 300.

Saturnia, 74, 235.

Saturnia Polyphemus, 75, 309. Luna, $75,294$.

Saxicola Sialis, 241, 327.

Sciurus Hudsonius, 32, 178.

Leucotis, 180.

Niger, 180.

Scutellera, 289.

Senecio Hieracifolius, 288.

Sesia Pelasgus, 263.

Silphidæ, 137.

Simulia —? 100.

Sirex, 5, 272.

Sirex Juvencus, 296.

Sitta Varia, 60.

Smerinthus Occellatus, 222.

Geminatus, 222, 248, 280, 295.

Smilacina Borealis, 299.

Solidago —? 183, 294.

Sorex Brevicaudis, 317.

Spargula Arvensis, 241.

Sphecodes Rubida, 196.

Sphinx Kalmiæ, 256.
Sphinx Cinerea, 259.

Spilosoma Acria, 97, 222, 245.

Virginica, 195.

$\longrightarrow 222$.

Staphylinidæ, 84, 136.

Staphylinus Villosus, 136.

Chrysurus, 136.

Chrysocephalus, 319.

Stenuris Divaricata, 232.

Strix Nyctæa, 54 .

Virginiana, 176.

Nebulosa, 203.

Sturnus Predatorius, 119, 213. Sylvia Blackburniæ, 131.

Magnolia, 131.

Castanea, 132, 213.

Striata, 168.

Troglodytes, 323 .

T.

Tabanus Affinis, 255.

Zonalis? 255.

Tabanidæ, 196.

Tachina - ? 263.

Tamia Striata, 178.

Tanagra Rubra, 134. Æstiva, 356.

Telephorus ? ? 125.

Tenthredinetæ, 122, 184.

Termes Fatale, 197.

Terrapene Clausa, 188.

Tethea —? 294.

Tetrao Umbellus, 86, 335 .

Tettigonia 4-vittata, 98, 324 . Mollipes, 98, 324 .

Thanatophilus Marginalis, 136.

Thuja Occidentalis, 12.

Thyatira Scripta, 249.

Thymele Brizo ? 184.

Tilia Glabra, 14, 175, 249.

Tillandsia Usneoides, 9.

Tineidæ, 84, 97.

Tipulidæ, 5, 51, 79, 185, 341 .

Tortricidæ, 51, 84, 122, 335 .

Tremex Columba, 279.

Trichocera Hyemalis, 354 .

Trichodium Laxiflorum, 269.

Trifolium Pratense, 87, 211.

Repens, 212. 
Trillium Fœtidum, 160, 298. Pictum, 160, 298.

Tringa Semipalmata, 234.

Pusilla, 234.

Trochilus Colubris, 163.

Rufus, 163.

Turdus Migratorius, 96, 332.

Rufus, 120.

Felivox, 168.

Tussilago Farfara, 112.

Typha Latifolia, 317.

\section{U.}

Ulmus Americana, 14, 140.

Ursus Americanus, 285.
Ursus Arctos, 286.

Usnea —? 9.

V.

Vanessa J. Album, 96, 247, 323.

Antiopa, 96, 261, 294, 305, 323, 356.

Furcillata, 107, 221, 248.

Veratrum Viride, 233.

Verbascum Nigrum, 283.

Vespa Marginata, 196, 269.

Viburnum Lantanoides, 175, 185.

$\mathrm{X}$.

Xerene Albicillata, 249. 
July, 1839.

○

BOOKS PUBLISHED BY

JOEN VAN VOORST, 1, PATrRAOSTER ROW,

【(O)

Bookseller to the Zoological Society.

Prof. Jones' Animal Kingdom. First Princlples of Religion. Prof.Bell's British Quadrupeds. The Holy Bible, illustrated.

The Book of Common Prayer. Select Poems and Hymns. Beale's Natural History of the Sperm Whale.

Jesse's Angler's Rambles. Bevan on the Honey Bee. Yarrell's British Birds.

Luxford's Ylora of Reigate. Bell's British Reptlles.

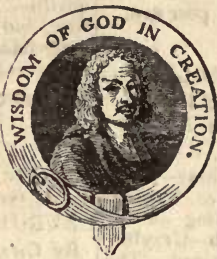

Bonsparte's List of Birds. Aikln's Calendar of Nature. Dodsley's Economy of Life. Yarrell's British Fishes. Miller's Rural Sketches. Bathurst's Notes on Nets. Little Fables for Little Folks. Elements of Knowledge.

History of Christ's Hospital. Gray's Klegy, illustrated. ___ Bard, 1llustrsted. Beauties of the Country. Yarrell on the Salmon.

A GENERAL, OUTLINE OP THE ANIMAL KINGDOM, And Manual of Comparative Anatomy. BY PROFESSOR RYMER JONEB.

This work will comprise a general view of the Animal Creation, exhibiting the structure and internal economy of every class of living beings, and their adaptation to the circumstances in which they are severally destined to exist.

* In Parts, at 2s. 6d. each; six published, containing 130 illustrations; the work, when complete in one volume, will contain about 300 .

\section{THE FIRST PRINCIPLES OF RELIGION.}

Re-edited by the Hon. Mrs. ЈоHN TALBOT. $18 \mathrm{mo}$. cloth.

\section{A HISTORY OF BRITISH QUADRUPEDS,}

Including the Cetacea.

By Professor BrLl.

Containing 200 illustrations, 8 vo. price $28 \mathrm{~s}$.
A CABINET EOITION OF The holp rible;

The Authorised Version, With Twenty-four highly-finished Steel Engravings ;

The Historical Subjects from the most esteemed Paintings of the Uld Masters, and the Landscapes from Drawings by W. W BSTA LL, A.R.A.

Price, in embossed binding, 10s.6d.

A CABINET EDITION OF THE 33ook of Common praper;

The Anthorised Version,

With Ten Engravings, executed in the best manner, on steel.

Price, in embossed binding, $4 s$. uniform with the Bible.

ORIGINAL AND SELECT

P O EM S A N D H Y M N ; A Companion to Sacred Poetry. Second edition, enlarged, $32 \mathrm{mo}$. half-bound, 28.61 . 
In 1 vol. post $8 \mathrm{vo}$. with 22 Illustrations, RURAL SKETCHES.

By Thomas Miller, Anthor of "Beauties of the Country," etc. Containing

\begin{tabular}{l|l} 
Home Revisited & The Old Woodman \\
Old Customs of Tra- & The Country Justice \\
velling & Rural Poetry \\
Railway Travelling & The Gamekeeper's \\
Country Courtship & Hut \\
The Old Coschman & A Stray Chapter \\
The Old Fisherman & The Haunted House \\
Tumbling Tommy & The Subsiding of the \\
Mary Gray & Waters. \\
Jack Grab & The Old Bull's Head \\
Bonny Bell & England's Helicon, \\
The Country Fair & etc.
\end{tabular}

\section{NOTES ON NETS; Or,}

The Quincunx Practically considered.

To which are added, Miscellaneous Memoranda.

By the Hon. and Rev. Charles

Bath URST, LL.D., late Fellow of All Soul's College, Oxford. $12 \mathrm{mo}$. price $4 \mathrm{~s}$.

\section{LITTLE FABLES FOR LITTLE FOLKS ;}

Selected for their moral tenilency, and re-written in Familiar Words, not one of which exceeds Two Syllables.

Designed as Reading Lessons, to amuse and Instruct. Illustrated with wood. cuts, price 1s.6d. cloth.

\section{ELEMENTS OF PRACTICAL KNOWLEDGE;}

Or, the Young Inquirer Answered.

Explaining in Question and Answer, and in familiar langnage, what most things daily used, seen, or talked of, are; what they are made of, where found, and to what uses applied. In. cluding articles of food and aliment; miscellanies in common use; metals, gems, jewellery ; and some account of the principal inventions, and most interesting manuactures.

In $18 \mathrm{mo}$. with Illustrations, price $3 \mathrm{~s}$. cl.

\section{A BRIEF HISTORY OF CHRIST'S HOSPITAL,}

From its Foundation by King Edward the Sixth.

Sixth Edition, with Six Illustrations, and a List of the Governors. By J. I. Wi Lson.

Small 8vo. cloth, 48.

\section{GRAY'S ELEGY IN A COUNTRY} CHURCHYARD.

Each Stanza Illustrated, from 33 original Drawings expressly made for the volume by the most eminent living Artists. Price 9s, cloth.

THIS EDITION MAY LIKEWISE BE HAD WITH INTERPage TRANSLATIONS in GrEBK, Latin, GrRman, French, AND Italian, SELECTED FROM THE MOST A PPROVED EDITIONS WHICH HAVE APPEARED IN THESE LANGUAGES.

Price 12s. cloth.

THE BAR D. By GRAY. With Illustrations from Drawings by the Hon. Mrs. John Talbot.

Uniform in size and general appearance with the Elegy of Gray, to which it forms a most appropriate Companion Volume. Price 7s. cloth.

\section{BEAUTIES OF THE COUNTRY;}

Or, Descriptions of Rural Customs, Objects, Scenery, and the Seasons.

\section{By Thomas MiLler.}

Post 8vo. with Twenty-six Illustrations, 12s. cloth.

By the Author of the History of British Fishes,

A PAPER ON THE

\section{GROWTH OF THE SALMON IN} FRESH WATER.

With Six coloured Illustrations of the Fish of the natural size, exhibiting its character and exact appearance at various stages during the first two years. Oblong, sewed, 12 s. 
Price 7s. 6d. demy 8vo., 15s. royal 8vo., or 22s. 6d. imperial 8vo., in cloth,

A SUPPLEMENT TO

THE HISTORY OF BRITISH FISHES.

BY WILLIAM YARRELL, F.L.S. V.P.Z.S. ETC.

This Supplement contains about Thirty Species new to Britain, which the Author has derived from various sources since the publication of the work, some of which are also new to Ichthyology. The volume contains a figure of each Species, and an equal number of Vignette or Anatomical Tail-pieces.

\section{In Preparation,}

A HISTORY OF BRITISH FOREST TREES, INDIGENOUS AND INTRODUCED.

BY PRIDEAUX JOHN SELBY, F.R.S.E. F.L.S. ETC.

Part I. with Figures.

A FLORA OF SHROPSHIRE. BY W. A. LEIGHTON, B.A. F.R.S.E. Part III.

A HISTORY OF THE FOSSIL FRUITS AND SEEDS OF THE LONDON CLAY.

BY JAMES SCOTT BOWERBANK, F.G.S.

Part I. with Figures.

A HISTORY OF THE FISHES OF MADEIRA.

BY RICHARD THOMAS LOWE, M.A.

BRITISH CHAPLAIN.

With Figures by the Hon. C. E. C. Norton and M. Young.

A HISTORY OF BRITISH CRUSTACEA.

BY PROFESSOR BELL.

The Figures by J. O. Westwood, Sec. E.S.

\section{A HISTORY OF BRITISH FERNS.}

BY EDWARD NEWMAN, F.L.S.

Illustrated with a wood engraving of every Species and named Variety, drawn on wood by the Author, and shewing the figure of the Frond, the Fructification, and Venation of each. 


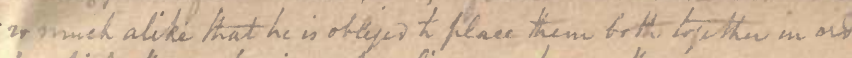
is which, the one having a peculiar snout over the eye. 


\section{DAY USE}

RETURN TO DESK FROM WHICH BORROWED

BIOLOGY LIBRARY

TEL. NO. 642-2532

This book is due on the last date stamped below, or on the date to which renewed. Renewed books are subject to immediate recall.

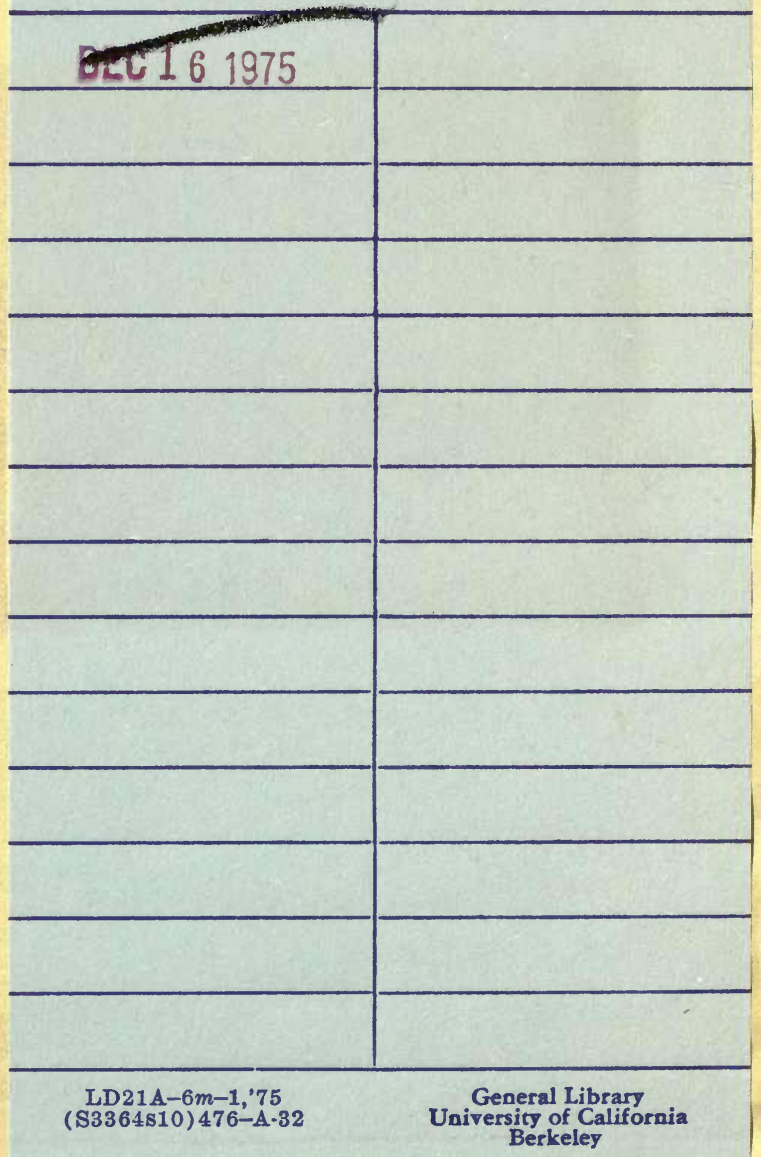




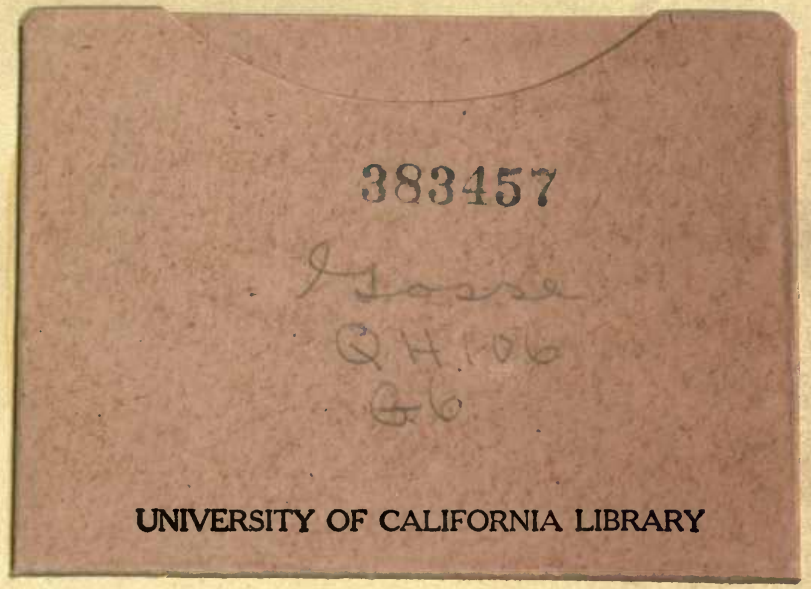

\& 


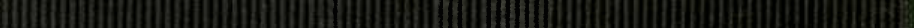

||||||||||||||||||||||||||||||||||||||||||||||||||||||||||||||||||

|||||||||||||||||||||||||||||

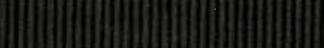

|||||||||||||||

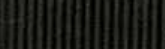

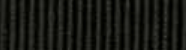

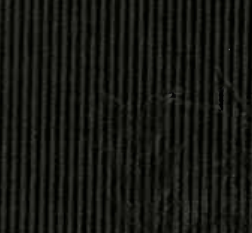

